\title{
Ultrasound travels : the politics of a medical technology in Ghana and Tanzania
}

Citation for published version (APA):

Müller-Rockstroh, B. (2007). Ultrasound travels : the politics of a medical technology in Ghana and Tanzania. [Doctoral Thesis, Maastricht University]. Maastricht University. https://doi.org/10.26481/dis.20070613bm

Document status and date:

Published: 01/01/2007

DOI:

10.26481/dis.20070613bm

Document Version:

Publisher's PDF, also known as Version of record

\section{Please check the document version of this publication:}

- A submitted manuscript is the version of the article upon submission and before peer-review. There can be important differences between the submitted version and the official published version of record.

People interested in the research are advised to contact the author for the final version of the publication, or visit the DOI to the publisher's website.

- The final author version and the galley proof are versions of the publication after peer review.

- The final published version features the final layout of the paper including the volume, issue and page numbers.

Link to publication

\footnotetext{
General rights rights.

- You may freely distribute the URL identifying the publication in the public portal. please follow below link for the End User Agreement:

www.umlib.nl/taverne-license

Take down policy

If you believe that this document breaches copyright please contact us at:

repository@maastrichtuniversity.nl

providing details and we will investigate your claim.
}

Copyright and moral rights for the publications made accessible in the public portal are retained by the authors and/or other copyright owners and it is a condition of accessing publications that users recognise and abide by the legal requirements associated with these

- Users may download and print one copy of any publication from the public portal for the purpose of private study or research.

- You may not further distribute the material or use it for any profit-making activity or commercial gain

If the publication is distributed under the terms of Article $25 \mathrm{fa}$ of the Dutch Copyright Act, indicated by the "Taverne" license above, 


\section{Ultrasound Travels}

The politics of a medical technology in Ghana and Tanzania 
(C) Babette Müller-Rockstroh, 2007

\section{ISBN}

Cover Picture: Mikki, Dar es Salaam

Printed by: Datawyse/Universitaire Pers Maastricht

The production of this thesis has been sponsored by:

Graduate School Science, Technology \& Modern Culture (WTMC)

Department of Science \& Technology Studies, Faculty of Arts and Social Sciences

J.A. Jurriaanse Stichting 


\title{
Ultrasound Travels
}

\section{The politics of a medical technology in Ghana and Tanzania}

\author{
PROEFSCHRIFT
}

ter verkrijging van de graad van doctor aan de Universiteit Maastricht, op gezag van de Rector Magnificus, Prof. mr. G.P.M.F. Mols volgens het besluit van het College van Decanen, in het openbaar te verdedigen op woensdag 13 juni 2007 om 16.00 uur

door

Babette Inge Müller-Rockstroh

geboren op 1 februari 1969 te Berlijn (Duitsland) 


\section{Promotor:}

Prof. dr. ir. W.E. Bijker

\section{Co-promotor:}

Dr. B. Pasveer

\section{Beoordelingscommissie:}

Prof. dr. K. Bijsterveld (voorzitter)

Prof. dr. M. Akrich (Centre de Sociologie de l'Innovation, Paris, France)

Prof. dr. S. van der Geest (Universiteit van Amsterdam)

Prof. dr. K. Horstman

Prof. dr. L. de la Rive Box (Institute of Social Studies, Den Haag) 


\section{TABLE OF CONTENTS}

1. ANALYZING ULTRASOUND TRAVELS - A RESEARCHER'S APPARATUS ............................ 1

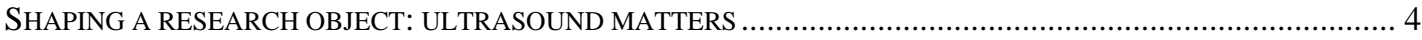

Classic stories: Magic Machines and Trojan horses ........................................................................ 5

New plots: Actor-Networks and Socio-technical Ensembles.......................................................... 8

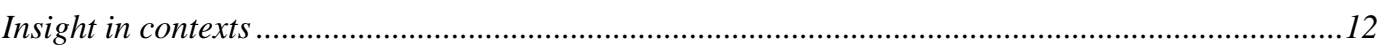

TRACKING A RESEARCH OBJECT: TRAVEL MATTERS .........................................................................12

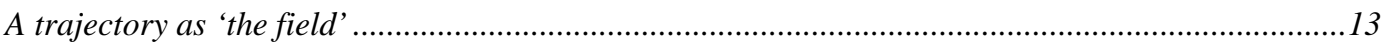

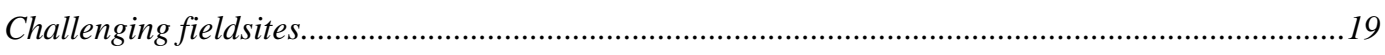

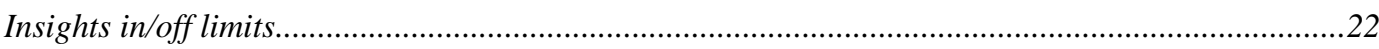

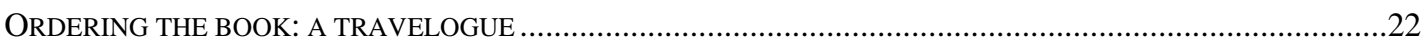

2. IMAGIN(IN)G THE WORLD - THE INTERNATIONAL APPARATUS ....................................24

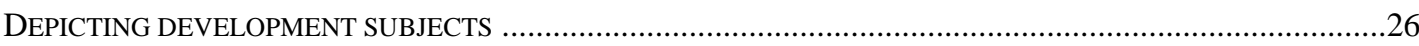

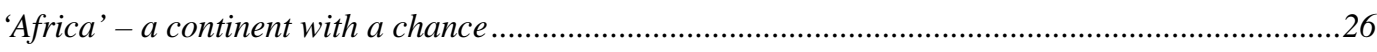

'Women and Children' - burden and brokers ................................................................................31

'Science and Technology' - man-maker and women-savers ..........................................................36

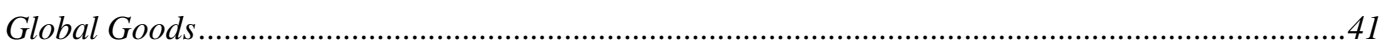

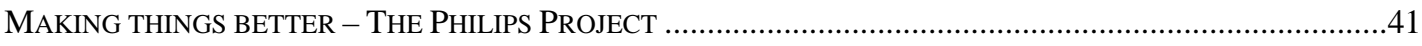

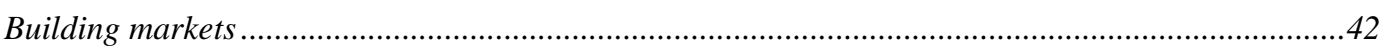

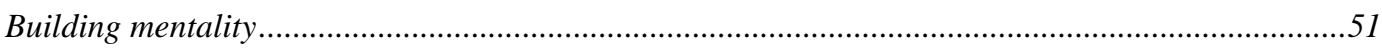

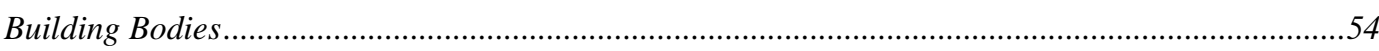

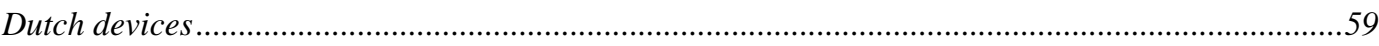

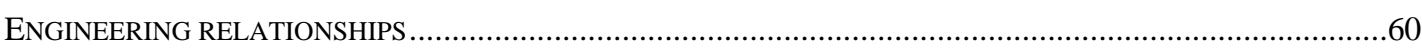

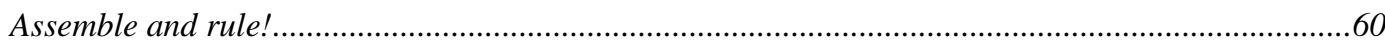

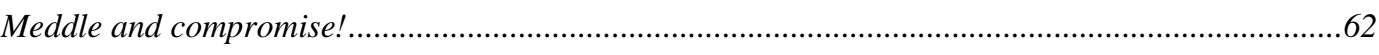

World order and Work order .........................................................................................................64

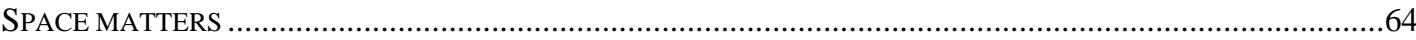

3. BUYING INTO IMAGING TECHNOLOGY - THE STATE APPARATUS...................................69

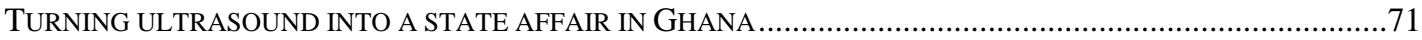

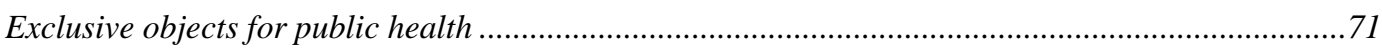

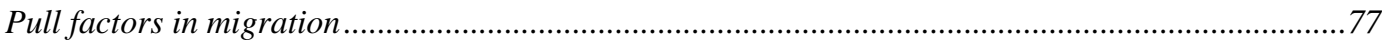

Means to "stemming the tide" .........................................................................................................81

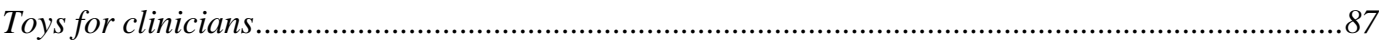

TURNING ULTRASOUND INTO A STATE AFFAIR IN TANZANIA ..............................................................87

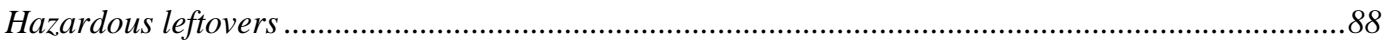




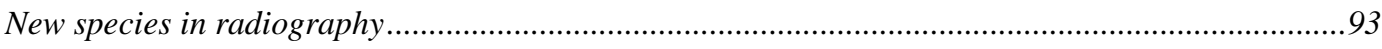

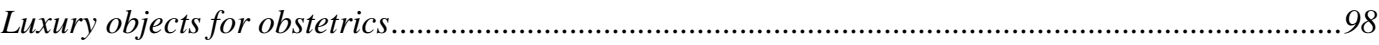

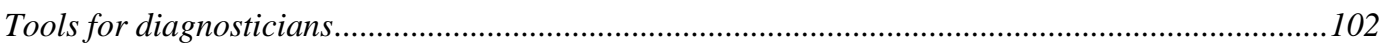

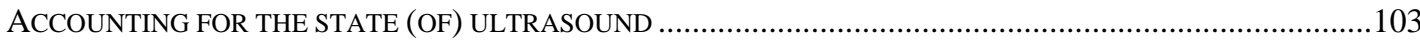

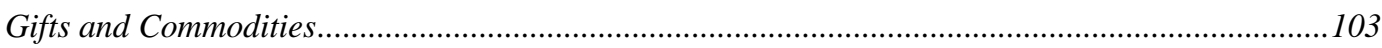

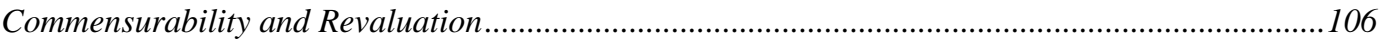

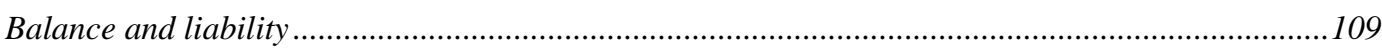

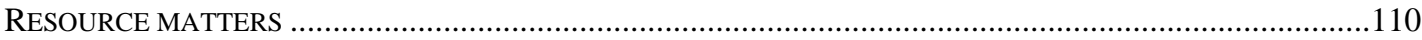

4. INSTITUTIONALIZING ULTRASOUND - THE HOSPITAL APPARATUS................................114

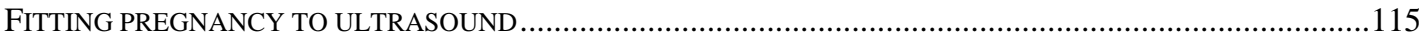

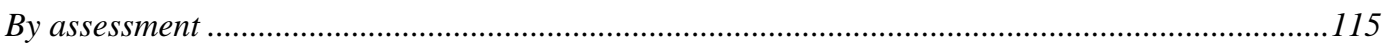

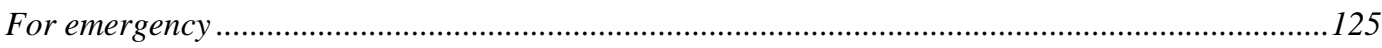

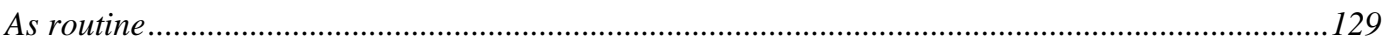

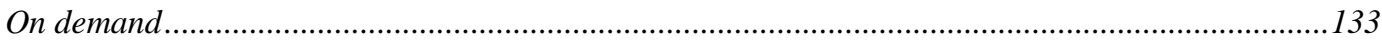

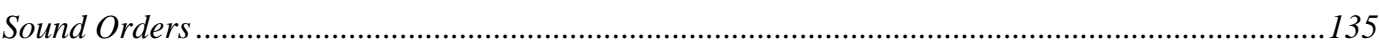

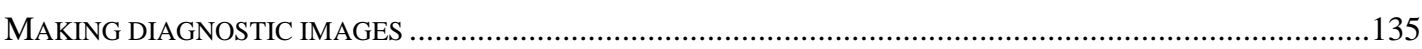

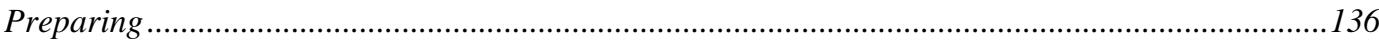

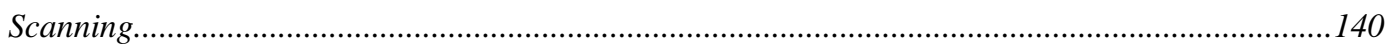

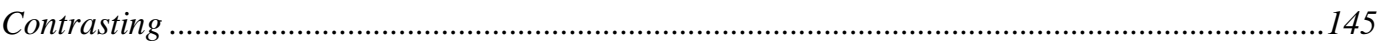

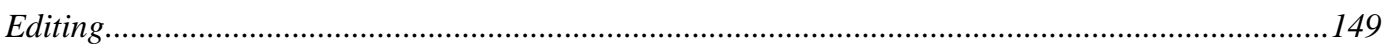

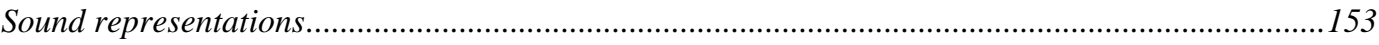

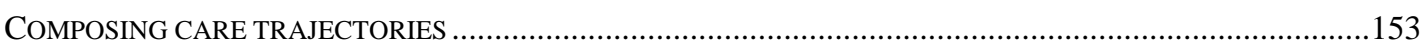

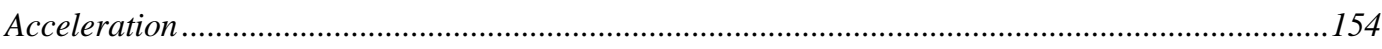

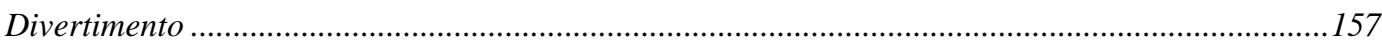

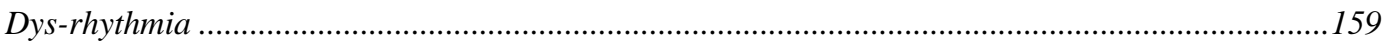

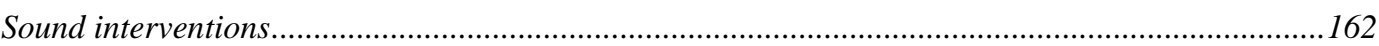

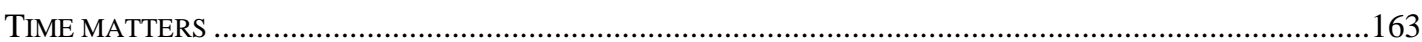

5. ‘DOING VIDEO’ AND ‘HAVING A KIOO’ - THE WOMEN’S APPARATUS .............................167

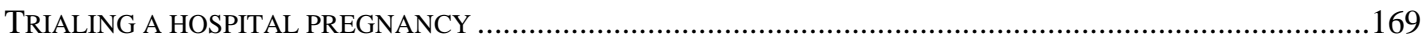

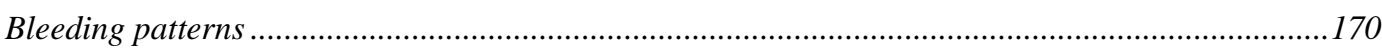

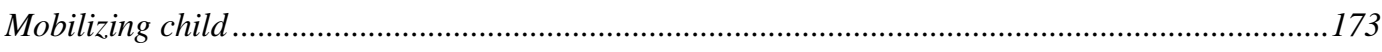

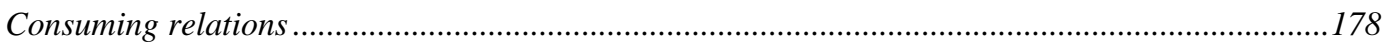

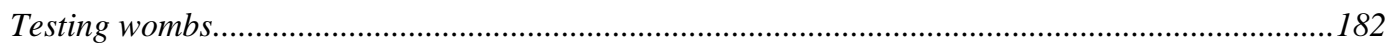

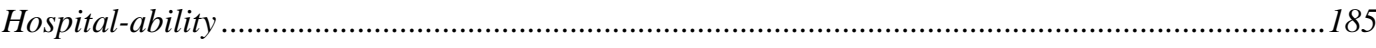

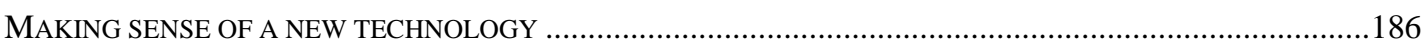

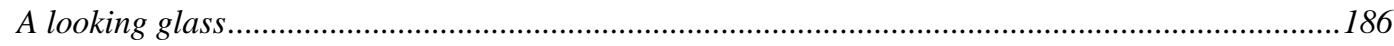




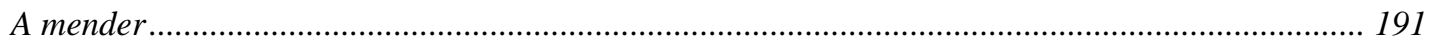

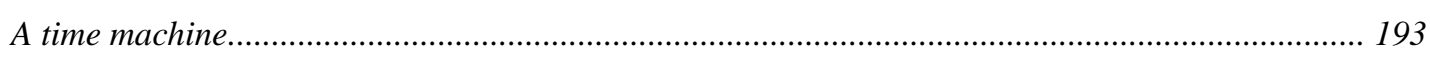

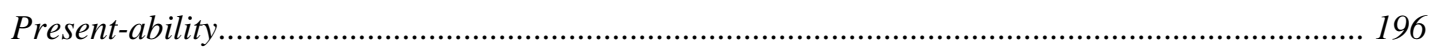

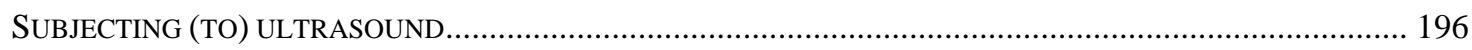

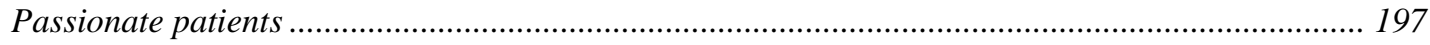

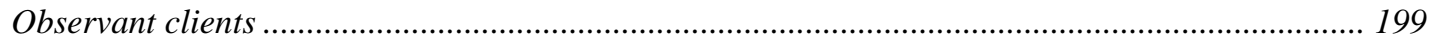

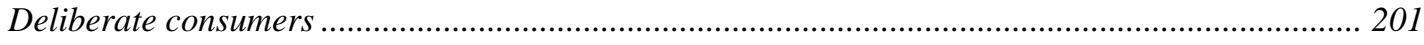

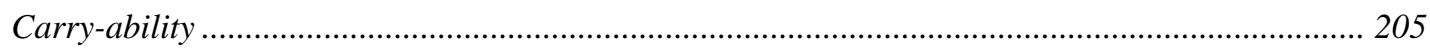

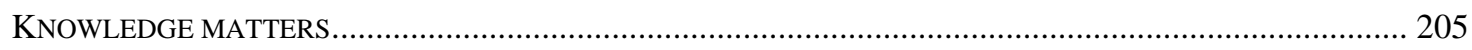

6. DOING TECHNOGRAPHY - AN ASSESSMENT APPARATUS ................................................ 210

REVIEWING: THE POLITICS OF ULTRASOUND IN GHANA AND TANZANIA .............................................. 211

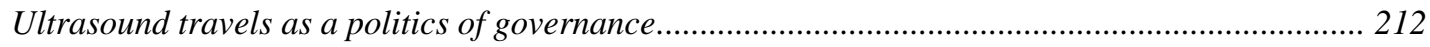

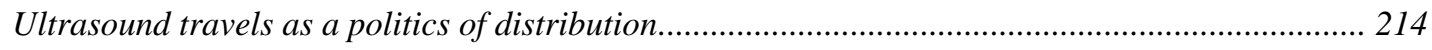

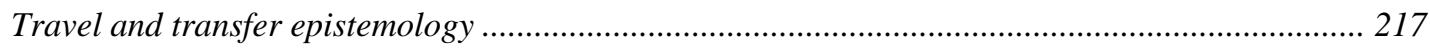

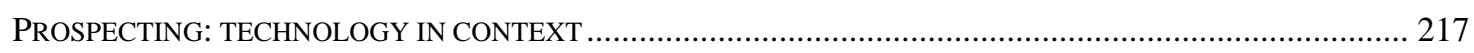

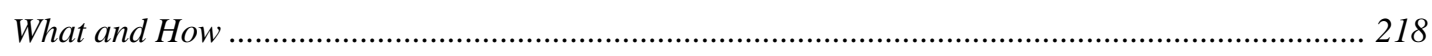

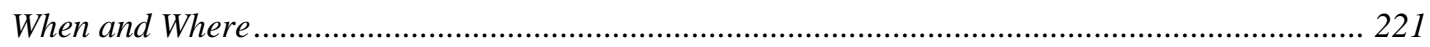

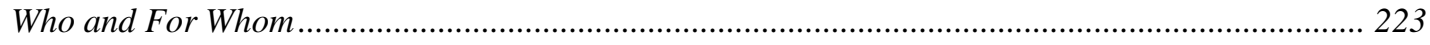

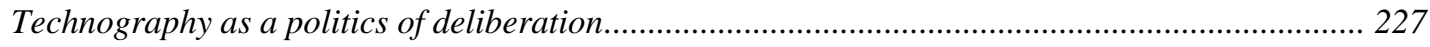

CONCLUDING: ‘WHITE MACHINES’ AND ‘BLACK BODIES’, OR WHAT WOULD BE A SOUND SCIENCE?....... 227

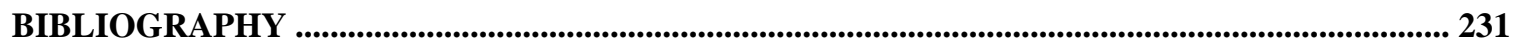

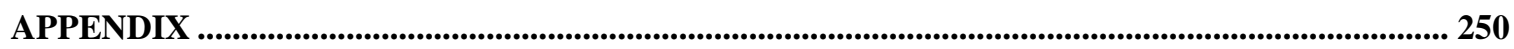

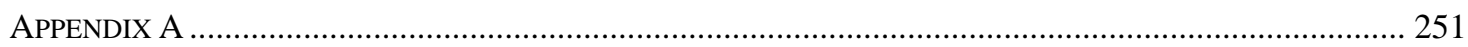

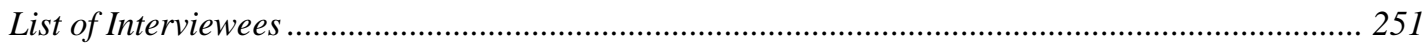

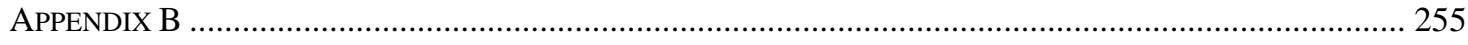

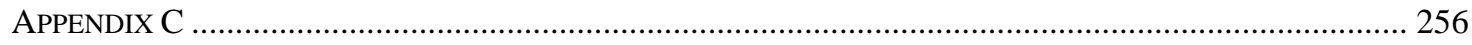

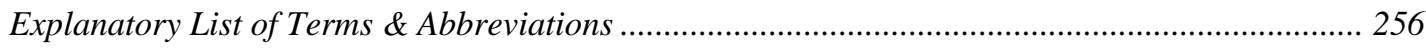

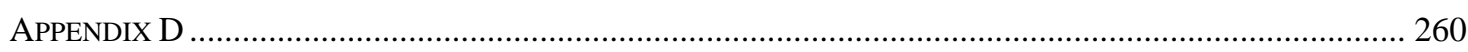

A note on the buying power of the Ghanaian Cedi and Tanzanian Shilling ..................................... 260

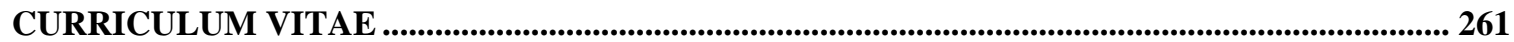




\title{
1. Analyzing ultrasound travels - a researcher's apparatus
}

Maastricht, The Netherlands: July 18, 2003. "Why do you want to study ultrasound in Africa?" Dr. Arnold, an expert in Public Health and Tropical Medicine employed by the German Development Service in Berlin, replies by email to my request to provide me with contacts to Tanzanian hospitals doing ultrasound examinations. He adds: "It might have become clear on the phone that I regard your topic as relatively farfetched. Limiting yourself to the field of human-machine interaction, it will be difficult to find suitable research objects to yield relevant results in a country such as Tanzania and in Africa in general. [...] If you look at the current real problems Africa has, why don't you do research on AIDS or malaria?"1

\begin{abstract}
Mwanza, Tanzania: March 3, 2004. "I do think that your research on ultrasound in the country can be very important." In his office at the National Institute for Medical Research, Dr. Dodoma, a parasitologist, expresses his enthusiasm about the utility of my research project: "You see, we don't have many studies on that. Neither do we here at NIMR study these kinds of things. What do we study? - AIDS, malaria and other tropical diseases. But with studies like yours, maybe we will be able to say: 'This is a good technology for the District Hospital for that and that reason. Or it is good for Regional Hospitals."”
\end{abstract}

On the table of a social scientist with a background in midwifery, a medical anthropologist and a newcomer to the field of Science \& Technology Studies (STS) ${ }^{2}$, 'Ultrasound in Ghana and Tanzania' appears to be both an inappropriate and an inappropriated ${ }^{3}$ research object. Dr. Arnold is not quite clear about his reluctance - is his (or eventually my) problem the lack of a representative number of machines, or is it the focus on human-machine interaction?

\footnotetext{
1 Translation from German original, BMR.

2 The discipline started out calling itself Science\&Technology Studies. Many of its proponents have meanwhile added Society to emphasize the interplay between society and technology as the discipline's focus. The commonly used acronym stays STS, which is also the one I will use throughout the book.

${ }^{3}$ I use the word 'to appropriate' here in the sense of 'to make something one's own', see also below.
} 
Seconded more politely by Dr. Dodoma the tone of his email clearly conveys the message that my research object is inappropriate because it is marginal in the sense of being of minor importance given the health problems that Africa faces and that Public Health has to deal with by means of scientific research. I agree on the marginality of my research object. In contrast to Dr. Arnold and Dr. Dodoma, however, I use marginality in the productive sense that the anthropologist Arthur Kleinman with reference to the Oxford English Dictionary has outlined it - as different "in texture from the main body" (1995, p.1).

Following Kleinman's definition, instead of inappropriate, my research object and the approach I have taken in conducting that research is inappropriated in the sense that it is (and has been) neither the focus of public health, nor of Medical Anthropology nor of Science \& Technology Studies. Rather, I suggest, 'Ultrasound in Ghana and Tanzania' is at the point of their encounter in its endeavor to answer the question how medical technology can help to solve public health problems in Africa, and it is here where the three disciplines also meet with feminist concerns about body politics. Thus I am bound to all these sites in my interest in studying the transfer of technology to cultural contexts that differ in many ways from the contexts that this technology was originally designed for. The two disciplines that have come to be my conceptual home by definition explore borderlands. Medical Anthropology works at the margins of medicine and anthropology, while STS writes at the margins of science, technology and society. By writing on ultrasound in Ghana and Tanzania, I build on the strengths of both disciplines, attempt to fill their respective gaps: the high-tech and often historical focus of STS mainly on 'the North", and Medical Anthropology's expertise on 'the South', but with regard to medicine's materiality rather than on low-key technologies, such as drugs, or injections. And I will use both disciplinary perspectives to challenge current Public Health (research) practices.

From a common public health point of view the mere question that this book poses - what happens when ultrasound travels to Ghana and Tanzania? - is not one that the discipline easily recognizes. For Dr. Arnold, as the vignette above makes clear, AIDS and

\footnotetext{
4 There are by now too many studies in STS to list them here. Yet, two classic STS studies with a historical focus are Wiebe Bijker's analysis of bikes and bakelite (Bijker, 1995a), and Bruno Latour's study of a Parisian transport system (Latour, 1996). In 'the West', or in terms of Africa rather in 'the North', several researchers have combined STS and Medical Anthropology to study high-tech in medicine. To name but two: Rayna Rapp's study of amniocentesis (Rapp, 1999), and Joseph Dumit's research on PET-scans (Dumit, 2004) These studies are a fruitful extension of work that has turned to study biomedicine as another 'ethnomedicine' in the wake of 'anthropology at home' (Good, 1994; Margaret Lock \& Gordon, 1988; Young, 1995).
} 
malaria are facts 'out there', overwhelming in the increasing number of patients suffering from these diseases. Likewise, what ultrasound does, or does not yet do in Africa, is also a fact. Yet, as STS has emphasized, facts are made. Emerging from practices and the technologies that enact them, 'facts' are real while, at the same time, they are also historical and cultural (see, for instance, Berg \& Mol, 1998; Daston, 2000; Haraway, 1991; Mol, 2002). As practices and technologies travel or are transferred from place a to place $b$, however, they meet with existing practices and objects at place b. In order to work in place b, technologies have to change and inevitably do so, and thereby may have unintended consequences (Akrich, 1992, 1993; De Laet 1998; De Laet 2000; De Laet \& Mol 2000). Yet in some ways technologies may also stay the same, while the places they travel to change and thus become connected to the places from which the technology originated. In short, I claim that, as ultrasound travels, it becomes both a changeable object and an object that brings about change - it is, so to speak, "world making" (Goodman, 1978).

Acknowledging the transformative capacity of technology, however, brings with it the question of how technology then can be assessed. If technology and objects change as they travel, yet are at the same made to travel in order to do certain kind of things, for instance to solve urgent health problems, technology assessment has to capture this technology 'in the making'. Ultrasound in Ghana and Tanzania becomes a strategic research site, not only because the topic has not yet been researched but also because the technology, other than in the United States, Europe, or India, is still quite new in both countries and not yet firmly entrenched in medical work practice. This relative malleability makes it easier for me to show that ultrasound becomes a different thing in different places. Instead of being a neutral thing that travels, my book thereby starts from the assumption that in its capacity to make worlds, technology has and makes politics. With the asymmetries inherent to technology transfer, be this from 'the North' to 'the South' or in the opposite direction 5 , technology assessment then becomes concerned with a highly political question: What worlds have (or are granted) the right to exist?

Throughout this book I will show that ultrasound matters in context. Heading my chapters with the term 'apparatus', I have aimed to catch the notion of the mutual shaping of

\footnotetext{
5 Anthropologist of Science Marianne de Laet, for example, contrasts the two modes of technology transfer in her study on patents (De Laet, 1999).
} 
ultrasound and particular social contexts, including that of the researcher. I thereby draw on the Foucauldian sense of an apparatus as being

... essentially of a strategic nature, which means assuming that it is a matter of certain manipulation of relations of forces, either developing them in a particular direction, blocking them, stabilizing them, utilizing them, etc. The apparatus is thus always inscribed in a play of power, but it is always linked to certain coordinates of knowledge which issue from it but, to an equal degree, condition it. This is what the apparatus consist in: strategies of relations of forces supporting and supported by, types of knowledge. (Foucault \& Rabinow, 1997, p. 196)

Linked to the knowledge coordinates provided by STS and Medical Anthropology, and working against the hegemonic discourse of Public Health as the main body involved in medical technology assessment, what I will write in the following is (a) technography ${ }^{6}$, an ethnography of technology. My aim therefore is twofold. I set out to write a complementary story to the existing descriptions of ultrasound as a camera shooting "baby's first picture" (Mitchell, 2001), the 'fetus-fetish' of 'the West' (see, for instance Morgan \& Michaels, 1999), and of a sex-selection device in India (Heesterbeek, 2000). Departing from these descriptions of ultrasound in particular contexts, I also propose technography as a heuristic device for assessing 'technology in the making'. Technography, as developed in this book is a dual analytical device - encompassing conceptual and dimensional frames - that aims to describe both how and why ultrasound and social groups as technology travels. Rather than being merely a research object fixed in specific locations and contexts, $m y$ ultrasound thus aims to also turn into an object for further research, that is, for assessing other technologies traveling to other places. Elaborating on ultrasound and travel matters, the following two sections will present the conceptual and methodological elements that make up this researcher's apparatus.

\section{Shaping a research object: ultrasound matters}

The question of 'How does ultrasound matter?' brings ultrasound users and uses into the picture. Two classic yet contradictory stories are endemic to contemporary policy debates, to common sense, to fiction and to some of the scientific discourse, their plots being that

\footnotetext{
${ }^{6}$ The term 'technography' was coined by the sociologist Holger Braun-Thürmann (2002)and colleagues in a research group headed by the techno-sociologist Werner Rammert.
} 
technology shapes society, either for the better in one scenario or for the worse in the other. Science \&Technology Studies, however, have long since told a third story, one that in contrast to the classic stories sees technology and society not as separate realms but as coproduced. Using the classic stories as stepping-stones, this section introduces the STS concepts that I consider to be the 'nuts and bolts' of technography and that draw attention to the politics that travel evokes.

\section{Classic stories: Magic Machines and Trojan horses}

The classic stories about the relationship between technology and society do not explicitly refer to technology transfer. Yet, as technology transfer to 'developing countries' expands the reach of technology's potential effects, the demands of the proponents of both story lines to be listened to and taken into account, increase in urgency. The first classic narrative is the story of the 'magic machine'. It is the optimistic story of hope, rationality and progress towards a better, peaceful world in which humankind will be freed from nature's vagaries. Medicine, in particular, has been enthusiastic about the ever increasing possibilities that new, and more and more sophisticated technologies provide for diagnosing, preventing, and treating diseases in pursuit of improving 'the quality of life.' ${ }^{7}$ This magic plot also feeds the so-called modernization approach in development theory and practice. This approach is rooted in the assumption that science and technology are interlinked with the ability of a country to promote economic growth. Hence, the evolution of more sophisticated technology is seen to carry with it more complex forms of society. Proponents of this classic story in development circles do not deny that technologies may end up as so-called 'white elephants' - a classic example being the tractor that instead of plowing African soil rusts away on it and works only to scare away the birds. Based on the overwhelming belief in technology's power to push and pull societies towards a better world, however, 'white elephants' are merely seen as the effect of faulty or insufficient information in the societies in question that by means of proper education could be remedied or avoided altogether (Gardner \& Lewis, 1996; Long \& Long, 1992; Rist, 1997; Shrum \& Shenav, 1995).

The second classic is the story of the 'Trojan horse'. It is the romantic story of despair about the technologically induced extinction of the natural, the loss of the subject

\footnotetext{
${ }^{7}$ For an elaborated critique on this technological determinism in the field of medicine, see Timmermans \& Berg (2003) and Barger-Lux \& Heaney (1986). An early and influential critic of medicine's claim of inevitable progress for the better was the sociologist Ivan Illich (1975).
} 
and of authenticity. While 'shiny' from the outside, modern technology embodies the seeds of destruction of social life and humanity, as these modern Cassandras warn. Among these story-tellers are many feminist-inspired scientists that raise their voices in favor of critical reflection on the ambivalent 'goods' of biomedical technologies with regard to their impact on women's lives. In particular ultrasound has been at the centre of these critiques.

Informing women about a yawning, waving or smiling child, "baby's first picture" (Mitchell, 2001), as is argued, 'quickened' pregnancy and allotted the fetus the status of a person. In consequence, this fetal personhood disembodied women's experiences of pregnancy and designated them as mere containers of 'fetal life'. Solely responsible for fetal well-being, women thus became easy targets for body politics by anti-abortion and health care prevention campaigns (Corea, 1985; Davis-Floyd, 1992; Duden, 1993; Hartouni, 1992; Rothman, 1986, 1989; Stabile, 1992). In development theory, this more critical attitude towards technology is echoed in the so-called dependency approach. Rooted in the political (Marxist) left, this approach sees science and technology as contributing to more rather than to less dependency from capital and market oriented societies and thus as supporting and enhancing unequal power relations (Gardner \& Lewis, 1996; Rist, 1997; Shrum \& Shenav, 1995). In this line of argument, transferring reproductive technology to other cultures means subjecting women worldwide to biomedical patriarchy and imperialism - its ultimate distortion being intrauterine 'girling' by ultrasound and subsequent abortion of unwanted female fetuses in India.

Denoting them as 'classic' stresses rather than diminishes the power and usefulness of these stories for the present: Feminist critique remains valuable in turning our attention away from the 'psychosocial impacts', with which medical literature has dismissed women's ultrasound experiences next to their 'hard' epidemiological facts, and towards the wider socio-political consequences of reproductive technologies (Ginsburg \& Rapp, 1995; Petchesky, 1987; Rapp, 1997). Concerns about sex-selection practices in India thus meet parallel concerns about practices that 'able' and 'disable' children in the womb in 'the North' (see, for example Rapp, 2000), both of which are aimed at (re)producing particular populations. Chapter 2, in turn, will present the stories of the 'magic machine' and the fear of 'white elephants' as driving forces for the transfer of those ultrasound machines which I followed to Ghana and Tanzania. 
There are, however, good reasons to be wary of these classic narratives. Both stories, for example, fail to be specific: society and technology are depicted as monolithic entities bare of the different interests and diverse histories that feed into them. Both technology and society are thereby treated as 'blackboxes', that is, as independent variables that explain social development in linear terms towards a world that is better or worse, but they are not themselves seen as in need of further scrutiny. Hence, both stories ignore the fact that technology and society mutually shape each other, and thus are co-produced. If both the social and the technical are to be taken seriously, however, then both have to be unblackboxed. As much work in the field of STS has shown, this requires that the interactions between technology and society have to be unraveled empirically without taking a particular technical or social ontology for granted. Instead, attention has to be paid to the mutual constitution of science, technology and society, to questions of agency and normativity, and to the values that come to bear on this process of mutual shaping. What do these insights mean for the question of how ultrasound matters in Ghana and Tanzania?

Dismissing the classic stories allows recognition that not only context and technology but also the objects this technology depicts are co-constituted, as sociologist Bernike Pasveer has demonstrated in her analysis of early x-ray images and the emergence of tuberculosis (Pasveer, 1992, 1994). Unraveling ultrasound in Ghana and Tanzania therefore means to be concerned with the conditions that enable or disable a particular ultrasound ontology: the 'sex-selection machine' in India, the 'pret-echo'* in the Netherlands or, as I will show in this book, the 'kioo' or 'video' in Tanzania and Ghana respectively. Society itself must be diversified in order to take into account different social groups touching and touched upon by ultrasound. This implies an inquiry about women and the unborn, but also about various health care professionals, policy makers, those that manufacture and supply ultrasound machines, and it asks to inquire about the images themselves. Who or what acts to (un)make a certain ultrasound, and who is empowered to act? Who is included in or excluded from acting? What do these inclusions or exclusions tell about, and how do they shape, the distribution of responsibility and guilt?

Dismissing the classic stories hence opens the door to a broader set of questions with which to review issues of (distributed) agency and normativity. The four sub-questions that guide this book therefore are: What are the obstetric facts that are depicted by ultrasound and what normative values do these facts carry? Why do women 'want' 
ultrasound, and how does this change their pregnancy experience? How does ultrasound affect existing health care arrangements and in turn how is it affected by them? And, to what extent are changes, both on the level of images and on the institutional level, be deliberately intended or accidentally developed? Taking into account these questions means bowing to the ontological flexibility of ultrasound and acknowledging its depicted objects as shaping and being shaped by society. In short they mean to consider ultrasound as an 'actor-network' or 'socio-technical ensemble', as STS has coined the constant togetherness of technology and (and in) society.

\section{New plots: Actor-Networks and Socio-technical Ensembles}

Focusing on 'actor-networks' or 'socio-technical ensembles', STS dismisses the technological determinism inherent in the classic stories and puts the processes of their mutual shaping at center stage. ${ }^{8}$ As I set out to describe ultrasound in Ghana and Tanzania as a process in which the technology, diverse social groups and the objects depicted by the technology are co-produced, I have chosen four concepts developed within this disciplinary field to form the first component of technography. These concepts, I argue, help to describe ultrasound as a changeable object and as an object for change when traveling from its original contexts to other places.

The first concept that technography therefore makes use of, is the concept of script. It is in the process of designing a technology, sociologist of technology Madeleine Akrich argues, that designers anticipate the future use(r)s of technology and inscribe these into the machines. According to Akrich, devices thus embody scripts, in the form of, for example, wire length, design of plugs, or of moveable or fixed parts. Similar to written manuals that accompany machines, the materiality of a technology also prescribes human-machine interaction in a particular way: "Like a film script, technical objects define a framework of action together with the actors and the space in which they are supposed to act" (Akrich, 1992, p.208). An ultrasound machine designed with a monitor that can be turned around as is the case for most ultrasound devices used in hospitals in 'the West', hence describes a medical world which emphasizes 'client-friendliness', 'consumer orientation' and 'the

\footnotetext{
8 The terms 'actor-networks' and 'socio-technical ensembles' emerge from the two different schools within the STS community that are commonly differentiated by the approaches they take towards the agency of non-human actors. Proponents of the so-called Actor-Network-Theory are, for example, Bruno Latour, Michel Callon, and John Law. 'Fathers' of the so-called SCOT-approach (Social Construction of Technology) who have coined the term 'socio-technical ensemble' are Wiebe Bijker and Trevor Pinch.
} 
informed patient'. At the same time, whilst it may prescribe the direction of a patient's view as she/he follows the examination of her/his insides on the monitor, it also prescribes to the ultrasound operator that he/she should provide the patient with an explanation of what is seen (see also Radstake, forthcoming). In contrast, a basic ultrasound machine without a moveable monitor may prevent professionals and patients from watching the screen simultaneously unless effort is made to turn the whole machine around. This different script does not necessarily mean that practice is patient-unfriendly; rather it may offer another kind of patient-professional relationship (see chapter 4).

The second concept is appropriation. Appropriation consists of practices by which users make a technology their own once it has left the world of designers, that is, by which they 'tame' a technology according to their need, and in order to build a certain group or individual identity. ${ }^{9}$ Practices of appropriation may consist of allocating a particular place to a new device, for example by deciding to put a PC in the living room or the basement (Aune, 1996). They may consist of designing schedules that regulate when particular members of a group are allowed to use the newly acquired technology (ibid.), or they may entail using the technology for different purposes than those for which it was designed. In short, appropriation includes acquiring skills and experience as to how, when and where to use a technology and what for. Time, placement and purpose thereby hang together: a placement of a PC in the living room for example serves the purpose of playing games while a placement in a study puts a PC to work as a type-writer (ibid.). In the process of appropriating a technology, users thus develop so-called user-scripts. These may follow the designers' scripts but may also counteract them. Portable ultrasound machines designed to be carried to patients' homes or hospital beds, for example, may end up fixed on a table in an ultrasound room which requires patients to move or to miss out on an ultrasound examination. Though such a (dis)placement may thereby mean that ultrasound fails to save patients, it may still work to turn an operator into a 'modern practitioner' (see chapter 4). Likewise particular placements can turn a state agency into a 'democrat' or a 'colonial emperor' (see chapter 3). While the initial meaning of script emphasizes the role of designers, the concept of appropriation emphasizes design as an ongoing and interactive

\footnotetext{
${ }^{9}$ The notion of 'taming' a technology derives from domestication studies that were the first to focus explicitly on the home as location to study the usage of technologies (see Lie \& Sorensen, 1996; Oudshoorn \& Pinch, 2003a).
} 
process throughout the life-cycle of a technology. Rather than passive recipients or neutral intermediaries, users here are seen as active mediators of a technology.

Both the concept of 'script' and that of 'appropriation' address the tension between the malleability and robustness of technology or, in the language of STS, between interpretative flexibility and subsequent closure (Bijker, 1995a; Pinch \& Bijker, 1987). In the process between scripting and appropriating, that is, in the travel between designers and users or between users and users, translations take place. ${ }^{10}$ According to anthropologist of science Bruno Latour (1987), translation is not merely to be understood as a matter of saying the same thing in another language. He argues that translation also involves transformation a change of form. A particular technological ontology may thus be the effect of translating the real world of users into a statistical user figure by means of surveys or by means of making the user the alter ego of the designer (Akrich, 1995). Latour demonstrates that translations happen inevitably. Yet, he also stresses that translations serve the strategic interests of actors: when put into a more acceptable form, things may help actors to stabilize certain knowledge claims. He warns though, that in translation some things get lost (Latour, 1987, 1999). Thus, when health care professionals in Northwest Tanzania claim that ultrasound is 'kioo', they do not only explain a technology within terms that make common sense - kioo meaning mirror when translated into English; they also enforce biomedical knowledge as the truth against local understandings of pregnancy and pregnancy diagnoses. What gets lost in this translation is the particularity of 'kioo' and the possibility that there is another reality, another set of relationships, and network of actors at play (see chapter 5).

As a fourth concept for technography I have chosen John Law's modes of ordering. ${ }^{11}$ With this concept, John Law (1994) points to steering principles embodied in, but also patterning, (existing) networks of social relations. These principles, he argues, do not determine precisely what has to be said or done but what those involved in the process of defining a problem and its solution consider to be relevant or peripheral. As they not only define but also create different materials (Law mentions devices, texts, agents, and architecture) and not only generate but also embody certain resources, modes of ordering

\footnotetext{
10 The concept of translation is fathered by the sociologist Michel Callon (1986).

${ }^{11}$ There are several terms found in the literature that refer to processes of ordering, e.g. Kuhn's 'paradigma' (Kuhn, 1962), Hacking's 'style of reasoning' (Hacking, 1992), Mol and Berg's 'logics' (Mol \& Berg, 1994), or Mesman's 'repertoire' (Mesman, 2002). I choose the term 'modes of ordering' as the concept explicitly stresses the materiality and multiplicity of practices that order worlds.
} 
distribute particular rights and plights and thus they may produce and reproduce asymmetrical relations. By generating and embodying particular worlds and world views, modes of ordering are thereby both reflexive and self-reflexive: " $[\mathrm{M}]$ odes of ordering tell of the character of agency, the nature of organizational relations, how it is that interorganizational relations should properly be ordered and how machines should be" (Law, 1994, p.20). Scripting, appropriation and translation are all modes of ordering. Whereas script and appropriation are actor-centered concepts, the concept of 'modes of ordering' also pays attention to structure.

These four concepts - script, appropriation, translation, and modes of ordering make up the first component of technography. They enable the critical description of technology transfer as a process of socio-technical change. In order to turn technography into a heuristic device for assessing the world-making capacity of technology, however, I need to add dimensions that explain why, and not only how, things change and travel gets organized in a particular way. The four dimensions I have chosen to that end, and that thus form the second component of technography, are: space, time, resource, and knowledge. Combining concepts and dimensions, technography as a heuristic device, as a methodology to see with, and as an assessment apparatus to judge with can be displayed in Figure 1.1:

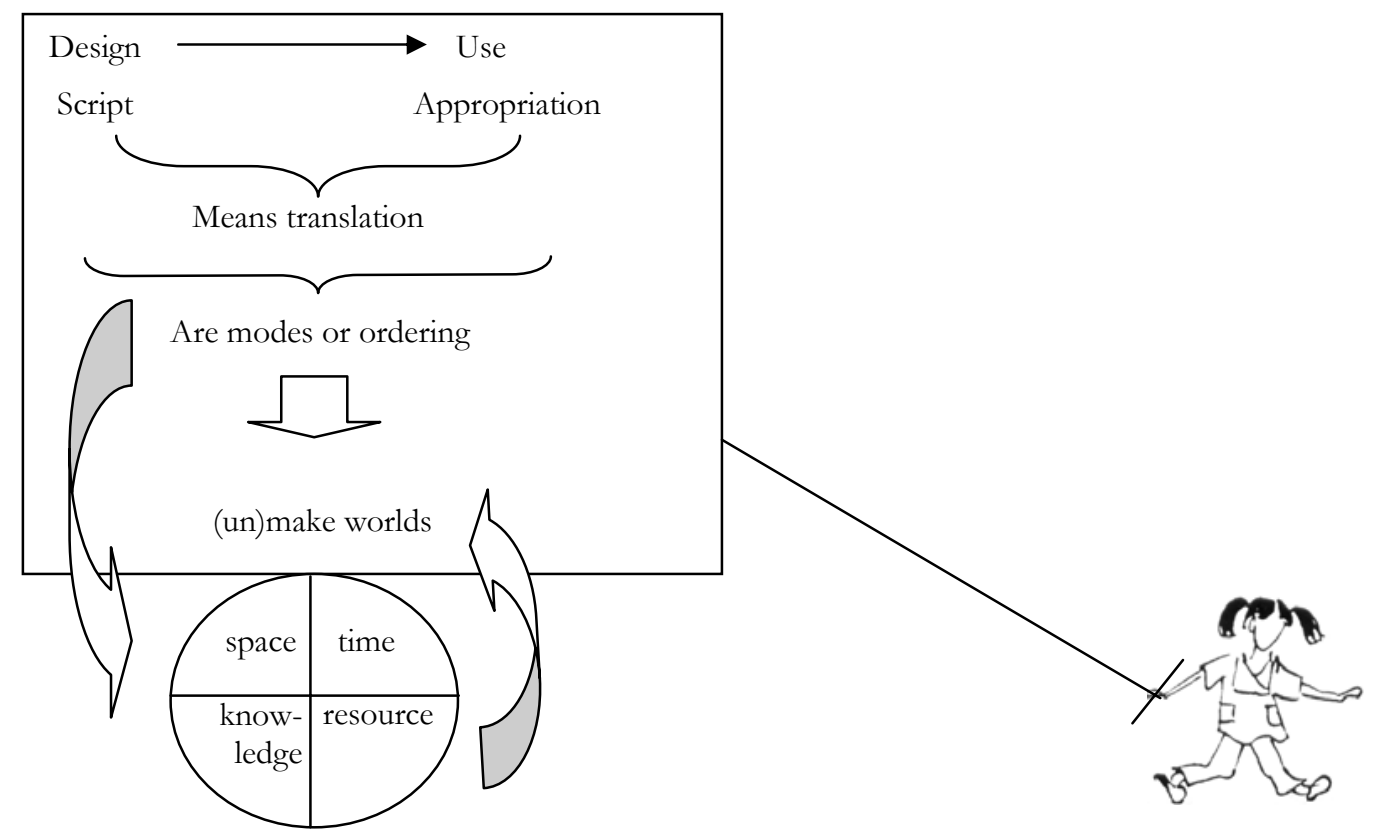

Figure 1.1 Technography as a heuristic device for assessing the politics of technology 'in the making' consists of four concepts - script appropriation, translation and modes - as well as four dimensions, within which worlds are ordered - space, time, resources and knowledge. Altogether, these concepts and dimensions form the baggage of somebody setting out to do technography - as displayed here in form of a cart pulled into the field. 
The focus on knowledge as a dimension for technography is an obvious choice: transfer of technology transfers knowledge. By definition transfer also implies a crossing of space, and any transaction requires resources as exchange matter (Appadurai, 1986b). The issue of technology's temporal affections runs through the literature, but has seldom been picked up as a parameter for its assessment: historian Barbara Duden, however, has noticed ultrasound's capacity to 'quicken' pregnancies and thus re-order body time (Duden, 1993).

All four dimensions are essential to social organization, thus are likely to affect and be affected by the introduction of a new technology. Taking the low-key terms space, time, resource and knowledge to be the dimensions on which to base assessment also serves to operationalize technography. Their usage in common language facilitates their travel beyond the example of ultrasound in Ghana and Tanzania. While these dimensions look straightforward, the following chapters will disrupt their immediate familiarity, make them ambiguous. Rather than abstract categories, space, time, resource and knowledge are the dimensions within which politics is situated. Accordingly, I claim that in order to transfer technology, one has to think along these dimensions.

\section{Insight in contexts}

Talking about 'ultrasound' as such, presupposes a common ground between the discussion partners. Talking about ultrasound in Ghana or about ultrasound in Tanzania adds a place but there is more. Studying ultrasound in Ghana and Tanzania means also exploring travel as a process in which different groups of people, interests, and other technologies are implicated. The 'in' thereby denotes the arena of politics where negotiations take place, struggles of influence and interests are fought over, where (il)legal matters may be involved, where people are included or excluded, where agency is distributed, and where choices are made. In short, it is in the 'in' where ultrasound matters, and where each of the four dimensions - time, space, resource and knowledge - is 'in the making'. Traveling after ultrasound to new places hence means involving and getting involved into this arena. What does this look like in practice?

\section{Tracking a research object: travel matters}

Studying 'ultrasound in Ghana and Tanzania' means tracking the encounters between technology and cultural contexts. It involves traveling after machines, paying attention to the 
transformations that this travel entails and documenting the jagged story-lines that emerge. This section is concerned with the questions raised by this joint move: How does the travel of ultrasound and that of the researcher intersect? And how do they inform each other? Elaborating on travel matters, this section describes my methodological approach in more detail. While travel hereby is presented as the mode and method for knowledge, limits to traveling can be at once obstructive and informative.

\section{A trajectory as 'the field'}

Following ultrasound machines as they travel from places of their manufacture in the Netherlands to Ghana and Tanzania turns the present book into a multi-sited ethnography. Coining the term multi-sited ethnography, anthropologist George Marcus proposed this new kind of ethnographic presentation in order to pay respect to the new contexts of anthropology's traditional fieldsites. Contemporary villages could no longer be regarded as isolated but should rather be seen as attached to 'the world of flows' (Appadurai, 1986a), as proponents of the so-called 'Writing Culture Debate"12 argued. Dong multi-sited ethnography, as outlined by Marcus, does not simply mean to extend one fieldsite to multiple fieldsites but to (re)construct the connections between different cultural sites. In order to connect sites, he proposed to follow people, things, metaphors, plots or stories, biographies or conflicts. ${ }^{13}$ Nevertheless, tracking these connections requires a "logic of association" (Marcus, 1998, p.90), rather than the systematic performance of traditional ethnographic methods. Pursuing different tracks, he argues, lead to paths of understanding and finally result in a trajectory, a central research statement. Hence, what is to be in the picture of a multi-sited ethnography is "an emergent object [...] whose contours, sites and relationships are not known beforehand" (Marcus, 1998, p.86). Multi-sited ethnography, hence, requires the imagination of the researcher in making and looking for associations: thinking about ultrasound as a device requiring repair, for example, meant studying

\footnotetext{
12 The Writing Culture Debate emerged in 1986 out of critique of the traditional anthropological claim that fieldwork based on participant observation presented 'the field' as objective truth instead of acknowledging it as an event constructed by the anthropologist. Prominent participants in the debate were George Marcus, Arjun Appadurai, and James Clifford . Nine years later, female anthropologists added another volume to this influential work called 'Women Writing Culture' (Ruth Behar, 1995; Ruth Behar \& Gordon, 1995). While George Marcus elaborated on multi-sited ethnography in 1986, here I cite from the reprinted original article published in his edited volume Ethnography through thick and thin published in 1998. ${ }^{13}$ Despite the claim of the medical anthropologist Sjaak van der Geest and others (Van der Geest, Speckmann et al, 1990) to make multi-sited ethnography the core research paradigm, few studies so far have taken up this challenge. Dilger (2005), for example, followed AIDS patients between urban and rural areas. Other anthropologists have followed particular metaphors (Karnik, 2001; Martin, 1994). Weissköppel (2004) traced the biographies of Sudanese living in the Diaspora, in Germany.
} 
international manuals and national regulations as well as maintenance schemes in hospitals and individual repair skills. The novelty of ultrasound in obstetric practices thereby led to situations where, at times, I was the one who introduced the technology into a setting, for example, making 'ultrasound', 'video', or 'kioo' a topic of discussion among women, thereby enforcing its emergence as an object of (my) interest.

The decision to follow particular ultrasound machines in their travel to Ghana and Tanzania transferred within a project set up by the Dutch company Philips Medical Systems situated in Eindhoven, made the choice of my first fieldsite seemed obvious. It was only after fieldwork in Ghana that subsequent talks with representatives of Philips Medical Systems revealed that they acquired the ultrasound machines for transfer from another, Maastricht based, company: Pie Medical. Traveling backwards, in terms of the actual origin of my research object, in turn illustrated a division of labor among the companies, the one being responsible for the 'nuts and bolts', and the other for the 'African attachments' (Figure 1.2). However, it also turned out that these manufacturers had a context that made me travel - virtually - to places as far away as Geneva and Washington (see chapter 2). While the factory at Pie Medical allowed me to observe the making of ultrasound machines, my methodological approach at the international level consisted mainly of document analysis and interviews with key figures in the business of technology transfer. 


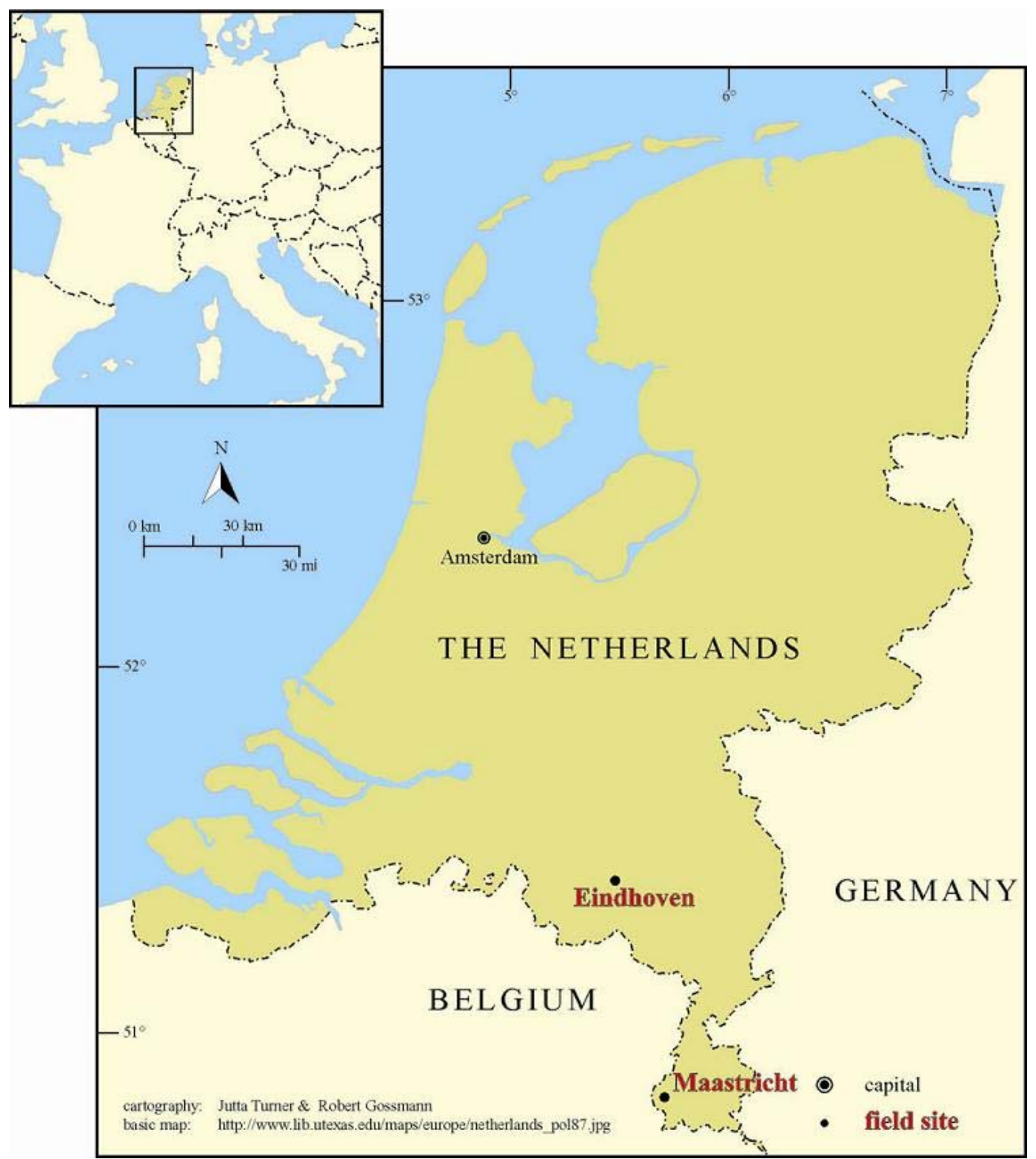

Figure 1.2: Map showing the fieldsites in the Netherlands. Maastricht hosts Pie Medical, while Eindhoven is the city where the headquarters of Philips Medical Systems are based.

The second fieldsite likewise emerged from an obvious trajectory, that is, from following these ultrasound machines to their immediate recipients: particular state departments of the Ministry of Health in Ghana and Tanzania. Similar to the fieldwork at the international level, my explorations into ultrasound at the state level involved interviews with state representatives, document analysis, and the fortunate opportunity to participate in an event where I became a witness to the making of reproductive politics in Tanzania (see chapter 3). 
The third fieldsite consisted of the actual working places of ultrasound in health care facilities at each country. Departing from the idea that ultrasound matters in context, I decided to study different hospital types. My choice of a big urban based and a rural district hospital was rooted in the assumption that the appropriation of ultrasound might differ with regard to the geographic distance of these places (and the people inhabiting them) from the 'world of flows'. In Ghana, I chose Korle Bu Teaching Hospital in the capital Accra as a fieldsite as well as the Baptist Medical Center in Nalerigu, a small village about 3-4 hours away by trotro* from the nearest big city Tamale in the north of Ghana (see Figure 1.3).

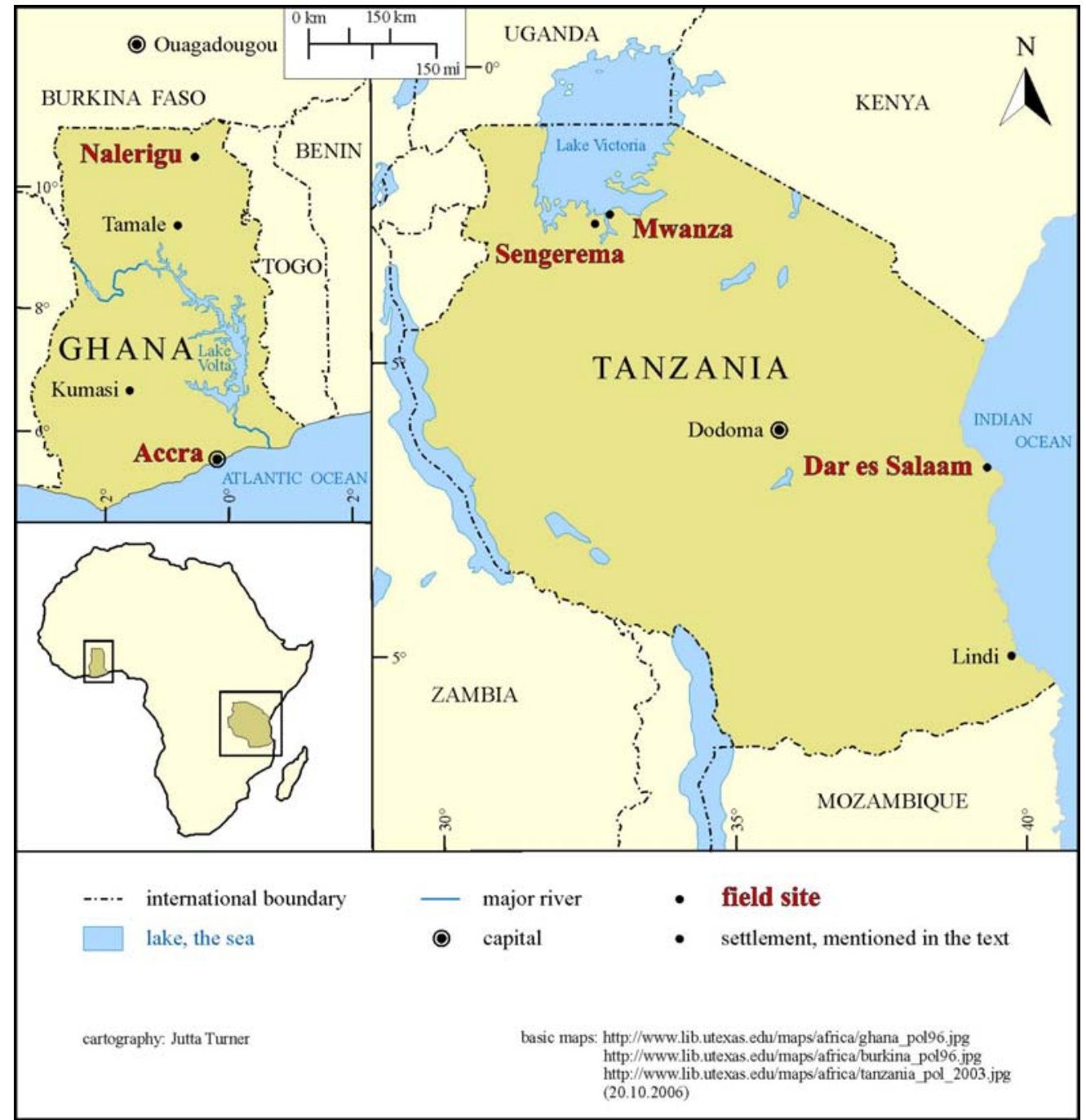

Figure 1.3: Maps showing the fieldsites in Ghana and Tanzania. Accra is the site of the Ghanaian Ministry of Health and Korle Bu Teaching Hospital. Nalerigu is the village that hosts the Baptist Medical Centre. In Tanzania, likewise, Dar es Salaam is the site of the Ministry of Health. Mwanza is the location of Bugando Teaching Hospital, Sekotoure Regional Hospital and Makongoro Antenatal Clinic. Sengerema is the village on whose outskirts Sengerema Designated District Hospital is situated 
I adhered to this basic choice in Tanzania as well. In contrast to Ghana, however, I did not choose the Teaching Hospital in the unofficial capital as a fieldsite - Muhimbili Hospital in Dar es Salaam ${ }^{14}$ - but a Teaching Hospital in a far away region in the Northwest of the country: Bugando Teaching Hospital, situated in Mwanza town at the shore of Lake Victoria. Although it is a big city, Mwanza, as I had heard, was much less a melting pot for various ethnic groups than Accra or Dar es Salaam, each of which attracted people from everywhere. The greater homogeneity, I hoped, would facilitate tracing ultrasound back into ethnic-specific worlds. Unlike Korle Bu in Accra or Muhimbili in Dar es Salaam, Bugando Teaching Hospital did not acquire a Philips machine during the project. Instead the 'Philips Project' involved Dr. Pumusi, the head of the gynecology department, who was among the first group of operators to be trained. He remained the only medical doctor trained in the project at all. His inclusion was based on the hope that he, as a key figure in gynecology, would spread the knowledge of ultrasound and of the presence of the new ultrasound machines beyond the geographical and temporal boundaries of the project. In contrast to Ghana, where the two hospital fieldsites were 14 hours apart and belonged to different regions, in Tanzania I chose a district hospital in the same region. As well as keeping an 'ethnic focus', I assumed that this choice of closer facilities might help me to explore ultrasound's role in the referral chain between hospitals. Sengerema Designated District Hospital was situated about $35 \mathrm{~km}$ away from Mwanza town, equivalent to 2 hours travel by ferry and bus or dalladalla* to the interior of Mwanza region (see Figure 1.3). In addition to these hospitals, an urban antenatal clinic (with the official status of a district hospital but without delivery facilities) in Mwanza town became a third hospital site for fieldwork in Tanzania: Makongoro Antenatal Clinic. My inclusion of this clinic in the study followed a suggestion by the local supervisor that I had been matched up with by the Tanzanian Committee for Science and Research (COSTECH) that had approved of my proposal. According to him I would not be able to understand ultrasound practices in Bugando without studying Makongoro Clinic as the latter facility provided the bulk of pregnant patients for Bugando. However, as Makongoro Clinic according to the official referral chain primarily referred women for ultrasound to Sekotoure Regional Hospital in town, I expanded my research to include Sekotoure's ultrasound room as well. In hospitals, my

\footnotetext{
14 The official capital of Tanzania is Dodoma. Dar es Salaam, however, is the unofficial capital with regard to its closeness to the 'world of flows' as a harbor.
} 
methodological approach consisted of participant observation and informal and formal talks with different staff members in antenatal wards, the ultrasound room, labor and maternity wards, laboratories, reception areas, and archives.

In order to trace ultrasound into women's worlds, I followed the individual trajectories of women who became ultrasound patients. Thus, I observed their preparation as ultrasound candidates, the actual ultrasound examination and the subsequent care trajectory. In many cases it was possible to trace ultrasound in a woman's trajectory in the hospital from antenatal care to the ultrasound room and back. Constrained by distances between people's homes and the hospital and my lack of transport, I only visited a few women at home, mainly in urban areas. In several cases, however, I missed parts of an ultrasound trajectory, meeting a woman only in the ultrasound room or losing track of her whereabouts thereafter. In order to understand pregnant women's worlds and practices before ultrasound, I talked to the women whose examinations I observed about what had brought them to the hospital. Where possible I also talked to women's husbands or other relatives, as well as chatted with women in the market, and interviewed mothers and grandmothers of friends. Realizing that pregnant women frequently attended the services of traditional healers in Tanzania or gave birth with Traditional Birth Attendants in Ghana, especially when the perceived their pregnancy to be 'at risk', I also incorporated traditional health care professionals into my approach to trace ultrasound in Ghana and Tanzania.

These fieldsites are connected by ultrasound and by my research. Conducting multisited ethnography, however, makes it difficult to say when 'fieldwork' actually begins. Studying processes of technological change that originated in my own cultural context, denies fieldwork the classical entry story that many anthropological works still adhere to. My first explorations into studying 'Ultrasound in Ghana' date back to November 2001, that is, to a point in time where I had just started working on the project. Searching the internet, I was provided with a well elaborated insurance plan to be paid for by Ghanaian expatriates for their relatives at home, ultrasound being part of the so-called 'silver', 'gold' or VIP-plans with discounts enabling it to be used routinely once a year (http://ghanacare.org.services.html; retrieved 3-4-2002). My initial discussions with Philips representatives, in turn, date back to the beginning of 2002, yet I gained access to archival material only in January 2006, shortly before my contract officially ended. The actual stay in Ghana, however, lasted six months between October 2002 and March 2003. My stay in 
Tanzania lasted seven and half months between February and September 2004, followed by a two week visit to the same sites in December 2005. I have followed up ultrasound in Tanzania since then by means of email-correspondence with friends, doctors, nursemidwives and operators.

As the sketching out of my methodological approaches demonstrates, tracking down an emerging object can be tedious and, as I will illustrate in the following section, also sometimes tricky work. Anthropologist Vered Amit has poignantly summarized the challenges of studying (in) emerging fieldsites with the following words:

[1]n a world of infinite interconnections and overlapping contexts, the ethnographic field cannot simply exist, awaiting discovery. It has to be laboriously constructed, prised apart from all other possibilities for contextualization to which its constituent relationships and construction could also be referred. This process of construction is inescapably shaped by the conceptual, professional, financial and relational opportunities and resources accessible to the ethnographer. (Amit, 2000, p.6)

In the context of constructing fieldsites and-objects I feel obliged to make a note about language: the grammatical has intellectual and, as the anthropologist Johannes Fabian (1983) has noted, also political significance. The use of an ethnographic present is connected to a conceptualization of culture as coherent and unchanging, and of anthropological subjects as exotic beings. In studying processes and practices, and departing from the notion of 'change', witnessing changes and perhaps contributing to some of them, I have chosen to use the historical past and keep the ethnographic present only for the little vignettes with which some of the chapters start.

\section{Challenging fieldsites}

"Travel", anthropologist Marianne de Laet states, "turns the ethnographer into an instrument, an apparatus, an inscription device, an object in its own right" (De Laet, 1998, p.226). Yet while travel has been the epistemological precondition for anthropology to tell about 'the other', few anthropologists openly consider themselves as travelers. Rather, she says, "we point to the ways in which we are part of what we study" (ibid., p.227). According to anthropology's disciplinary ideals, ethnographers take over particular roles, learn the language, and adapt their styles of clothing. This transformation of a researcher into somebody partaking in her/his new community holds true for single-sited as much as for multi-sited ethnography. Multiple field-sites, however, multiply roles, languages and dress 
codes. Following ultrasound machines to hospitals made this multiplicity condense in limited space. Tracing ultrasound across different wards, into doctors' offices, the archive, to patients' beds, the outpatient department or the storeroom thus meant that I had to change roles and language, and sometimes also dresses, not only every day, but several times a day.

Although an 'object in its own right', as De Laet suggests, an ethnographer is also bound to certain roles that she is attributed with: for the ultrasonographers at Korle $\mathrm{Bu}$, for example, I was somebody similar to their medical students who wanted to learn how to do ultrasound; for the nurse-midwives, in contrast, I was 'one of them', a colleague with whom to share midwifery concerns; the interns requested that I become a mediator to convey their need for more standards to the specialists, and for women I seemed to be somebody with an open ear and a source of influence. Kept apart, these multiple roles can nicely co-exist, yet in the limited space of a hospital they can also clash. The following story illustrates a clash of rights I became the object of:

Eight weeks after I had started my fieldwork at Korle Bu Teaching Hospital in Ghana I was summoned to the Head of the Department of Gynecology and Obstetrics. In quite a tense atmosphere he told me that 'the board' thought that I had been sent by the Ministry of Health to check on professional practices and report malpractice, that I was telling doctors what to do, that I was inciting patients and inquiring about ultrasound from unqualified personnel, and that I was taking pictures that showed the torn mosquito nets on the wards with the aim of publishing these photos at my home place. His accusation of my being "a spy" instead of a scientist resulted in my expulsion from the facility. It finally led to the withdrawal of the Ministry of Health's support of the research, my premature departure from the country and a limited or, euphemistically termed, other kind of research of ultrasound in Ghana based on the interviews I had made, written materials and information by friends while remaining at my desk in Maastricht.

Claiming the four dimensions of space, time, knowledge and resources to be fit for assessing technology 'in the making', what would they say about the researcher's apparatus? In terms of 'space', the allegation of the Head of the maternity block, for example, points to a particular social geography - a strained relationship between the Teaching Hospital and the 
Ministry of Health. In terms of 'time', I learned only later on, the former relationship had been one of absolute authority of the Ministry over the Teaching Hospital. In the wake of a policy of increasing decentralization, the new order that provided the Teaching Hospital with more independence led to considerable unease among the doctors. Had I come before that change or so long after it to allow new hierarchies to solidify, the story might have ended otherwise or never occurred at all. In terms of 'resource', his accusation referred to particular absences of undamaged mosquito nets, for example, or money to exchange torn ones, and particular presences, for example the ever watchful eyes of donors, and the authority of images. His allegation that I had told doctors what to do, however, remained a puzzle to me until I came to understand a difference in knowledge making practices between health care professionals in Ghana and my own knowledge about ultrasound. The following excerpt of a talk with one gynecologist at Korle Bu Teaching Hospital in Ghana illustrates this cultural difference:

BMR: Why did you send this woman for ultrasound?

Dr.: She is 28 weeks by gestation age but the fundus* is just about 24 weeks. So I sent her for ultrasound to find out how far the pregnancy is.

BMR: Aha. So the next time you had a woman with this discrepancy between gestation age and fundal height you would also send her for ultrasound?

Dr.: The next woman, I will know when I see her. I will send her for ultrasound if she needs it. (FN 01.11.02)

The misunderstanding in this conversation pertains to the different kinds of ultrasound that were put forward by the participants. Originating from a context in which ultrasound is standard, and in pursuit of possibly emerging ultrasound standards, $I$ inquired about a pattern. The answer I got, however, demonstrated a different order: in terms of 'time', ultrasound was not a routine but part of a contingent order; and in terms of 'knowledge' not a technical decision but one based on professional art.

The smooth story of choosing fieldsites outlined in the previous section - a quasi natural sequence of following ultrasound to Ghana and then to Tanzania - hence, is only partly true. While conceptually sensible in terms of my argument underlying the research that context matters - studying ultrasound in Tanzania was also sheer necessity. The example above thereby illustrates that fieldsites may be challenging for the researcher, but that a researcher is also challenging for fieldsites. 


\section{Insights in/off limits}

Travel has limits, and so insights into contexts also face limitations. Shaped by financial or professional relations and resources (see Amit, 2000 above), some fieldsites can be 'off limits'. I would have liked to study ultrasound at the governmental District Hospital on Ukerewe Island, a 'far away'-place in many respects, where due to a broken generator and the subsequent return of the Philips-trained operator to the mainland, ultrasound examinations were not performed any longer. My cooperation partners at the Ministries of Health in both countries and in Tanzania also at the Ethical Committee, however, insisted that I worked where ultrasound 'worked'. Their advice met with my interest to also study women's actual experiences of ultrasound examinations which I could not have pursued with machines incapable of performing scans. The rural health care facilities in both countries that I ended up working in thereby turned out to be former mission hospitals. The insistence that I attend 'working' facilities, hence, reproduced the persisting asymmetries between urban and rural hospitals on the one and governmental and mission hospitals on the other hand. Working with(in) boundaries, in sum, does not only constrain but also reveals much about the intricacies of technology transfer. Transgressing these boundaries may have a price: it can lead to resistance towards technologies and researchers alike.

\section{Ordering the book: a travelogue}

Following ultrasound machines from their context of origin to various contexts in Ghana and Tanzania, my book is a travelogue. Based on the researcher's apparatus outlined in this chapter, the following four empirical chapters describe the transformation of ultrasound from a device-to-reduce-maternal-mortality-statistics (chapter 2 ) into a device-to-boostnational-health care-with (chapter 3), into a device-to-run-a-hospital (chapter 4) and finally into a device-to-support-carry-ability (chapter 5). Each of these empirical chapters foregrounds one of the four dimensions - space, time, resource and knowledge - while the other three are back-grounded. This separation only serves analytical clarity. In order to assess technology 'in the making', all four have to be taken into account.

Exemplifying the dimension of space, chapter 2 deals with the international apparatus in pursuit of the question of how ultrasound shapes and is shaped by space (or spatial practices). Preceding the transfer of ultrasound, space is re-ordered: particular social groups, here African women, are turned into subjects with 'needs' that can only be remedied 
by the envisioned technical solution. The collective enterprise of international agencies and multinational companies to assemble local data and display this information in a universal manner answers these constructed global needs with appropriate global goods. The selfreferentiality of the international apparatus, hence, is systematic. Chapter 3 addresses the question of how this international apparatus is being appropriated by Ghanaian and Tanzanian state agencies. Using the dimension of resource as an analytical point of departure, I explain the transformation of ultrasound into a 'national health care booster', and device-to-do-professional-politics-with as the effect of a process in which the state apparatus mobilizes and is mobilized by particular resources. These resources gain or lose value within the process of being exchanged. Concentrating on the dimension of time, chapter 4 pursues ultrasound in various types of hospitals in Ghana and Tanzania. The success and failure of ultrasound in reducing maternal mortality statistics are explained in terms of the (in)capacity of ultrasound to link with the diverse temporal orders of the clinic. 'Running a hospital' in terms of providing health, I conclude, requires ultrasound to be used not only in passing patients through the hospital but also in the active creation of passages that link different temporal orders. Subjected to these passages are pregnant women and mothers. Focusing on the dimension of knowledge in chapter 5, I will show that the women's apparatus rests on local bodies of knowledge that enact any body as a collective of relationships to visible and invisible entities. Informed by and informing these local bodies of knowledge, the Ghanaian 'video' and the Tanzanian 'kioo' assist women to design and follow a variety of care trajectories. Knowledge thereby does not necessarily undo uncertainty but it increases women's security that everything is being done to ensure their ability to carry children. In conclusion, chapter 6 will return to the question of the politics of ultrasound travels to Ghana and Tanzania, and will embed technography into existing apparatuses of assessing technology.

Now that the travel schedule is set, the potential readers (and travelers) are assembled, the 'beware' section has been added, and instructions are given on how to understand technological change, the journey may begin. In the following chapter, it will take us as far as to Washington and Geneva and as near as the manufacturing hall of the ultrasound machines that this book has followed to Ghana and Tanzania. From the table of the researcher the latter part of this travel is short - by bike it is only fifteen minutes over the old bridge that crosses the river Maas. 


\section{Imagin(in)g the World - the international apparatus}

Other than at the table of the social scientist, ultrasound in the manufacturing hall of Pie Medical in Maastricht is not an object for but an object of many years of international research. ${ }^{15}$ According to the World Health Organization (WHO) and the World Federation for Ultrasound in Medicine and Biology (WFUMB), ultrasound belongs to the category of diagnostic imaging technology. Equipped with a piezoelectric transducer that emits sound waves and receives their reflection by body tissue, it is an observing apparatus. Electronically enhanced, these reflections can be displayed in different shades of grey on a monitor, which allows the diagnosis of bodily formations and malformations (Palmer, 1995, p.3; see Figure 2.1).

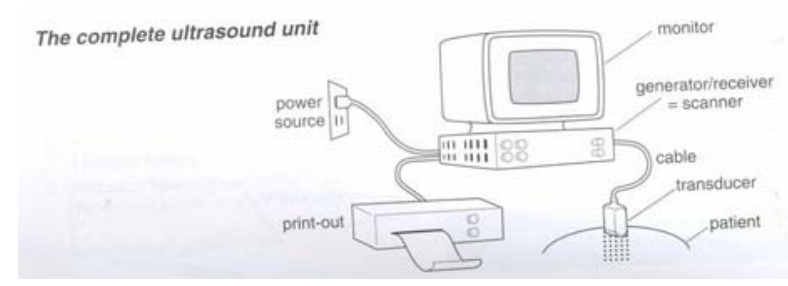

Figure 2.1: A complete ultrasound unit consisting of a transducer connected to a generator and monitor. A printer is not obligatory. (Source: Palmer, ibid.)

Certified according to international standards set by the European Union and the American Food and Drug Administration, Pie Medical's ultrasound machines have long been international: they travel to a range of European countries and the United States. By the end of the 1980s, however, these machines extended their internationality. This expansion was provoked by the observation of Philips Medical Systems, another company situated in the Netherlands, that "in Africa a lot of people were either pregnant or sick, or both" (Ai 1a). ${ }^{16}$ This discovery turned particular ultrasound machines into imaging devices for Africa in order to reduce maternal and perinatal* mortality within a project which I will refer to as 'The Philips Project' in the following discussion. ${ }^{17}$

It is this international apparatus that the present chapter is concerned with. Looking at this apparatus with attention to the dimension of space, I argue that this 'ultrasound for

\footnotetext{
${ }^{15}$ For a history of ultrasound see Stuart Blume (1992).

${ }^{16}$ Interviews with Ghanaians are referred to as $G$, interviews with Tanzanians as $T_{2}$, all other interviews whether held in Ghana, in Tanzania or elsewhere are referred to as $A i$. The number indicates a particular person - see Appendix A listing pseudonym, date of interview, and the language in which the interview was conducted.

17 The company itself refers to their projects in Africa as ORET projects (see below).
} 
Africa' rests on tying together particular conceptualizations of Africa, African women and ultrasound technology in such a way that the latter is seen as an appropriate solution to the problems of the former. I am thereby interested in exploring a space where this observed relationship is not considered to be bizarre, but to make perfect sense. Taking 'space' into focus allows seeing ultrasound machines not as isolated artifacts but as part of and constitutive participants in what I call 'Health Care International'. ${ }^{18}$ With this term I aim to grasp the network of international institutions, research centers and conventions, transnational corporations and multi- and bilateral donors that have come to shape health care worldwide with a variety of transportable vehicles, among them also ultrasound. ${ }^{19}$

I will pursue my argument in four sections. In the first section I will present the discursive practices - the images - with which international development agencies currently depict 'Africa', 'Women and Children' and 'Science and Technology'. Conceptualized both as 'in need' and as needed for Africa's development, African women turn into legitimate targets for technical interventions including ultrasound. Transformed into statistical figures, 'women' and 'Africa' become global goods that circulate beyond their actual localities to end up in a variety of places, among them design tables, manufacturing halls, and policy papers in the Netherlands. In the second section I will describe how 'The Philips Project' drew on, and was drawn into, this international regime while designing 'ultrasound for Africa'. Other than what the simple term 'global goods' implies, building Africa into a market involved considerable work and for the company meant they had to go 'local' in both expected and in unexpected ways. In the third section I will highlight the similarities and differences among practices employed by transnational agencies. Following ultrasound to the international level, thus at the same time provides insights into contemporary development policy and practice. ${ }^{20} \mathrm{I}$ will conclude that the world order imagined by 'Health Care International' and enacted by Philips' imaging devices rests on pragmatic shifts between 'the local' and 'the global'. In the last section I will draw from these insights to show how the dimension of space matters in and for technography.

\footnotetext{
18 This term is inspired by James Fairhead and Melissa Leach's analysis of the working of 'Tropical Forest International' in Guinea and Trinidad (Fairhead \& Leach, 2003).

${ }^{19}$ An example of 'Health Care International' is the so-called Task Force Health Care, an alliance consisting of health care technology manufacturers (Philips Medical Systems, Siemens, Drager, etc.) and of research institutions such as the Royal Tropical Institute in Amsterdam and parts of Maastricht University.

20 These practices and policies have been poignantly subsumed under the term 'development apparatus' by the anthropologist James Ferguson (1990).
} 


\section{Depicting development subjects}

The ultrasound that travels from the Netherlands to Ghana and Tanzania rests on particular conceptualizations of 'Africa', 'Women and Children' and 'Science and Technology', all of which are key subjects in current development discourse and practice. Official documents of internationally operating agencies resemble each other in the tropes through which Africa and women are commonly depicted: as marginalized entities in relation to either other continents or other population groups. In order to bridge these gaps and to provide Africans with equal rights, international agencies promote the transfer of mobile, portable and low key technologies; for some time ultrasound has been among them.

\section{'Africa' - a continent with a chance}

According to the World Bank's millennium report Can Africa claim the $21^{\text {st }}$ century?, Africa finally is a continent with a chance (World Bank, 2000). This chance, or so the authors argue, rests on the international consensus that all efforts shall now be bundled to fight Africa's most salient feature and greatest source of death and disease for its people - poverty. Africa's poverty, it is argued, results from a "growth crisis" (World Bank, 2000, p.18). This crisis is sketched out in detail in the fourth chapter headed 'Africa's Human Development Crisis', in which the first sentence of each subsequent paragraph presents another act of the African 'drama'. Following the logical sequence of the argument, this drama starts with overpopulation and ends with wars and droughts that quasi naturally emerge out of the first problem:

In only a few African countries has fertility started to decline. [...] So high has been the growth of the school age population that African countries have had trouble keeping enrolment rates constant. [...] Low primary enrolments seriously undermine economic growth and poverty reduction. [...] The content and quality of African education is also in crisis. [...] Another major factor affecting school performance is the health and nutrition of students. [...] Ill health in Africa results much more from infectious diseases and nutritious deficiencies than it does elsewhere. [...] Indeed the burden of disease is dramatically higher than elsewhere. [...] Every three seconds an African child dies [...]. Life expectancy in Africa increased between 1950 and 1990, though at a lower rate than elsewhere. [...]. As noted, there are more than 8 million orphans in Africa as a result of HIV/AIDS, 1 million in Uganda alone. [...] Though perhaps the most dramatic element undermining family structures and threatening income security, HIV/AIDS is not the only one. [...] War and conflict come on top 
of other external shocks for many people, such as more than 30

years of drought in the Sahel. (World Bank, 2000, p.104-110)

This description suggests that Africa's growth crisis results from growing (in) the wrong way. Africa is poor because it is not growing economically; and it is not growing economically because many of its countries only grow in the number of uneducated, diseased people who in turn produce costs that "double those from other developing countries" (World Bank, 2000, p.23). These increased and increasing costs stand in sharp contrast to the income that the continent yields. With reference to one West European country, the World Bank outlines the severity of the problem: " $T \mathrm{~T}]$ he region's total income is not much more than Belgium's and is divided among 48 countries" (2000, p.83). In consequence, half of the population, "some 300 million Africans" (ibid.), live below the poverty line, that is, on less than one dollar per day (UNDP, 1997; World Bank, 2000). Poverty, however, does not limit having something but also being somebody in the sense of a respected member of one's community, as the World Bank stresses: "The poor are not simply the rich with less money. They often live in different areas, frequently the most degraded areas" (World Bank, 2000, p.84). Of great international concern therefore is that poverty in Africa is progressive, as the Bank diagnoses with regard to the time when many African countries acquired their independence: "The average income per capita is now less than it was in 1960 " (2000, p.83). Africa, the authors conclude, may thus face a "dynasty of poverty" (2000, p.10) whereby the descendants of the poor are likely to remain poor too.

Notwithstanding these problems, the World Bank is convinced that on the verge of the new millennium Africa is "not doomed to poverty or its poor development record" (2000, p.12) but that the continent has a chance to "overcome the development traps that kept it confined to a vicious cycle of underdevelopment, conflict and untold human suffering for most of the $20^{\text {th }}$ century" (2000, foreword). This conviction is based on three observations. The first is that Africa's condition in 2000 resembles that of Asia in the 1960s. Against all predictions of a lasting stagnation, this latter continent nowadays encompasses many of the fastest growing countries. The second observation is that some African countries have meanwhile made it from "headlines" to "headway", as the World Bank puts it (2000, p.7), and thereby have proven that there is a way out of fate. The achievements of individual countries are illustrated by separate textboxes scattered throughout the report (2000): 'Decentralization in South Africa' is the title of one such a textbox, 'Uganda's 
Commitment to Basic Education' another, 'Improving Nutrition in Madagascar', 'Privatization in Cote d'Ivoire', 'The Winners and Losers from Reform and Recovery in Ghana and Guinea' or 'Chad's Health and Safe Motherhood Project' still others. Referring to Botswana as an example of "one of the world's fastest-growing economies in recent decades" (2000, p.7), the Bank points to the motor of profit - better economic management.

The third observation underlying the conviction that Africa is not doomed to remain poor forever is simply the beginning of a new era from which Africa in particular will be able to profit. This new era emerges from the end of the world's bi-partition into colonizers and colonized, as embodied in Africa's people: “[W]hile Subsaharan Africa (Africa) entered the $20^{\text {th }}$ century a poor mostly colonized region $[\ldots]$, the new millennium will consist of a majority of Africans born after colonialism" (ibid.). The new era is also characterized by the end of the postcolonial tri-partition into First, Second and Third Worlds. With the end of the Cold War, the authors stress, African countries finally ceased to be "ideological and strategic battleground[s]" (World Bank, 2000, p.2). Formerly provided with development assistance according to ideological alliance and "regardless of their record on government and development" (ibid.), Africa's independence has reached a new stage, the authors conclude: "Africa has been experiencing its own Renaissance, in the true sense of a rebirth of thought on governance and development policies" (2000, p.14).

The way out of poverty, however, requires an overall transformation, the World Bank warns in its foreword to the millennium report, stressing that " $[t]$ here is no simple formula". It can therefore not be walked alone but has to be taken by all countries. Based on a "coherent and comprehensive vision of development and nation-building" (ibid.), the Bank proposes that countries have to learn best practice from each other and to sincerely dedicate themselves to overcoming traditional distances:

Claiming the future involves enormous challenges - not least of which is resolving the problems of the past. Much of Africa's recent economic history can be seen as a process of marginalization - first of people, then of governments. Reversing the process requires better accountability, balanced by economic empowerment of civic society - including women and the poor - and firms relative to governments, and of aid recipients relative to donors. Without this shift in power and accountability, it will be difficult to offer the incentives Africa needs to accelerate development and break free of poverty. (World Bank, 2000, foreword) 
Furthering this transformation means turning the four "circles of cumulative causation" that underlie Africa's problems from "vicious" to "virtuous" ones (2000, p.39), as the authors argue. The first virtue to embark on is decentralization. Claiming decentralization as a solution to Africa's problems is by no means new. High on the international agenda in the field of health since the Primary Health Care Initiative set up by WHO and UNICEF at Alma Ata in 1978, decentralization has underlined the promotion of change from urban hospital to rural and community based basic health in developing countries. In developed countries, in contrast, decentralization fed into the switch from project to program based aid, and thus from vertical to multi-sector approaches. Central in the Bank's concern with decentralization since 1987 has been the issue of governance. 'Better governance', the Bank repeats its old argument in the millennium report, is exerted by a government that reaches its people. Instead of clinging to central ruling, African governments therefore are to move power to districts and regions. This move, according to the authors, will counteract both the marginalization of the people from their governments and the latter's marginalization from aid brought about by this distance from democratic values.

The second virtuous circle concerns the requirement to invest in people. Instead of focusing on natural resources, Africa should instead pay attention to its human resources. Using the latter as "productive base" (2000, p.41), the World Bank claims, will put an end to what the World Bank has located as the beginning of all of the problems - Africa's high fertility. Key strategies to employ in this context are health care education and the promotion of gender equality to eventually profit from the "strong interrelationship between investing in people, accelerating the demographic transition, and promoting savings and growth" (ibid.).

Similar to the first, the third circle too consists of practices that have long since been promoted by the World Bank. Geared to "increase competitiveness and diversify its economy" (2000, p.42), these practices condense in privatization policy. In the Structural Adjustment Programs for Africa in the 1980s, private institutions were promoted by the World Bank and the International Monetary Fund as a parallel system to government institutions (see World Bank, 1993). Since the 1990s, privatization has taken on a new face in the sense that the state is now given a major role as the manager of a range of health care providers (see World Bank, 1997). The price that national governments embarking on these programs have had to pay - the abandonment of the socialist inspired provision of free 
health care for all people - is to be reimbursed, or so the ideology of the new privatization policy argues, by the fact that government hospitals can now charge user fees which relieves the government from having to pay for all their expenses. Moreover, the proponents argue, increasing private practice creates incentives for government hospitals to improve their performance (Bennett \& Ngalande-Banda, 1994, p.14, 33). ${ }^{21}$ So-called public-private partnerships (PPP's) in the health care sector are the more recent solution put forward in international (health) policy circles. Doctors in governmental hospitals are thereby permitted to offer, and hence charge for, private services. Formerly private facilities, such as mission hospitals, are transformed into so-called designated district hospitals. This transformation is promoted as a win-win situation for both parties: it enables the government to extend public health care to rural areas and submit private hospitals to government regulations, and it allows the participation of private hospitals in the national central supply system and the take over of staff salaries by the government. Not only for the rural population but also for the growing urban population, these partnerships were held to be important as they would increase the job satisfaction of health care professionals which in consequence would serve political stability and create a "competitive democracy", as the Bank concluded (World Bank, 2000, p.84).

The fourth vicious cycle that needs to be turned into a virtuous one, according to the World Bank, concerns Africa's attitude towards aid. Admittedly, the World Bank states, aid has been a "two-edged sword" (2000, p.44). While it has permitted a "higher investment for growth and higher consumption to reduce poverty" (ibid.), it has often also resulted in aid dependence and debt service. The new approach that the Bank envisions for Africa in the era of globalization therefore requires a "business plan conceived and owned by Africans" (2000, p.2). In its design, the Bank promises, Africa will be supported by donors "through coordinated long-term partnerships" (World Bank, 2000, p.27). This new relationship in consequence requires new commitments from both parties: donors have to subject to the new terms, and Africa has to take advantage of this "window of opportunity" (2000, p.15).

\footnotetext{
${ }^{21}$ Designed on a structural level to serve institutions, the introduction of user fees for hospital services in most African countries has led to a drastic decline of patient attendance. The approach taken by the World Bank and IMF has often been criticized as heavily eurocentric and solely calculated in economic terms. Attending to this critique is beyond the scope of this thesis. For a detailed description of adjustment politics and its impacts on African health see for example Turshen (1999).
} 
The work that has to be put into re-turning to the outlined virtues is worth all efforts, the World Bank promises. Abandoning traditional practices will not only solve Africa's growth crisis “in one generation” (World Bank, 2000, p.103). ${ }^{22}$ Embracing decentralization, human investment policy, economic diversification and the notion of 'partnership in development' will also provide the continent with essential human rights: nutrition, education, health, and protection against vulnerability. Declared to be basic human needs, and hence on the international political agenda since the 1980s, these rights as well as the idea(l) to answer them within one generation have recently been recycled within the UN Millennium Goals.

All in all, the image of 'Africa' depicted by international agencies presents a continent that has been marginalized, first by world and subsequently by local politics and practices. Whereas the world has transformed and abandoned its 'apartheid' attitude, Africa's transformation is presented as not yet being fully conceived. Africa's rebirth, international reports imply, now requires donors as midwives and Africa to do the labor in pursuit of the 'economic empowerment of civic society', that the World Bank imagines

\section{'Women and Children' - burden and brokers}

The coupling of one entity defined by sex and the other by lack (of money and belongings) in the foreword of the millennium report that claims to address "women and the poor", genders poverty and points to the group considered to be the most marginalized in Africa women and their dependents. This emphasis on women mirrors the paradigm shift in development policy. While Structural Adjustment Programs according to their own terms pursued a gender-neutral policy, female researchers and activists inspired by the women's movement increasingly voiced their concerns that the traditional policy and project set up was biased towards men (Petchesky, 2003; Turshen, 1999). ${ }^{23}$ The 'discovery' that international policy had ignored women's culturally specific contributions to economic activities, their unpaid labor and their ownership of land, led to an intense effort by international agencies to make women's work and lives visible to the world (see e.g. World Bank, 1979). With the proclamation of the International Women's Year in 1975 and the

\footnotetext{
${ }^{23}$ Ester Boserup's (1970) focus on 'Women's Role in Economic Development' was the first study that highlighted the unique contribution of women to economy in so-called developing countries.
} 
succeeding Decade for Women (1976-1985) that claimed equality, development and peace for all women, women's experiences increasingly gained international authority and acknowledgement. Ever since, 'Women in Development' (WID) consists of a set of qualitative and quantitative methods, with which women are being researched and have been represented as development subjects with the same rights and unique plights. To these performances belong the International Women's Conferences (Mexico City 1975, Copenhagen 1980, Nairobi 1985, Beijing 1995), other international events (e.g. the International Conference on Population and Development in Cairo 1994; the Vienna World Conference on Human Rights and the World Food Summit in Rome in 1996) and most recently women's obligatory presence in the UN Millennium Goals. ${ }^{24}$

In contemporary international reports, women appear in three main forms: as sexualized, maternal and productive bodies (see also Harcourt, 2005, p. 43). As sexualized bodies, women are depicted as traumatized victims by existing gender relations that expose them to domestic violence, rape, genital mutilation and sexual exploitation. With reference to the work of an Ethiopian researcher, the World Bank, for example, states: "Women are beaten at the house for any reason. They may also be beaten if the husband comes home drunk or if he simply feels like it." (World Bank, 2000, p.85) According to the World Health Organization this sexual inequality has already begun at birth:

A baby girl born in one of the least developing countries in 1993 can expect to live barely 44 years -2 years more than a baby boy in the same year. Her problems begin before birth since her mother is likely to be in poor health. [...] She has a 1 in 10 chance of dying before her first birthday and a 1 in 5 chance of dying before her fifth. In some African countries her chance of being vaccinated is less than 1 in 2. [...] She will have a 1 in 3 chance of ever getting enough schooling to learn how to read and write. She may be circumcised at puberty with consequent effects of her life as woman and a mother. [...] As well as caring for her family, she will work hard in the fields, suffering from repeated attacks of fever, fatigue and infected cuts. (WHO, 1995b, p.5)

As the figures of WHO demonstrate, it is in the form of 'being with child', that is, as maternal bodies, that women are particularly vulnerable and disadvantaged, especially in low income countries. ${ }^{25}$ Thus, WHO claims that of the 600.000 women who annually die due to

\footnotetext{
24 These are the Millennium Goals 3 'Promote gender equality and empower women', 4 'Reduce child mortality', and 5 'Improve maternal health'.

25 According to political scientist Meredeth Turshen, maternal mortality is in fact the health indicator that displays the greatest difference between so called developed and developing countries (Turshen, 1999, p.19).
} 
complications during pregnancy and childbirth, all but 4000 occur in developing countries and most of the remaining are located in Africa (AbouZahr \& Royston, 1992, p.43; see also Boerma, 1987; WHO, 1985b, 1986b, 1996). Already in 1986, the World Health Organization turned the attention of the general public to the extent of the "maternal mortality crisis in Africa" (WHO, 1986b, p.3) by illustrating the problem with the catchy picture of a plane $\operatorname{crash}^{26}:$

Every four hours, day in, day out, a jumbo jet crashes and all on board are killed. The 250 passengers are women, most in the prime of life, some still in their teens. They are all either pregnant or have just delivered a baby. Most have growing children on board, and families that depend on them. (ibid.)

Thus, while women in low income countries similar to their sisters in 'the North' share an in-principal advantage in life expectancy over men, they are severely disadvantaged in relation to African men and to 'white' women in terms of the high mortality rates due to their reproductive capacity. Speaking of continents, this general difference reads as follows: "The lifetime risk of women dying from complications related to pregnancy in Africa is 1 in 16, which far exceeds the risk of Europe or North America showing one in 4,000 and one in 3, 700 respectively (Perrin, Matthews, Carter, \& Perry-Casler, 2001, p.23). Speaking of particular countries, the meticulous data collection of international institutions also enables the comparison of individual countries, for example Tanzania, with 'the North' (see also figure 2.2):

With a mortality rate of 200 to 400 deaths ${ }^{27}$ per 100,000 births, every year in Tanzania 2,000 to 4,000 women die as result of pregnancy and in childbirth. Maternal mortality rates are sixty times greater in Tanzania than in countries of Northern Europe. High risks during individual births combined with the higher numbers of children borne by women in Tanzania mean that women in Tanzania are more than 200 times more likely to die as a result of childbearing in their lifetime than are women in Northern Europe. (UNICEF, 1990, p.21)

\footnotetext{
${ }^{26}$ For children, the World Bank found equally engaging pictures, for instance in the World Bank Report 1994: "In the time that it takes to read this sentence, somewhere in the world a baby has died in its mother's arms." (World Bank, 1994, p.1) ${ }^{27}$ This range of figures mirrors the problem of data collection in many African countries. Most often figures obtained include only those women who delivered in hospitals. However, a large proportion of women in Ghana and Tanzania, for example, still deliver at home. Women's death due to "death while pregnant within 42 days of termination of pregnancy irrespective of duration and side of pregnancy from any cause related to or aggravated by pregnancy or its management", the official definition by WHO, hence, is often not registered under 'maternal mortality' (Boerma, 1987; Hammerslough, 1991; Piraino, 1991).
} 
Becoming a mother in Africa, these facts suggest, hence means being doomed to an early death. Or, in case a woman survives childbirth, to be doomed to suffer from gynecological, obstetric or contraceptive-related diseases: "For every mother who dies, between 10 and 15 are handicapped" (Sadik, 1990, p.10; see also WHO, 1989).

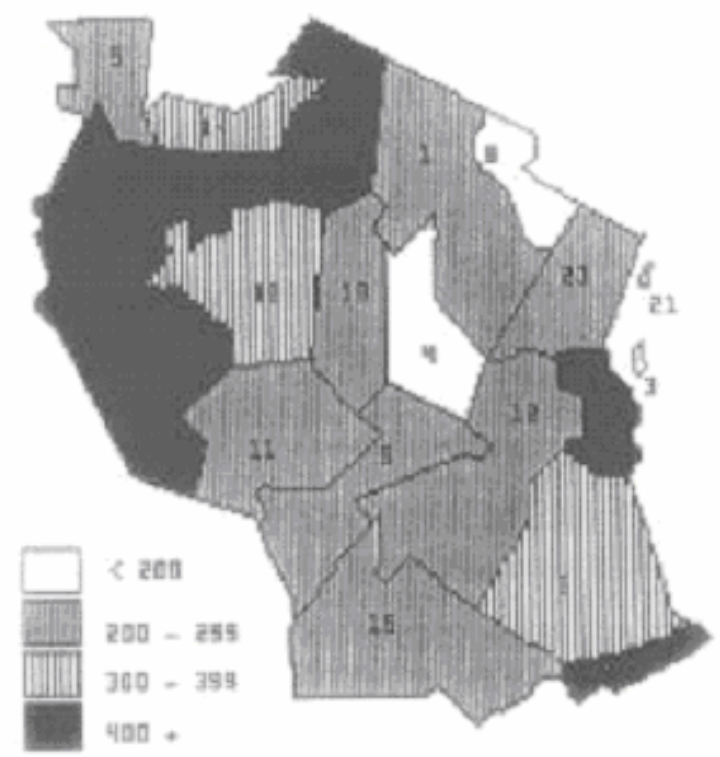

Figure 2.2: A map of Tanzania displaying regional differences in terms of maternal mortality (Kaisi, 1988).

Of great concern to international agencies is also the effect maternal death has on other family members, in particular on children, be it that the unborn dies with the mother or that older children die due to lack of appropriate breast milk substitutes and hygiene or simply due to lack of care by remaining relatives, as UNICEF stresses (1990, foreword). According to a representative of the WHO Reproductive Health and Research Unit, the four million annual deaths of newborns due to pregnancy and delivery related problems maternal morbidity and mortality, in medical jargon - is even higher than the number of children dying from malaria and AIDS altogether (Dr. Merialdi, Reproductive Health Research Unit, WHO/Geneva, personal communication, 21.04.2006). In the same vein, Carla AbouZahr and Erica Royston from the Maternal Health and Safe Motherhood Program of the World Health Organization stress that:

[T] he impact of poor health and inadequate care of mothers during pregnancy is passed on to the next generation. Seven million infants die annually because of complications that develop during pregnancy and because of the poor management during delivery. 
The condition of many children, particularly girls, is highly exacerbated by maternal ill-health or death, and the cycle of deprivation is thus perpetuated. (1992, p.45)

Hence, international agencies conclude, maternal mortality has to be regarded as a complex issue that is fed by and feeds into other problems of Africa, e.g. into the lack of education, or of health service attendance (see e.g. World Bank, 1982). Uneducated mothers, for example, tend to give birth more frequently without skilled birth attendance, which has an impact on maternal mortality statistics. According to findings by the United Nations Development Program Tanzania's maternal mortality rate ${ }^{28}$ of 770 in the period between 1990-1996 went hand in hand with 53\% unattended births. Numbers in Ghana were similar with $44 \%$ unattended births and a maternal mortality rate of 740 (UNDP, 1997, p.175). Matching maternal education with infant mortality UNICEF illustrates that 'no formal education' corresponds with high infant mortality in both urban and rural areas while 'post primary education' in urban areas shows the lowest infant mortality. When "every three seconds a child dies" (World Bank, 2000, p.105), their death is the effect of women's local roles, labor division and work pressure in African society that subject women to care for family members rather than to attend school, these analyses suggest (UNICEF, 1990, p.60; 1999, foreword).

Whereas WHO and UNICEF focus on maternal morbidity and mortality as individual or family problem, the World Bank regards these as problems the whole continent suffers from. As productive bodies, women, and even more so diseased women, are Africa's "missed potential", the Bank argues (World Bank, 2000, p.24). While proven to be better in the distributive allocation of products, women are still denied access to land. Known to spend money more carefully than men, women often do not have funds of their own. And while working harder than men, women are often too sick to work, or are not educated enough to get a good job. Adhering to "persistent gender inequality" (World Bank, 2000, p.23) rooted in African traditional attitudes means that Africa "loses half of its workforce", the Bank stresses (ibid., p.24). Yet, concentrating on women's productivity literally pays off,

\footnotetext{
28 The maternal mortality rate combines the two common statistical measures of pregnancy associated maternal mortality: the maternal death rate, defined as the annual death rate from maternal causes of women of reproductive age expressed in terms of death per 100.000 women-years of exposure, and the maternal death ratio, defined as the proportion of women who die from maternal causes around the time of child birth (Hammerslough, 1991, p.2). According to Hammerslough, however, the term 'maternal mortality' misleads as it also includes women's death due to septic abortion, a condition whereby a woman has never become 'mother'. He proposes a re-naming into 'reproductive mortality', a term used by several demographers, to include the excess mortality due to contraceptive use as well (ibid.).
} 
as the Bank illustrates by displaying a table in its millennium report. Under a heading consisting of the question 'How fast must Africa grow to reduce poverty?' (2000, p.14), the $\mathrm{y}$-axis of this table lists fertility, infant mortality, maternal mortality, contraceptive prevalence and health budget spent per capita between 1990 and 1996. On the x-axis, these "indicators of a demographic transition" (2000, p.16) are matched with three different country incomes, 'lowest', 'low' and 'middle'. Read from left to right, this matrix thereby suggests that high maternal and infant mortality, low contraceptive prevalence and low health care budget correlate with lowest income countries and that a reverse relationship holds true for middle income countries (table 2.1).

\begin{tabular}{lcccc} 
Indicator & Lowest & Low & Middle & All \\
\hline Fertility (percent), 1990 & 6,5 & 6,1 & 4,4 & 6,1 \\
Fertility (percent), 1995 & 6,2 & 5,3 & 3,3 & 5,7 \\
Infant mortality (per 1,000 live births), 1990 & 108 & 87 & 59 & 97 \\
Infant mortality (per 1,000 live births), 1995 & 101 & 80 & 55 & 90 \\
Maternal mortality (per 100,000) & 1,015 & 606 & 277 & 822 \\
Contraceptive prevalence (percent) & 8 & 20 & 62 & 17 \\
Health spending per capita (dollars), 1990-96 & 7,25 & 22,73 & 162,59 & 30,80 \\
Public & 3,19 & 9,58 & 71,99 & 11,22 \\
Private & 4,06 & 13,15 & 90,60 & 19,58 \\
\hline
\end{tabular}

Note: Lowest-income countries are less than $\$ 300$ per capita. Low-income countries are $\$ 300-765$ per capita. Middle-income countries are more than $\$ 765$ capita.

Source: World Bank data

Table 2.1: The table matches different income levels with 'indicators of a demographic transition'. In the configuration of the table with common reading conventions, the table puts forward particular causalities (Source: World Bank, 2000, p.37)

In sum, based on piles of collected data international reports depict 'women and children' in Africa as vulnerable groups, demarcated from both African men and 'white' women by their reproductive rights and plights. The emphasis on their productive capacity, however, adds another aspect to the importance of women as target groups of help. From being seen solely as Africa's burden, women thereby turn into the continent's brokers - if addressed with the right means. What kind of means do international agencies envision in this context?

\section{'Science and Technology' - man-maker and women-savers}

Consistent with their situation analysis of Africa's condition in general and that of African women and children in particular, international experts see the solution to their 
marginalization through a new generation of technologies that come with the millennium and globalization:

Globalization and new technology offer great opportunities for Africa. World markets are far more open than ever before. [...] Advances in the information economy offer huge gains to Africa, historically a sparse region with a population largely excluded from information. (World Bank, 2000, p.46)

The promotion of technology as 'motor for development' is not new. Ever since US President Harry Truman's inaugural address in 1944, which is regarded as the official start of development cooperation, 'technology' and 'science' became the magic words used to proclaim the beginning of a new world. ${ }^{29}$ In the past, the technologies that were meant to provide connections, however, consisted of 'hardware' - of water, sanitation, and transportation systems. The new kind of technology, in contrast, consists of devices that are either portable, thus mobile themselves, or allow virtual mobility by providing a connection to the world while its user seems to stay put to one place. Connectivity is thus provided without demanding the actual physical presence of its owner at the places s/he wants to reach. Internet and cellular phones bridge the information gap, reduce Africa(n)'s isolation as a 'sparsely populated region' (see also UNDP, 2001, p.29) and enable Africa to "leapfrog intermediate stages of development", according to World Bank promises (World Bank, 2000, p.123, 153). Reaching the world, in the Bank's opinion will finally also enable Africa to make itself known and consequentially get to know itself: "There is a dearth of scientific and technological information on Africa from Africa" (2000, p.156).

Invesment in information and communication technologies (ICT) is also likely to revolutionize developments in the field of health care. The Bank sees telemedicine, for example, as the means of choice for the future. While working on tele-radiology as a global project together with leading companies in the field of imaging such as Philips Medical Systems, WHO at the same time promotes mobile and portable low-key technology. Among these low-key technologies promising to bridge the distances between people's homes and hospitals, between different departments within hospitals or between hospitals in the referral

\footnotetext{
${ }^{29}$ In his inaugural address on January 20, 1944 Harry Truman announced a 'fair deal' for the entire world, proclaiming: “We must embark on a bold new program for making the benefits of our scientific advances and industrial progress available for the improvement and growth of underdeveloped areas. [...] For the first time in history humanity possesses the knowledge and the skill to relieve the suffering of these people. [...] Greater production is the key to prosperity and peace. And the key to greater production is a wider and more vigorous application of modern science and technology" (Truman, [1949]1964, no page numbers).
} 
chain, for example, are new kinds of contraceptives. The injectable contraceptive, Depo Provera, promoted throughout Tanzania, for example, bypasses the endemic transport problems of women in 'developing countries'. In the field of obstetrics*, reporting technology designed to provide a quick overview of bodily states and thus to facilitate referral or the take over of care by succeeding professional shifts has gained in importance in recent years. The partograph is one example of these technologies: an inscription device that displays the progress of labor and thus allows easier monitoring, according to the designers. In Tanzania, the partograph is an integral part of the so-called antenatal record, which in itself is an example of a mobile reporting technology. Designed as a 'home based maternal record', the antenatal card "provides a link between mothers and health care providers, promotes self-care, and can serve as dynamic educational tool" (WHO, 1995a, p.5). With a few alterations concerning routine drugs in pregnancy, for example, this record has been basically the same as pregnancy cards used in 'the North'. Recently, however, WHO has adjusted the routine schedule for antenatal care visits to fit the specific local problems of women in developing countries in terms of transport constraints after testing the new scheme in Cuba, Argentina, Saudi Arabia and Thailand, countries which were seen to bear greater resemblance to 'developing countries'. While the former antenatal care scheme based on Western standards called for women's monthly attendance, the so-called Focused Antenatal Care (FANC) scheme consists of four visits only, each of which focuses on particular aspects of pregnancy (Villar \& Bergsjo, 1996).

Considered a low-key technology, but nevertheless imbued with the potential to be linked to telemedicine, ultrasound's position in debates on health care technology transfer has strengthened in recent years. Its promotion as an 'appropriate technology' for developing countries, however, dates back to the mid 1980s. On the basis of specifications set by the WHO Scientific Committee for Appropriate Technology (WHO, 1985a), appropriate technologies in general include devices that are inexpensive, portable and solidly constructed. According to this committee, in the case of ultrasound, appropriateness furthermore required the provision of operators that would (have to) be trained for at least six months unless they were doctors (Volodin \& Hanson, 1996). Although internationally acknowledged as an important contributor to achieving 'Health for All ${ }^{30}$, dissemination to

\footnotetext{
30 At this First World Congress ultrasound was presented as an indispensable item within the WHO campaign 'Health for All by the Year 2000' (Kurjak \& Kos, 1998).
} 
developing countries has been too slow, as the president of the Mediterranean and African Society of Ultrasound (MASU), Prof. Gharbi complained, ten years after its first promotion at the First World Congress of Ultrasound for Developing Countries:

Despite considerable and growing worldwide investment in diagnostic imaging technology, about two-thirds of the population in developing countries does not have access to even the most basic x-ray or ultrasound diagnostic services. In 1988 there were only about 1000 ultrasound units for the 600 million people in Africa. [...] It would not be an exaggeration to say that ultrasound has revolutionized medical practice in terms of providing easier access and increased quality of diagnostic service for patients. However, much work is still needed to make this useful technology accessible to all who could benefit from it. (Gharbi \& Wachira, 1994, p.17)

Furthermore, while in principle acknowledging ultrasound's appropriateness for developing countries, international experts also expressed their concerns with regard to the technology's sustainability in these countries. The prestigious medical journal The Lancet, for example, pointed to the general shortage of indigenous radiologists to operate machines and to the fact that expatriate radiologists often had only "short-term contracts" (Mindel, 1997, p.426). Given the shortage of radiologists and doctors, especially in rural areas, some health scientists therefore proposed midwives as ultrasound operators for the performance of primary level diagnostics (Vangeenderhuysen, Abdellahi, \& Isselman, 2002). Not so much the question of who should be trained but rather the dedication of professionals to commit to training, in turn, was stressed by the international journal World Health Forum, the official organ of WHO: "Skills have to be learnt to produce the intended benefits [...] and can only be acquired through the efforts of the indigenous people" (Perry \& Marx, 1992, p.375). Yet other experts expressed their concerns with regard to the supply of consumables. While some proposed to supply alternatives, e.g. by locally producing ultrasound gel from cassava in Ghana (Langenscheidt, Wilbrand, \& Clarke, 1996), general consensus among experts was that given their incalculable risks in terms of technological working capacity and lack of consumables, donations were a "logistic nightmare" (Thompson, Gustafson, Diefenthal, \& Knoedler, 1993). The World Health Organization pointed out therefore, that, especially with regard to more costly technologies, appropriateness had to be carefully assessed. Using the example of incubators, the organization argued that it would not suffice to have children survive for a couple of weeks when they would die later due to a lack of proper information for parents and adequate feeding possibilities: 
Clearly, the advanced technologies introduced to these countries failed because appropriate resources were not in place. Had strong health technology assessment programmes existed in these countries, the decisions might have been made to fund more appropriate or more easily sustainable technologies. Alternatively, resources might have been allocated to public health measures or non-technological initiatives. (Perry \& Marx, 1992, p.356-357)

According to these international experts, once the problems of cost, sustainability and consumable supply were resolved, ultrasound had the capacity to significantly improve the situation of the most deprived in Africa. Referring to an incident he witnessed in Tanzania, the president of the non-profit humanitarian organization Assist International, for example, emphasized the transformative power of ultrasound technology for a(ny) developing country as follows:

Ultrasound systems are one of the items most requested by hospitals in developing countries because they are so versatile, portable and can be used for a variety of diagnostic purposes. [...] Not long ago, in Zanzibar, I witnessed a German doctor having to select those children who would travel three hours by boat in order to receive an ultrasound scan at a hospital in Dar es Salaam, Tanzania. There were many more kids who needed to go but there were not enough funds for all of them to travel. [...] Ultrasound will go to places such as Zanzibar where they will have great impact on the quality of health care offered by local hospitals. [...] I do know that lives will be saved and health care will be improved for literally thousands of the world's poor needy. (cited by www.ge.com, retrieved 27.03.2003)

Similar to the past, international development discourse continues to depict technologies (and science) that undo distance as the appropriate means for solving Africa's problem of marginalization. According to their proponents, the promise that these technologies carry, is that they will free Africans from being passive recipients and instead equip them to become managers of their own lives, that is, to turn from being nonconsumers into producers of knowledge, and from being faulty producers of too many, into working producers of (fewer but) healthy children. Equipped with this kind of technology, Africans hence would turn from nobodies into somebodies, or as UNDP puts it, from "homo miserabilis" into "homo habilis" (UNDP, 2001, p. 27). ${ }^{31}$

\footnotetext{
31 In its essence, international discourse thereby reproduces a notion prevailing since the $19^{\text {th }}$ century, that is, the argument that science and technology are the markers of civilization, or as Michael Adas calls them "the measures of men" (Adas, 1988).
} 


\section{Global Goods}

International agencies handle and set into motion a variety of global goods: 'Health for All', one of the first goods to travel the world, was joined by 'Food for All', and later by 'Energy' and 'Education for All'. The most recent proclamation of 'ultrasound for all' designates ultrasound as the messenger of a new world order. Providing images for and from the 'dark continent', ultrasound for Africa represents an enlightened world bare of ideological separation. The new world is 'One World', its central feature being the potential connectivity of everybody with everybody else. Underlying this 'one world' is the image of the market. Liberated flow and consequently a sharing of the same goods will finally turn people, seen as essentially the same, into equal partners - a precondition for a world self-governed by need and supply. This form of governance rests on another set of global goods: the packaging of 'Africa' and of 'women' into neatly comprised statistical figures that can circulate. As these global images of African women in need reach the table of scientists, of (inter)national policy makers and of companies, they convey the same message independent from where these agents are located: Helping women in Africa is a moral obligation and trade of technologies is the appropriate way to fulfill it. In short, to 'traid' [trade/aid] is to do good. How are these discursive entities put into practice though?

\section{Making things better - The Philips Project}

According to Philips Medical Systems basic ultrasound in the 1990s had lost its users in 'the West'. Originally sold to individual health care professionals, midwives and general practitioners, rapid advancement in the diagnostic imaging sector posed limits to the market for simple machines as the industry went along with the call for more sophisticated technology and specialization. In this situation Africa appeared as a 'blank spot' characterized by the absence of ultrasound machines and potential competitors and the presence of masses of potential patients. Having this market potential in view, the company started to cover Africa with a series of successive transfer projects of diagnostic imaging technology: Kenya (1988), Zimbabwe (1993), Ghana (1996), Tanzania (1999), Zambia (2003) and Uganda (2004). ${ }^{32}$ In accordance with its logo to 'make things better ${ }^{33}$, the company thereby re-designed ultrasound for Africa.

32 The named African countries are not the only ones that possess ultrasound machines designed or supplied by Philips Medical Systems. These six countries, however, are the ones that received ultrasound machines by means of a 


\section{Building markets}

In contrast to the ultrasound-saturated market in Europe, North America or Australia, 'Africa' provided huge market potential. At the same time, however, 'Africa' also stood for high risk business in terms of the lack of security of financial payment, for example, or of operative and maintenance skills. Recalling the company's decision to enter Africa with imaging technology, Peter Bruggen, one of the project managers in Ghana, referred to the company's earlier business engagement with several African countries. Pointing to their natural resources, his statement hints at the obligation to stand by one's partner in bad times and in good times as well as at the expectation to be able to yield profit again in the future.

Why did we start in Africa as a whole? [...] Initially, of course, we were faced with the continent being quite rich in certain countries. Ghana, for example, was quite a rich country in the past; just beyond the colonial times, in the beginning 60s, in the Gold Coast as it was called at that time; a lot of gold was explored over there, so the country was quite rich but due to the times a lot of things happened. During those times, the early times, Philips delivered a lot of equipment to very many African countries. [...] X-ray equipment. And a lot of these countries never replaced any of these imaging devices since that time. [...] Because they have never been updated for 25 years, they are also not taught anymore in the new techniques of imaging. While ultrasound here was all around then, they had never heard of ultrasound even and in many hospitals in many countries ultrasound was still a blank point, a black area. (Ai 1a)

In the dilemma of having to balance high market potential against high business risk, the company enrolled (into) the so-called ORET/MILIEV program. ${ }^{34}$ Developed by the Dutch Ministry of Foreign Affairs in cooperation with the Ministry of Economic Affairs, this financing program fostered so-called 'business development' - trade/aid in the very sense of the word - with the aim of benefiting both the Dutch and the economies of

\footnotetext{
comprehensive project other than getting sold or donated single machines. While the Kenya project was financed by a soft loan, all other country projects were ORET financed. The Zimbabwe and Ghana projects differ from the others in the sense that they focused on mere technology transfer whereas the company in successive projects turned towards a so-called turn-key approach (see below).

33 "Let's make things better" was the well-known logo of the Philips Company until 2004. It then changed to "Sense and Simplicity", a move that one of the employees I talked to, commented upon with reference to the internal logics of this sequence as follows: "By now everybody knows that we make things better, but how do we make them better? This is where sense and simplicity comes in. Our things are better because they make sense and are simple" (Ai 2)

${ }^{34}$ The Dutch acronym ORET stands for Ontwikkelingsrelevante Export Transactie [official English name: Development Relevant Export Transactions]. MILIEV stands for Milieu en Economische Verzelfstandiging [official English name: Industry and Environment Program]. As a grant program ORET had been running since 1983. In 1998, it fused with the MILIEV program, which had started in 1993 with a specialization on environmental project impacts (DGIS \& Ministry of Foreign Affairs, 2002).
} 
recipient countries. The program implicated the Dutch Investment Bank for Developing Countries (NIO).$^{35}$ Working as agent for the Dutch Ministry for Development, the Investment Bank granted part of the necessary project budget, provided a loan agreement with any other Dutch bank could be secured for the remaining project costs. While the loan agreement that had to be negotiated by the company thus served as the precondition for being eligible for the grant, the NIO in turn guaranteed the possibility of insuring the loan with the Dutch governmental insurance company $(\mathrm{NCN})$. This insurance protected the company from financial loss in case payment by project partners was delayed or not made.

In return for the financial security network that ORET/MILIEV provided, Philips Medical Systems became subject to the program(matic) regime. Not all countries, for example, were possible project partners. Unconditionally, ORET granted money only to socalled 'active countries'. Active countries were those that fell under the definition of 'Least Developed Countries' by UNDP and OECD, among them Tanzania (see www.un.org). Countries belonging to the list of so-called 'passive countries' were eligible for a grant only when the company could prove either that a company from another country competed with the same product or when the projected country was already involved in a particular aid regime, for example the $\mathrm{HIPC}^{36}$ initiative, as was the case for Ghana. Moreover, ORET called for detailed information to be delivered prior to grant assignment. This information included a listing of the health problems of the prospective recipient country, projected costs, provision of safety measures, possible failures, projected demand development according to health care level, the legal status of the partners in the transaction and the "sustainable impact" (DGIS \& Ministry of Foreign Affairs, 2002) of the project. This impact had to be specified according to four "development objectives": savings, poverty reduction, the position of women, and the environment. Obtaining this information was the responsibility of the company applicant who could make use of official sources such as the World Bank, USAID or the WHO, as the program mentioned. For an independent evaluation of whether a proposed project aligned with the national health care politics of the recipient country and project partner, however, ORET regulation implicated the Dutch Embassy of the respective country. A final requirement to be fulfilled by the company was

\footnotetext{
35 The Dutch Investment Bank for Developing Countries was set up in 1965. It is a specialized financial institution that supports the Dutch government in bilateral development cooperation.

36 HIPC = Highly Indebted Poor Country. The HIPC initiative is a debt relief scheme established since 2001.
} 
to provide all of these partner institutions on the Dutch side with regular reports on progress, possible failures and projected solutions every six months.

Enrolling ORET, and with it a range of other institutions, enabled but also required the company to embark on what it called "a comprehensive project with a systematic approach" (Ai 3). While previous projects to improve diagnostic imaging services had been uncoordinated in the sense of "a donation here, another donation there" (Ai 1b), as the company also stressed in its application to the Dutch government, once bound to ORET the company would be able to transfer a large number of devices. In line with ORET requirements, the company offered a choice between two basic ultrasound machines. This restricted option promised to solve the problem of feasible maintenance and training simply by the sameness of machines. Furthermore, the secured financial background allowed the company to turn to so-called "turnkey operations" (Ai 3) which included refurbishment of the technology's future environment starting with the immediate working room the ultrasound or x-ray room itself and ending with the rehabilitation and equipment of theatres and labs.

So if you talk about the project in Ghana, we had [...] a seven year project, consisting of the rehabilitation of existing buildings because also the buildings are pretty poor most of the time. That is why, you see, not only equipment is needed but also the building where it is housed in is in a terrible state. There is no $\mathrm{x}$-ray protection anywhere. If there is an $\mathrm{x}$-ray room, you just have a wooden wall on one side, and behind the wall, a pregnant lady is sitting waiting for an ultrasound. And x-rays are fully blasted into that room. All these things were upgraded by Philips as well, all the 98 hospitals, countrywide. [...] As for ultrasound, okay, only in $2 \%$ of the cases we found an ultrasound unit and then this was more than 10 years old. (Ai 1a)

In contrast to merely taking their information from other international agencies however, the company decided to conduct its own fieldwork in order "to see for ourselves" (Ai 1a), as the project manager Ghana put it. Key actors in this context became the local suppliers who had mediated Philips business in Ghana and Tanzania in the past. In Ghana of Lebanese and in Tanzania of Indian origin, these local suppliers had remained in the countries when the company withdrew in times of economic crisis and structural adjustment in the 1980s. Offering repair services for Philips technology transferred during these former business engagements, these agents had kept the name and reputation of the company alive in each country. As the company attempted to return to business, these agents played a 
crucial role as they decided whom to contact at the Ministry of Health and subsequently facilitated the contact making procedure. In Ghana the state department with the capacity to make decisions about imaging technology was the Biomedical Engineering Unit, a subdepartment of Hospital Services; in Tanzania, the company was referred to the Unit of Diagnostic Imaging at the Department of Curative Health Services. Backed up by this good reputation, re-entering business thus proved to be comparatively easy, as the project manager in Ghana remembered:

We had to go to the Deputy Minister, to the Primary Secretary and try to sell our idea, as simple as that. It was not simple [laughs], it sounds simple but you have to convince them of our good will, and yes, of course, we as Philips had a good reputation, that was one big benefit. It is easier to come to a country, to a Primary Secretary, to a minister, and say: "I am from Philips." than to say: "I am from a firm X." Philips is still regarded in Africa as being a very reputable, stable company. That makes a big difference. [...] most of the countries had Philips factories, even Ghana had a Philips' factory in the past where they produced light bulbs in the $50 \mathrm{~s}, 60 \mathrm{~s}$. $[\ldots]$ So there is a lot of knowledge of the name of Philips, even from the past, that is really good. So that there are also Philips $\mathrm{x}$ ray machines sitting around sometimes, still working, 25, 30 years old, being put together with small pieces of thread - which of course gives a good reputation. (Ai 1a)

Based on these contacts, the surveys in both Ghana and Tanzania took place as joint endeavors of one representative of Philips Medical Systems and one representative of the respective Ministries of Health. Sometimes also accompanied by local contractors or other civil servants, these two representatives traveled each country to visit and assess a range of hospital facilities as future worksites of the technology to be transferred. The facilities for visit had been pre-selected according to ORET policy to serve 'the poor': they had to be decentralized, public hospitals offering primary health care services. Teaching Hospitals were thus excluded from the project. In both Ghana and Tanzania, about 25-30\% of the hospitals that fulfilled these basic criteria were considered to yield representative information for those in the remaining country. Equipped with a pre-designed checklist, the company set out to obtain information on the number of hospital beds, of in- and outpatients, of the kind of endemic local diseases, of the number of x-ray and (if already present) ultrasound examinations, of the general condition of buildings and in particular of existing power supply and radiation protection for each hospital. These quantitative data were complemented by interviews with the key professionals, such as the head of the hospital, the x-ray operator as 
well as the regional or district medical officers responsible for health care services on the local administrative level. Subsequently, each hospital got a record upon which was based the decision of what had to be in place in order to sustain the working and proper environment for the device.

In both countries this first survey (in Ghana 1993, in Tanzania 1994/95) evaluated the project's feasibility according to ORET requirements. The replacement of old x-ray machines with new ones did not seem to be a problem. Rather, it was the introduction of the entirely new technology of ultrasound that generated high expectations in particular for the technology's capacity to improve the lives of women, a fact that the company also stressed in its report to the Dutch government:

We came to the conclusion, we in the Project Office, that what you see in all those countries is that pregnant women will profit. Most of all, it is them who will profit. So far there is no possibility to diagnose for them. If you break your arm, okay you can go to have an $\mathrm{x}$-ray, maybe it is old but you can have one. If you are pregnant there is nothing. At the same time, you see high mortality rates. They die from all sorts of things. And ultrasound can diagnose them. Maybe it is a tumor, you do an abdominal ultrasound and you can operate. But most of all, you can see all kinds of complications in pregnancy. And, you know we as Philips, we are dedicated to reproductive health issues. (Ai 1a)

The survey, however, was not only meant to obtain but also to disseminate information about the new technology to come to the local population. In Ghana, for example, the company used traditional forms of community gatherings, so-called durbahs, to present the project. Winning local chiefs as project supporters was considered very important, the project manager Ghana stressed in our interview while pointing to a photograph which showed him in front of an x-ray machine in a hospital surrounded by nurses in uniform, Africans in business suits and an old man dressed in traditional Ghanaian cloth:

For example, if you are in the rural areas, what is most important is that the local chiefs will understand about the project, that they understand what these technologies will do, how they work.

Because if you only convince the professional people but the chiefs are against it - maybe because they do not understand but also may be because you neglected their position because you did not pay your respect, you did not speak to him or invite him, he might speak against the project. Maybe he tells his people not to come to the hospital because these white machines will harm them. (Ai 1a) 
In order to win the trust of the new partners, however, the company did not only travel to Africa and visit hospitals but also invited a selected group of health care professionals and civil servants of both countries to travel to the company's site in the Netherlands. For the group from Ghana this visit included a stop over in Harare, Zimbabwe, where a similar project by the company had already started. One could elaborate at length about the advantages of a project that combined the transfer of imaging technology, training and maintenance elements, yet seeing such a project in practice in another African country would more easily convince the Ghanaian partners of the respectability and capacity of the company, the project manager Ghana explained: "They may believe me, but if they can ask another African, a colleague of theirs and he will tell them the same, they will simply trust more" (Ai 1a). For the Tanzanian group this visit to another African country could be spared as the local supplier won over the Tanzanian Ministry of Health representative by pointing to the fact that a similar Philips project in the neighboring country Kenya had worked very well.

The visit of this group of professionals and civil servants to the Netherlands included the company's show room displaying the company's past and up-to-date medical technologies. My own visit to the same showroom in 2002 left me with an overall impression of deliberate show business, as displayed in my fieldnotes:

In the middle of the hall stand MRI and CT scanners, none of which are yet in Ghana or Tanzania. On the right there are x-ray and fluoroscopy machines, some of which are in the African projects. On the left side, there is a set of ultrasound machines: the four machines currently made available for Africa, ordered by size and degree of sophistication. "This one is the one we sent to Tanzania", the manager points to the machine on the very left. SD 100 is portable and compact: keyboard integrated in the main body of the machine, no extras, fixed on a simple open trolley. "This one", he points to the second left, "we used in Ghana". SD 240 has an extra keyboard which furthers its resemblance with a PC. Not portable anymore, monitor and keyboard are integrated in the trolley. Both devices are switched off in contrast to their neighbors: the third machine to the left runs black-and-white pictures of very thin tissue layers; the last one in the row displays color pictures. 'Read' from left to right, the particular ultrasound configuration seems to me to convey a double message: As 
you develop, there will be a machine satisfying your needs! And, as machines develop, so can or may you! (FN, 29.08.2002)

The particular make up displaying technological development did not fail to leave its impact on the African delegations either. The Ghanaians, for example, wanted to have the "Mercedes Benz Version", the manager remembered when showing me around and laughed:

Of course, they see these two other machines, they want those. But we tell them, these are not basic machines. These are for a later stage. In principle they are the same, the same hardware, but with those [on the right] you can do color scanning, Doppler, cardiovascular diagnosis. But in Africa, you need basic machines. (Ai 1a)

For the Ghana project these market(ing) strategies resulted in a "smooth roll out" (Ai 3; Ai 6). ${ }^{37}$ With the survey data compiled in a project proposal, the company applied for ORET funding in early September 1994. On the basis of the letter from the Ghanaian Ministry of Finance to the Dutch Embassy in Accra requesting the latter to support a mixed credit "for the rehabilitation of diagnostic (x-ray) imaging services" (November 7, 1994), the reimbursement scheme with the NIO and the two Dutch banks (ABN AMRO and ING) selected by the Ghanaian Ministry was set up for a loan of $60 \%$ of the total costs. The supply contract $^{38}$ between the company and the Ghanaian Ministry of Health had been signed on October 7, 1996 for the project to start on December 17, 1996 (and end December 17, 2003). It encompassed the transfer of 65 ultrasound machines of type SD 240, 25 with one transducer and 40 with two transducers. Moreover, it outlined the project's conduct in two successive phases: a two-year phase of building rehabilitation of 13 polyclinics, 85 district hospitals, among them 29 mission facilities, and 8 regional hospitals, training of operators and actual technology transfer in three batches to be started in April 1997 every half year; and a five-year phase of what the company called 'comprehensive maintenance'.

Amendments to the contract added the liberty of the Ghanaian Ministry of Health to inspect load prior to shipment, its sole accountability for taxes, clearance and import duties as well

\footnotetext{
37 The experience of a 'smooth role out' mirrored the opinion of the representative of the Dutch Embassy (Ai 6). In contrast, the Netherlands Economic Institute (NEI) expressed its doubts on the financial and institutional viability of the project after the project end in its project evaluation report to the Dutch Ministry of Foreign Affairs. As the project proceeded nevertheless, this concern either was not taken up or could be dissipated by the company. The archival material did not provide conclusive information of what had happened; the only verbal remark I received with regard to this discrepancy was the statement of the former project manager that they had by then "convinced the Ministry that we [they, BMR] had thought about these matters" (Ai 2).

38 The supply contract between Philips Medical Systems and the MOH was only one of many. The technology transfer project furthermore involved contracts between the Ghanaian $\mathrm{MOH}$ and ORET, a financing contract between the MOH and $\mathrm{ABN} / \mathrm{ING}$, and a loan agreement between the Ghanaian Ministry of Finance and the Dutch banks.
} 
as the company's full responsibility for storage in the country prior to dissemination and the for the availability of spare parts for the project period.

Building a market in Tanzania proved to be more difficult. One of the obstructing actors for the processing of the project was the Dutch Embassy in Dar es Salaam. While its counterpart in Ghana had immediately assigned the project's alignment with national health care objectives, the responsible civil servant in Tanzania hesitated to give a positive response when first approached by the company in 1994. Pointing to the high-tech status of the deliverable artifacts, Tanzania's concern with primary health care objectives and the problem that PIE Medical ultrasound machines needed cooling, the embassy insisted on a second survey to be carried out by an independent consultant to prove alignment and sustainability of the proposed project. ${ }^{39}$ Moreover, the embassy stressed the need to establish a steering committee in the country which should consist of representatives of the Tanzanian Ministry of Health and of Finance, of the company and of the embassy in order to guarantee "transparency" (Ai 7). The second proposal was taken up by the company, which even paid 50 liters of fuel for the car of the National Coordinator of Radiology Services in order to allow him to follow the project. The consultant proposed by the embassy, however, met with the disapproval of the company, which strongly felt that the choice of consultants should be left to Philips Medical Systems. After agreement was reached to appoint a Dutch consultancy bureau, the survey carried out did not satisfy the embassy in Dar es Salaam which felt that issues of water and electricity had not been dealt with sufficiently. Inclusion of these factors to the extent demanded by the embassy, however, made the existing project proposal unfeasible under ORET conditions. The solution for this dilemma was finally provided by ORET itself, which had meanwhile raised the grant to cover $70 \%$ of costs in special cases instead of its former policy to cover 50\% maximum. This extension of coverage allowed the company to write generators and the refurbishment of existing water pipe systems into the proposal. ${ }^{40}$ With the embassy's positive advice, the proposal was in turn processed by ORET. The first supply contract signed in May 1997 consisted of the transfer of 92 ultrasound units, 72 of the type SD 100 and 20 of the type SD 240 as well as 83 x-ray units (NEI, 1997, p.3).

\footnotetext{
${ }^{39}$ Letter Royal Netherlands Embassy (RNE) to Philips Medical Systems (PMS) (20.04.1997).

${ }^{40}$ Letter PMS to RNE Tanzania (17.01.1997).
} 
The second obstruction derived from the Tanzanian supplier. In Ghana the local supplier had only worked as a broker in establishing a business network. The local supplier in Tanzania, however, had negotiated to become a partner in the new network by claiming $4 \%$ of the company's tasks in terms of supply and repair. His inclusion raised the percentage of the non-Dutch content in the project which in turn transgressed ORET regulations. ${ }^{41}$ In order to solve the problem, the company had to re-design and fabricate basic ultrasound and $\mathrm{x}$-ray machines with Dutch 'nuts and bolts' so to speak.

The third obstruction concerned the collision of repayment schemes fixed by the Dutch banks and company with the Enhanced Structural Adjustment Program (ESAP) set by the International Monetary Fund that Tanzania had embarked on. ORET had finally granted approval for the project to commence in February 1998 with a grant covering 60\% of the total costs. The proposed start of the project in April 1998, however, had to be delayed since the Tanzanian Ministry of Finance according to ESAP regulations could not apply for a loan, which was needed for up-front repayment to the Dutch banks before any technology could be disseminated to the selected health care facilities. ${ }^{42}$ This delay bore consequences for the company and for the country. It prolonged the company's responsibility for safe storage of machines in a country whose conditions in many ways were not favorable to technology, as Peter Bruggen explained: "There is always the problem of rats and dust. So by the time you get the machines from the store and distribute them, maybe some of them do not even work" (Ai 1b). At the same time, this delay shortened the warranty's validity for the recipient country that had started with the contract signature. While the distribution of ultrasound machines in Ghana according to plan had taken two years, it took four years until all devices ended up in their working places in Tanzania.

Transferring ultrasound to Africa first of all meant getting various partners interested in the transaction. Building Africa into a market thereby involved the creation of meeting places: at the show-room at the company's location in Eindhoven, at the market places in villages in Northern Ghana, at ministerial offices, or at bank lounges. Engaging in business development for the company thereby meant refraining from immediate profit interests but building on trustworthy relationships. In this process of building markets, the company in its

${ }^{41}$ Letter Dutch Ministry of Foreign Affairs to PMS (30.10.1997).

${ }^{42}$ Letter Ghanaian Ministry of Finance (MoF) to RNE (09.07.1998). 
own words "learnt" from project to project: experiences from Zimbabwe were extrapolated to Ghana, and experiences from Ghana to the project in Tanzania.

\section{Building mentality}

In principle, the transfer of a high number of the same kind of machines afforded feasible maintenance services. However, both the surveys in Tanzania and in Ghana had hardly found any technicians skilled in looking after imaging technology, and the few that had been found were rather busy with repairing simple technology. Feasibility was also rendered more difficult than in Europe as the same number of machines that would be found within 5001000 square kilometers there was spread over 850.000 square kilometers in Tanzania, for example (De Leeuw, 2005).

In order to sustain the working of its machines, the company employed two strategies. For the long term, it offered to train technicians of the respective Ministries of Health. For the time frame in which maintenance was the sole responsibility of the company, young male secondary school graduates were trained and paid as technicians by Philips Medical Systems with the expectation that these technicians could perhaps later be taken over by the Ministry:

Of course we could have been interested in maintaining our machines only for the time of the warranty; you know, the time when the machine breaks down it is our money spent to repair it. But this is not what we wanted. Because if the contract ends, and the machines break down and cannot be repaired, the machines do not work again. And then patients can not be diagnosed anymore, but also we have a reputation to lose because people might say: "You see these Philips machines..." - because, you know, they regard them as Philips machines - “... these Philips machines do not work!" So this is why we started to train technicians over there to do the maintenance, preventive maintenance. (Ai 1a)

Almost as an afterthought, the remark of the project manager in Ghana points to a novelty that the company brought to Africa together with its machines: a new kind of repair. 'Preventive maintenance', as this new kind of repair was called, consisted of a regular, scheduled visit of technicians to the hospitals to check the correct working of the machine and to replace spare parts known to have a high likelihood of breaking down, such as dust filters. Instead of waiting to be called to repair machines that had already broken down, this 'repair' was to prevent breakdowns in the first place. 
This kind of repair required a new kind of mentality the current lack of which, according to the company, was the reason why neither the Ghanaian nor the Tanzanian Ministry of Health had taken up the offer to have their own technicians trained:

What you have to do is to teach them the good mentality, that what is needed is preventive maintenance. Of course they never had had the chance to do that. You know it is also quite a new concept in our countries as well: to act preventively instead of waiting and let go because if you do that, it will cost you a lot more in the end. [...] This is what we tried to explain to the Ministry: "Come on, send us your people, and we will train them!" They just did not do it. So you understand that this is what makes life [and] business development very difficult here: they often don't have a maintenance mentality. (ibid.)

While negotiating with the respective Ministries of Health, the company had to solve the problem of granting its own technicians access to their objects of care. In both Ghana and Tanzania, each transferred machine carried a sticker with the company's name, its local telephone number and the remark to "call in case of need". Whatever the mode of repair, any technical care had to overcome the remoteness of some health care facilities, the distances involved and the absence of phones in many of them. In Ghana, the company managed this difficulty by establishing three service offices: one in Tamale that cared for the three regions in the North, one in Kumasi responsible for the central part of the country, and one main office in Accra for the South. Each office was equipped with at least one Philips trained technician, a range of common spare parts and a car equipped with radio transmission to allow communication regardless of the technician's location.

According to the project manager of Tanzania who himself lived in Nairobi in Kenya the vast size of Tanzania discriminated against copying the Ghanaian solution. Instead, any kind of repair was to be carried out from Dar es Salaam. Both on a regular basis as well as when called for a faulty machine, a technician would take an office car, load it with spare parts and set out for the respective hospital(s). This arrangement did not satisfy all employees. The Customer Support Manager in Dar es Salaam who formerly had worked in Ghana, for example, repeatedly but unsuccessfully proposed decentralized services. Based on his experiences in Ghana, he claimed that the more local the service offered the fewer breakdowns occurred. He therefore suggested establishing another office in Mwanza. Located in the Northwest of the country, Mwanza town and region were difficult to reach by 
car: either the travel route had to deal with the bad roads when taking the direct route through the country, or it was very long when taking the better road via Nairobi.

Let me compare for you the differences from having more than one office for technical support, like we had in Ghana, with the situation here, in Tanzania. [...] What we saw in Ghana was that the fact that equipment could be regularly maintained by technicians who were close, led to a significant reduction of breakdowns because of their closeness to the facilities. Instead of seeing each facility and each machine maybe every half year, it could be seen every three months. So what might happen, can be more easily prevented because you replace parts more often, you check more often. Now here, in Tanzania, this is not possible. This technician, for example, that goes up North, to Mwanza, he cannot see the facilities more often than maybe every five months. You know the roads are so bad. It causes a problem not only for maintenance but also for repair: if a machine is out of order, maybe it cannot even be transported back by car, it has to be flown out. (Ai 5)

The immediate difficulties with maintenance could thus be solved. The lack of response by the Ministries of Health in providing plans for maintenance after the project's end, however, remained of serious concern to the company. In Ghana, negotiations with the Ministry about the take over of maintenance by the $\mathrm{MOH}$ or the continuation of maintenance service by Philips' technicians who were then to be paid by the Ministry had already started in the last year of the project. They were not resolved until two years after the project had ended, when the Ghanaian Government in 2005 opted for a follow-up maintenance contract for another five years. In Tanzania negotiations in the eyes of the company were comparatively more fruitful. Not only was a follow-up maintenance contract agreed upon within the first project period which prevented a period of no-care for the technology; The Tanzanian government also negotiated the inclusion of Philips medical technology in the new maintenance contract that had not been part of the ORET project but had entered the country before or on an individual basis. This proved that the company had succeeded in conveying "the rules of the game" (Ai $4 \mathrm{~b})$ to Tanzania, as the project manager Africa told me proudly, these 'rules' being the understanding that engaging in preventive maintenance went along with "a better chance to get another Dutch grant" (ibid.). Becoming attentive to their own interests, making bargains and getting the most for their money, Tanzania thereby demonstrated "maintenance literacy" (Ai 3), which turned the country into a "true partner in sustainable business development" (ibid.) in the eyes of the company. 
Building Africa into a market did not end with the preparation of meeting places. According to the company, it also required the transfer of an understanding of market principles. Among these market principles, for example, is the idea of a win-win-situation as the core of any proper transaction. Another principle is the right attitude towards caring for artifacts - a maintenance mentality, as the company put it.

\section{Building Bodies}

Next to a market and a maintenance mentality, the company built 'bodies': a new professional faculty, and parallel to it a new patient body. In order to make the new professional body sustainable, training of operators was planned to be carried out in three successive steps. First, a group of trainers was to be trained. This group was to consist of health care professionals holding key positions in the national health care system and preferably already accustomed to operating ultrasound. Second, the actual operators of the transferred machines were to be trained according to the batches in which the machines were disseminated in order to enable close linkage between the teaching course and subsequent hospital practice. Last, a refresher's course was to take place one year after the initial training in order to "integrate their [the operators', BMR] local experience" into ultrasound operations, as one of the Dutch teachers explained (Ai 8b).

In former projects in Kenya and Zimbabwe, training sessions had been given by Philips Medical Systems itself. Directly after training the group of trainers in Ghana, however, the company enrolled Fontys University located in Eindhoven in the Netherlands in its successive Africa projects. What made this institution attractive for the company were its long term experiences in teaching imaging technology in the Netherlands and in developing countries. Based on the experiences in the latter contexts, Fontys University had developed a particular teaching method, the so-called methodical scanning approach, which promised to teach any health care professional the basics of ultrasound in two weeks - a valuable asset for the project's budget and time frame.

The cornerstone of the new teaching method was an overall methodical approach that started with scanning and ended with the reporting of findings. Regardless of sex, age and clinical diagnosis of a patient, methodical scanning began by a longitudinal section through the abdominal aorta. Imagining the abdomen to be divided in four quadrants, a scanning search to the left and to the right subsequently enabled an experienced 
ultrasonographer to "see each and everything in ten minutes", according to one of the Dutch teachers (Ai 8a). In principle very simple in practice, the challenge of this new method lay in turning the clinical vision of health care professionals into a proper sonographic gaze, as another Dutch teacher explained:

The problem is to teach them to think methodical and not disease related. When you ask a participant how to do an ultrasound of the pancreas, he will start to tell you which disease he will probably find in an organ. [...] The Methodical Scanning Model is an efficient and safe way to start learning to do ultrasound examinations given the short time and resources that developing countries are faced with. It allows fast-track learning. (Ai 9)

Subsequently, the reporting of findings followed the methodical seeing process, which ordered a body's inside into a particular topography according to international standards. Reporting a placental position, for example, would require first stating the fetal position and condition, then that of other organs and finally that of the placenta. On the level of theory, teaching was complemented by the Manual of diagnostic ultrasound published by WHO and WFUMB (Palmer, 1995) each participant got a copy during the course. Adhering to this methodological standard and taking the images in the book as reference tools transformed any African body into a transparent entity, Fontys promised.

Naturally, the company admitted, a short course of two weeks only could only teach ultrasound basics. Evoking the similarity of operating an ultrasound machine with operating a car, the project manager in Ghana expressed his firm conviction that notwithstanding the short duration, the course offered was sufficient for African operators to move forward:

This is fast track, you know. It is not really to give them all the skills but how to use the basics. This is what we call the driver's license. Then of course, you still have to learn how to drive. (Ai 1b)

In turn, the refresher's course after one year of 'driving alone' in turn was to pick up experiences made in the meantime, to deepen understanding and to fine tune skills.

The two weeks of the basic course were split into one week of theory followed by one week of extensive practice. They were furthermore allocated to different places and different spheres of responsibility. While the first week took place in the rooms of the Philips office in Accra and Dar es Salaam and was led by the Dutch teachers, the second week took place at the respective government Teaching Hospitals, Korle Bu in Accra and Muhimbili Teaching Hospital in Dar es Salaam, under the supervision of the African group of trainers. While the first week was meant to familiarize professionals with a "hands-on" (Ai 
1b) training in so far as it taught the handling of the transducer, this second week was meant to provide the future operators with "practice and patients under the real conditions of the country" (Ai 4a).

In Ghana, the company had originally planned to conduct practical ultrasound examinations on patients with minor problems. Transferring patients from the hospital to the Philips' office, however, turned out to be impossible under existing Ghanaian law. This restriction affected the possibility of transmitting practical experience to operators prior to their exposure to the reality of Ghanaian or Tanzanian hospitals, yet it did not affect all types of ultrasound equally. In order to experiment with abdominal ultrasound, the Dutch teachers proposed that the operators simply use one another as quasi-patients. For pelvic ultrasound, however, this solution was not feasible as the body region in question was considered to be too intimate. For obstetric ultrasound the company came up with a very different solution: it recruited healthy pregnant women who, in return for their willingness to serve as 'fake patients', received free ultrasound services and some money. This solution circumvented legal constraints and provided future operators with extensive possibilities for scanning pregnant women under 'lab conditions' with time, the manual, the Dutch teacher and their colleagues at hand. Moreover, it favored the focus of the teaching method on acquiring the ultrasound gaze through its attention to physiology rather than pathology, as well as the focus of the company on reproductive health issues (see above). Learning from this experience in Ghana, the company repeated the same teaching scheme in Tanzania.

Both Fontys University and the project managers at Philips Medical Systems had originally proposed to train a variety of different health care professionals to operate ultrasound. However, as the company regarded sustainability as the most crucial factor, the final choice of who to train as future ultrasound operators was left to the Ghanaian and Tanzanian partners. Choosing the future operators was part of the agenda of a so-called kick-off meeting shortly after each contract had been signed. At this meeting the respective project managers, ministerial representatives and the group of trainers discussed conditions and procedure of training. In Ghana this group of trainers consisted of five doctors: the head and vice head of the Radiology Unit and two gynecologists from the Maternity Department at Korle $\mathrm{Bu}$ and a radiologist from the urban Regional Hospital referring to Korle Bu. Following the advice of the Ministry of Health, in Tanzania, the trainers encompassed two radiologists and two radiographers from Muhimbili Teaching Hospital in 
Dar es Salaam. While the Tanzanian group went along with the advice by Philips Medical Systems and Fontys University and opted for the training of radiographers and nursemidwives, the Ghanaian group of trainers chose to train medical doctors only. Initially, this decision did not meet with the company's approval. Yet, as operators should be "locally accepted" and "fit into the system", as the project manager in Ghana pointed out (Ai 4a), the company ultimately accepted this choice. In giving in to the choice of the Ghanaian partners, the project manager drew on the experience he had had when approached by an American ultrasonographer who had complained to him that the ultrasonographers she had trained had difficulties in finding permanent jobs afterwards. In the manager's view she had clearly trained not only the 'wrong' people - nurse-midwives and secondary school graduates - but had also disregarded the partnership principle:

She just trained anybody, people who had just left secondary school, not people with a professional background. And then what happened? These people got trained but they could not find a job because they were not accepted by the doctors. When her project was finished, she came to me and asked Philips for help securing the knowledge of the people trained, maybe refreshing it. But we could not help her; these were just not the right people to be trained. [...] You cannot come and follow your own ideas. What we did is we asked our partners: 'whom do you choose?'(Ai 4a)

While the basic training course proceeded reasonably smoothly, the company encountered several problems when the refresher's courses started. In both countries, entirely new professionals turned up at the refresher courses claiming to be the new ultrasound operators at their hospitals. In the attempt to keep up the workings of their machines in the hospitals, the company attempted to provide these new operators with the basic skills while at the same time trying to give the real refreshers some additional ones - a 'split' that severely stretched project budgets. Eventually, the company turned to the respective Ministries of Health and requested them to put an end to this problem, a move that alleviated the problem to a certain extent but did not manage to put an end to it entirely (PMS Status Report No.15).

In Ghana, the company faced the additional problem that doctors trained in ultrasound were suddenly posted to other hospitals, which left the doctor without an ultrasound machine on which to use his new skills and left the ultrasound device orphaned by its operator. When this problem first came up, the company decided to leave the machine 
in place and train a new operator. ${ }^{43}$ Yet, as this quickly stretched the budget limits, the company decided to have the machine follow its doctor. In this process of re-locating machines, hospitals which had originally not been eligible for the project suddenly owned an ultrasound machine. This was the case for the Teaching Hospital in Tamale in Northern Ghana, for example - a move that the company had to explicitly account for to ORET. It eventually did so by stressing that the criteria of decentralization and rurality in terms of staff, knowledge and equipment held true for this Teaching Hospital despite its status and officially urban location. Furthermore, the company's practice of re-location was met by resistance from the hospitals in question to let go of 'their' ultrasound machines, a problem that required extensive negotiations. These were left to the representative of the $\mathrm{MOH}$ as the company felt he would "know better how to deal with his own people" (Ai 1b). In order to prevent such a situation in Tanzania altogether, the company proposed a system of temporary professional bondage. This proposal, however, was dismissed by the Tanzanian Ministry of Health with the same argument that the Ghanaian partner had used when called upon to do something about this professional mobility: that nothing really could be done in this respect given the universal right of freedom of labor that the Tanzanian and Ghanaian government as modern democracies naturally adhered to.

Notwithstanding these difficulties, the company was finally fully satisfied with the outcomes of their attempts to build a sustainable professional body of ultrasound operators. In the 2002 evaluation report, one year before the official end of the Ghana project, the company proudly claimed that " $80 \%$ of all those trained by us" (PMS Status Report No. 15) were still working. Moreover, one of the participants in the courses had designed his own ultrasound manual for gynecology, general medicine and obstetrics (Rubayiza, 2001). Due to the bad quality of its print-outs, this manual was not used as an official teaching device for Ghanaian operators; distributed to visitors, however, the manual served the company in demonstrating the degree of empowerment the 'Philips Project' had been able to install in local people. In Tanzania, the project final report found that " $85 \%$ are still working with our equipment" (Ai 3). In contrast to Ghana, in Tanzania the company saw technological sustainability as secured by the fact that ultrasound had obtained a robust position within the new national curriculum for radiographers that Fontys had designed in cooperation with the

\footnotetext{
${ }^{43}$ Contracted to train 63 operators only, the company had trained 100 doctors already by September 1999, and ended up having trained 133 by June 2002 (PMS Status Report No. 9, 14)
} 
Medical School of Muhimbili Teaching Hospital in Dar es Salaam (MUCHS, 2002).

Moreover, an e-learning space had been established at the same hospital, which enabled radiographers, radiologists and students to exchange information with colleagues in Holland that, according to an evaluation by Fontys was widely and enthusiastically used (Van Prooijen, 2005; see also www.fontys.nl/internationalprojects).

In addition to winning business partners and installing a particular form of care for machines, the Philips Project also set out to install ultrasound in the heads and hands of health care professionals. According to the visions of the company, building a new faculty of operators with the proper sonographic gaze would enable them to make the hitherto 'dark continent' - women's bodies in Africa - transparent and open them up for diagnosis and subsequent treatment.

\section{Dutch devices}

The ultrasound devices manufactured in Maastricht and supplied by Philips Medical Systems to a series of African countries are global in many ways: taking over maternal mortality statistics as the measure for women's health, they were equipped with batteries, European and US American fetal growth charts that mirrored the idea of a universal body. Resembling the devices sold to Europe and the United States in hard- and software, the ultrasound machines for Africa became inevitably Dutch in other ways. Going global by including Africa into the ultrasound business, required the company to rebuild some of the hardware: some of the 'nuts and bolts' had to be made in the Netherlands in order to fulfill the regulations of the Dutch transnational funding scheme ORET. Furthermore, taking up international concerns about donations, maintenance, and teaching, the ultrasound machines for Africa, in contrast to the devices that travel to France, for example, carried attachments. Rather than simply transferring machines, the company shipped technology - machines attached with teachers, teaching schedules, particular maintenance practices and technicians, and financing schemes. ${ }^{44}$ These attachments, however, were meant to be only temporary. In order to do business as usual, they were to be abandoned as soon as 'Africa' could take over - making ultrasound machines again global, equal to their European fellows.

\footnotetext{
${ }^{44}$ In my usage of the term 'technology' I hereby refer to Wiebe Bijker's definition of technology as encompassing physical artifacts, human activities and knowledge (Bijker, 1995b, p.231).
} 


\section{Engineering relationships}

International agencies and multinational companies such as Philips Medical Systems use imaging technology to design new relationships and communities. This engineering process is constituted by two practices: assembling data from various localities that provide detailed information for models displaying global processes, and integrating these global models into local projects. Conceived on paper, a new world order thereby comes to be inbuilt in material vehicles that are set to work in particular places. Making ultrasound work in these localities, however, does not always go smoothly. Rather, meddling with local realities requires compromising on certain things.

\section{Assemble and rule!}

The practices of both international agencies in the field of health or development policy and of Philips Medical Systems bear a striking resemblance to each other in their emphasis on local information. Statements made in international reports are not abstract. Rather, they are based on data assembled in particular countries and localities, and through interviews with international and local experts knowledgeable about the scenery at the spot. Reports, hence, are not the outcomes of the solitary endeavors of foreign agencies but are written in cooperation with African partners. The Millennium Report, as the World Bank stresses for example, is a "JOINT PRODUDCT OF FIVE COLLABORATING institutions" (World Bank, 2000, acknowledgments; original emphasis): the World Bank, the United Nations Economic Commission for Africa, the Global Coalition for Africa, the African Economic Research Consortium, and the African Development Bank, some of whose representatives sound African by name. Likewise, the Dutch company goes local. Rather than relying on information provided by big international organizations as the ORET framework invites, the company opted for conducting own fieldwork. This fieldwork included visits to local hospitals and interviews with local key figures for the conduct of the project, the final report being the result of the data assembled by representatives of the company in cooperation with the representative of the Ghanaian, respectively the Tanzanian Ministry of Health.

This local information is not assembled randomly but according to categories and parameters used all around the world. The global parameter for expressing life conditions found in international policy reports, for example, is 'GNP' (gross national product) that since 1948 has been correlated with poverty. 'GNP' is expressed in terms of 'standard of 
living', which operates with a limited and easily obtainable set of elements: income, production, consumption, need, and scarcity (Latouche, 1992). Other common labels in this context are 'life expectancy', 'Least Developed Country', or 'maternal mortality'. Likewise, the complexity of clinical practice in the facilities visited by Philips Medical Systems is transformed into certain parameters, in 'electrical light fitting', 'theatre requirements', or 'common diseases'. The usage of global terms - an equal measure for all countries, between countries or within one country, or other spatial entities - allows comparison. Countries can be compared with regard to a particular parameter, for example, that then turns Tanzania into a country with 'high' and the Netherlands into a country with low maternal mortality (see above). Information obtained in different countries for the same parameter can be used to aggregate certain countries into displaying a regional profile. A classic example for such an assemblage is the so-called 'reproductive health profile' that compiles information on the condition of sexualized and maternal, and thus of the expected unproductive bodies. Based on WHO and UNDP data (Anonymous, 1996), SubSaharan Africa's profile in 1995 looked like the one below:

\footnotetext{
Population (1995): 582 million

15-49 year old women (1995): 130 million

Contraceptive users (1995): 24 million

Maternal mortality ratio: 640 per 100.000 live births

Infant mortality rate: 95.3 per 1000 live births

New cases of STDs per year: 33.7-55.2 million
}

The icon of this transformation of local data into global categories is the map. Maps come in many forms, as graphs, tables, or literally as a map, such as in the representation of Tanzania as parceled regions distinguishable by different maternal mortality rates (Kaisi, 1988, see figure 2.2). Compressed in maps, local lives and worlds are transferable: they travel as facts from the field to the capital city or from a particular African country to Geneva and Washington and then further to The Hague, Eindhoven and Maastricht in the Netherlands. Complex and variable local worlds thereby turn into "immutable mobiles" (Latour, 1987, p.227) that keep their form and remain legible wherever they go. 
Maps give their users a handle on the world, without requiring them to ever having be in the places mapped or to ever have themselves observed the phenomena presented. By allotting coordinates, maps first of all allow orientation. What is the position of Tanzania, for example, with regard to a particular millennium goal to be achieved by the year 2015? How much distance is there between a present coordinate and the final objective? For all spectators, maps thus enable the identification of groups, regions, and countries that are yet far from a set objective, and that are hence, still in need of help in getting there. Allotting coordinates enables particular spatial entities to turn into targets for aid, and allows planning and coordinating of material and human efforts to put together papers, programs and projects. Qualification of those who are 'in need' thus enables quantification of what is needed: how many ultrasound machines have to be transferred, how many plugs have to be installed beforehand, how many operators have to be recruited for the training course, and how much allowance has to be paid in order to interest them in the training?

Abridging complex realities, maps hence make the world legible. Simplifying local complexity and transforming it into a common metric, into administrable units, is the art of modern statecraft, as anthropologist James Scott (1998) has argued. It is thus in the assembling of local data under global categories and their subsequent re-aggregation, for example into 'African women in need', that the supranational entity 'Health Care International' rules and sets the 'terms of traid' that include technological fixes such as ultrasound. In short, by being turned into global projects, local prospects get things going somewhere.

\section{Meddle and compromise!}

If maps, numbers, and models would remain on the tables where they are drawn together, in the offices of multinational companies or international agencies situated in Geneva or Washington, all efforts at assembling data would be lost. It is but when they are built into other mobile forms, such as ultrasound machines, that these models do not stay as mere rhetoric but they return to sites of consumption, to hospitals, for example. Not all global models, however, travel easily. Drawing on the two key-concepts of 'partnership and sustainability' that pervade contemporary international development practice and consequently frame the 'Philips Project' in its pursuit of making things better, I will show that this re-localization can be quite tricky. 
In reports, conference speeches, and project application forms 'partnership' and 'sustainability' go together smoothly. What is more, they appear in a particular sequence that underlies a causal relationship: sustainability is the effect of a partnership relation. On Ghanaian and Tanzanian ground, however, this relationship becomes strained. Handing over the choice of operators to the Ghanaian partners, for example, puts the sustainability of the Philips ultrasound machines at risk, as access to operating the technology becomes highly selective. A further risk to ultrasound's sustainability in both Ghana and Tanzania is the fact that to the surprise of the Philips Company the African partners do not take over maintenance according to the terms originally envisioned. Moreover, sustainability seems endangered when new operators come to refresher courses, trained health care professionals are (or let themselves be) re-posted to other facilities and leave their machines, and attempts to repair this situation quickly bring the project to its budget limits. Committing to a partnership relation, hence, threatens sustainability. Moreover, it seems that the relationship of these global models at the local level works the other way round: only when machines and their suppliers appear to be sustainable, do recipients commit to a partnership relation.

Having to meddle with local(e)s, Philips Medical Systems here faces an interesting problem. This problem arises from the potential longevity of technology in Africa way beyond the expected life-time of artifacts by means of innovative kinds of repair or simple usage despite the trespassing of expiry dates, and the short duration of technological artifacts due to donation practices. The transferred ultrasound machines thus have to be sustainable enough in order to prevent the company from losing Africa as market again, and not sustainable for too long to allow profits from selling the next generation of machines. It is, thus, within the 'lab space' of two weeks teaching and seven years 'repair'-services that the company has to turn Philips Medical Systems into an obligatory passage point forging the relationships that make ministries and hospitals stick and return to Philips for aid and trade. In pursuit of establishing itself in a prominent position in the diagnostic imaging landscape in Africa, the company designed a unique ultrasound technology. This uniqueness, however, contradicts the equality principle inherent in the vision of 'One World': in order to be essentially the same, Ghana and Tanzania are to be treated like France and The Netherlands. Stripping ultrasound from its attachments, however, removes the uniqueness - its Dutchness and specific Philips identity - that made the devices fit for Africa and for working globally. Devoid of its particular attachments the Philips ultrasound becomes global in the 
sense of becoming equal to any other ultrasound machine from any other firm. It thereby becomes exchangeable for any other machine too: retreat in pursuit of equal treatment also means to being treated equally in the market in response.

The problem that Philips Medical Systems faced with regard to aligning 'sustainability' and 'partnership' in its ultrasound transfer projects, points to the difficulty in re-localizing global models. While paper-work is patient and allows project-planning, actual project-work holds surprises: global prospects do not necessarily make or keep local projects going unless things are compromised, for example, the democratic access to new technology in terms of professional groups, or the limited access in terms of professional numbers.

\section{World order and Work order}

'Ultrasound for Africa' as part of the vision of a new world order works by intertwining two complementary practices. The first practice - globalization - consists of framing local phenomena in global terms. The second practice - relocalization - returns these global models to work in particular localities. World order comes to rest on a double transformation of 'local things' at different places. The misfits that occur when things are relocalized thus are systematic rather than being the results of recipients' resilience - they are the inevitable effect of the double transformation enacted and required by a working world order. Imagining the world in a particular way, in short, enables imaging devices to travel the globe, yet it is only in their intertwinement with the local that they actually get to work. As an international apparatus ultrasound, hence, describes and prescribes the same relations to be the case everywhere - global in the sense of universal and equal - yet it rests on relations that are essentially bound to specific places - local in the sense of being specific and diverse.

\section{Space matters}

By exploring the international apparatus, that is, the mutual shaping of ultrasound and the social group of transnational agencies and companies, this chapter has aimed to show how the dimension of space matters in and for technography. Focusing on the dimension of space reveals a multiplicity of spaces, or spatial forms, that come to bear on ultrasound transfer. Among them are physical geography (in terms of landscapes, regions, or countries), social geography (such as gender roles, professional positions, etc.), architecture (for example, 
hospitals, or particular wards), body geography, or as it is more commonly termed anatomy, space in form of play area, and conceptual space.

In the conceptualization of ultrasound transfer by both international policy agencies and Philips Medical Systems, a multinational company, space appears foremost as an expanse to travel across. In the Philips's account this expansion features as a voyage of discovery: 'blank points' or 'black areas' are to be filled in or enlightened with imaging devices. International agencies' story of expansion is that of globalization, the unimpeded flow of goods. Be it the more traditional or the more modern mode of narrating expansion, however, both accounts are alike in the expectations they attach to ultrasound: it is to free African women from undue death, and thus make them like women in 'the North' and African men, and to liberate them from traditional gender roles, allowing women to develop their productive potential. In short, the argument goes, ultrasound is to increase African women's and Africa's play area with regard to a better quality of life in the future. Tying together subjects and objects to one another in a particular immutable way - based on numbers, figures, and the like - ultrasound thus creates an order of free individuals. This argument is powerful as it is the premise on which democracy rests, while at the same time it is dependent on that very system.

The effects of imagining the new world order brought about by imaging devices lie in the kinds of space that these discursive practices evoke (see Massey, 2005). The Philips' discovery story, for example, depicts places as static - blank of any world developments and passively awaiting the arrival of new goods. The globalization story, in contrast, renders places alike: essentially equal, places become superfluous. This loss of place as dynamic and heterogeneous entity does not become apparent right away in the emphasis of international agencies on particular locales and in the mapping of variety. Maps, however, are distinct modes of representation. Seemingly independent from the cartographer and the practices of map-making, they provide an aura of fact-ness, of authenticity and objectivity. In short, they suggest that the object mapped is a correct relational model of the terrain and phenomenon it originates from (Harley, 2004). Yet maps first of all constitute 'documentary reality' as an essential feature of modern institutional organization that rule by administration. This reality is based on categories that exist prior to the encounter of map-making institutions with local worlds. Labels and categories thus prefigure the observations made (Escobar, 1995; Moore, 
2001; Mueller, 1987; D. Smith, 1974, 1984). ${ }^{45}$ The global space that is created by using the 'same measures for everybody' thereby conjures a seemingly neutral space upon which the new order is inscribed and the new individual - a freed African woman - is created. All movements envisioned, however, rest on terms that stress that some have less, rather than that some have more, than others (Rist, 1997). The usage of global terms thereby disguises that the open future put on paper consists of unidirectional development towards a goal set as common, but not set in common. Differences between countries or people turn into a temporal order - into a 'not yet there-ness'. As time and technology proceed, or so the logic goes, there will be any thing 'for All'. Lost to the equal measures of (wo)men, hence, are the diversity of local histories and multiplicity of trajectories. Not only does the future of 'One World' thus get closed, also space empties out. Yet while erased on the surface that space thus becomes, diversity returns via the discourse that links early and modern forms of (imperialistic) governance of health matters (Hunt, 1999) and that continues to run underneath the sanitized language of scientific percentages and apparent political correctness. In the description of the complex causes of 'poverty in Africa', for example, not only external shocks expose Africans to poverty. Rather, it is reported that Africa's fertility, hygiene, feeding practices, in short, its overall 'sleeping mode' (Kapuscinski, 2001) and its belligerent attitude contribute to lack of health, peace and education. This notion of an 'African poverty' also represents a unity but one whereby poverty is part of an African habitus that is inevitably bound to a particular space. ${ }^{46}$

All three spatial practices described - the erasure of place as dynamic entity, the flattening of space and the upholding of the notion of an essential otherness - result in spacing: they keep Africa and Africans apart. The space-making practices of international agencies and multinational companies hence expose these seemingly global places as rather closed epistemic communities, as sealed 'labs' that carefully guard the entry doors into their territory. Being drawn into 'Health Care International' hence allows and requires companies to talk and think about an 'African maintenance mentality' and how to remedy it. It furthers

\footnotetext{
45 In her critical analysis of 'Women in Development', sociologist Adele Mueller summarizes poignantly, for example: "Women in development texts do not, as they claim, describe the situation of Third World women, but rather the situation of their own production. [...] The Women in Development discursive regime is not an account of the interests, needs, concerns, dreams of poor women, but a set of strategies for managing the problem which women represent to the functioning of development agencies in the Third World" (Mueller, 1987, p.4).

${ }^{46} \mathrm{I}$ am indebted to Simon Watney for the conceptual distinction between 'African AIDS' and 'AIDS in Africa', which I extrapolate here to the dimension of poverty (Watney, 1990, p.94ff.).
} 
the idea that ultrasound experiences made in Ghana can be extrapolated to Tanzania, after all 'Africa' is all the same. It opens the way to organize the teaching of rural operators in urban Teaching Hospitals with the aim of making them acquainted with 'African reality', as if there was only one such reality and not multiple. And it keeps research on technology apart from the actual introduction of technology into work practice. This enables international agencies doing the research not only to shift responsibility for machines that are not functioning to national state agencies responsible for the latter, but also to keep the technical apart from the political. The international apparatus in sum is the effect and effects a particular "space of thought and action" (Escobar, 1995, p.42), wherein some borders are visibly undone, while other are newly (and subtly) erected or renegotiated. ${ }^{47}$ The synoptic view that enables the administration of aid may thereby turn into a panoptic view that keeps a record on 'the other', while being the map-maker grants a spectator a point of view from above. While promoting the increase of play area for African women, moving ultrasound first of all increases the play area of multinationals, thereby potentially limiting the movements of other actors.

Focusing on space as a dimension for analysis hence contributes to being attentive to the fact that speaking, thinking and acting are always done from somewhere. The problem of bracketing this 'speaking from somewhere' is not so much the simplification of complex worlds such as, for example, the reduction of women's lives to mortality statistics, but that depending on the site different things may be bracketed. Not only the degrees of openness and closure of a world envisioned, but the terms by which openness and closure are established therefore have to be scrutinized. Bound to a certain place, however, categories other than those already known of, become literally unthinkable. Taking over the singleminded global terms and categories, hence, does not necessarily result in seeing better or more. It may as well result in leaving residual categories and phenomena that are bound to other places out of sight. A hospital, health care practice, professional conduct, or a pregnancy may then appear to be deceptively familiar, exposing its otherness only at closer sight.

The questions that this chapter leaves us with for technography are the following: Which relationships (of technology and society) are fore grounded, and which are bracketed?

\footnotetext{
${ }^{47}$ That this apolitical performance is systematic has been nicely coined by anthropologist James Ferguson with the description of the development apparatus as an 'anti-politics machine' (Ferguson, 1990).
} 
What kind of space do these relationships embody and exert? Who is setting the terms? Whose play areas are privileged, that is who moves, who is to move, and who or what controls the movements? These in turn require finding out what is in place in the places where a new technology travels to. By following ultrasound to the immediate partners of Philips in the transaction of ultrasound in the following chapter, my first answer to the question 'what is in place?' is resources. 


\section{Buying into imaging technology - the state apparatus}

Accra, Ghana: February 15 $5^{\text {th }}, 2003$. Dr. Aryeetey repeats my question whether ultrasound was meant to help Ghana reduce maternal and perinatal mortality. He is the head of the Biomedical Engineering Unit, the advisory board to the Ghanaian Ministry of Health concerning medical technology, and, thus, was recently involved in the Philips Project. Dr. Aryeetey replies that he would not know right now. "That research has still to be carried out", he says. I must have shown that I am baffled. He explains: "The impact of medical devices on the service, how to quantify it? We haven't carried out research like this yet. We would need funding to be able to do something like that. It would be interesting to find out. You know - if you introduce ultrasound into a community: what is the impact? Does it increase our patient attendance? Does it affect maternal mortality? Maybe infant mortality? That would be interesting, but all these things need funding of some sort. [But] funding is difficult and you first have to buy the machine with the funding and then [you need] another funding to find out how the machines are working and then another to determine the impact of the device on the health care system."

Dar es Salaam, Tanzania: March 15 th 2004 . The radiographer Mr. Chanika does not need to think about whether ultrasound was meant to help Tanzania to reduce maternal and perinatal mortality. Mr. Chanika is a civil servant at the Department of Curative Hospital Services in the Tanzanian Ministry of Health, and is responsible for diagnostic imaging services. He was appointed Head of the Radiology and Imaging Section with the beginning of the Philips Project in 2000. He laughs, and then bends forward as if the secretaries in the front room or a suddenly entering colleague should not listen in on us. "Actually, we did not really cry for ultrasound. It was more like a little brother coming along with x-ray. And $\mathrm{x}$-ray is what we had been asking for to put the health care system back on its feet", he says, referring to the deplorable state of x-ray equipment in Tanzania since the 1980 s. 
In the previous chapter I showed how Philips Medical Systems introduced ultrasound into Ghana and Tanzania for the purpose of improving maternal mortality statistics. The ultrasound that left the Netherlands and was sold to the Ghanaian and Tanzanian state agencies, in other words, was this maternal-mortality-reducing-device. Anything sold, however, also has to be bought; and so any transaction requires resources. Using the dimension of resource as my analytical point of departure in this chapter, I will explain why the ultrasound bought was not primarily a device to improve maternal mortality statistics, as the two brief accounts of Dr. Aryeetey and Mr. Chanika show. For the immediate partners in the transaction, ultrasound instead turned into a device to boost the national health care system. It is this state apparatus that I am interested in this chapter. I will argue that this transformation of ultrasound has to do with a shift in problem definition. The primary problem for the state agencies in both Tanzania and Ghana was the functioning of the national health care system. Focusing on resources will enable me to show why this problem - and in turn, ultrasound - assumed a different shape in the two countries.

I will trace the evolving of ultrasound as state apparatus in Ghana and Tanzania in two separate sections. These processes were, as I will show, quite different. This may seem surprising, since both countries share a similar history in terms of their British colonial relations, a socialist phase after independence and subsequent economic structural adjustment programs. At the same time, the countries differ substantially too: while English remained the prominent language in Ghana, Kiswahili became the national language in Tanzania; Tanzania's socialist phase lasted longer than that of Ghana, and so several international policies that are already in place in Ghana have not yet been fully realized in Tanzania. For a good understanding of the 'landing' of ultrasound in Ghana and Tanzania, I need to describe the respective health care systems in more detail. My emphasis will thereby be on the expectations, deliberations, and practices of the state agencies with respect to the ultrasound transaction. In the third section I will present the particular state-ultrasound in Ghana and Tanzania as the effect of the respective state agency's (in)ability to mobilize certain resources. Following ultrasound to the state level thus provides an insight into current practices and problems of African state agencies to keep up (or restore) a national health care system. In the fourth section I will summarize what exploring the state apparatus teaches us about the question how resources matter in and for technography. 


\section{Turning ultrasound into a state affair in Ghana}

The earliest ultrasound in Ghana in the 1980s was quite an exclusive technology: it was only available in certain places and certain types of hospitals and only accessible to a certain portion of the local population. This led to a migration process of patients and health care professionals away from the public health care system. When Philips offered their comprehensive package allowing the purchase of a large number of ultrasound machines, the state agencies sought to counter these migrations by strategically distributing and installing ultrasound equipment. This has not been completely successful: ultrasound is still exclusive, and migrations still continue. Yet it did produce another, unexpected, effect: the state gained more control of ultrasound in the private health care sector.

\section{Exclusive objects for public health}

Ultrasound's exclusivity in Ghana in the mid 1980s derives from its mode of acquisition: one by one ultrasound machines traveled in the hand luggage of white medical missionaries to work in mission hospitals 'up country', that is, predominantly in rural areas. While some Ghanaian patients thereby had already been in contact with ultrasound, the majority of Ghanaian health care professionals at the state supported Teaching Hospitals, Korle Bu in Accra or Komyfo Anoche in Kumasi, encountered ultrasound either as merely hear-say or in written form as a 'standard tool for obstetric diagnosis' in their British textbooks. In the latter form, ultrasound paradoxically enabled a medical student to graduate as a full fledged member of the medical profession without necessarily ever having seen or operated ultrasound in reality, as Dr. Aryeetey vividly remembered:

For instance, I finished medical school without knowing what an ultrasound looked like. I had seen pictures of ultrasound and even attempted to interpret them in the clinical exam but I had never seen an ultrasound. (Gh 1)

Having followed specialization to become a biomedical engineer in the United Kingdom, upon his return to Accra in 1993 Dr. Aryeetey noticed a change: ultrasound had become publicly visible in the streets of the capital (see Figure 3.1):

Between 1991 and 1996, there was a proliferation of ultrasound machines in the private sector, rather than in the government sector. Several bought it; and they were actually not all hospitals, 
they were private owned laboratories, which were set up around most of the hospitals, providing ultrasound services (ibid.).

His story can simply be read as an account of the rapid increase in quantity of ultrasound machines in the country between the mid 1980s and the mid 1990s. At the same time, the three ultrasounds mentioned - the mission and the government ultrasound of the 1980s and the private ultrasound of the 1990s - display particular features of the health care landscape of postcolonial Ghana. I will outline these features in the following section as they help to understand how the Ghanaian state agency appropriated the Philips ultrasound.
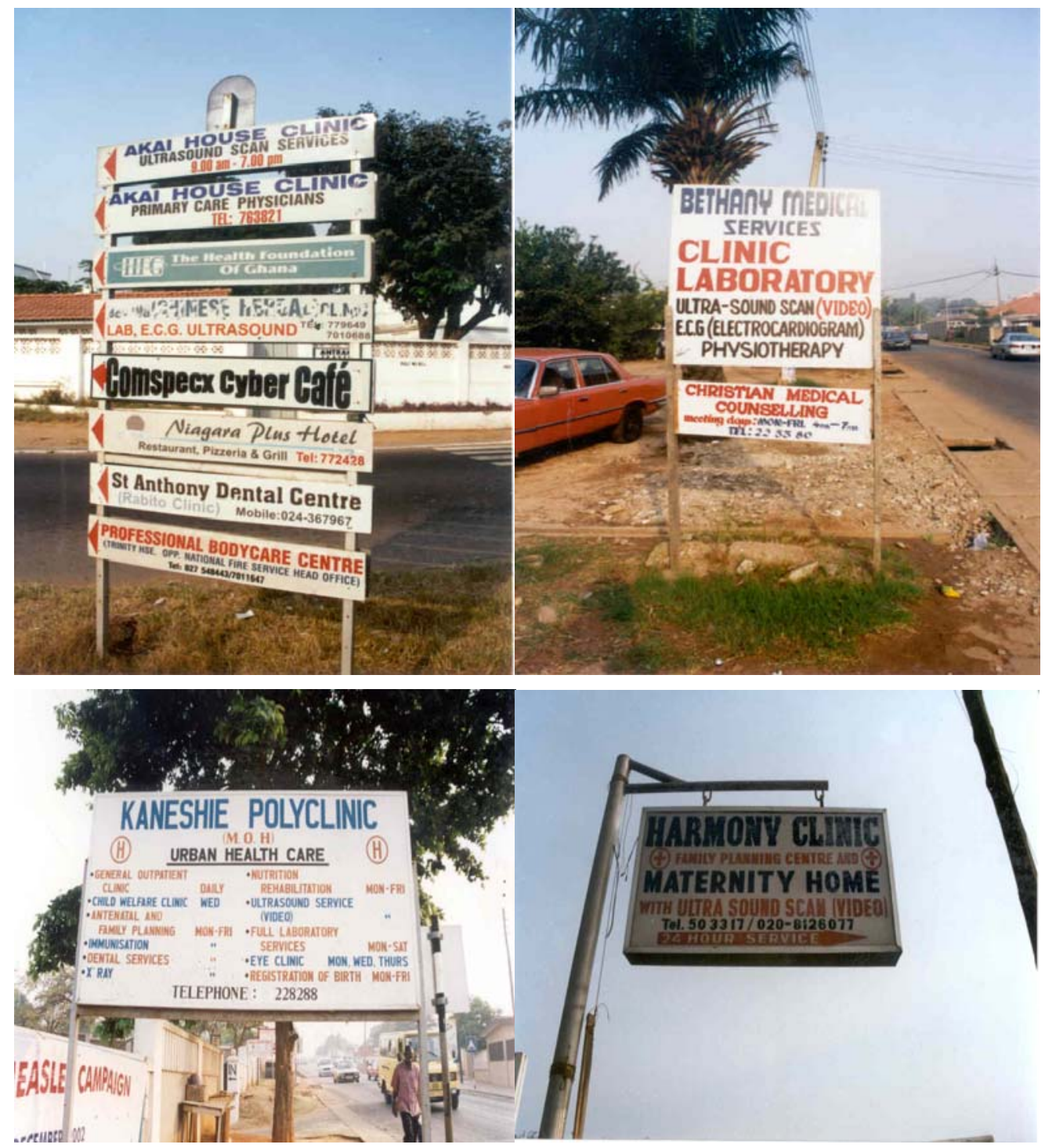

Figure 3.1: Advertisements of ultrasound / 'video' services in the streets of Accra: in the city centre in Osu, in Kaneshi, in Adenta, a suburb - in order of their appearance from top left to bottom right. 
The exclusivity of ultrasound in the 1980s demonstrates the particular position that mission hospitals in Ghana enjoyed since their initial establishment during colonialism. In most cases mission hospitals were set up in rural areas and concentrated on curative services, in particular in the field of reproductive health. They thereby complemented the focus of the urban based hospitals established by the colonial government on Europeans and the Ghanaian male workforce, and on preventive services. In line with Christian ideology and the public health concerns in their mother countries, infant mortality in many European countries had come to be understood as compromised by bacteria and thus by a lack of hygiene for which mothers were seen as responsible (see e.g. Bruchhausen, 2003, p.96). In their pursuit of potential converts, medical missionaries furthermore regarded African mothers as "producers of Christian babies" (Raikes, 1989, p.448) and as future workers (e.g. Hunt, 1999). In many African countries mission hospitals therefore were the first to introduce Western midwifery practices and health care education classes to teach mothers about childcare practice and hygiene. As they also provided the vast share of medical care for the indigenous population, mission rather than governmental hospitals have come to be seen as the main agents in introducing biomedicine and its executive forces - hospitals, personnel and technologies - into Africa (see Bruchhausen, 2003 for Tanzania; Hunt, 1999 for the Congo; Patterson, 1981 for Ghana; Turshen, 1984 for Tanzania; Twumasi, 1981, 1982, 1992; Vaughan, 1991 for East Africa in general). ${ }^{48}$

In Ghana, the most active congregations were the Basler, a Swiss protestant, and the Catholic mission (Twumasi, 1992). From the start, mission hospitals had been financially supported by the colonial government as compensation for their services to the majority of the population that lived in rural areas. This practice was taken over after independence by the Ghanaian Government, which supplied mission hospitals with so-called state enrolled nurses who replaced their former foreign (mostly British) colleagues. Yet as well as being supported by the government, mission facilities also relied on a second supply chain via their mother-congregation situated abroad. This supply consisted (and still consists) of staff and of technical equipment both of which made (and make) mission hospitals independent from the economic conditions and constraints of supply by the government. ${ }^{49}$ Via this external

48 See also Ranger (1992) for a critical review of the 'blessings' of missionary medicine.

${ }^{49}$ During colonialism mission facilities had been staffed with foreign doctors and nurses as well as with Ghanaian converts serving as auxiliary personnel. They began to be staffed with Ghanaian nurses after the establishment of the first nursing school for Ghanaians in 1944 in Kumasi, which moved to Korle Bu in Accra in 1984 (Opare \& Mill, 2000). The first 
supply chain, mission hospitals in Ghana received their first ultrasound machines when the technology became standard practice in 'the North'. In this context the Baptist Medical Center in Nalerigu, for example, was donated their first ultrasound machine by their mother congregation, the American Southern Baptist Church.

As the mission ultrasound mirrored the economic and political condition of its institution, so did the kind of ultrasound that circulated at the government supported Teaching Hospital Korle Bu. Built in 1924 as a health care facility for colonial civil servants and black workers, Korle Bu had turned into a governmental Teaching Hospital in 1958 during the 'Africanization' program initiated by Ghana's independence leader Kwame Nkrumah. ${ }^{50}$ Since 1964, it has hosted the first and biggest Ghanaian medical school (Patterson, 1981)..$^{51}$ The major objective of this program was the decentralization of health care service away from urban based to rural district hospitals - an idea that in 1978 was officially declared the WHO position in its Primary Health Care Initiative. By the mid 1980s, the restructuring into a multi-layered system of health care provision consisting of health care centers and dispensaries as primary level, better equipped regional hospitals as secondary and specialized Teaching Hospitals as tertiary level facilities, was not fully realized. Instead government-supported health care remained as curative and urban-based as it had been during colonialism, and used the main part of the health care budget while serving only a small part of the population (Patterson, 1981; Quaye, 1996, pp.1-3; 123; see Turshen, 1984; 1999 on Tanzania and Zimbabwe).

midwifery school in Ghana opened in 1928 at Korle Bu Hospital (Patterson, 1981, p.17). In many mission hospitals, however, doctors still remain foreigners, an effect of the unwillingness of many Ghanaian doctors to practice in rural areas (see below).

${ }^{50}$ The set of policies and techniques to cope with the remnants of colonialism is therefore also known as Nkrumahism (Quaye, 1996, p.24).

51 The other two medical schools are at Kumasi and at Tamale. Tamale, however, only recently resumed full functioning, one of its biggest problem being the lack of teachers and students due to the undesirable geographical position of the town in the far North of the country. 


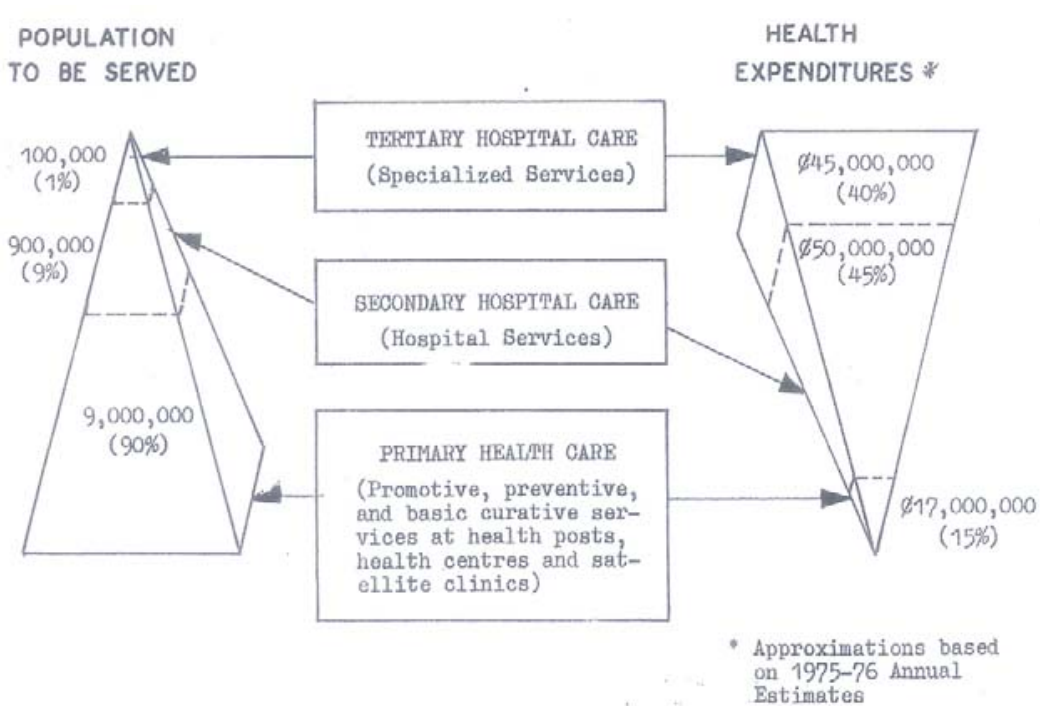

Table 3.1: 'The health care dilemma in Ghana'. This table shows that the distribution of funds and personnel for primary health care compared to specialized hospital-based care is in inverse proportion to the number of people that these services are required to reach $(\mathrm{MOH}, 1977$, p.53). Cassels\& Janovsky cite the same percentages in their report 1991, referring to a source from 1986 (Cassels \& Janovsky, 1991, p.4)

Throughout the Africanization program initiated by the independence government, Korle $\mathrm{Bu}$ Hospital had continued to operate with a professional health system based on British medical education. According to the health scientists Mary Opare and Judy Mill (2000), this take-over of the British system by the independent state continued for pragmatic reasons: it allowed an easy turn-over of Ghanaian and British nurses when, shortly after independence, Ghanaian personnel was still scarce. Ghanaian doctors also profited from being 'trained British'. The new medical school provided only basic medical training but no specialization. Trained 'as if British', doctors could easily pass on to the medical system in the United Kingdom or other countries based on the British system for work and further training. ${ }^{52}$ Upon their return to Ghana, this specialization allowed Ghanaian doctors to obtain specialist positions in government hospitals and in addition to acquire jobs in private practice. One of them was Dr. Bonsa, the former Head of the Radiology Unit at Korle Bu, who, after his specialization in radiology, obtained a position in an American company that had set up a private clinic for its employees. Together with others, he thereby constituted the prototype of the African medical specialist who splits his working day between two

\footnotetext{
${ }^{52}$ In the socialist phase of Ghana under Nkrumah, medical doctors also went to the USSR, Poland, Bulgaria and Hungary for specialization.
} 
employers: working from $8 \mathrm{am}$ to $2 \mathrm{pm}$ in public health service, thereby being entitled to all government allowances (cars, books, housing), and shifting to private practice thereafter instead and thus being able to "make the real money", as Dr. Bonsa explained (Gh 2).

The private ultrasound performed by professionals such as Dr. Bonsa and witnessed by Dr. Aryeetey upon his return at the beginning of the 1990s, was a visible manifestation of the privatization policy that Ghana had embarked on since 1983 as part of the structural adjustment program. ${ }^{53}$ Under this policy the Ghanaian government had also been engaged in several public-private partnerships with rural mission hospitals, such as Nalerigu Baptist Medical Center. This subjected the hospital to government regulations concerning user charges and exemption regulations pertaining to services for paupers, pregnant women and children. In urban areas, decentralization policy led to the opening of health care facilities for the general public which formerly had only served particular population groups, such as the Military or Police Hospital in Accra (Twumasi, 1982). In this process, Teaching Hospitals acquired greater financial and administrative autonomy. Turned into parastatal referral facilities, Teaching Hospitals were allowed to impose user fees on anyone attending their services as first line contact, for example, and to use this money to cover their expenses. Moreover, the Health Care Sector Reform carried out after the first democratic elections in 1992 resulted in the establishment of the Ghana Health Service (GHS). Taking over executive authority from the Ministry of Health, which in turn was left with the legislative authority, a major task of the newly established National Health Service was to contract Teaching Hospitals for patient treatment (GHS, 2002). On the one hand, the reform thereby alleviated the government from sole responsibility for sustaining these costly colonial remnants. On the other hand, the state agency still bore the responsibility for investing in training, while their authority and control over the key agents required to carry out government policy loosened (see Hiscock, 1995).

A further effect of the privatization policy was the increasing establishment of private practices that offered diagnostic imaging or laboratory services, particularly in urban areas. Requiring patients and short distances for treatment, many of these private facilities

\footnotetext{
53 By 1983, 38 African countries had entered the Structural Adjustment Programs (SAP). In Ghana the first Economic Recovery Program took place from 1983-1986 to be followed by a First SAP 1987-1988 and a Second SAP 1988-1990 (Agyepong, 1995, p.66 ff.). A discussion about the problematic effects of SAP on indigenous populations is beyond the scope of this chapter. A good summary on SAP policy on women in Ghana can be found in Gabriele Kruk, (2000); see also Turshen (1999) for SAP effects in Eastern Africa.
} 
situated themselves in the neighborhoods of polyclinics or hospitals. Right in front of the main entrance of Korle $\mathrm{Bu}$, for example, three private facilities offered 'video' services, one of which was owned by the head of Korle Bu's maternity department. As Ghana demonstrated the economic growth and political stability that international programs had envisioned, it also benefited from increasing donations of more sophisticated technological equipment. On the grounds of its traditional ties with Germany, for example, the Military Hospital in Accra received a Siemens ultrasound machine as a donation while Korle $\mathrm{Bu}$ received two ultrasound machines via an American NGO.

Starting out as an object exclusively owned by mission hospitals and hidden in rural areas, between the 1980s and 1990s ultrasound had been transformed into a publicly visible item on Ghanaian streets in Accra and into an item accessible to Ghanaian professionals in private clinics and at Korle Bu. For public health care on a broad basis, however, ultrasound remained an exclusive object.

\section{Pull factors in migration}

The unequal distribution of ultrasound, that is, their installation in private-for-profit and private non-profit rather than in public health care facilities, had consequences: professionals and patients emigrated from public to private health care in pursuit of fully equipped services. "Women in the North", Dr. Aryeetey recalled, for example, "traveled as far as to Ouagadougou" (Gh 1), the capital of the neighboring country Burkina Faso in order to get an ultrasound. His remark reflects the Ministry of Health's general concern about the health seeking behavior of its people. In the year 2000, for example, "only one third of the population use[d] formal health sector services" (GoG \& MoH, 2000, p.55), stated a report of the Ghanaian Ministry of Health, adding that this percentage had declined since the early 1990s. While people in rural areas would attend mission hospitals or traditional healers, urban areas saw a flight to private facilities or to specialized hospitals. Women in and around Accra, for example, went to either one of the private ultrasound providers, or as many of them could not afford these private fees, massed in the Teaching Hospitals Korle Bu at Accra or Komfyo Anoche at Kumasi. In Korle Bu, women's pursuit of ultrasound thereby led to paralyzing work situations as Dr. Aryeetey vividly remembered:

You have to imagine 200 pregnant women a day [were] waiting for the ultrasound in that corridor. [...] They came from La Polyclinic, 
from Kaneshi, from everywhere and [...] that led to severe congestion of Korle Bu. ${ }^{54}$ (Gh 1)

In his opinion ultrasound on the one hand caught on rapidly because the technology had been introduced shortly after another imaging device attracted the fascination of the general urban public: color television and, in its wake, the first video recorders. In fact, it was this other technology that provided ultrasound with the vernacular name 'video' by which private practices promoted their diagnostic services and health care professional referred to ultrasound in their explanations (see Figure 3.1). On the other hand women's interest in ultrasound and travel for it, according to Dr. Aryeetey, could be explained by the general desire of women to know whether what they carried was "a rabbit or a human being" (Gh 1). In that sense, Ghanaian women would not differ from other women in the world. The consequence of the unequal distribution of ultrasound in the country, he concluded, was that Ghanaian women, and especially the poor among them, suddenly faced discrimination with regard to basic human rights. Moreover, while before the introduction of ultrasound all pregnant women in Ghana had been able to get an x-ray in case imaging diagnostic was necessary, adoption of the international prohibition against the use of $\mathrm{x}$-ray in pregnancy now favored non-Ghanaians:

Even if we don't have a regulating system in the country to regulate or to support the system, we still subscribe to international standards. At other institutions where an expatriate in Ghana is pregnant and requires an ultrasound scan, and there is none in Ghana, [she] flies out of the country. You want to do ultrasound but it is not three months, so you have to fly out of the country. Meanwhile a Ghanaian has the same problem and you decide: 'Okay, let's forget about it.' (Gh 1)

The unequal distribution of ultrasound does not only directly affect women's access to imaging diagnostics. Its also affects women's attendance at public health care services through the consequences this inequality has on professional presence in the public sector and in the country in general. Prior to the Philips Project, Dr. Aryeetey remembered, doctors had in fact been asking him for ultrasound for years - a request that the government could not fulfill due other budget priorities. In our interview this remark was immediately followed by him making a joke that I had heard previously from others when explaining that I did research on ultrasound technology in hospitals: 'Where do you meet the most Ghanaian

\footnotetext{
54 The polyclinics La and Kaneshi are the urban equivalents to rural district hospitals. Kaneshi Polyclinic is situated in the urban district Kaneshi, La Polyclinic in the city center.
} 
doctors? ... In New York!' Telling this joke in the context of ultrasound, he linked the new technology to the problem of professional emigration and emphasized the role the state agency attributed to ultrasound as a remedy for this diaspora of doctors.

According to a report by the Ministry of Health in 2000, lack of proper equipment to allow practice of the high quality medicine taught at the Teaching Hospitals, had contributed to decreased job satisfaction amongst health care professionals and had increased their low morale. In the face of open borders, this low morale provided new possibilities for health care professionals to migrate either to the private sector or beyond national borders altogether:

Health workers increasingly operate in regional and international markets. It is no longer possible to imagine that the national labour markets are 'closed'. Skills are mobile and follow rewards. Ghana has invested in its people for many years. The result is an enormous pool of educated talent to export quality. This is now telling against the health sector. (GoG \& MoH, 2000, p.47)

In its 1999 health sector review report, Consolidating the Gains: Managing the Challenges, the state agency reported a general "annual wastage rate of health care professionals" of $4,5 \%$ (ibid.). According to a survey undertaken by the Ghanaian Nurses and Midwife Council for the same year, the absolute number of nurses feeding into this wastage rate was 328. While at first glance not a very high number, the report revealed its significance by relating this number to others: 328 nurses, it noted, not only equaled 2,6\% of the nurses working in the whole country, it also equaled the total output of State Registered Nurses for the year 2000. Furthermore, this number doubled the 'loss' of nurses of the preceding year (GoG \& MoH, 2001), thus constituting a progressive development for the worse. And although the precise number of 'wasted' doctors, this report stated, was not known, according to "anecdotal evidence [...] 40 per cent of all graduating medical students leave the country" (ibid., p. 60).

This continuous loss of health care professionals increased the difficult staff situation that the Health Care Reform of the newly elected government had started out with: the first democratic era after years of military dictatorship under Jerry Rawlings began with a personnel shortage of $15 \%$ with regard to the staffing norms the Ministry of Health had put into place in order to ensure quality care. In absolute numbers this shortage represented 529 nurses and 233 doctors, including 195 specialists (GoG \& MoH, 2001, p.56). The general shortage aggravated the disproportionate distribution of staff in urban and rural areas of the 
country, a remnant from colonialism that had never been fully overcome despite attempts by the postcolonial government. Comparing the two Teaching Hospitals with the rest of the country, the state agency in 2001 described this inequality as follows:

Korle Bu had 285 doctors (26 per cent) and Komfyo Anoche had 184 doctors (16,5 per cent) compared to $6,8 \%$ of medical doctors available in the three Northern Regions. (GoG \& MoH, 2001, p.59)

The unequal distribution of health care professionals thereby is in reverse to the distribution of people these professionals are to serve and take care of, as the Ministry of Health had noted a year earlier:

Greater Accra (including Korle Bu) has 1,216 nurses and 150 medical officers compared to Upper Western Region which has 96 and 14 respectively. However, the population of Greater Accra is only about 3,5 times greater than that of UWR. Of the 2, 037 staff recruited in 1999, 50 refused their first posting (mostly to northern regions) and some did not take up any posts and are now lost to the system. (GoG \& MoH, 2000, p. 47)

While official reports exposed the visible failure to keep health care professionals in the country and in public health care during the preceding years, a more recent phenomenon is their appearance in the public press. This publicity was a novelty for the ruling class, including the medical elite which under Jerry Rawlings' government managed to keep accounts of its (mal)functioning - if they were put into written form at all - within closed walls (Gh 9). Within the new democracy, however, the press turns the persistent inequality into a public concern. A story with the headline "Police Hospital in Coma" in the most popular weekly newspaper, The Mirror, outlined the staffing situation awaiting any patient who attended the facility: since 2000, 12 doctors out of 32 have left, the remaining 20 care for 300 patients a day, 10 of these doctors are specialists, one has moved into administration and two are in further training programs, which leaves the remaining 7 with the task of running the Outpatient Department on a 24h shift (Asiedu, 2002, p.1). The Daily Grapbic highlighted the regional differences in the inadequate doctor-patient-ratio: "The doctor to patient ratio in the Upper East Region is one doctor to 60.000 patients, in Accra it is one doctor to 12.000 patients" (Armah-Idan, 2002, p.1). And the weekly newspaper Public Agenda cited the Head of the Maternity Block at Korle Bu as he expressed his sympathy for colleagues who left the Teaching Hospital in pursuit of work conditions fit for their high quality of training, but also his conviction that maternal mortality could be decreased if there was better equipment and - as a consequence - more staff: 
The staff here is very skilled. They have the know-how. They can work anywhere in the world and the problem is they very often do. Staff is leaving all the time to seek better conditions in the West, leaving us shortly staffed. We train them and they just get up and go, sometimes without any notice. And who could blame them? We train around 80-90 doctors and many more nurses, a high percentage of whom leave after training. We could decrease maternal death and cancer deaths for women as well as preventing diseases before they occur if we had better resources. (Imrie, 2003, p.5)

Facing the migration of professionals and patients from the public health care system, the Ghanaian government's dilemma lay in the promise it made in the report Medium Term Health Strategy towards Vision 2020. Improving the health of the nation was herein stated as one of the preconditions in Ghana's pursuit of becoming a middle income country:

The Government of Ghana is committed to improving the health of all people living in Ghana regardless of age, sex, race, ethnic origin, religious conviction, political affiliation, or socio-economic standing. Such a broad goal encompasses many specific objectives both for individuals and populations, e.g. increased life expectancy, reduction in avoidable deaths, improvement in quality of life. These objectives do not necessarily conflict with each other but will always be in competition for limited resources. (GoG, 1999, p.6)

While this policy statement is carefully formulated with regard to the presence (or absence) of national resources, people in the meantime literally vote with their feet and leave national health care or the nation altogether. Providing access to ultrasound for a wider and rural public, hence, was a necessity if the government wanted to stay true to this democratic commitment and leave the colonial past, with its focus on urban and expatriate elites behind.

\section{Means to "stemming the tide"}

At the same time that ultrasound poses a problem as it leads to professional and patient migration, it also carries the solution to this problem, as the statements of Dr. Aryeetey and his colleague at Korle Bu point out: professionals need rewards in order to stay. In particular, Philips ultrasound promised to solve several problems at once. According to Dr. Aryeetey, in charge of the purchase of medical technologies for the country since 1993, its main advantage was that it required the investment of money. Comparing purchased with

\footnotetext{
55 (MoH \& GoG, 2000, p.48)
} 
donated technology, he explained that while a donation might at first come for free, it would not pay off in the long run:

You know this preaching of poverty as a reason of not buying technology that makes practice easier, I don't buy it. Personally, I don't think the issue is a lack of money but to get a device that is not working in the first instance. Whether one likes it or not, if I don't buy it, it will be donated. (Gh 1)

He underlined his opinion with a simple computer generated drawing (see Figure $\mathrm{x}$ ) that he had designed for donor conferences in order to illustrate the fragile arrangements between the various entities that were required to make health care technology work.

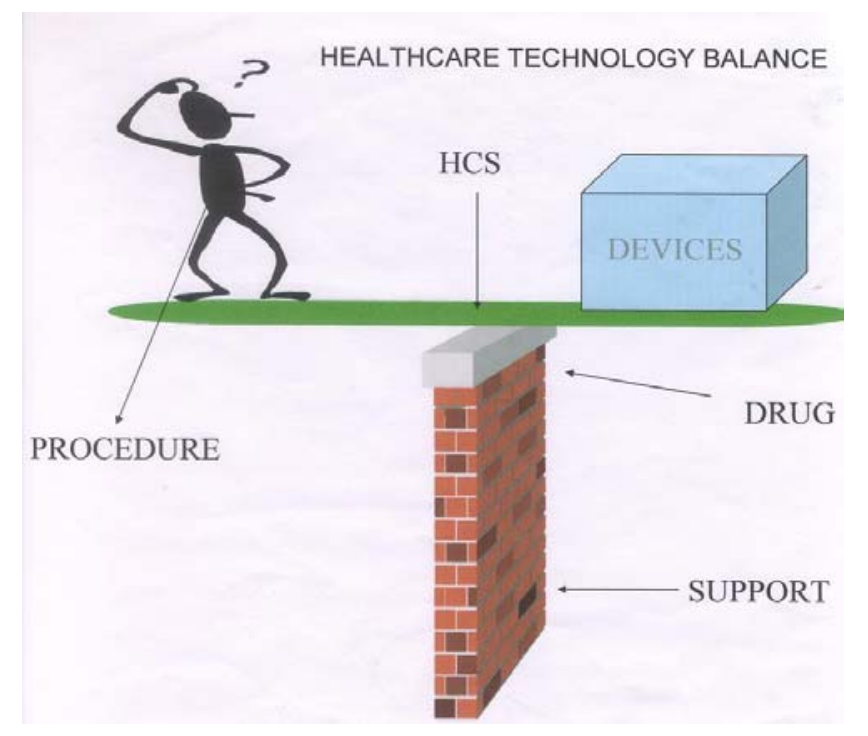

Figure 3.3: A computer generated illustration of the fragile balance between various health care technologies. A supply system represented in form of a brick wall topped by a box of drugs, carries a board balanced by a box named 'device' on the one and a little black man obviously symbolizing professional skills on the other side. Overweight of either 'devices' or 'manpower' without their respective counterweight as well as a lack of 'bricks', the drawing emphasizes, lets the system tumble or crash (Author: Dr. Aryeetey).

In contrast to the donated ultrasounds of the past, he emphasized, the Philips ultrasound kept this balance by providing the necessary 'bricks' - consumables, spare parts and technical know-how - and manpower. Moreover, the Dutch interest in investigating the field before investing in it provided the Ghanaian state agency with time to "prepare things", instead of "quick money only", as Dr. Aryeetey put it (Gh 1). 
Buying Philips ultrasound machines in order to keep up this balance, though, was not as simple as the drawing indicates. Rather, 'preparation' involved intensive negotiations with several actors who had to be convinced that (t)his was the way to go. First of all, the Dutch company had to be politely rebuffed with their proposal to teach Ghanaian technicians at the Ministry in ultrasound maintenance as their proposal did not match Ghanaian reality: "Anybody with extra skills just goes away to the private sector to make money out of it" (Gh 1). Moreover, in the view of the Ghanaian partners, the Dutch proposal was considered to be discriminatory in terms of proposing to have Ghana take over maintenance. Recalling the explanation he gave to the company in that context, he explained:

I asked them whether they [would] expect any European country they provide with these machines to repair those themselves. No! Any European country, facility or ministry would get a telephone number to call when a machine is broken down and they, the company, would send its technicians to repair it. So that is what we wanted as well - a telephone number. To be treated as equals. (ibid.)

The second group of people who needed to be convinced of the purchase of the Dutch machines consisted of his fellow colleagues at the Ministry. In particular, the selection of operators to be trained by the state agency prior to the installment of machines was seen by many civil servants as revolutionary:

On the top we [who] were planning it, we even had to struggle to have our own people at the Ministry accept the training component of the project. We were used to buying equipment, pass it on, deliver it, and then another group of people would come and decide whether they could install it or not. And then another group would decide whether they wanted to do the training. (ibid.)

The third party involved in the argument for 'The Philips Project' was the Teaching Hospital Korle Bu itself, in particular the Head of the Radiology Unit who was in charge of any diagnostic imaging apparatus in the hospital, Dr. Bonsa. Dr. Bonsa, however, was of the opinion that the decision of which medical technology to get, when to get it and for whom, should remain the decision of the technology's user. In my interview with him, he outlined the common procedure to acquire new equipment in the past: advised by Korle Bu doctors who provided the Ministry with the desired specification, the Ministry approached donors for aid - a sometimes tedious procedure but one that guaranteed that the technology transfer fitted the end user Korle Bu. 
When we purchased the equipment, the user, the end user, the one who is going to use the machine should make the final decision. It is not the politicians who sit in the Ministry who decide this: 'We are going to give you this!' No, you have to decide because you are the radiologist who is going to use the machine. So it is you who have to decide: 'This is what I want!' [...] Sometimes, I remember some 15 years ago, I was sitting in my office and then a politician came with a list of bullshit saying: 'Select the equipment you need!' I refused: 'Oh, no you have to give me time and I am going through it!' So we looked through it and advised the politician [...] of the various articles. And then [they] pushed that equipment through either by grant or aid or whatever - that was the approach. [...] So we kept on pushing them, we need ultrasound; it is a most useful tool and cheapest among others. [...] But politicians, they tell you: 'Oh, we don't have the money.' So you try and try, and $[\ldots]$ you have to put your head up to convince them to raise money to buy that equipment for you. (Gh 2)

Negotiations between the state representative Dr. Aryeetey, who represented a new way of getting technology, and Dr. Bonsa who stood for this traditional 'purchasing attitude' became more difficult when, simultaneously with the Philips project proposal, an American company offered highly sophisticated Doppler ultrasound machines. Dr. Bonsa favored this offer as it would have allowed him to perform ultrasound examinations in the highly prestigious cardiovascular unit of Korle $\mathrm{Bu}$ and to extend the influence of the radiology unit into other departments.

The argument between Dr. Aryeetey and Dr. Bonsa mirrored the particular, and rather new, position of the state agency. Whereas in the past the Ministry of Health could have simply ordered Korle Bu to go along with ministerial decisions, the newly acquired quasi-autonomous position of the Teaching Hospitals forbade such an order. Moreover, the Ministry of Health needed Korle Bu to do the teaching required for the Philips ultrasounds and, as Dr. Aryeetey explained, Dr. Bonsa's “seniority" (Gh 1) required a respectful approach. ${ }^{56}$ Dr. Bonsa, on the other hand, could not simply ignore the wishes of Dr. Aryeetey. While the latter was 'younger', the new multi-sector policy nevertheless put Dr. Aryeetey in charge of any medical technology that might enter Korle $\mathrm{Bu}$ in the future.

After many negotiations compromises were reached. The state agency would go with the Dutch offer and purchase basic ultrasound machines while Korle Bu was allowed to

\footnotetext{
${ }^{56}$ Dr. Aryeetey's remark points to a cultural hierarchy that pervades institutional hierarchies. While in official terms a state representative is ranked higher than the head of a hospital department, older age in many SubSaharan African countries implicates obedience to the traditional seniority principle. 'Older age' does not necessarily imply seniority in the biological sense but can also mean seniority according to professional career.
} 
keep the ultrasound machines originally intended only to stay there for training the rural operators for the time of the project. Thus, Korle Bu got the opportunity to use these machines for further training of its medical students - a solution that re-installed the facility as the main teaching institution of the country. Dr. Bonsa, in turn, revised his position towards the Dutch ultrasound and explained that his opposition at the time of purchase was based on a misunderstanding of the device's purpose:

You see, this was a training program; there was no point for sophisticated equipment, just simple basic equipment. Like one that would do a little bit more than the ordinary. [...] Not the top equipment because there was no point taking a bigger machine to a small area, you know. In big centers, like Korle Bu, you could do with a bigger machine, more sophisticated. We discussed it, you know. I remember asking for a bigger machine for Korle Bu and Philips did not agree because they said that the machine was for training, $[\ldots]$ so it is the same equipment that was sent to the district. The same equipment that we have here in Korle $\mathrm{Bu}$ because that is the one we used for training. Otherwise there was no other major misunderstanding between the groups, not that I can remember. (Gh 2)

The compromise further included an agreement about the kind of operators to be trained for the rural hospitals. Dr. Aryeetey himself had been open to considering the Dutch proposal to train a variety of health care professionals on ultrasound, he told me in the interview. In contrast, Dr. Bonsa favored doctors as operators. At the kick-off meeting he supported his opinion with reference to his personal experience of once training a midwife as an operator, an enterprise that had taken him six months. In his opinion teaching a nursemidwife in two weeks, as planned by the Dutch project, was entirely impossible. In our interview he told me later that there had once been an exception from the rule in the Dutch teaching courses where a nurse from Kumasi had been taken on as participant. Yet, he added, it turned out very quickly that "the man did not understand enough of obstetrics to cope with the technology" (Gh 2). According to Dr. Bonsa only doctors had the necessary anatomical knowledge to understand the new technology fast enough. His opinion was strongly supported by his medical colleagues who had been chosen to be the trainers of the future operators due to their previous experience with ultrasound: his deputy, who during the time of my fieldwork had become the Head of the Radiology Department, a third radiologist, and Dr. Battir and Dr. Tennison, two gynecologists from the Maternity Block. Moreover, Dr. Aryeetey added, the Ghanaian Nurse-Midwifery Council at that time had not 
seemed particularly interested in participating in the project. Rather, he remembered, nursemidwives "were mainly interested in [...] working in Safe Motherhood: doing antenatal care, vaccination, family planning, [those] kind of things" (Gh 1).

With the decision to train doctors as operators for rural hospitals came the decision for the more sophisticated type of the two basic machines in order to "create enough reward" as the Dr. Aryeetey explained (ibid.). This option allowed the total purchase of 65 ultrasound machines within the budget frame. These were to travel to the hospitals Dr. Aryeetey had considered appropriate for the project: not only were these geographically remote but also each was staffed with two doctors. This latter criterion, not required by the Dutch partners, he said, was born out of his observation in Zimbabwe during the trip organized by Philips Medical Systems and the talks he had had with the doctors there (see chapter 2). These had disclosed that training one doctor not only paralyzed hospital services for the two weeks of training but led to permanent difficulties in balancing the clinical and diagnostic work of this one doctor. In order to "maximize profit out of the training” (Gh 1), Dr. Aryeetey furthermore privileged youth of these doctors. In his opinion the criterion of biological age would also serve to prevent the head of the hospital from applying for training in order to get the allowances paid by Philips - although the extensive administrative workload associated would prevent anybody in such a position from carrying out a single ultrasound examination. These preconditions resulted in the disqualification of some of the remote governmental district hospitals in favor of less remote - decentral(ized) - ones, or in favor of remote mission (public-private) rather than government facilities.

Retrospectively, Dr. Aryeetey expressed overall satisfaction with the project as well as his conviction that the state ultrasound provided a 'rock in the tide' of the professional brain drain from public health care:

I might not know the technical implications of the technologies but I know that my doctors are demanding them and if I don't buy, they will leave the country. So one reason for buying this item is to keep them in the country, they have job satisfaction and therefore they stay. They are leaving in big numbers. They are still leaving anyway. But if we can keep them there with a piece of ultrasound that he can use, at the end of the day this person can also increase his pay pocket a little. [...] I have achieved a lot more than if I had not bought the ultrasound machine and let another doctor leave and go to a hospital not known to anybody. (Gh 1) 
Furthermore, he added, the project showed impacts on the role of the state in the private health care sector. To his surprise, private ultrasound providers in Accra and Kumasi were increasingly approaching him, asking for advice in the purchase of a second-hand device or for a check-up of the specifications and quality of machines already bought. The Philips Project in sum, he concluded, had thus put the state "back on the map" (ibid).

\section{$\underline{\text { Toys for clinicians }}$}

From devices to reduce maternal mortality statistics, ultrasound machines at the state level in Ghana turned into toys for clinicians, their purpose not primarily being a medical application. Imbued with the value of being a 'whiteman's thing ${ }^{57}$, the Ghanaian state apparatus' lost, or rather changed its specificity: its new script was to keep doctors both in the country and $u p$ country - a script that could have been exerted by any other medical technology as well. In this process of appropriation, ultrasound became gendered, not with regard to patients but with regard to operators: as doctors, in particular in rural areas, are (still) mainly male, thus the Philips machines turned into 'toys for the boys'. However, the continuous presence of the state apparatus - in form of running technicians and machines and perhaps also with the exclusive focus on doctors, had an unintended spillover. It provided the state agency with a grip on the hitherto 'wild' practice and service quality of the private ultrasound sector. This increase in control, however, pertained again to urban areas, and so the state ultrasound remained in many aspects exclusive.

\section{Turning ultrasound into a state affair in Tanzania}

The earliest ultrasound in Tanzania was not of great interest to the state agency that came to partner the 'Philips Project' by the end of the 1990s. Similar to Ghana, these early ultrasound machines presumably entered the county in the same time period as their fellows in Ghana, and were mission-based. The state agency was more concerned with the national condition of another diagnostic imaging technology - x-ray - and the decaying quality of its operating discipline with regard to international standards, radiography and radiology. When Philips offered their comprehensive package consisting of $\mathrm{x}$-ray and ultrasound machines, the state

\footnotetext{
${ }^{57}$ I owe this expression to the title of Peter Ventevogel's anthropological study of traditional healers and healing practices in Ghana (Ventevogel, 1996).
} 
agency sought to counter this development by strategically selecting different health care professionals for training as operators at different levels of care. This has been successful: with the intended purchase of $\mathrm{x}$-ray and the originally unsought acquisition of ultrasound technology, Tanzanian radiography and radiology have regained international status. At the same time, the state apparatus has produced a hybrid profession, a nurse-midwifeultrasonographer, whose needs and potentials remain unacknowledged by official reproductive health policy.

\section{Hazardous leftovers}

The despicable state of x-ray technology in the country was the result of a decade-long lack inability to replace the donations of the 1960s with new machines. Rather than contributing to national health care, $\mathrm{x}$-ray machines were 'hazardous leftovers' endangering both professionals and patients, as Mr. Chanika recalled:

You know, we had $\mathrm{x}$-ray machines. They were leftovers from donations in the 60s. Now imagine, we are talking now about years after they were put to use. [And] machines have a certain life-time only, like people. After a certain time they get frail. And die. So in the 90s when we were looking around, we saw that some were not working any longer. Or, they were still working but they did not work properly. Radiation was a problem, first of all, to the operator. [But] if the room is not closed, also maybe there is a pregnant woman sitting in front of this room, and she gets exposed $[\ldots]$ because the room is not properly closed off. You can check radiation of your providers, just give them a badge. But you cannot do that with all patients. So there is a hazard. (Tz 1a)

The beginning of x-ray in Tanzania after independence had been rather promising. ${ }^{58}$ The very first x-ray machines that had entered the country, presumably in the 1930s, had been run by either white colonial government or Asian doctors in the context of providing curative services for an urban (mainly white, or Asian) elite or by white missionaries in a few peripheral mission hospitals. ${ }^{59}$ Within the First Five Year Plan (1964-1969), and in particular after the Arusha Declaration of 1967 that initiated the so-called policy of Ujamaa (Tanzania's

\footnotetext{
58 Tanzania is the name adopted by the independent government of Tanganyika in 1964 after the union with Zanzibar. I use the name Tanzania throughout this book to refer to the mainland only unless I state otherwise. Zanzibar has its own Ministry of Health, thus the state agency I am talking about has executive power only over the mainland.

59 Similar to Ghana, reports of these early diagnostic imaging machines are scarce. One of the earliest x-ray technologies in the country seems to have been a so-called Siemensroentgenkugel [Siemens x-ray ball, BMR] in the mission hospital Ndanda in Southeast Tanganyika donated by the German Ludwigs Mission Society (Stinnesberg, n.d. [1960?], p.15). For 1943, the Annual Medical Report Southern Province records this Ndanda x-ray machine as six months out of order and as the only one for the entire southern province. In 1942, purchase of x-ray was called for by the hospital in Lindi (TNA 16/19/37, p.11)
} 
socialist inspired way to development), the independent state promoted the extension of health care and diagnostics in terms of quantity. ${ }^{60}$ Throughout this period, $x$-ray machines increasingly entered the country as part of international tuberculosis and leprosy programs in rural areas (United Republic of Tanzania, 1990). The two main suppliers of x-ray machines at that time were Philips Company from The Netherlands and Siemens Company from West Germany who closely cooperated in repair matters according to the memory of Dr. Chanika: "They helped each other like brothers" (Tz 1a). ${ }^{61}$

The Second Five Year Plan (1969-1974) focused on the training of qualified personnel to staff the new facilities. The introduction of $\mathrm{x}$-ray equipment on a large scale within the First Five Year Plan had furthered the establishment of the first training facility for x-ray operators in Dar es Salaam in 1964, which certified so-called radiography auxiliaries after a training course of one year. During the period of the Second Five Year Plan, in 1972, the first School of Radiography was opened. After three years, the five people taken in for the first course became the first Tanzanian radiographers. Under the auspices of the Tanganyika Medical Training Board, the training followed a British curriculum but was taught in the official national language Kiswahili. Also in 1972, two Tanzanian radiographers and one radiologist commenced x-ray practice at Muhimbili Teaching Hospital after their return from training in the UK where they had been sent after independence (MUCHS, 2002).

The Third Five Year Plan (1976-1981) during which the Tanzanian state agency adopted the Primary Health Care concept calling for the "expansion and strengthening of preventive services" (United Republic of Tanzania, 1990, p.3), was to serve as a booster for $\mathrm{x}$-ray as the only high-tech diagnostic technology in the country next to basic laboratory and curative services. In fact, training was upgraded again when the School for Radiography became part of the University of Dar es Salaam in 1980 thus providing its graduates with

\footnotetext{
${ }^{60}$ With the Arusha Declaration Tanzania adopted a policy of non-alignment and placed emphasis on national self-reliance. Ujamaa (Kiswahili) can be translated as a 'sense of caring for extended family members' that was based on three traditional principles: respect, common property and work towards the common good (Swantz, 1996, p.42). As the core of Nyerere's socialist policy Ujamaa enforced the nationalization of banks, mills, and houses, villagization with the aim of providing health care and education facilities within people's walking distance (e.g. a dispensary for every 10.000 people), as well as Kiswahili as official language (Ahluwalia \& Zegeye, 2001; a detailed description of the compulsory villagization program is given by Scott, 1998, Chapter 7, pp.222-261; Swantz, 1996, p.9ff.). In $198272 \%$ of the population indeed lived within 5km of a health facility, and a further $20 \%$ about 5-10km away (Swantz, 1996, p.10).

${ }^{61} \mathrm{Mr}$. Chanika's reference to the concept of 'brothers', with regard to both artifacts and companies, is interesting. I don't have an explanation for this particular reference to kinship terms. It seems to me, however, that while the first mention of 'brothers', x-ray and ultrasound, stress a hierarchy that links with the traditional kinship system where the elder brother has a greater say than the younger, the latter reference rather points to solidarity, perhaps with a hint of socialist ideals.
} 
diplomas instead of certificates only (MUCHS, 2002). By the end of the 1970s, however, Tanzania faced severe economic problems. ${ }^{62}$ Under President Ali Hassan Mwinyi, the failure to overcome these problems independently made the Tanzanian government finally turn to the International Monetary Fund for aid and embark on successive donor-sponsored Economic Recovery Programs (ERP), the first starting in 1986 (Benson, 2001, p. 1905; Kiondo, 1994). In our interview, Mr. Chanika referred to these "harsh times" (Tz 1a) rather vaguely. Reluctantly, he finally provided further information, being that with regards to x-ray service, these 'harsh times' meant that there were neither films, nor chemicals, nor spare parts, and that the only governmental Teaching Hospital had to limit its diagnostic services to very urgent emergencies and rely on external help: "Muhimbili, our national pride, had to rely on help from the mission" (Tz 1b).

Although through the ties with their foreign mother congregations on a more advantageous side with regards to supplies (see Ghana, above), during that time rural mission hospitals in Tanzania faced similar difficulties in the provision of $\mathrm{x}$-ray services. Presenting the x-ray statistics of Sengerema Mission Hospital between 1962 and 1988, table 3.2 demonstrates a similar silence as well as an eloquent illustration of the account of Mr. Chanika.

\begin{tabular}{|l|l|l|l|l|l|l|l|l|l|}
\hline Year & 1962 & 1963 & 1964 & $\mathbf{1 9 6 5}$ & $\mathbf{1 9 8 4}$ & 1985 & 1986 & 1987 & 1988 \\
\hline $\begin{array}{l}\text { \# of x-ray } \\
\text { examinations }\end{array}$ & 257 & 350 & 380 & 594 & 1.609 & 1.291 & 968 & 303 & 394 \\
\hline
\end{tabular}

Table 3.2: This table lists the numbers of $\mathrm{x}$-ray examinations at Sengerema Mission Hospital in selected years as they are provided by the historical self-description of the hospital. For the entire 1970s no numbers are given in the report. The 1980s clearly echo the difficult economic situation of Tanzania that also pertained to the supply of x-ray films, reagents and sometimes water (Source: Anonymous, 1999, p.26-27; emphasis BMR).

\footnotetext{
${ }^{62}$ Reasons for this economic decline, among others, was the adoption of unrealistic development policies, which made Tanzania depend on foreign aid despite the national rhetoric of self-reliance. The economic crisis was exacerbated by a rapid decline in exports and Tanzania's inability to import even basic commodities. The Ujamaa villagization program turned out to be a failure as farmers did not produce effectively on a co-operative basis, which led to an overall decrease in agricultural production. The economy was also adversely affected by the oil shocks of the 1970s, by drought and war with Uganda (Ahluwalia \& Zegeye, 2001, p.4-5; Cromwell, 1996, p.110-114; Swantz, 1996, p.11). According to Swantz, Tanzania's delay in embarking on Structural Adjustment Programs, however, meant that the country benefited from bad experiences that the World Bank had made in pushing user charges too quickly. User charges were finally introduced within the Health Sector Reform in 1993, yet their introduction was delayed in rural health centers and dispensaries. In 1996 maternal and child health services, epidemic diseases and people with diabetes were exempted from any fees, similar to the policy in Ghana (Swantz, 1996, p.39; United Republic of Tanzania \& MoH, 2002, p.25).
} 
The history behind both the figures and the apparent gap of the 1970s is filled in by the accompanying text that rather unemotionally accounts for the life of a medical technology in rural Tanzania: from 1959, the hospital has a Siemens Mobile Army Unit built in 1940 but, as the authors state, "luckily still working in 1963" (ibid.); in 1964, the facility obtains a modern x-ray machine via the Lake Victoria Tuberculosis Scheme; in 1966, the hospital cannot generate sufficient power to run the machine; in 1968 a generator is donated and thereafter "all kinds of x-ray" (ibid) are performed; in 1973, however, the operation suffers from lack of personnel; between 1977 and 1979 there is "a great shortage of $\mathrm{x}$-ray films and chemicals" (ibid.); and in 1976, the report notes, Sengerema Mission turns into a Designated District Hospital and is then supplied by the Medical Store Department. ${ }^{63}$ In 1980, the machine breaks down - patients have to be sent to Bugando Hospital in Mwanza until the facility is able to borrow an x-ray device for some time from its sister-hospital in Geita, some kilometers further into the country's interior; in 1981, the hospital finally gets a new x-ray tube, donated by Misereor ${ }^{64}$ but this tube cannot be installed until 1982 due to lack of professional skills; in 1983, the first radiography assistant returns from his training at Bugando Hospital. Between 1986 and 1988 there is a decline of x-ray use again, this time due to a shortage of water for the development and fixation of films. In 1993, the hospital history reports, the x-ray department "required rehabilitation" as well as an "overhaul" of the equipment - an issue that did not escape the notice of the National Radiation Commission; the commission's threat to close down the unit leads to serious efforts at a general rehabilitation, which is completed by 1996, three years later (ibid.).

The meticulous documentation of the decline of $\mathrm{x}$-ray and service provision in a rural area supports Mr. Chanika's general impression of the bad state of x-ray affairs in the 1990s in the country. The state of x-ray personnel was not much better. First of all, the policy objective to have a radiologist at every district hospitals had not been met, thus overloading the only radiographer, or radiography assistant, with work (United Republic of Tanzania, 1990). Moreover, existing radiographers and assistants were increasingly exposed to radiation and "demoralized" by the faulty equipment, as Mr. Chanika observed. At that time he had worked at Bugando Hospital as a radiographer and functioned as supervisor of

\footnotetext{
63 The Medical Store Departments are the Tanzanian equivalent to the Central Medical Stores in Ghana (see the account on Ghana in this chapter).

${ }^{64}$ Misereor is a German catholic development organization.
} 
the of $\mathrm{x}$-ray equipment in the Lake Zone, a position that enabled him to redistribute spare parts and consumables in such a way as to make at least a few machines fully functional. This loss of morale had mainly to do with the feeling that radiography did not make a contribution to public health any more but rather put it at risk.

While the 'hazards' of the old machinery pertained to all patients, pregnant women were doubly affected. With the adoption of the IAEA prohibition against exposing pregnant women to radiation, the Tanzanian Ministry of Health allowed x-ray for pregnant women only for 'pregnancies at risk', for example in case of a suspected head-pelvic-disproportion or of placenta previa. As a 'vulnerable group' already at the center of national health care policy (United Republic of Tanzania, 1990), women with risky pregnancies - thus the most vulnerable - were exposed to an even higher risk by uncontrollable radiation. The poor condition of many x-ray machines in the Lake Zone, Mr. Chanika remembered, moreover made proper diagnosis quite difficult. As radiography failed to serve clinical practice, many Tanzanian doctors returned to the traditional practice of 'seeing by c-section', instead of using x-ray as a "virtual scalpel" first (Barad, 1998, p.119):

They [doctors, BMR] did what they had done in Africa before. The only thing they could do was to open up the body. So, without xray, diagnostics was done by cutting. [laughs] It was actually not diagnostics but simply cutting open, then look! ( $\mathrm{Tz}$ 1a)

In the late 1980s, Mr. Chanika recalled that he and his colleagues working at the state supported Muhimbili Teaching Hospital in Dar es Salaam began to hear more about ultrasound. Yet, while as diagnosticians they were sometimes in awe at the extraordinary capabilities of ultrasound, the few cases that were referred from the periphery to the Teaching Hospital for an operation revealed that their doctors were still ultrasound illiterate:

It seemed to us [radiographers, BMR], it could do wonders as it saw things that you could not even make seen with $\mathrm{x}$-ray. [...] But you know, there was nothing much that the doctors could make out of it. (ibid.)

Mr. Chanika's statement above, and the particular kinship term he used to describe ultrasound as 'the little brother' to $\mathrm{x}$-ray at the beginning of this chapter, suggest that for the state agency the history of ultrasound was closely related to that of x-ray. Given the desperate condition of the latter I had to understand, he said in the interview, that by the end of the 1980s “ultrasound was not on our [the state agency's, BMR] mind” (Tz 1b). 


\section{New species in radiography}

The new liberalization of travel brought about by Structural Adjustment Programs allowed both international goods to increasingly fly in, as well as Tanzanians to increasingly fly out. Health care professionals, often for the first time, visited international conferences. Together with other radiographers Mr. Chanika, for example, was invited to attend a couple of workshops and seminars organized by the International Atomic Energy Commission. These visits disclosed to them that the country was not only lagging behind with regard to x-ray technology. They also revealed that another technology had meanwhile become standard as the second status symbol for a radiographer: ultrasound. Mr. Chanika described their discovery of 'a new species' in the discipline in the interview as follows: "We had been living on an island. But there we would go, and some radiographers were calling themselves not radiographers anymore but sonographers" (Tz 1a).

The decline of both x-ray technology and its operating profession, however, had already been identified as a core issue at a national meeting of the Tanzanian Association of Radiographers at Morogoro in 1990. This meeting had resulted in three resolutions. The first was to strengthen their political presence through a representation within the Ministry of Health. This resolution resulted in the establishment of the Radiology and Imaging Section at the Department of Curative Health Services, of which Mr. Chanika became head with the start of the Philips Project. The second resolution called for the acquisition of new x-ray technology for regional and district hospitals in line with the new national policy of decentralization. The third resolution concerned the emphasis on training of existing and new personnel in these facilities and on new imaging technology. In the long run, the Association aimed to increase the number of radiologists, as by 1990 the country had only ten. Mr. Chanika explained this small number with reference to the fact that in the past the poor condition of $\mathrm{x}$-ray technology had kept doctors away from specialization in radiology. A “problem of today's" (Tz 1b; [thus 2004/5, BMR]), in contrast, was that radiologists in contrast to their fellow specialists could hardly hope to open up a private practice due to the enormous costs required to maintain safety standards.$^{65}$ In the short term, the training focus thus should be on radiographers.

\footnotetext{
${ }^{65}$ This disadvantage is likely to disappear as radiologists under privatization policy are now also allowed to use hospital rooms and equipment for private patients and practice and share the profits with the hospital (see Ghana).
} 
In order to realize the second objective, the professional association decided to approach "Tanzania's old friends, the Dutch and the Germans", as Mr. Chanika put it (Tz 1a). Both candidate's advantages and disadvantages had been discussed at the meeting: while the Germans were known to produce "very robust machines" (ibid.), their way of channeling technological aid via the CSSC, a Christian organization, bore the risk that mission hospitals might be privileged. 'The Dutch', in contrast, were known to handle things "state - state wise" (ibid.). Moreover, what spoke for the involvement of the Dutch was that during the 'harsh times' the Philips supplier had remained in the country, while Siemens had called its agent back. The hope to have easy access to the Dutch company via this supplier and to benefit from the supplier's presence in terms of sustainable maintenance made the Tanzanian state agency approach the Dutch Embassy in the beginning 1990s with the request to refurbish the state of $\mathrm{x}$-ray.

This first request to the Dutch Embassy to support the standing offer from Philips to transfer x-ray machines, however, was turned down. In the opinion of Mr. Chanika, this rejection was quite understandable given the lack of scientific information supporting the Tanzanian claim. The Dutch behavior, as he explained, demonstrated state responsibility towards its citizens' tax money and adherence to the state's responsibility to account for expenses on the basis of 'hard facts':

You see, the Dutch government was just afraid of its taxpayer's money. This is what I think. Because if you spend money on anything, be it in your own country or be it in Tanzania, you have to account for it. [...] But [by] then, you see we had not made a research, so we did not have exact numbers, these and these hospitals to be refurbished, theatres in place, $\mathrm{x}$-ray equipment what to replace, skills of staff. We just did not have these numbers at the time. (Tz 1a)

In order to support a second request to the Dutch government, the Tanzanian state agency thus needed 'numbers'. Philips' need to survey the country came in very handy at this point, as it provided the state agency with recent statistics on the existence and status of machines, potential operators and technicians likewise. "We then had the knowledge", Mr. Chanika summarized the survey's output for the Tanzanian state agency. The survey, however, did not only yield numbers; it also served the self-representation of the state agency as an active contributor to solutions, as Mr. Chanika said: "We showed them that we were not only poor but that we had thought about these things, and that we needed the 
money but that we could think for ourselves" (Tz 1a). That 'having numbers' indeed turned the odds he saw confirmed by the fact that the second request made by the Tanzanian government to the Dutch Embassy to support the delivery of imaging technology by Philips was accepted. "We got better in delivering the message!" was how he summarized the achievement of this learning process.

Having numbers from the survey first of all revealed the lack of sufficient radiographers to become the sole operators of ultrasound as the state unit had wished for. In particular, district hospitals caused a problem. Most of them had only one radiographer or radiography assistant. Sending this one person for training for either the new x-ray or the ultrasound machine, would already restrict service provision albeit only temporarily. Training this single radiographer in the operation of both technologies would mean permanently compromising the performance of good quality diagnostic imaging services. In response to this dilemma, the state agency chose to train nurse-midwives as ultrasound operators at the district level. In line with the long term goal to professionalize radiographers, however, it was made clear that ownership of ultrasound machines remained with the radiography department and its representative(s) and that nurse-midwives were only given a "mandate for the time being" ( $\mathrm{Tz}$ 1b). The wish to uphold the professional hierarchy fed into the decision about which ultrasound machines to purchase. The 72 basic machines of type SD 100 were meant to be used by nurse-midwife operators. Regional Hospitals, which were staffed with more radiographers, received the 20 machines of the type 240 that Ghana had selected for the whole country. As the SD 100 was considerably cheaper, the differentiation in operators thus enabled Tanzania to buy more machines within the same budget frame than Ghana.

Especially in rural areas the decision to train nurse-midwives as ultrasound operators, born primarily out of lack of sufficient radiographers, also carried an advantage. As nursemidwives, other than radiographers, were the professionals who routinely dealt with pregnant women, they were more likely to win women's acceptance of the new technology. This was an asset given the many suspicions that women had with regard to 'the big brother x-ray', as Mr. Chanika said:

You know, our women are quite suspicious about x-ray. Or, let's say, some are. Where you are going to, there in Sukuma-land, people are particularly suspicious. They have all kinds of strange ideas about what $\mathrm{x}$-ray might do to them. Because Wasukuma believe in witchcraft a lot still, you find $\mathrm{x}$-ray taking on witchcraft beliefs. [laughs] So tell me, what can you do in such a case? [...] 
What we did in the case of ultrasound, we let it run by midwives. They [women, BMR] know them and they trust them because we know that midwives have a better contact to pregnant women. ( $\mathrm{Tz}$ 1a)

The second problem that the survey numbers brought to light was the issue of maintenance. Yet, other than the operator issue which was left to be solved by the Tanzanian state agency, the maintenance issue revealed dissension between the partners in the survey. In accordance with the new national policy of decentralization, Mr. Chanika rejected the Dutch proposal to train $\mathrm{MoH}$ based technicians situated in Dar es Salaam. Instead, the Tanzanian state agency proposed to (re)train technicians of the Hospital Maintenance Workshops at each of the referral hospitals: Bugando Teaching Hospital, Kilimandjaro Christian Medical Center, Muhimbili Teaching Hospital and Mbeya Hospital. This proposal, in turn, was rejected by Philips - a decision that Mr. Chanika explained by referring to the company's concern that these technicians might charge money which risked continuous working of ultrasound:

You know, in my opinion what they wanted was that the machines would not break down. [...] But you cannot prevent any breakdown, so you need technicians who know to repair. And there we had fundis* with a great experience to repair; some of them had even been trained to repair ultrasound machines that were donated before. In Bugando, for example, our chief engineer had been trained to repair Philips ultrasound. (Tz 1a)

For the duration of the project, the compromise found foresaw Philips maintaining the machines according to contract (see chapter 2). Mr. Chanika's proposal, however, was reviewed in the wake of a new maintenance contract after the project ended in December 2005.

Similarly to its Ghanaian counterpart, the Tanzanian state agency also appreciated the possibility and time for preparation that the 'Philips Project' provided. Also similarly to Ghana, this preparation consisted of negotiations with potential allies the Dutch ultrasound required. While the purchase of large numbers of similar machines made maintenance feasible in principle, Mr. Chanika's concern was to ensure this maintenance after the project's end. In this attitude he saw himself following Julius Nyerere and President Benjamin Mkapa who both repeatedly reminded the people that the "era of donation [was] over" and a "new era" (Guardian Reporter, 2003, p.1) had begun - a claim that Mkapa's 
government had translated into restrictions on the acquisition of second-hand donated technology (MoH Tanzania, 2004, p.19):

We were not in the position any longer to have our machines waste away. [...] Nyerere, the mwalimu mkubwa* told us this: 'Let's forget depending. One day, they [the donors, BMR] will say no. And then, what shall we do?' (Tz 1a)

In his position as a member of the steering committee Mr. Chanika therefore traveled the country and assembled the respective regional, district medical officers and radiographers at meetings to counsel them on their responsibility to take over the care of the new technology. In order to translate the 'new era' to his fellow colleagues he used a metaphor that African men would understand, he told me: a man should treat ultrasound like his wife:

I told them to treat the technology like a wife, an item of their power and richness. After all, they are all men; they should know how to treat a wife. So I just told them: 'This is your wife, make sure you dress her properly!' (ibid.)

A further effort he undertook was to standardize ultrasound requirements according to hospital level and add them to the national standardizations of other health care technology in the Manual for Quantification of National Requirements of Equipment and Supplies for Laboratory, Radiology, Dental and Health Care Services in Tanzania (2002). Following the manual, level 1hospitals were entitled to have a basic ultrasound unit for 14.000 USD. Level 2-hospitals, however, had the right to obtain a unit for maximum 27.000 USD. The same manual also listed the essential consumables for these units such as the amount of ultrasound gel and toilet paper (to wipe off the gel). Furthermore, it provided examples of how to quantify, calculate and budget the amount of ultrasound gel needed per month with regard to number of patients, theft, expiry and time span between request and supply of consumables.

As the state ultrasound took on form, a new kind of Tanzanian radiographer emerged: not only was s/he a paramedic but also a planner, an accountant and potential entrepreneur, but first of all s/he was to be somebody who would restore the intellectual life of Tanzania. In the national curriculum for radiographers that had been developed in cooperation with Fontys and that now anticipated an education in English, the description of this new species reads as follows:

[Radiographers shall] contribute to the intellectual life of Tanzania, to act as a focal point for its technical advancements, [...] should 
be able and be motivated to meet current community needs. They should be able to use different kinds of $\mathrm{x}$-ray and ultrasound machines [...] in a hospital of any size. [They should] have a clear concept of the professional responsibilities to patients, colleagues and the nation through service, research, education, continuing, self-professional development and adherence to professional ethics. [...] And to have appreciation of the material and financial constraints that affect professional decisions and be able to make the best decisions for patient care. (MUCHS, 2002)

Close to the end of the project, in December 2005 when I last met Mr. Chanika, he expressed his overall satisfaction with the project: with the revision of the curriculum that now included basic ultrasound imaging as obligatory course subjects, Tanzanian radiographers had reached international standard; he himself had acquired a vital position in the steering committee to influence the project's trajectory; due to the wide dispersion of $\mathrm{x}$ ray and ultrasound, the state agency had been able to influence politics with regard to health care technologies in the country as a whole; and radiography had been enabled to contribute to clinical practice and in particular to extend its imaging targets to pregnancy again. In contrast to the absent-minded-status ultrasound had had in the 1980s, Mr. Chanika emphasized, in the new millennium "ultrasound [was] meant to stay" (Tz 1b).

\section{Luxury objects for obstetrics}

In his account of ultrasound in Tanzania, Mr. Chanika never left any doubt that he himself and the state agency he represented saw the new technology as immensely valuable for achieving safety for mothers and pregnant women. Asked whether he or his department had cooperated with the state department officially responsible for mother and child health care, the Unit for Reproductive and Child Health at the Ministry of Health, he stressed that 'safety' was theirs to keep up with. They had done this by replacing old x-ray with new machines and by replacing $x$-ray with ultrasound examinations in pregnancy. Triggered by his statement (that echoed Dr. Aryeetey's explanation in Ghana) that those professionals mainly responsible for the care of mothers and children did not have (or did not want) to be included in the project, I made a detour from the physical trajectory of the Philips ultrasound machines. I decided to pursue its conceptual path to serve maternal mortality reduction as well and thus approached the Unit for Reproductive and Child Health at the Tanzanian Ministry of Health. 
The head of the Unit for Reproductive and Child Health in charge of pregnancy and maternal care was terse: they would not do ultrasound but 'Safe Motherhood'. If I wanted to know about their work, I was invited to attend a conference about current maternity politics to be held in Dar es Salaam on March 29-31, 2004. At the conference approximately 50-60 people, most of them Tanzanian obstetricians, participated. They next largest group in attendance were politicians including the head of the Unit for Reproductive Health, and a number of Europeans: one mission doctor, representatives of the German Association for Technical Cooperation (GTZ), researchers from a big EU funded international project called MATCARE, representatives of the two organizations that had funded the conference, the Tanzanian German Program to Support Health (TGPSH) and the Netherlands Society of Obstetrics and Gynecology (NSOG). According to the opening lecture by the Head of the Unit for Reproductive and Child Health, the conference pursued three main objectives: it was to provide a forum for dialogue between researchers, health care providers and policy makers; it was to bring together recent evidence and experience from research and implementation projects concerning care in pregnancy and child birth in Tanzania and beyond; and it was to develop a way forward based on key issues identified during the presentations. The conference was to be closed by a membership meeting of the Association of Gynecology and Obstetrics in Tanzania (AGOTA), which had been dormant for several years prior to the conference.

Other than the focus identified by the Head of the Unit for Reproductive and Child Health, the conference Improving Maternity Care: Concepts, Evidence and Local Adaptation, however, turned out to include a presentation on the role of Doppler ultrasound in the detection of fetal growth retardation. This presentation was furthermore placed in the first session on "The state of maternal and perinatal health in Tanzania" during the opening day of the conference, and was followed by a series of papers that pointed to the lack of basic resources and in consequence the presence of so-called 'unmet obstetric needs'. ${ }^{66}$ The session on contraception and abortion, for example, emphasized the lack of contraceptives, women's lack of knowledge of how to use them and men's lack of the proper attitude

\footnotetext{
66 The concept of 'unmet obstetric need' is based on the estimation of needed interventions (for example, caesarean sections) in relation to the expected number of deliveries and to epidemiological data about the abundance of particular complications. This estimation is then compared to the number of actually performed intervention. Hence, the extent of the deficit is considered to be an indicator for the efficiency of the general system of obstetric care (see Belghiti, De Brouwere, Kegels, \& Van Lerberghe, 1998).
} 
towards contraceptive usage after unsafe abortion. Others focused on the lack of quality in the existing services, of maternal mortality reviews and of blood safety, on the improper number of caesarean sections (too high in urban, too low in rural areas), on the lack of, or lack of knowledge with regard to, proper nutrition in pregnancy and on the problem of sepsis.

With the exception of ultrasound, none of the issues and facts was new. Basically all of them had been published or presented before internationally, e.g. the lack of health care providers at birth (RCHS, 2000; D. P. Urassa, Carlstedt, Nystroem, Massawe, \& Lindmark, 2002; E. Urassa, Massawe, Lindmark, \& Nystroem, 1997), of laboratory and theatre equipment or theatres altogether (E. Urassa, Massawe, Lindmark, \& Nystroem, 1997), of blood, 24 hour anesthesia and c-section services (Nyamtema, 2004), of partographs (Bosse, Massawe, \& Jahn, 2002), of proper notification of births and deaths (RCHS, 2000), or simply of beds as The Guardian illustrated for one of the District Hospitals in Dar es Salaam with a photograph showing how three or four women with their newborns were expected to share one bed (Nguvu, 2004, p.5). Moreover, many of these issues had also been discussed in the First Tanzanian National Safe Motherhood Conference in 1990 (Allen, 2002, p.53 ff.; MoH, 1992). In contrast to this previous conference that had involved international agencies and local NGOs such as the Tanzanian Media Women's Association in forming a common task force, the 2004 conference explicitly targeted obstetricians.

As the conference unfolded, it became obvious that it was framed to deliver dramatic messages about the urgent need for doctors to commit themselves to the newly induced reproductive policy of the state agency, the focused antenatal care scheme (FANC). As the Head of the Reproductive and Child Health Unit made clear in her introductory speech, the urgency to introduce this scheme was based on the failure of the existing national standard, the National Package of Essential Reproductive and Child Health Interventions in Tanzania, to attract pregnant women to hospital maternity services. This 'National Package' rested on four institutional pillars that together formed part of the national referral system. On the community level a so called health worker was to identify problems in mother and child health and refer them to the dispensary. Dispensaries were to conduct standard testing, immunization, initiate malaria treatment, sell ITNs*, develop individualized birth plans, and manage minor problems in pregnancy such as anemia, $\mathrm{PIH}^{*}$, and episodes of slight bleeding, while referring major problems to Health Centers. Staffed with trained nurse-midwives, 
these Health Centers were in turn to deal with mild pre-eclampsia* and incomplete abortions, and to attend deliveries of women between the second and the fifth pregnancy, similar to dispensaries. Hospitals, in contrast, were to manage ectopic* pregnancies and carry out deliveries of women referred with 'pregnancies at risk', women with their first baby or any pregnancy above the fifth. With this package of "essential preventive and curative interventions [that] outline[d] the most feasible, efficient and effective methods to reduce the leading causes of morbidity and mortality in Tanzania" (RCHS, 2000), the state agency pursued the Tanzania Development Vision 2025 in the sector of reproductive health:

... to improve the health and well being of all Tanzanians with a focus on those at risk, and to encourage the health system to be more responsive to the needs of the people. (MoH, 2002, p.4)

To the Unit for Reproductive and Child Health, the focused antenatal care scheme seemed to be the new coordinating tool as it equated patient number and patient demand with the presence of skilled personnel, rational use of the available resources and scientifically proven positive outcome parameters such as service satisfaction. The new policy had already been introduced to nurse-midwives. However, the scheme also called for doctors' cooperation, although for them it meant either suffering a cut in income or facing possible sanctions due to non-compliance with national health care politics and development visions.

The state agency's intention to commit doctors to its new policy was evident in the conference's structure: the two and a half day-conference started with an afternoon lecture held by a Tanzanian obstetrician who had won the 2003 annual award of the International Federation of Gynecology and Obstetrics (FIGO) for his success in reducing the maternal mortality rate in his rural district hospital from 933 in 1984 to 186/100.000 life births in 1991 (G. Mbaruku \& Bergstroem, 1995). Following Nyerere's call to 'go rural', even as a specialist, this award was not only honorable for the individual doctor but for Tanzania as a whole - a fact that the Head of Unit for Reproductive and Child Health referred to with the following words: "While we thought he had been buried in the bush, he has actually traveled the world. And now, he has brought Tanzania back unto the map of the world."

Not only as an international award winner but also as a national hero, the words of this obstetrician carried weight. In the fierce discussion that followed the state agency's call for commitment to reduce the number of antenatal care visits, he proved to be an asset for national policy. When several conference participants pointed to the high antenatal care 
attendance in Tanzania compared to other African countries and accused the state agency of reducing quantity before improving quality, he reminded them that their opinion merely demonstrated their "urban bias". The officially cited overall antenatal care attendance of 95 percent referred to one visit only; high antenatal care attendance above this one visit, in contrast, was an urban phenomenon rather than mirroring Tanzanian reality. Referring to the pictures with which he had illustrated his presentation (2004) during the first day of the conference - of a water tank, an ordered archive and himself - he repeated that the reduction of maternal mortality was simple. And, as if directly addressing the speaker who had succeeded him as speaker on this very first day, he concluded: "It is commitment of the doctor, his presence. Not fancy colorful technology. Ultrasound is a luxury for obstetrics" (FN 30.03.2004).

Similarly to the Unit for Diagnostic Imaging Services, the main concern of the Unit for Reproductive and Child Health was the safety of pregnant women and mothers. In contrasts to the immediate partner of Philips, the latter state department, however, saw their safety compromised by the persistent lack of infrastructural resources classified as essential by the Safe Motherhood Initiative. In view of these (inter)nationally sanctioned resources, the colorful pictures of Doppler ultrasound failed to enter national reproductive policy.

\section{Tools for diagnosticians}

From devices to reduce maternal mortality statistics, ultrasound machines at the state level in Tanzania turned into tools for diagnosticians, their purpose being to contribute to clinical practice. Imbued with the value of a worldwide status symbol for radiographers and radiologists, that only Tanzanians still seemed to be deprived of, ultrasound's script was to keep the radiographers in the country up to date. In this process of appropriation, ultrasound lost part of its specificity for maternal matters. In the hands of radiographers, wombs, placentas and fetuses turned into organs such as livers, kidneys and gallstones. At the same time, ultrasound restored gender equality at the level of patients as, at least at the regional level, men also became ultrasound patients. However, as they were not enough radiographers, nurse-midwives - as intended by the Dutch company - became ultrasonographers too. This inclusion of second-choice operators, originally foreign to the field of imaging diagnostics, enabled the state agency to gain more control over the imaging 
sector in that, via the parliament, it attempted to fix professional responsibilities with regard to imaging, thereby re-ordering the field of diagnostic medicine in the country. ${ }^{67}$

\section{Accounting for the state (of) ultrasound}

The stories of Dr. Aryeetey and Mr. Chanika are at once narratives about the state of ultrasound in Ghana and Tanzania and accounts that legitimize the state ultrasound as a purchased commodity in the face of national budget constraints. Accounting for the investment of money despite the possibility of waiting for donated ultrasound machines, the state apparatus mobilizes particular resources. By buying imaging technology, state agencies buy into more than a simple machine: they seek to balance their liabilities towards different creditors in order to restore national integrity and their own position.

\section{Gifts and Commodities}

The state ultrasound is a novelty: it is to be purchased. In their accounts, Dr. Aryeetey and Mr. Chanika compared this new kind of ultrasound machine - the commodity - with regard to its predecessor, the ultrasound machine that entered Ghana or Tanzania as gift (or donation, to speak in common development jargon). In the evaluation of these two kinds of transaction other factors enter the exchange. These are considered to be both resources for and resources of ultrasound.

Among these resources required for ultrasound is first of all money. Having money means being able to buy the 'Mercedes Benz version' of ultrasound technology (see chapter 2). Having no money instead increases the possibility of getting ultrasound for free - as a gift. Yet, as both state representatives deliberate, since a gift-horse is not to be looked at in the mouth, accepting these kinds of ultrasound donations often results in later costs, for example in irreparable breakdowns due to lack of spare parts and repair guarantees, or in a poor quality of pictures. Saving money now may mean having to pay (more) later. Investing money did not only allow the state agency to get rid of these kinds of problems but also enabled it to make money - to get a grant for free while repaying loan fees, and thereby purchasing first-hand, high quality machines together with technicians and teaching capacity.

\footnotetext{
${ }^{67}$ The idea of a parliamentary regulation was conceived during the time of my fieldwork. When I last spoke with Mr. Chanika in January 2006, (t)his regulation had just passed the first round of negotiations but was not yet ready to go public.
} 
Closely related to money is a second resource mentioned in both accounts: time. Receiving ultrasound as gifts, as both state representatives point out, implies having to deal with machines in an ad hoc manner. Purchasing ultrasound, in contrast, allows a gain in time. This time can be used for negotiating specifications and conditions, for preparing the ground in terms of selecting and building workplaces for the technology, and for winning allies in accepting the beginning of a new era in development business. Spending more time in and for preparation means to potentially extend the lifetime of a technology, or to prevent the working of machines whose lifetimes have already expired. Gifts, as the state agencies will have it, signify the past while commodities ring in a new and independent future.

Capacities are a third resource. They may come in material form, for example as plugs, bricks (for refurbishing), spare parts, and consumables such as printing paper or gel. Whereas donated ultrasound machines often came without any such resources, the Philips machines came with a stock of printing paper and five liters of gel in the installation package, and with the guarantee that more of these material resources were held in stock by the national medical stores or, in the case of spare parts, by Philips Medical Systems. Capacities also come in form of humans. In fact, 'human resources' is one of the central categories in national policy reports both in Ghana and Tanzania. In these reports, 'human resources' list the kind, number and educational degree of professionals in service and in training in the public sector, and the kind and, if obtainable, the number of those professionals lost to the national health care system. As gifts, ultrasound does not do much to intervene in these numbers as the machines end up in hospitals selected by donors. Mission hospitals and Teaching Hospitals thereby were privileged recipients. In particular the former, however, were equipped with health care professionals who remained in service due to the efficient functioning of the institutions anyhow, while in the latter ultrasound operators were likely to be specialists remaining due to allowances. It is the state ultrasound that, at least according to the expectation of the Ghanaian state agency, is to alter this state of affairs, broadening the range of recipients to include those most likely to leave. Tanzanian documents report the same small number of radiologists that work in the country, and the continuous absence of doctors specializing in radiology. It is Mr. Chanika's self acuired knowledge of the retardation of Tanzanian radiographers with regard to world standards, however, that devalues current radiographers as a resource for more sophisticated diagnostic medicine, even though they are at hand. 
A fourth resource encompasses knowledge, information, and experience and the technologies used to obtain them, such as language skills. Ultrasound as gift in this respect is simple: it does not make any demands with regard to prior knowledge, information or experience but it may also obstruct the spreading of ultrasound knowledge beyond individual usage or the walls of the individual hospital. Scattered throughout the country without central planning, donated machines may or may not work. It is only when knowledge of them becomes centralized that their work can be coordinated. Mr. Chanika's investment in knowing about the different $\mathrm{x}$-ray departments, the condition of their x-ray machines and their stock of reagents and films as radiographer in-charge of the Lake Zone during the harsh economic times of the 1980s, enabled him to draw together scattered resources to perform x-ray examinations at least for emergency cases. As commodity, ultrasound promises to distribute knowledge to a broad group of professionals. It also requires knowledge and information, though: both accounts speak of statistical figures that that had to be obtained, but also could be obtained about the state of rural affairs with regard to imaging services.

A fifth resource is risk. In principle, both state representatives said, risk - or patient safety, as they called it - was not to be considered a currency for exchange. As gifts compromise safety by faulty workings, missing manuals, and bad quality pictures, reported 'risk' for patients and professionals can be traded for the claim to need safer technology. In these claims patient safety can take different forms. It can come in the form of Safe Motherhood, as is apparent in the accounts of Dr. Aryeetey in Ghana or of the head of the Unit for Reproductive and Child Health at the Ministry of Health in Tanzania. Patient safety then is a set of clearly defined practices targeting nurse-midwives as key players, and of research approaches geared to verify the existence and extent of pre-defined unmet obstetric needs in a particular country. Yet patient safety can also take the form of safe motherhood in the sense that Mr. Chanika uses it: as a safety brought about by technically proper workings and consequentially the possibility of making 'good pictures'.

A final resource, which both accounts refer to, is authority. In gift exchange, the authority of where to put an ultrasound machine and whom to train as operator lies with donors. The authority of state agencies is exhausted in being the nominal owner of machines resulting in the creation of technological cemeteries at hospitals as 'government property' cannot just be thrown away. Purchasing ultrasound, in particular in the context of competing 
foreign donor interests, turns the state agency into the position of a recipient who is able to make demands of donors and into the position of a donor towards hospitals as end users. ${ }^{68}$

Exerting authority may involve the further resource of trust. Mr. Chanika thereby had an advantage over Dr. Aryeetey: himself a radiographer with long years of experience as practitioner and teacher, he was and is well known by the leading radiographers all over the country. Moreover, he occupies a position created by the professional association of radiographers. Although sitting in the Ministry, Mr. Chanika in the eyes of his former colleagues remains 'one of them', as I was assured by several radiographers and radiologists at Mwanza, Dar es Salaam, and Moshi. Dr. Aryeetey, in contrast, abandoned the medical profession in favor of a specialization in biomedical engineering. His attempt to bridge the gap between the Ministry and his fellow medical colleagues showed in the decision to move his office from the official government area to the grounds of Korle Bu Teaching Hospital.

As the accounts of Dr. Aryeetey and Mr. Chanika demonstrate, ultrasound as gift and ultrasound as commodity do not so much differ with regard to the kind of resources they mobilize, or that have to be mobilized in order for the technology to work. Where they differ, however, is in their capacity to include or exclude the national state agencies in the transaction and the relations that are being forged in this exchange process. According to the principles of reciprocity underlying any exchange, the main relationship is between donor and recipient. As a gift, ultrasound creates a relationship between foreign donors and hospitals; as a commodity, ultrasound turns the state agency into a pivotal agent: as an obligatory passage point for imaging technology to enter the country, the Ministry of Health becomes a central manager of health care.

\section{Commensurability and Revaluation}

In this exchange not all resources have the same value. Both state representatives, for example, make a difference between different kinds of people: throughout their accounts, and in particular in official reports, professionals are more highly valued than patients. While professionals are referred to as 'human resources', patients make it into government reports as an amorphous mass to which the health care policy of a democratic is 'naturally' and nominally committed to. Any hierarchy of value, anthropologist Arjun Appadurai has

\footnotetext{
${ }^{68}$ Social scientist Julia Hiscock, for example, argues that the contemporary interest of a multiplicity of donor agencies in
} Ghana that significantly increased the role of the Ghanaian Ministry of Health in policy negotiations (Hiscock, 1995). 
argued, rests on the distance between the desired object and the one who desires it, that is, upon "the space between pure desire and immediate enjoyment" (Appadurai, 1986a, p.3). Professionals with their tendencies to leave the country, thus, gain value by practicing in New York, Botswana, South Africa and the United Kingdom, whereas patients are many and most of them have to remain in the country due to lack of travel opportunities. This revaluation of professionals shows in the difference with which the enactment of citizen rights is granted to both groups, and used to blame or excuse the right to free (labor) movement and the pursuit of health and equality. While patients' migration in pursuit of equal treatment, for example by traveling to Burkina Faso for ultrasound (see above), was considered their right, the move of professionals (at least in Ghana) was considered to be a demonstration of low morale and a failure to fulfill their professional responsibility. Thus, the conflict between individual rights as a person and trained professional and the responsibility to meet unmet needs in their home country, leaves medical specialists trapped between professional rights and 'plights' ${ }^{69}$ Dr. Kwame, an ear-nose-throat specialist whom I met in Accra, in this context pointed very poignantly to the shift of professional ideology that had taken place in his country within one generation:

Of course, we went outside to get special training. Me, I went away to become an ENT* specialist. But we, my generation, we went away and came back. [...] We took our posts out there in the rural areas. But there is nothing, no school, no jobs, no private patients to make some extra money. I commuted to Accra for some years because my wife and children stayed in town. Then I took up a job down here as well. [...] So now I am a specialist at this hospital here [a private clinic in downtown Accra, BMR], and I work at other places too, even at Korle Bu. (Gh 14)

Not only do both state representatives attribute additional value to professionals over patients, also among professionals different groups are valued differently. Doctors and radiographers were more highly valued than nurse-midwives, for example. Several interpretations are possible in accounting for this particular hierarchy. ${ }^{70}$ It does not seem

\footnotetext{
${ }^{69}$ In my view this dilemma between professional rights and plights mirrors the difficulties of transition of a health care system from a communitarian to a consumerist mode, as described by medical historian John Pickstone for 20th century Great Britain (Pickstone, 2000). In the former the state is supposed to be the main health care provider while professionals work out the plight to serve the people. In the consumerist mode the state is supposed to be the manager of health care while its provision lies in the hands of health care professionals. Dr. Kwame's experience mirrors this shift from the ideologically PanAfricanist imbued communitarian model of health care during the socialist period of Tanzania to a consumerist model, wherein doctors permanently leave in pursuit of what my interviewees referred to as 'greener pastures'. ${ }^{70}$ From a Western feminist point of view it is tempting to attribute this (d)evaluation of nurse-midwifery to gender (for a critique of the dominantly male control of pregnancy and childbirth see, for example Davis-Floyd \& Sargent, 1997;
} 
implausible to attribute the decisions to train doctors as operators in Ghana and radiographers as operators in Tanzania to the respective profession of those in charge of these decisions. Following this argument, dealing with a doctor as partner at the Ministry of Health, as in the person of Dr. Aryeetey, thus makes doctors into operators, while dealing with a radiographer, such as Mr. Chanika, creates radiographer-ultrasonographers. Whether dealing with the Unit of Reproductive and Child Health as a business partner would have turned nurse-midwives into ultrasonographers or rather gynecologists, remains a hypothetical question. It is a provocative question, though, considering the absence of the Council of Nurse-Midwifery in the negotiations in both countries. Giving doctors and radiographers a chance for further specialization, however, may also be rooted in the state agency's consideration that these professional groups were not safely 'tucked' into international regimes in the way that nurse-midwives were due to Safe Motherhood's emphasis on primary health care and on nurse-midwifery as the executioner of this policy.

While nurses and nurse-midwives in Ghana leave the country as often as doctors do, their value may be less as their education costs less in terms of money and time whereas medical education costs a lot more in both regards. Moreover, doctors are a historically scarce resource - hence 'immediately enjoying' the presence of doctors in the country in the sense of Appadurai, remains difficult. An argument made by the medical historian John Iliffe may be helpful for further understanding the high value given to doctors by national state agencies. Higher education and the building of universities, Illife argues, came with medical training. Doctors thereby often became the new urban elite taking over administrative and political posts in the newly independent states. Rather than merely building health, doctors built the nation (Iliffe, 1998). A glimpse of this glorious role echoes in the job description for radiographers in the new national curriculum designed in the wake of the Philips Project that describes radiographers not simply as paramedics but as contributors to an 'intellectual elite' (see above).

Not everything may thus be commensurable with any other thing. Moreover, in the process of revaluation some things may have, remain, or gain dubious value. Knowledge, for example, is a resource that is highly ambiguous: it may make people, including technicians and operators, stay or it may make them leave. Ultrasound knowledge for greater 
independence therefore can also turn into a drawback. It is with regard to knowledge that language and history make a difference between the Ghanaian and the Tanzanian state apparatus. The choice of Ghana for English as official language allows a fast uptake of international things, including biomedical technology whose manuals in either case include an English section. It is the training in English that also allows health care professionals an easy departure for countries where their 'British training' pays off in hard currency and possibly job satisfaction. The choice of Kiswahili as the official language in Tanzania made the country lag behind in some respects, especially with regard to international information (technologies). As nurse-midwives returned to being been trained in English, they became an ambiguous resource for ultrasound operations similar to that of Ghanaian doctors - easy to be updated but also easily lost to the ultrasound business. Radiographers' training in English commenced only with the introduction of ultrasound and the new national curriculum (see above). Even provided with English training, Tanzanian radiographers still lack the expertise with the sophisticated imaging technologies that meanwhile have come to inhabit radiology units in 'the North', such as MRI or CT scans.

Ultrasound thus brings certain resources into flux: it is bought by the Ghanaian state agency to reverse the flow of medical brains from public health care and from the country, and it is bought by the Tanzanian state agency to fly in knowledge for brains in order to improve public health care again. Stimulating flux and new exchanges, ultrasound at the same time also fixes certain things to particular positions in the social fabric.

\section{Balance and liability}

The state is not a monolithic block but is 'many': it consists of different state departments and governmental bodies, of professionals and professional associations, of the "common people', of the press, and of donors. Liable to each of these parties, the democratic nation state in Ghana and Tanzania has to work to keep their competing claims in balance in order to ensure national integrity. Sandwiched in between these different claims, the state apparatus is multitasking: it is endeavoring to create a solid national health care system while simultaneously upholding democratic principles. In this context ultrasound visualizes less a fetus but the return to institutional stability. Buying ultrasound machines, the Ghanaian state agency ends up working as an advisor for private health care providers thereby broadening governmental influence, while the Tanzanian state agency ends up in a seat at the steering 
committee providing a better overview and control of Dutch donor policy. In short, by buying into imaging technology, Ghanaian and Tanzanian state agencies buy manageability of a health care system that has got out of hand, and subsequently became the arena of (too) many actors.

\section{Resource matters}

Concentrating on the state apparatus, this chapter has demonstrated how resources matter in and for technography. I have shown how ultrasound shapes and is shaped by resources. This chapter has listed authority, money, time, buman and material capacity, trust, knowledge, and risk as resources. However, in principle, any thing that has or acquires exchangeability for something else is a resource, that is, a thing with "commodity candidacy" (Appadurai, 1986a, p.13; emphasis in the original). ${ }^{71}$

Whether a resource turns into a commodity for exchange is dependent upon other resources. Resources are relational and value is determined reciprocally - in the process of exchange. Money becomes a resource for ultrasound that becomes a resource for time and human resources, for example. Yet, if money is scarce, then scientific figures, trust and authority become more important. The potentiality of revaluation of resources by means of exchange leads to what anthropologist Arjun Appadurai refers to as "tournament of value" (Appadurai, 1986a, p.21). In this process things acquire a "social life" (Appadurai, 1986b), or a "cultural biography" (Kopytoff, 1986), as long as commensurability of values is achieved At stake in such tournaments, Appadurai argues, is not only rank or fame but the disposition of the central tokens of value in the society in question. In the field of Ghanaian and Tanzanian national health and in the face of the ongoing braindrain, these tokens are the health care professionals.

Yet, whether a resource enters into exchange also depends on where something lands. How something works as a resource is linked to physical and social geography, for example. What Philips Medical Systems in Eindhoven takes to be a resource for ultrasound in Africa - biomedically trained health care professionals who are lacking only in knowledge - turns out to be the reverse case for the Ghanaian and Tanzanian state agencies in Accra

\footnotetext{
71 Anthropologist Igor Kopytoff (1986) proposes two terms for things in exchange: commodity and singularization, the status in which a thing is socialized in new roles in its society before it may be recommoditized. Following the argument of Appadurai that the interesting stuff takes place in the state between these two terms, I here propose to (re)turn to the term of 'resource' that carries the candidacy aspect of Appadurai, yet only within the context in which it is embedded.
} 
and Dar es Salaam - ultrasound is a resource for having (and keeping) health care professionals in the first place. Likewise, the difference between the Ghanaian and the Tanzanian state apparatus is a function of the relation between space and resources - as much as are the unintended consequences. At the BEU* in Ghana, Dr Aryeetey, according to current international policy, has authority over multiple sectors of health care when installing technology. Mr. Chanika's Imaging Unit, in contrast, still works sector-specific; his authority pertains only to the group of imaging professionals. It is in Ghana, however, where ultrasound-access is limited to one professional group, whereas Mr.Chanika's unit allows a wider access to ultrasound in terms of professional operators - albeit also out of necessity. Hence, there are different "regimes of value" (Appadurai, 1986a, p.4) in space and in time.

However, resources do not only change with space but also change space. It is ultrasound's strategic placement that serves both state representatives for installing themselves/their department in the position of health care providers. In addition, and unintended, ultrasound also increases Dr. Aryeetey's control of the private ultrasound sector, and provides Mr. Chanika with a seat on the steering committee and the possibility of regulating ultrasound access by means of parliament. Ultrasound and men, hence, are agents that define each other's value. The latter thereby manipulate the strategic potential of the ultrasound as resource for other things, thus diverting the artifact from its intended path so that the movement of machines enhances their own ends. The creation of value thus is a politically mediated process resulting in each nation becoming a world-player and being 'on the map' again.

The effect of this principle of convertibility of things is that they can go anywhere. Any thing that moves (is moved), however, requires another movement of things, and in order to be exchanged things have to be commensurable. As value is subjective and is spatially dependent, the certainty of value presupposed for an exchange that has taken place somewhere is not necessarily the same somewhere else. Dr. Kwame's account, for example, makes apparent that ultrasound bought as a 'whiteman's thing' does not compensate doctors in a rural area for the lack of infrastructure, the lack of higher education for their children, the lack of jobs for their wives and of private patients to fill their purse in a similar way to fellow colleagues in New York or Accra. His account thus points to the problem that the stability of any exchange - here of an ultrasound machine for a doctor - hinges upon the mobilization of other resources, or it results in gaps. Thus, if a nurse-midwife is turned into 
an ultrasound operator, the staffing of nurses runs short which might lead to bottle-necks in care if $\mathrm{s} /$ he is not replaced by someone else. Likewise, moving anybody into the position of an operator means that the increase in their knowledge or authority has to compensate for the costs of this move, for example, for different working hours, the loss of immediate patient care or of belonging to a clear-cut professional group. Being able to fill gaps and to sustain services and patient safety, an overview is required. This overview pertains to the knowledge of the resources at hand at a particular moment, and to the ability to communicate with the places holding these resources. Given this overview, virtual situations can be created in real-time allowing for refilling of gaps (see Peters, 2006). It is ultrasound alone, however, that provides state agencies with an overview of what is at hand and a more central position. Once obtaining such a position, the intent to freeze exchange and to establish regulations, which fix the link between value and exchange, increases, for example by determining what is desirable, what is a proper resource for exchange, and who is permitted what kind of demand in what circumstances (see the difference in citizen rights, I mentioned above). Yet these regulations have the tendency to be breached and hence to disturb political control.

The dimension of resources contributes to technography by explaining why some things are not convertible, for example why ultrasound at the state level fails to become a device to reduce maternal mortality statistics. As scientific figures become the 'measure of humans and machines', any thing that cannot mobilize the resource 'science', fails to realize: where there is a lack of a statistical apparatus due to lack of money and human capacity as in Ghana, or where scientific figures point to other crucial needs, as is the case in national reproductive health, ultrasound turns into a different thing. Science here hits back. Adding the dimension of resource to that of space, also provides answers to some of the questions the previous chapter has left us with, for example, why the state agencies refused to train their own technicians, or why other professionals came to the refresher courses than those who had been originally trained. Where the knowledge of technicians may enable them to leave, independence is better secured by falling back on the Philips' technicians; but where ultrasound courses come with allowances, more people than the originally trained ones may want to profit. $^{72}$ Similarly, where having an ultrasound machine increases the candidacy of a

\footnotetext{
${ }^{72}$ International organizations usually pay allowances for courses, so-called per-diems (for a critical analysis of the 'workshop mentality' thus created see D. J. Smith, 2003). At Sokoine Regional Hospital, for example, the problem that everybody
} 
hospital to get another doctor, attempts to remove a machine that appears to be standing 'idle' meets with resistance. The focus on resources furthermore serves to reconsider the value of cost-benefit analyses common to transfer projects: as the value of ultrasound (and other things) emerges in exchange, the question of what are costs and what are benefits cannot be established prior to the transaction.

The questions that this chapter leaves us with for doing technography, hence, are the following: What are the resources at hand in a particular place? What are the resources required for a new technology? But also, what are the resources that can be and are mobilized for and of the new technology? And, how does an exchange transform places, and whom or what does a move include or exclude? Transformed into national health care boosters, ultrasound machines still move on to work in hospitals as intended. Having lost their specificity for working towards the reduction of maternal mortality statistics, their meeting with pregnancy is more accidental than systematic: reducing maternal mortality is instead delegated to individual professionals. The next chapter will turn to the problematic assumption that both international and state agencies make in this context: that ultrasound patients are there. Following ultrasound to various health care facilities in both countries in the following chapter, I will show that ultrasound patients are not a resource already at hand but that it takes time to make them.

wanted to profit from the allowance paid for the refresher course, led to fierce negotiations among the staff. In this context the Medical Officer in charge complained about Philips' practice to send invitations for the refresher course by fax. As any fax landed with the secretaries, such a course immediately became public knowledge. Instead, he argued, they should have called him. 


\section{Institutionalizing ultrasound - the hospital apparatus}

In the previous chapter I have shown that ultrasound turned from a device-to-reducematernal-mortality-statistics into a device to boost the national health care system. In this process of translation, ultrasound became a device to keep doctors up country in Ghana, and to keep radiographers up to date in Tanzania. This transformation did not prevent ultrasound from traveling further to their new workplaces. When, in pursuit of suitable fieldsites, I visited one of them, Sokoine Regional Hospital in Southern Tanzania, however, the facility's ultrasound registry recorded only three examinations: one on account of 'lower abdominal pain', the other two for hernia, but none for pregnancy. The ultrasound operator whom I met in the ultrasound, an $\mathrm{AMO}^{*}$-radiographer, had recently returned from his training course in Kilimanjaro Christian Medical Center (KCMC) in Moshi. His return had been keenly awaited as the original operator trained by Philips Medical Systems, a nursemidwife, had resumed her duties as a nurse and according to the nurse-rotation-scheme, had been posted in the internal ward. Recalling his experiences at KCMC, where "at least forty pregnant women were waiting daily for ultrasound", the AMO-radiographer expressed his surprise about the absence of pregnant women despite the huge antenatal clinic nearby.

The scarcity of my research time made me choose another region for fieldwork than Southern Tanzania. In contrast to the absence of pregnant patients for ultrasound at Sokoine, health care professionals in the facilities under study could provide me with a clearcut list of ultrasound candidates: women with pv bleeding*, with twins, with intrauterine fetal death, with inconsistency of dates and fetal mal-presentation. The difference in presence of patients for ultrasound at Sokoine Hospital, KCMC and my hospital fieldsites undermines the assumption of a 'natural' presence of ultrasound patients held by both international and national state agencies in Ghana and Tanzania. Rather than 'being there', ultrasound patients have to be made. This requires ultrasound to be inserted into the normal sequence of clinical practices that deal with pregnancy and pregnancies 'at risk'. Taking time as my dimension of analysis in this chapter, I argue that ultrasound turns into a device to 'run hospitals', yet, may thereby become a different thing in different kinds of health care facilities and for different professionals. I will show how in the process of ultrasound's institutionalization new temporal orders emerge that may align but also clash with existing ones, or that work on each other in unexpected ways. 
I will pursue the appropriation of ultrasound by Ghanaian and Tanzanian hospitals in four sections. In the first section I will describe the clinical practices before the ultrasound examination, those practices that turn a woman into somebody to get an ultrasound. I will show that in this process of transformations, pregnancy is re-ordered to fit ultrasound. In the second section I will concentrate on the practices that take place during the ultrasound examination. These practices turn a woman's body into a representation that is able to outlast the real-time images generated in the ultrasound room and to travel back to the clinic. In the third section I will focus on what happens 'after the images', that is, when ultrasound images travel back to clinical space and feed into the composition of particular care trajectories. In exploring the transformation of ultrasound at the hospital level, this chapter provides insights into current obstetric practice in Ghanaian and Tanzanian hospitals. In the fourth section I will draw from these insights to argue for including time matters in technology assessment.

\section{Fitting pregnancy to ultrasound}

In the hospitals under study I observed four practices by which women were turned into patients for ultrasound: by assessment, for emergency, as routine and on demand. Not all of these four modes of ordering ultrasound and pregnancy were present in all hospitals, nor should they be regarded as mutually exclusive. Instead, by passing through the hospital women may switch between them, so that these modes interlink or follow one another. Working to make pregnancy fit to ultrasound, these modes of ordering draw on and react to both international obstetric standards and regional specificities.

\section{By assessment}

The majority of the ultrasound examinations I observed were the effect of a trajectory of measurements. Coordinated by the antenatal record card, these measurements resembled those of antenatal care in Germany or the Netherlands in many ways. Differences appeared to be only slight or temporary such as when the measurement of hemoglobin in Nalerigu was a matter of checking the color of eyelids and tongues rather than being a matter for the laboratory; or when at Makongoro Clinic the device to measure hemoglobin was broken for months, and women were sent to a private laboratory in town which required them to pay for services they would otherwise have received for free. Whether in Ghana or in Tanzania, 
types of hospitals resembled each other, the similarities displaying a similar history of health policy both countries were subjected to: in both Teaching Hospitals women had to buy themselves into hospital services by purchasing an antenatal record, while cards were free at District Hospitals. This antenatal record was a simple pasteboard. It consisted of a cover page listing personal data and a table on the back page in Ghana (see Figure 4.1), or on the middle page in Tanzania where the back page displayed a partograph. ${ }^{73}$

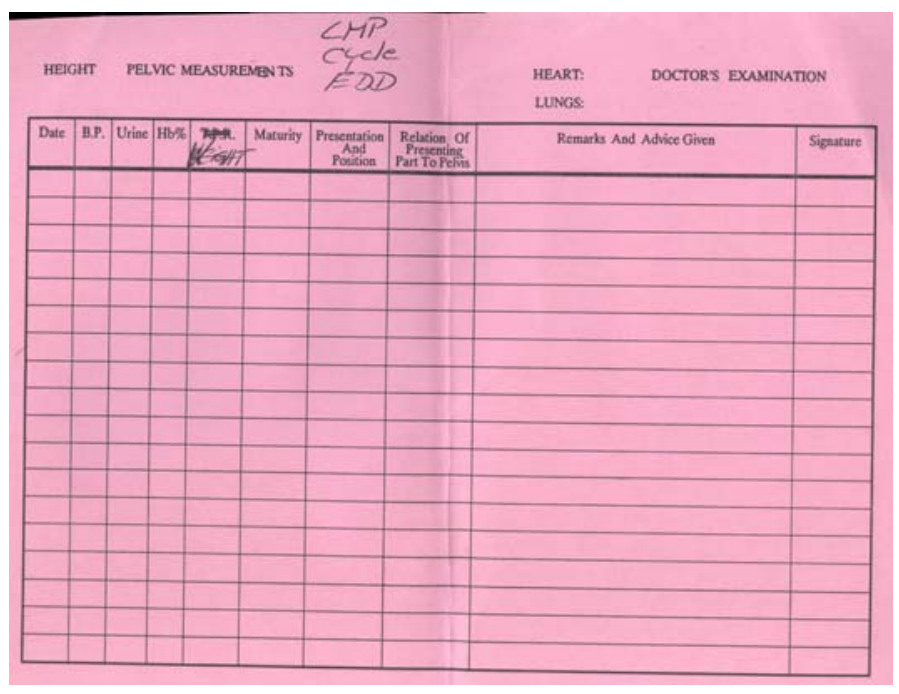

Figure 4.1 The back page of the antenatal record card used at Korle Bu

The antenatal record is first of all a "distributing and collecting device" (Berg, 1996). In pursuit of filling the table's empty boxes, the antenatal record moves women in a standard sequence through clinical space: from the place where a woman's obstetric history is taken and the cover page filled in, to the balance and length scale where her weight and height are measured, to the table where her blood pressure is checked, and to the place for testing her urine. This passage ends in a room separated from this public space by curtains or walls. In this private sphere pregnant women are palpated to assess fundal height, fetal lie, heart beat and the number of fetuses. By requiring these measurements to be taken at every antenatal care visit, the record produces the antenatal clinic both as a sequence of practices and as the

\footnotetext{
${ }^{73}$ During the time of my fieldwork in Ghana, the record cards of government hospitals differed in color and size according to level of care. Recently, the Ghana Health Service introduced a national antenatal record, which in contrast to the former cards, is a booklet that comprises several pregnancies in one document. In this respect, it resembles the German antenatal record that lists three pregnancies in one document, the so-called Mutterpass. In Tanzania, all government hospitals regardless of the level of health care use the same antenatal records. Supply shortages, however, frequently led health care professionals to turn simple school exercise book into self-made records. Shortly before I left the country in September 2004, the new FANC card was introduced into clinical practice via the Central Medical Stores.
} 
space performed by these practices. The socio-techno-gram of a normal antenatal care visit at Korle Bu Teaching Hospital thereby mirrors a particular labor division characteristic for tertiary care facilities: while nurse-midwives are responsible for the public sphere, palpation, and thus, the determination of gestation time, is the responsibility of doctors (Figure 4.2).

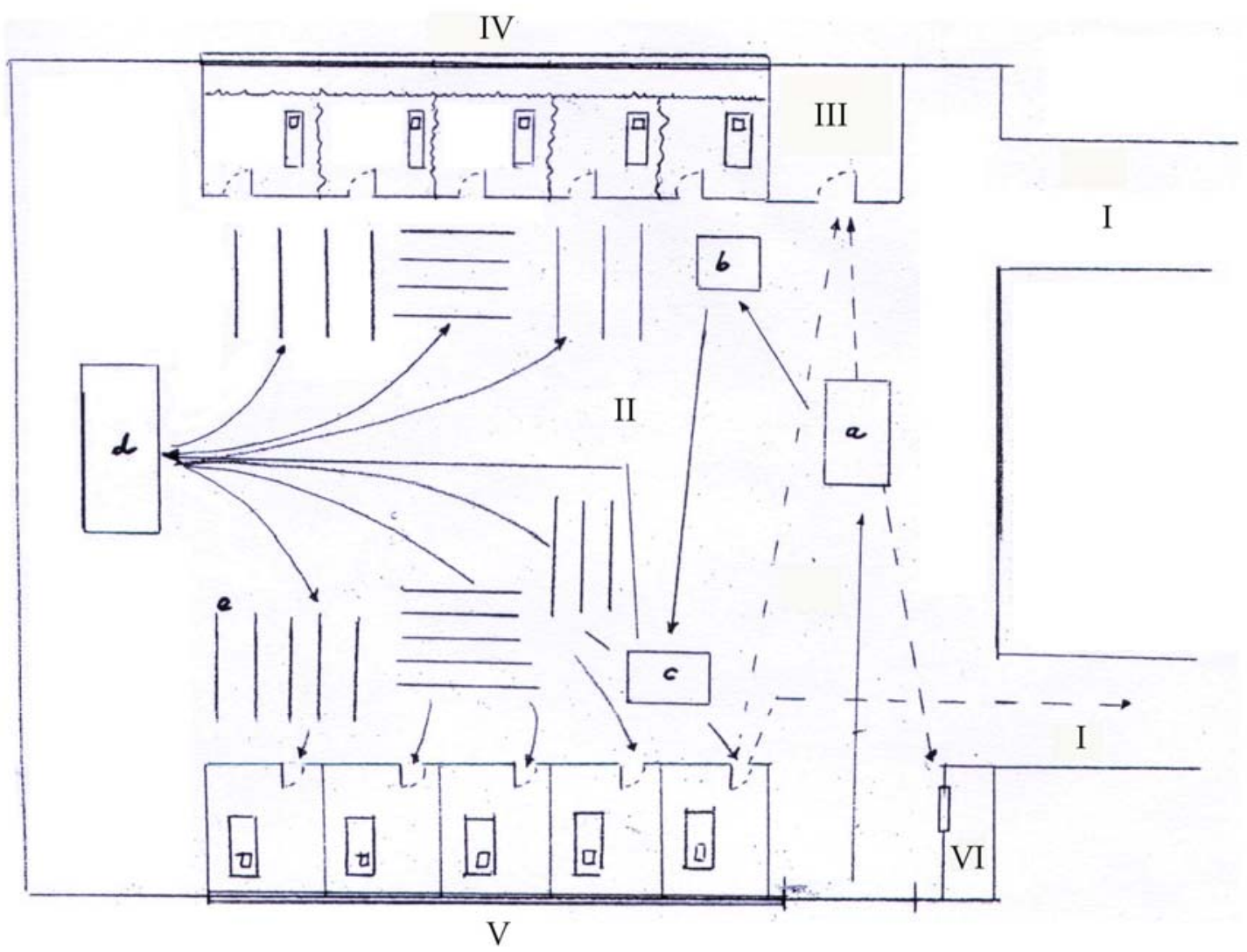

\begin{tabular}{|ll|}
\hline \multicolumn{2}{|l|}{ Legend } \\
\hline \multicolumn{2}{|c|}{} \\
\hline I & corridor to doctor's office, uts-room \\
\hline II & outpatient clinic \\
\hline III & laboratory \\
\hline IV & palpation (interns) \\
\hline V & palpation (specialists) \\
\hline VI & accountancy \\
\hline & \\
\hline a & medical history \\
\hline b & weight, height \\
\hline c & urine \\
\hline d & blood pressure \\
\hline C & waiting benches \\
\hline & \\
\hline & obligatory trajectory \\
\hline-2 & upon referral \\
\hline
\end{tabular}

Figure 4.2: A map of the temporal-spatial configuration of the Outpatient Department (antenatal care room) of the Maternity Block at Korle Bu Teaching Hospital in Accra, Ghana (2002). 
Displaying a table of measurements the antenatal record card is also a center of representation that provides information about the state of pregnancy. The table can be read vertically and horizontally. Read vertically, the table in Tanzania ${ }^{74}$ represents a pregnancy in its anatomical "geography" (Berg \& Bowker, 1997, p.518), as a collection of body parts that voice the existence of pregnancy - blood pressure in the arms, protein or sugar in the urine, water in the feet (edema), hemoglobin in the blood, tongue or eyes, and a child in utero present at a particular date. As the majority of information is given in numbers and abbreviations, this reading requires some knowledge: LL stands for long lie, or CP and BP for 'cephalic' and 'breech presentation', RR 140/90 for a particular blood pressure, and + or - for the presence or absence of certain conditions, of fetal heart beats or protein in the urine, for example. Combinations of letters also point to particular treatments: FS reads as iron supplementation, which is a standard practice in 'the North' too; SP, in contrast, stands for sulfadoxine pyrimethamine and refers to a disease specific to Africa - it is the standard drug for treating malaria in pregnancy. To an experienced reader, the antenatal record provides 'normalcy' or 'risk' at a glance: the blood pressure of 140/90 and the positive diagnosis for urinary protein, for example, turned Elimika Pande ${ }^{75}$ into a case of Pregnancy Induced Hypertension $\left(\mathrm{PIH}^{*}\right)$ with a high likelihood to develop eclampsia*, a high risk condition for both mother and child, when left untreated. Read horizontally, the table accumulates successive pregnancy 'geographies' into a history. Displaying a development over time, the record enables to witness changes: it displays deterioration of certain parameters, or amelioration of conditions after treatment aiming to return the pregnant body to normalcy according to the parameters prescribed by the record.

The key parameter to be recorded is the time of pregnancy. There are two practices with which pregnancy time can be established, each of which takes a particular point in time as referent. 'Gestation age' is obtained when professionals take a woman's history: it is based on her knowledge of the first day of her last menstrual period before getting pregnant.

Subjected to a standard formula based on a regular 28-day cycle, the subtraction of three months and the addition of seven days and one year yield an expected date of delivery. Gestation age present at a particular visit is calculated on the basis of this expected date of

\footnotetext{
${ }^{74}$ In Ghana, the horizontal and vertical axes are exactly the reverse.

75 Appendix B displays a genealogy of hospitals that links all pregnant women I refer to in this and the following chapter to their respective health care facilities, and displays some personal data.
} 
delivery, yielding a pregnancy time in weeks and days. 'Fundal height', in contrast, is obtained by palpating. Other than relying on women's knowledge, this pregnancy time relies on the 'hand-knowledge' of health care professionals to determine the height of the upper edge of the uterus - the fundus - in relation to particular landmarks on a woman's body. According to cosmopolitan obstetrics, each of these landmarks corresponds to a particular week of gestation: a fundal height just above the pubic bone equals 12 weeks, at the umbilicus 20 weeks, just under the ribs 36 weeks. In between these landmarks, fundal height is measured with transverse fingers, each finger thereby equaling two weeks - a standard I had learned during my midwifery training as well. With the FANC scheme, a second measurement tool a tape measure - had entered antenatal practice in Tanzania. During the time of my fieldwork only the nurse-midwives at Makongoro Antenatal Clinic practiced it though, explaining that the tape measure provided them with the "true measurements":

Fingers may be different from one to another while with the tape everyone will measure the same - it is more, more what? ${ }^{76}$ It is more scientific. In fact, we have been told to use the tape in the course where they taught us about FANC (Tz 13).

The interplay of 'gestation age' and 'fundal height' is most obvious in the Tanzanian record card, which lists these two pregnancy times as successive boxes, allowing for easy comparison (see Figure 4.3).

\footnotetext{
76 This question mirrors a rhetorical figure often used in Kiswahili - ni nan? answer given thereafter.
} 


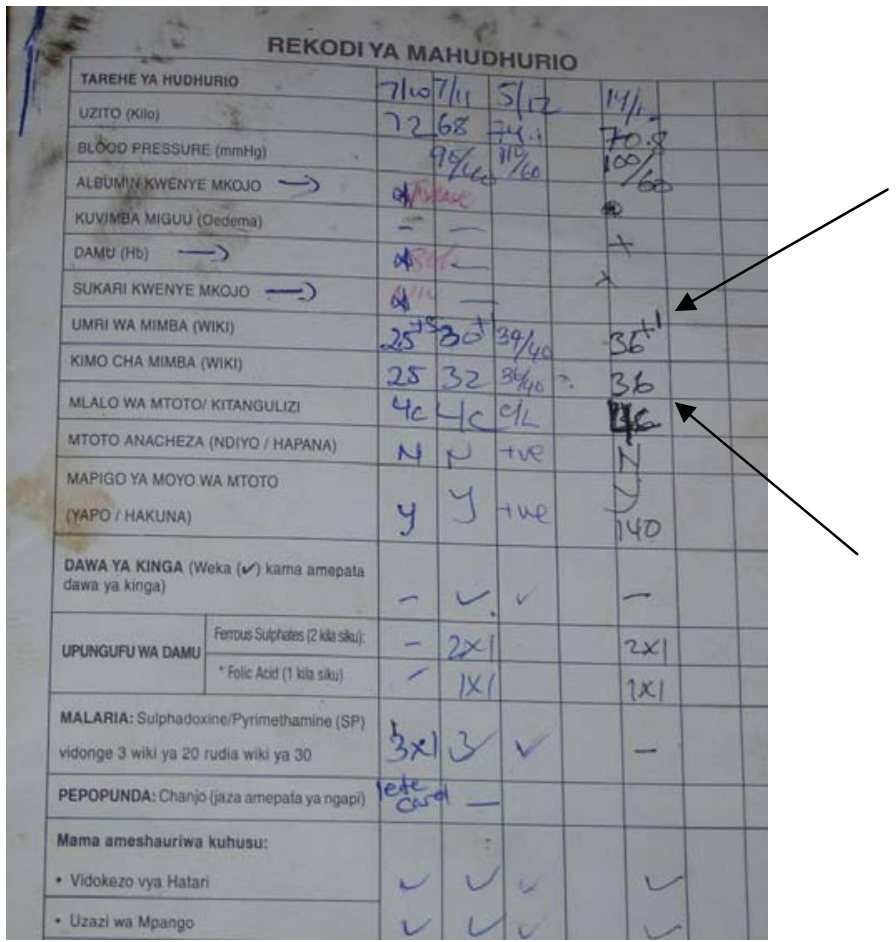

Figure 4.3

The Tanzanian antenatal record card with parallel running gestation age (umri wa mimba) and fundal height-time (kimo cha mimba). In sequence of their appearance the measurements called for are weight, blood pressure, protein (urine), edema, hemoglobin, sugar (urine), gestation age, fundal height, fetal lie, fetal movements, fetal heart beat, administration of iron and folic acid, malaria treatment, tetanus vaccination, and health education. This record shows the linear growth of gestation age, and the actual growth of the child underneath that differs from gestation age.

Starting from a fixed point in time, gestation age by definition ascends linearly. Once obtained, the duration between each antenatal care visits adds precisely this period of time to the gestation age present at the date of an antenatal care visit. Fundal height-time, in contrast, measures the age of a pregnancy and fetus not in terms of a 'should be' but in terms of an 'is'-lifetime. It actually measures fetal growth: the older the child the bigger it is, and the higher is the fundal height. Obtaining both pregnancy times, gestation age and fundal height, enables health care professionals to use their comparison as a means of assessing whether a pregnancy is 'at risk'. As long as both times were the same - with a margin of two weeks or "one finger", as my interviewees said, a pregnancy was considered to be 'normal'. Further deviation pointed to a potential risk factor. A fundal height bigger than gestation age, for example, could point to a twin pregnancy, or to a big child or to a polyhydramnion*. Inversely, a fundal height that was smaller than the gestation age was a sign of possible intrauterine growth retardation, or oligohydramnion*. In order to be certain 
whether a deviation was a sign of pathology, however, miscalculation or mis-remembrance of the last menstrual period on the part of women had to be excluded.

Knowing the precise time of pregnancy moreover is crucial because other parameters acquire a different meaning in relation to fetal lifetime, and may in consequence require another treatment. A low $\mathrm{Hb}^{*}$ at the beginning of a pregnancy in Ghana and Tanzania, for instance, was treated with iron supplementation and nutritional advice. Close to delivery, however, a low $\mathrm{Hb}$ resulted in hospital referral, hospital admission and often in blood transfusion, such as was the case for Ester Matatu at Sengerema Hospital. The application of certain drugs, too, was strictly scheduled: in Tanzania, malaria treatment and tetanus vaccination $^{77}$, for example, were only to be given up to the $24^{\text {th }}$ week as thereafter both drugs were known to cause fetal malformation. Furthermore, failing to hear a fetal heart beat with the fetal stethoscope before 20 weeks of gestation was considered 'normal' as the technology in combination with the human ear was often not sensitive enough to pick up the heartbeat. Not being able to hear a fetal heartbeat after 20 weeks when an unborn child was big enough to be overheard, in contrast, was considered a sign of alarm. Combined with women's remarks such as that of Janice Mtutu at Sengerema Hospital that her child was not "playing nicely" (Tz 25), failing to hear the fetal heart beat might point to intrauterine fetal death.

The problem with establishing gestation age was that women were often "ignorant" or "lied" about their last menstrual period, as health care professionals in both Ghana and Tanzania complained. At Korle Bu, the nurse-midwives at the outpatient clinic, for example, told me that women often pretended not to know their last menstrual period in order to bypass national regulations that allowed access to specialized care only after 14 weeks of pregnancy. At Sengerema District Hospital, the assistant medical officer Dr. Mbeki summarized the particular 'African problem' for me as follows:

You cannot rely on women. Especially here in the rural, but even in towns, women are just ignorant about their LMP*. So whatever they say, you cannot trust them. For example, some of them will tell you that they just bled last month, although her belly shows a pregnancy of eight months; others will tell you they have not bled for three years but the belly is just small $[\ldots]$. And others, they just

\footnotetext{
77 As women, particularly in rural areas, give birth at home frequently, tetanus vaccination in pregnancy is the means to prevent infection. Other than in many West European countries where tetanus is a standard vaccination for children, it is the frequent lack of girls in SubSaharan Africa to get school education that constrains routine administration of tetanus vaccine at that time. Thus, instead, pregnant women are target groups.
} 
want to give birth here at Sengerema, those will tell you that they are term but they are not. ( $\mathrm{Tz} 24)$

Also the establishment of fundal height could become a problem, even for experienced professionals. Establishing accurate fundal height time as a measure of fetal growth requires a long-lie of the fetus. The transverse lie of Ester Matatu's child at Sengerema Hospital thus made it impossible to know how old the pregnancy actually was. Admitted on account of dizziness, the diagnosed anemia had been successfully treated with two units of blood, leaving the health care professionals with the question of whether to send her home again or to admit her to the Waiting Home of the hospital depending on the closeness to the date of delivery. While Ester Matatu claimed to be only eight months pregnant, the admitting AMO* had palpated her to be on term. Laurentsia Shitindi, also at Sengerema Hospital, was another case where establishing fundal height turned out to be a difficult matter. By eyesight far advanced in pregnancy but on her own account only six months pregnant, Laurentsia Shitindi had been referred to Sengerema Hospital by her village dispensary on account of the discrepancy of dates. Mama Bukumbi, the MCH Aide* working at the antenatal care room, initially suspected the lack of skills of the peripheral facility to be the cause of this discrepancy. It quickly turned out that it was the over-tight belly contracting at even the slightest touch that was the problem in assessing an accurate fundal height.

Bodily resilience in establishing fundal height in principle qualified women for ultrasound. Thus, Laurentsia Shitindi was considered to be a "perfect candidate for the new machine", as Mama Bukumbi explained (Tz 25), and similar to Ester Matatu she was immediately referred to ultrasound. A missing gestation age, in contrast, did not automatically qualify a pregnant woman for ultrasound. The senior staff members working at the antenatal room at Sengerema Hospital, for example, simply left out the box asking for gestation age and filled in their findings after palpation. The young nurse-midwifery students, however, sent all women without a gestation age for ultrasound, especially in the absence of senior staff they could call upon in case of doubt. Rather than requiring this gestation age only for the present pregnancy, they explained that they needed ultrasound to "fine-tune their hands" with regard to their future work in facilities that might not have an ultrasound machine yet and thus required them to trust their hands. At Makongoro Antenatal Clinic, the nurse-midwives told me that they increasingly sent women with a missing gestation age for 
ultrasound since the introduction of the new governmental FANC scheme (see chapter $2 \&$ 3). As this scheme required the spacing of visits over time instead of seeing a woman every four weeks, they said they had become more uncertain in relying only on fundal height for risk assessment. This uncertainty was aggravated by the increasing number of women who do not know their last menstrual period anymore due to the use of the three months injection-contraceptive Depo Provera (see chapter 2). Furthermore, they had witnessed an increasing number of women becoming 'overdue'. While formerly their clientele had delivered at 36 weeks, women now frequently carried their pregnancies beyond the time where the new antenatal care scheme allowed a visit. Both factors made it extremely difficult for them to refer women to hospitals 'in time'.

Time discrepancy above the normal margin of two weeks, however, did not as I had expected lead to an immediate referral to ultrasound. Rather, as I observed, health care professionals tended to 'repair' time in different ways. At Makongoro Clinic, discrepancies between gestation age and fundal height-time only made it to ultrasound after the obligatory malaria treatment had been completed by the $24^{\text {th }}$ week and the syphilis test had shown to be negative. Both diseases, as nurse-midwives explained, led to 'natural' fetal growth retardation, that is, to a false discrepancy that disappeared after treatment. Only when a time discrepancy showed up at two successive visits, or when a woman was close to delivery, was a woman referred to ultrasound. Asked whether they did not mind knowing what was the case at a rather late stage, the nurse-midwives explained, that according to their experiences, the later they sent a woman for ultrasound, the more correct the expected date of delivery was in terms of women actually giving birth before that deadline instead of passing it. At Sengerema Hospital, Mama Bukumbi simply did not take the discrepancy between gestation age and fundal height as indicator for the presence of twins. Instead, she based her diagnosis on the presence of "many small parts" ( $\mathrm{Tz} 25)$, thus on pregnant topography characterized by quantity rather than by time. At one of the outreach clinics of Sengerema Hospital I witnessed yet another kind of 'time repair'. Mama Iringa, the nurse-midwife had palpated 32 weeks and without any hesitation recorded this pregnancy time on the record which showed that the fundal height had been 32 weeks already four weeks earlier, at the woman's last visit. When I asked her whether this apparent discrepancy of four weeks would not make that woman a case for ultrasound, it turned out that Mama Iringa located the discrepancy at another time and place. Not the 32 weeks palpated this time pointed to something wrong but 
the 32 weeks reported previously was "not the right time" (Tz 23). Most probably, she said, the previous fundal height-time had been the result of a full bladder that had pushed the uterus upwards. Furthermore, she added, she only trusted her own hands. Yet if that woman returned again in another four weeks with 32 weeks of pregnancy, then she clearly was to be referred to ultrasound.

At Korle Bu Teaching Hospital in Ghana, nurse-midwives faced a very special problem with regard to time discrepancy and ultrasound. As palpation was doctors' territory, yet they had to check women's eligibility to Korle Bu's services in the first place, nursemidwives found themselves in the dilemma of having to deal with women's ignorance or deliberate lies and national regulations restricting access by pregnancy time. In case of inconclusive bellies by history and eyesight, nurse-midwives therefore often sent women back home to return four weeks later until a pregnancy showed more. It was them, they told me, who actually needed ultrasound in order to know whom to admit and whom to reject. Separated from this possibility, they feared they would be considered incompetent by the young doctors that now were taught in ultrasound.

While questions of time led to different detours in assessing the normalcy or pathology of a pregnancy before an ultrasound was being ordered, missing the fetal heart beat beyond the $20^{\text {th }}$ week resulted in immediate referral to ultrasound requesting confirmation in all facilities. At Nalerigu Baptist Medical Center in Northern Ghana, however, nurse-midwives used another technology in between listening with their ears and "seeing with sound" (Yoxen, 1987) to confirm a clinical suspicion: an electronic fetal monitor (EFM). While health care professionals at the other facilities said that ultrasound 'sped things up', in the sense of enabling termination of a pregnancy by inducing abortion before a fetal death might lead to maternal sepsis*, the nurse-midwives at Nalerigu's antenatal clinic saw the EMF taking over this role. Situated at the hospital's labor ward, they said, the electronic fetal monitor was more rapidly accessible. Referring women for ultrasound, in contrast, meant having to wait a long time for the diagnosis to come back as the doctor performed his examination only in the afternoons:

We don't know the machine, so we don't use it. It is used by the doctor. So if you send for ultrasound, you have to send a woman to the doctor and she may have to wait a long time because pregnancy care is the job of midwives. We use the EFM and if we cannot hear it then, we say: 'The child is dead'. (Gh 11) 
Ultrasound by assessment, in sum, is the effect of a lengthy process of differentiating between a 'normal' and a pregnancy 'at risk'. This differentiation rests on international standards such as the FANC scheme, on standardized menstrual cycles and universal body landmarks, on the completion of certain treatment cycles, on professional careers, and on certain (and seemingly other) time preferences. 'Repairing' discrepancies in pregnancy time, and thereby further ruling out pathology, turns ultrasound into the last resort of certainty as to what is at stake with a particular pregnancy.

\section{For emergency}

"Lift her! One, two three! Now go!" - the short precise orders I overheard at the Outpatient Department of the Maternity Block at Korle Bu belong to the mode of ultrasound as emergency. Brought in a private car, Mercy Prempeh was put on a stretcher and rolled directly to the ultrasound room on the basement floor a few meters away from the main entrance. In front of the door to the ultrasound room she had to get up because the door to the room that used to be a doctor's office before the arrival of the Philips ultrasound was too narrow for the stretcher to pass through. Standing, she revealed a backside soaked in blood while a small puddle of blood formed at her feet before she was hurriedly ushered in to lie down on the stretcher again inside the ultrasound room.

Ultrasound for emergency bypasses the time-consuming process of careful differentiation of those 'at risk' from those who are not. Thus, at first glance, it looks as if it is the opposite of ultrasound by assessment. Ultrasound for emergency, however, builds on assessment practices. It draws on the professional knowledge that vaginal bleeding and pain are risk factors and point to pathology rather than to physiology, for example: to a placenta previa* in case of painless but severe bleeding, or to an ectopic* pregnancy in case of painful but spotted bleeding. It also works on particular information stated on the cover page of the antenatal record. The recording of the woman's name, the name and workplace of her husband (in Ghana) and the balozi* (in Tanzania), the number of previous pregnancies, deliveries and dead children, the last menstrual period and expected date of delivery, are information that is also registered in the hospital's record books that have to be handed over to the Ministry by the end of each year. Every antenatal record card thus enacts its holder as a legal entity entitled to service. Mercy Prempeh's card at Korle Bu Teaching Hospital, for example, got her an emergency ultrasound on the basis of stating the name and work of her 
husband that indicated the existence of somebody who could be charged for fees.

Furthermore, her antenatal record stated 'blood' on the cover page, indicating that two of her relatives had donated one unit of blood each at an earlier visit. It is this additional information about money and blood that entitles women for fast-track emergency diagnostics. Not being able to provide these currencies delays a trajectory even when a condition is severe. Kathleen Atta, for example, was taken to Korle Bu as a case of domestic violence. According to her information, she was about 20 weeks pregnant. Yet, whether her child had survived the assault by her husband could not be confirmed throughout the entire week that she stayed at the hospital as she could not pay the 30.000 Cedis for ultrasound. ${ }^{78}$ Filing a request for the social welfare department to take over these costs would take too long, the attending intern said. Without the currencies to pass on, she was finally discharged without ever having had an ultrasound although the request was repeatedly noted down in her file during ward rounds.

An ultrasound for emergency may bypass the waiting order described above. At Korle $\mathrm{Bu}$, this queue consisted of all the women that had been referred to ultrasound after assessment and who gathered in the waiting hall in front of the ultrasound room after the daily morning meeting had finished at around 9am. According to the nurse-midwife Lucia Owusu, the ultrasound assistant, the ability to bypass this queue, did not depend only on professional knowledge. Rather, it required a bodily disorder to be made visible to the waiting ultrasound patients as well:

You see, they will say: 'We waited. So, this one has to wait as well.' If you try to pass them without them seeing this is serious, this woman is bleeding, they will just riot. (Gh 4)

Ultrasound for emergency catches unforeseen, suddenly emerging disorders. These may occur during pregnancy as well as during labor, at day-time but also at night-time. Of the fieldsites, Makongoro Antenatal Clinic was the only hospital that rarely had emergencies. Responsible for antenatal care only, it neither had a labor ward nor an operating theatre, nor was it open at night. When experiencing sudden bleeding, for example, women in Mwanza in such cases went directly to Sekotoure Regional or Bugando Teaching Hospital.

Disorders in pregnancy, such as the sudden onset of bleeding for example, may happen at any time of the day or night. In all facilities, ultrasound working hours, however,

\footnotetext{
${ }^{78}$ See Appendix D for a list of prices for several items and buying power of the Cedi during the time of my fieldwork.
} 
depended on the kind of operators and their particular working schedules. The two gynecologists operating ultrasound as a teaching device at Korle Bu, for example, had divided the week evenly between themselves, with Wednesday being a day free from ultrasound. Working fulltime as a specialist, Dr. Tennison spent two afternoons per week performing ultrasound from $2 \mathrm{pm}$ to $5 \mathrm{pm}$. His colleague, Dr. Battir had been called back to duty from retirement due to his previous experiences with ultrasound. He operated ultrasound on the two other afternoons at Korle Bu on top of his work at a private facility in town. At Bugando Teaching Hospital in Tanzania, ultrasound services were offered during the regular working hours of the radiography department from $8 \mathrm{am}$ to $4 \mathrm{pm}$. Other than its 'big brother' $\mathrm{x}$-ray, however, ultrasound did not have the 24 hour presence of an operator. After $4 \mathrm{pm}$ only one ultrasonographer was on call and s/he had to be fetched from home when needed.

Outside the regular working hours of ultrasound, what counted as emergency for ultrasound - and inversely as ultrasound for emergency - changed. This happened in the case of Paulina Mkumbi at Bugando Teaching Hospital, for example. During the regular schedule of ultrasound Paulina Mkumbi would have immediately made it to ultrasound, the intern on duty at Bugando Teaching Hospital told me: at 33 years old, she had just one living child of nine, and had already lost one tube to an ectopic pregnancy. During his night shift she reported with severe abdominal pain, spotted bleeding and three months cessation of menstrual bleeding. The laboratory test positively confirmed a pregnancy. According to the intern's knowledge, all clinical signs pointed to either another ectopic pregnancy or a missed abortion. In daytime, his doubts would have made him send Paulina Mkumbi straight to the ultrasound room. Her arrival at night, however, changed "everything", as he remarked (Tz 4). For him as an intern, getting an ultrasonographer from home implied getting into contact with 'supervision' in order to make a telephone call first, then calling his immediate superior doctor and convincing him of the urgency of an ultrasound. Upon approval from the resident doctor to call the ultrasonographer at home, he would then have to call one of the drivers to fetch the ultrasonographer. Or, in case the resident decided to he wanted to see the case for himself, he would first have the car fetch the resident and then the ultrasonographer.

Night-time ultrasound, hence, implicated 'sleeping' cars, gasoline, telephones, and resident doctors (who were not always residing on the hospital compound in reach of the 
interns). It therefore required a careful balance between 'knowing enough' to convince one's superiors and legitimately 'knowing too little' to warrant the mobilization of these extra resources. An ultrasound for emergency at night time thus needed more time in order to make the right decision. In the case of Paulina Mkumbi, in the end the intern decided not to refer her for an emergency ultrasound but to admit her and ask for an 'urgent' ultrasound the next morning. Paradoxically, it was the presence of ultrasound that discriminated against him acquiring the certain knowledge he needed to call his resident and get the emergency ultrasound going:

What they old ones did, someone such as this old mzee*, the physician you met at $\mathrm{H} 2$ [the emergency or casualty unit, BMR], for example, they simply took a syringe, injected it and drew blood. If the blood clotted, most certainly it was ectopic*. So, they needn't to do ultrasound. But you see that were the old days. We cannot do that anymore, simply because it is not practiced anymore, it is not scientific. If you open a textbook, it will say: for diagnosis of ectopic, use ultrasound. ( $\mathrm{Tz}$ 4)

Similar to Bugando Teaching Hospital, night time in other health care facilities changed what was regarded as legitimate ultrasound for emergency. At Sengerema District Hospital, for example, for a woman in labor at night ultrasound was not done when the nurse-midwives were uncertain whether that woman was pregnant with twins. Rather, ultrasound was done only when they were certain that a woman was carrying twins but wanted to know their exact position fearing a condition called 'locked twins'. The first twin hereby lies in breech* while the second lies with its head downwards (cephalic position); as the first twin descends during delivery the two heads may become 'locked' leading to an undeliverable position for both twins, and if not solved by c-section, to the death of the children and potentially of the mother as well. Similarly, at Nalerigu District Hospital in Ghana, the nurse-midwives called the doctor to do an ultrasound for emergency in cases where they already knew that a woman was delivering a child in full breech position, and wanted to know the size of the head.

In contrast to ultrasound by assessment, ultrasound for emergency is thus an immediate answer to a problem that has suddenly emerged and is visibly life threatening. It requires certain things, such as relatives, money, a record card, the visible overflowing of bodily boundaries, but it also hinges upon the time of the day, working schedules, pension age, and professional degrees. Other than ultrasound by assessment, ultrasound for 
emergency may also take place at night but then requires even more resources, like cars, torches, drivers, and more, or different, knowledge. The knowledge-requirement was a constant source of unease for the interns in both Teaching Hospitals responsible for admitting patients and for first decisions on how to proceed. This unease became particularly obvious to me when I was approached by some interns at Korle Bu requesting me to ask the specialists for an ultrasound standard that was valid day and night.

\section{As routine}

The request of the intern doctors at Korle Bu Teaching Hospital to establish an ultrasound standard did not mean that there were no routine ultrasounds. Korle $\mathrm{Bu}$, for example, had established ultrasound as routine in the form of a so called 'booking scan'. Dr. Lema, a senior gynecologist, explained this routine with reference to the scientific obligations that being a leading teaching institution implied:

$[\ldots]$ to do a booking scan, that means you do real science. You see, with a late scan what you do is rock science, you estimate but the machine does not actually give you the right dates. But if you do an early scan, say 20 weeks, you have a scan for reference if you need another scan later on. You are sure about her dates. (Gh 3a)

Korle Bu's routine scan, thus, introduces another framework of time: it is, so to say, a preventive ultrasound. Not in the sense that it prevents a condition but in the sense that it prevents complete surprises because it deploys diagnostic potential as a stable reference to fall back on for comparison of dates or for placenta location.

Similarly, Bugando Teaching Hospital had a kind of 'booking scan'. Unlike Korle Bu, however, this booking scan was carried out whenever anybody was referred from Sekotoure Regional Hospital. On the same night that the intern Justin Itete decided against an emergency ultrasound for Paulina Mkumbi, Celina Kondo was referred from Sekotoure Hospital on account of a suspected placenta previa. Similar to Paulina Mkumbi, she presented with spotted bleeding, yet without pain, and a further advanced pregnancy. Accounting for his decision to do an ultrasound at night, the intern referred to Bugando's routine of counterchecking any diagnosis from Sekotoure:

She was bleeding only lightly upon admission but she told me she had bled very severely before, and this is why she had gone to Sekotoure where they admitted her and had made an ultrasound that diagnosed placenta previa. That is what I had thought too, antepartum hemorrhage*, what can it be? It may be just normal 
labor, or it is placenta previa, or it is abruptio placenta*. [...] So I sent her for ultrasound because she was an emergency case, and because we cannot believe Sekotoure ultrasound - who knows who is operating the machine? ( $\mathrm{Tz} 4)$

This routine scan was based on national regulations that held Teaching Hospitals ultimately accountable for treatment in general, as well as on the mistrust of the diagnostic capabilities of this Regional Hospital in particular. Referring to maternal death as the crucial indicator of good clinical performance, Dr Pumusi, one of the leading gynecologists at Bugando, pointed to the case of Celina Kondo as one of the examples that warranted this routine ultrasound: after hours of 'conservation' at the Regional Hospital she had finally been referred when night approached. This not only delayed proper management and risked the life of mother and child, but in case of maternal death also counted adversely on Bugando's maternal mortality statistics:

We have started with maternal audits, maternal mortality meetings. When there are some cases, we will meet, from gynecology, and will discuss cases when a mother died to find out what was responsible for her death. [...] What we find in many cases is that it is not Bugando but the periphery -at district level but at the regional level as well. [...] Sekotoure, for example, keeps patients until very late although it is known that nothing can be done for some of them - there is not even a blood bank nowadays - but they keep them and by the time they refer, we cannot do anything anymore, but the death counts for Bugando. [...] So what we do when someone comes from Sekotoure, we check everything again because they don't have qualified doctors there, so you cannot trust their diagnosis. ( $\mathrm{Tz}$ 2)

Bugando Teaching Hospital had established other routine scans too: every woman suspected of intrauterine fetal growth retardation was to have a series of ultrasounds according to 'the book', as the interns called it. One of the cases to which this routine applied was Elimika Pande. Her history was discussed at one of the morning rounds: 30 years old, gravida four, para, three dead three ${ }^{79}$, among which two stillbirths* (the first and the third child), and a second baby, described by Elimika Pande as having been born "very small" which had died after a couple of months. For all interns at the ward round this history conveyed the message that the present baby was precious. This message was supported by the reported effort of Elimika Pande to attend services at Bugando while living at Ukerewe

\footnotetext{
79 This reading refers to the written standard G4P3 +3 by which obstetric cases are being referred to. It means that a woman is pregnant (gravida) for the fourth time and has given birth (para) three times. The little cross refers to dead children, whereby only those children that are legally considered as births and not as abortions anymore count. In Tanzania the legal border distinguishing between stillbirths and abortions is 28 weeks.
} 
Island, a location that called for a three hour trip by boat and a payment of 500 Tanzanian Shillings one way. Her first antenatal care visit in the present pregnancy had revealed high blood pressure, a condition that the health care professionals retrospectively presumed to be responsible for the two previous stillbirths. Attending the local dispensary at Ukerewe Island during her first two pregnancies, however, her blood pressure had never been measured. In order to ensure a better outcome Elimika Pande had reported to Bugando Hospital in her third pregnancy and had been admitted on account of high blood pressure. One morning, close to term, however, the fetal heart beat had disappeared. During the current pregnancy the last ultrasound examinations had shown a slow increase in fetal growth, up to the time where the unborn was considered to be mature by gestation age and the fetal lungs had been matured with surfactant*. This condition routinely called for a scan to establish the expected birth weight before a decision was taken on how to proceed. Using ward rounds as teaching events, the specialist reminded the interns that in order to make a decision they had to weigh intra- against extra-uterine survival chances given the facility's infrastructure:

You have to think, what kind of children we can handle. Our neonatal ward is not equipped for children below $2 \mathrm{~kg}$. So, if you take out the child and it is very small, you have not done a good job as it will simply die outside. (Tz 6)

In contrast to the routine scans in pregnancy at the two Teaching Hospitals, routine ultrasounds at Sengerema District Hospital were after-birth scans. They were applied to women who had given birth before their arrival in the hospital (so called BBAs*), to women with severe bleeding after the delivery of the child or the placenta (so called $\mathrm{PPH}^{*}$ ), to women who delivered either fresh or macerated stillbirths, and to women who delivered premature babies. As such, routine ultrasound agglomerated conditions that were considered to be extra-ordinary and despite their variety shared the same risk in the end. All were known to go along with so called 'retained products of conception' (RPOC), pieces of placenta or fetal body tissue or of the amniotic sac that remained in the womb after delivery and carried the risk of causing either severe bleeding or uterine infection (e.g. also puerperal sepsis*). The routine ultrasound thus united conditions that are internationally acknowledged risk factors such as $\mathrm{PPH}$, with regional particularities such as a high incidence of syphilis that is considered to be one of the main factors for prematurity and stillbirths. The risk relation 'syphilis-prematurity-RPOC' that fed into the routine scans at Sengerema District Hospital was the effect of a previous scientific project on syphilis that had involved the present nurse- 
midwife-ultrasonographer as participant. On the other hand, the routine ultrasound 'remedied' conditions brought about by failed national policy: while the Tanzanian nation state promoted hospital deliveries, women frequently still gave birth at home. In the wake of a desired switch to 'modern' obstetrics, the government had discontinued the teaching courses for so called Traditional Birth Attendants (TBAs). According to the nurse-midwives ultrasound provided the solution for a problem that had formerly been dealt with by educating TBAs in the proper management of the placenta phase. ${ }^{80}$

What we taught them, the TBAs, was mainly how to treat the placenta. They just pull and thus you have incomplete placentas. So what we taught them among other things was management of [the] third stage [of birth, BMR]. (Tz 35)

At the same time, however, the ultrasonographer saw the new national regulation on how to manage the placenta phase in hospitals - by cord traction instead of waiting for the placenta to tear off - as contributing to more cases of severe bleeding post partum - and thus making more ultrasound patients.

While ultrasound by assessment is the last resort to turn to after all other means are tried out, and while ultrasound for emergency responds to any sudden, emerging problem, ultrasound as routine becomes part of a preventive frame of care. This turn to prevention is most obvious at Korle $\mathrm{Bu}$ where the booking scan is done as reference for potential future conditions, which may in fact never occur. Yet, this notion of prevention is also part of the Sengerema routine scan performed to prevent a later onset of infection. In Bugando, in contrast, the routine ultrasound seems to prevent the devaluation of a medical reputation or too early an intervention into a pregnancy.

\footnotetext{
${ }^{80}$ It remained unclear to me whether the number of retained placentas really had to do with the ceasing of health care education classes of Traditional Birth Attendants by biomedical personnel. According to Sukuma ideals, a Msukuma woman is to give birth alone without the help of others. The institution of the Traditional Birth Attendant, thus, is actually unused. Many of the traditional healers in the Sukuma region, who also provide treatment for women with pregnancies considered to be at risk, however, have been made into Traditional Birth Attendants by international projects. These projects established special workshops and distributed delivery kits in order to improve the knowledge practices of the apparently unknowledgeable birth attendants without realizing that many of their participants were not actually attending births. The making of 'Traditional Birth Attendants' by assembling bonesetters or women who are known to have attended some births, however, is a widely spread practice. For a critical review of the category of TBA as an actor for development see Stacy Leigh Pigg (1995).
} 


\section{On demand}

While the first three modes of ordering ultrasound that I observed were clearly medically driven, the fourth seemed to be ordered by the patient: "Women demand it!" professionals in both Ghana and Tanzania repeatedly told me, and added that this demand was a sign of “modernity”. In contrast to this reported new 'epidemic of wanting women', however, only twice did I witness a situation in which a woman had actually demanded an ultrasound. In Korle Bu, Proclaim Winston, whom I met in the waiting room for the consultant offices, told me that she would demand an ultrasound from Dr. Battir in order to know whether she was pregnant or not. In Bugando Hospital I met Eunice Hokoro. Her Outpatient Card signed by one of the registrars at the casualty department reported her to be "30years, G3 P0, 3/12 $2^{81}$, believes to be pregnant, UPT* neg, for ultrasound". Accompanying her to the registrar to read the ultrasound report after we had met in the ultrasound room, Eunice Hokoro told me that she had in fact demanded the examination. The registrar confirmed this, adding that otherwise he would not have sent her for ultrasound because her pregnancy test had been negative and he saw no medical indication for ultrasound.

The apparent discrepancy between the observations of health care professionals of a 'patient order' and my failure to get hold of this 'ultrasound on demand' may be the result of the limitations of a time-restricted research period. But I suggest that it was also the simultaneous presence of ultrasound and absence of other clinical diagnostic means that generated perceptions of demand. I will support this suggestion with reference to two cases which health care professionals defined as 'ultrasound on demand', though I had not heard any such demand expressed.

Pregnant with her first child, Venicia Machame had come with her husband explicitly to see 'an expert'. This demand had channeled her through antenatal care service to one of the gynecology specialists. In reply to the question of what had brought her to Bugando, she presented the print-outs of two previous ultrasound examinations done at a private facility in town. Both recorded an expected date of delivery but had obviously failed her expectations as by the time of the present consultation both of these dates were past history while she had remained pregnant. Concerned with this obvious 'misconduct', Venicia Machame and her husband wanted the specialist to tell them what was the matter [Kiswahili: ni kitu gani

\footnotetext{
${ }^{81}$ These abbreviations stand for: pregnant (Gravida) for the third time, never given birth to a child (Parity, which means three abortions, three months (out of 12) pregnant.
} 
sasa?], a question that Dr. Kamenga answered by filling out a request form for ultrasound. Later on, he explained to me that:

You know, it was not really necessary, medically. But she is afraid that something is wrong and she wanted to have another ultrasound. She comes in as a private patient, she pays for it, I send her. $(\operatorname{Tz} 7)$

His statement provides a first hint of why demands to know 'what is the matter' may be read as demands for ultrasound: 'ultrasound on demand' pays off. Any pregnant woman for ultrasound who gets an ultrasound without medical indication is automatically classified as a private patient. And as private patienta, pregnant women have to pay 6000 Tanzanian Shillings for the consultation of a specialist and 5000 for an ultrasound. ${ }^{82}$

His statement, however, also provides a second hint for the interpretation of 'ultrasound on demand': it is the perceived reversion of the traditional professional-patient relationship in which a health care professional orders and a patient complies. Having followed all possible means, Venicia Machame remained 'noise' in the smooth running of a hospital. The only way to play out authority was to order another ultrasound even if this scan would not provide any significantly different information. I observed a similar re-reading of 'resistance' by a patient body as 'a wanted ultrasound' at Sengerema District Hospital. According to the routine, Janice Mtutu, who had been diagnosed with intrauterine fetal death by ultrasound on a Friday, should have had a second ultrasound to check for retained placental products after aborting. Instead, I saw her - still pregnant - sitting in front of the ultrasound room on the following Monday. When I asked one of the nurse-midwives why she had another pregnancy ultrasound, the nurse-midwife replied: "She refuses the induction. She says that the baby is moving again. So we send her again - for proof' (Tz 24).

'Ultrasound on demand', as my interview partners described it, is a novelty. It is part of the new times in which health care professionals increasingly find themselves in a position where their practices are being questioned by pregnant women that have higher education, or as in the case of Proclaim Winston have read British pregnancy journals that list ultrasound as a standard examination in pregnancy. The perception of a changing professional-patient relationship here seems to translate woman's quest for knowledge about what to do into a request for ultrasound that doctors find hard to resist.

\footnotetext{
${ }^{82}$ At the time of my fieldwork in 2004 these sums amounted to 5-6, respectively 4-5 Euro (see Appendix D).
} 


\section{$\underline{\text { Sound Orders }}$}

In the practices that turn women into ultrasound patients ultrasound seems to be the last resort to turn to before a decision is taken on how to proceed. Perhaps ultrasound 'on demand' demonstrates best, however, that the sound decisions for ultrasound in fact rest on ultrasound already being in the minds of health care professionals, and in their expectations and knowledge about what ultrasound does. Problems that 'ask' for ultrasound, for example for 'RPOC?' or 'fetal lie?' result from pregnancies that have been made fit the technology already. In this acquired fitness the failure to hear a heart beat thereby loses its potential to be simply 'missed', and inducing abortion without a prior scan becomes malpractice. As 'at risk' becomes the need to pass the ultrasound room before heading further to the theatre, women are required to have the necessary currency at hand. In becoming an obligatory passage point, ultrasound interacts with different standards ranging from new government regulations, and traditional referral schemes, to a perception of 'modern times'. On the request forms these four different modes of ultrasound are no longer distinguishable except when 'urgent' written on a form indicates the request for fast-tracking. How do these modes feed into the ultrasound room? How are answers to these requests generated, and how do these make their way back to the clinic?

\section{Making diagnostic images}

Precise locations of ultrasound rooms varied in the hospitals under study. Whether situated in the maternity ward, the radiology unit, or whether an ultrasound machine was simply cramped in an office, all ultrasound rooms resembled each other in terms of equipment. All ultrasound machines were surrounded by a bed or stretcher, a table, and a chair or stool. In the Teaching and Regional Hospitals ultrasound rooms were furthermore equipped with a curtain separating the actual examination from a space used by the ultrasonographers for writing reports or by women for undressing. Making diagnostic images requires the cooperation of all these materials with health care professionals and patient bodies. Four main practices - preparing, scanning, contrasting and editing - transform a pregnant woman into a series of images, which once translated into stable forms enable women to return to the clinic. 
Preparing

The first practice in making diagnostic images consists of preparing the woman and the ultrasound machine for each other. A woman is thereby cleared as a surface that allows free access to ultrasound. This clearing involves her partially undressing, exposing her naked belly, covering her private parts, making her lie down, and covering the belly with ultrasound gel. At the same time, the ultrasound machine is cleared for the woman. Switched on, the monitor displays the triangular shaped representation of the transducer and the present date. Manually the name, age, and date of birth of the woman can be added - this is preparatory work, important for print-outs. After every examination, pushing the button 'new patient' returns the screen to its clear surface anticipating the next woman and her abdominal insides that will fill the screen. In essence, preparatory work in all hospitals was the same. In case of emergency, these gross preparatory steps were also sufficient. In all other cases, hospitals differed in how flexible, or how rigid, they were in seting up the configuration of human and non-human actors. I will illustrate this by describing the preparations at Korle Bu Teaching Hospital in Ghana, and at Bugando Teaching Hospital and Sengerema District Hospital in Tanzania in more detail.

Korle $\mathrm{Bu}$ had a very rigid preparation. This preparation began well before the actual examinations started. At $1.30 \mathrm{pm}$, half an hour before the operator on duty arrived, Lucia Owusu, a retired nurse-midwife who had been called back to duty due with the arrival of the Philips' ultrasound, started preparing the waiting women for ultrasound by means of a lecture. Prior to this lecture, Elias Kudzi, who worked as a receptionist for the waiting area that the ultrasound room shared with the consultants' offices, had been responsible for the first selection of waiting women. When I met him, he introduced himself to me as "timekeeper" (Gh 5). His job, he told me proudly, was to make sure that ultrasound results were "fresh" (ibid.) with regard to the antenatal care visit that would follow. Unless doctors wrote 'urgent' on an ultrasound request form, he therefore sent women back home and ordered them to come back at $8 \mathrm{am}$ on a day closer to their next appointment. Thus, ultrasound results would not get "old” (ibid.). The lecture Lucia Owusu delivered to this pre-selected group was a mixture of Twi, English and gestures. It emphasized how women had to prepare themselves in order to make 'video' a success:

I ask them: 'You children, [do] you think this examination is for free? It is not! It is not because it is a professional procedure. It 
costs money. You have to pay 30.000 Cedis $^{83}$ for a normal scan.' Then I tell them they have to go in four by four, they have to hurry. Then I tell them the video requires them to pull up the shirt, pull up the beads and pull down the panties, down, down, down to their thighs. At last, I tell them, they have to drink because the video cannot be done properly without water. [...] So I tell them to get water and drink it and not go to the toilet until after the video. (Gh 4)

The (self)discipline that women were subjected to before entering the ultrasound room, continued inside. Women were made to enter the front part of the ultrasound room in batches of "four by four" according to the order that they had on the waiting bench, and to undress before progressing further one by one into the back part of the room for the examination to take place. Subsequently, preparing a pregnant woman as a surface for scanning subsequently was a cooperative task between Lucia Owusu and Mary Amkama, one of the four nursing aides sent for ultrasound assistance. Mary Amkama was responsible for the first positioning of a pregnant woman on the stretcher. She thereby used the joint between the upper and lower part of the stretcher as a marker for where she directed women to sit down. Once a woman laid down, Mary would stretch her legs, stuff a little pillow under her head, pull her arms and fold them in such a way that the head came to lie in the woman's palms, and then cover the genitals with a cloth. Next, Lucia Owusu would take over.

Drawing an imagined line between her chair's left armrest, the table, the ultrasound machine and the stretcher, she would "fine tune" (Gh 4) a woman's position in such a way as to make the upper part of a woman's right pelvic bone form one plane with the lower end of the ultrasound keyboard (Figure 4.4). While Lucia Owusu translated the doctors' questions about name and age from English into Twi, Ga or Fante, Mary Amkama covered the belly with gel. This last preparatory step would finally made the doctor, sitting fixed right in front of the ultrasound machine, put the transducer on the belly.

${ }^{83}$ During the time of my fieldwork this sum amounted to about 5 Euro (see Appendix D) 


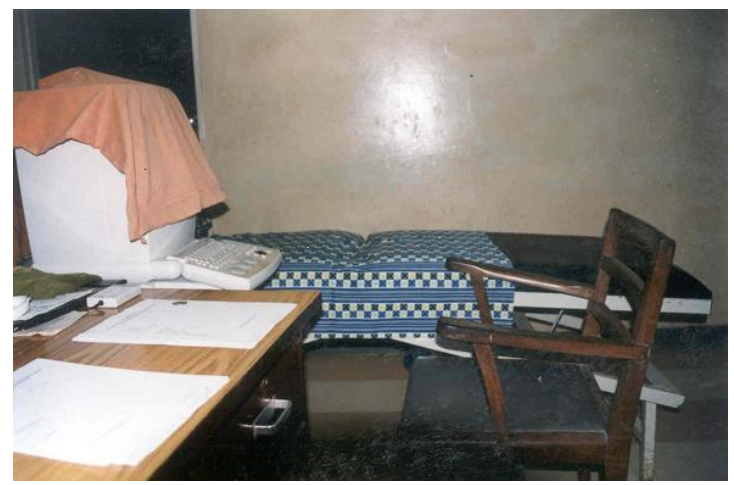

Figure 4.4: Socio-technical configurations of the ultrasound room at Korle Bu Teaching Hospital, Ghana. The photograph also shows the more sophisticated ultrasound machine the Ghanaian government had chosen for, the SD 240. (Photo taken by author)

At Sengerema District Hospital, preparation was much more flexible. Prior to the introduction of the Philips ultrasound, pregnant women had gone to the operation theatre equipped with a portable Aloka machine for ultrasound. While antenatal care attendees were thus covered, the Philips machine had been placed in the office of Stella Ndogo, the matron of the labor ward, who had undergone the Dutch training. Stella Ndogo recruited her clientele herself: palpating those pregnant women that had come for admission to the labor ward, she selected women by means of the same assessment methods as her colleagues in the antenatal ward. The second group of her clientele consisted of the routine ultrasound cases delivered by the maternity ward. Assembling a number of women in front of her office, she called them into her room one by one according to urgency. Women in advanced stages of labor got an ultrasound before the maternity cases, which in turn got an ultrasound before the less urgent pregnant cases. This sequence kept up with the routines of the maternity ward that scheduled uterine excavations shortly after the morning ward round in order to allow women to rest afterwards and still go home in daylight. Once in the room, Stella Ndogo would tell them to lie down with "the head up" and "the feet down", wait until a woman had put her shoulder khanga* as cover on the bed and had arranged her skirt khanga to cover her legs and genitalia. Re-examining every pregnant woman that she had not earlier palpated herself and asking her in Kiswahili or Kisukuma about her problem, she would then stand next to the belly of the woman, holding the transducer with her right hand while directing movements of the mobile ultrasound machine with her left hand in accordance 
with a woman's position on the stretcher (Figure 4.5).

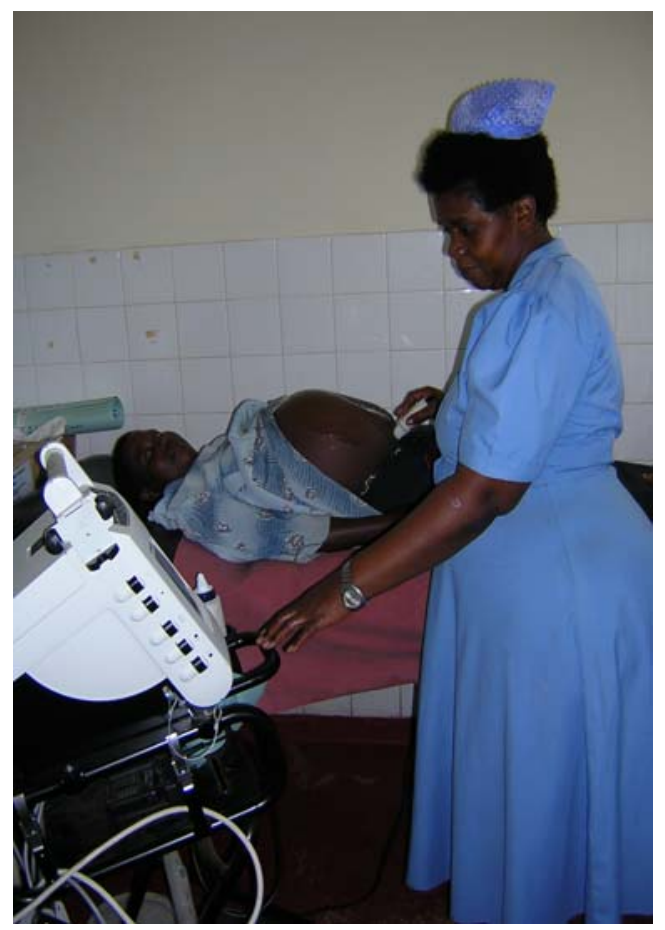

Figure 4.5: Ultrasound examination Sengerema District Hospital performed by the nurse-midwifeultrasonographer in her office at the labor ward. The photograph also shows the less sophisticated SD 100 the Tanzanian government chose for District Hospitals (photo taken by author with permission of those photographed).

Bugando Teaching Hospital occupied a middle position between the rigid preparation at Korle Bu Teaching Hospital and the flexible preparation at Sengerema District Hospital. Similarly to Korle Bu, ultrasound machines at Bugando Teaching Hospital were fixed in one place. Other than at Korle $\mathrm{Bu}$, however, ultrasonographers sat on stools or chairs on wheels which gave them mobility to move up and down along the stretcher (Figure 4.6). Furthermore, after every examination, the ultrasonographers would leave the examination space and move into the more public part of the room in order to write their reports. While the rigidity of preparation at Korle $\mathrm{Bu}$ was an effect of the positioning of all health care professionals inside the room, Bugando Teaching Hospital solved the coordination between the waiting room area and the ultrasound room by means of a messenger. A male nurse, James Tukuyu checked whether patients had paid the required 3000 Shillings for a normal and 5000 Shillings for a private ultrasound to the $\mathrm{x}$-ray accountant, explained the upcoming procedure, called in patients according to the order set by the ultrasonographers, guided and helped them onto the stretcher, covered them and 
announced their 'readiness'. His preparatory work for each ultrasound day began in the afternoon of the day before with boiling tap water and filling bottles for women in early pregnancy such as Paulina Mkumbi, for example, or with placenta previa such as in cases like that of Celina Kondo.

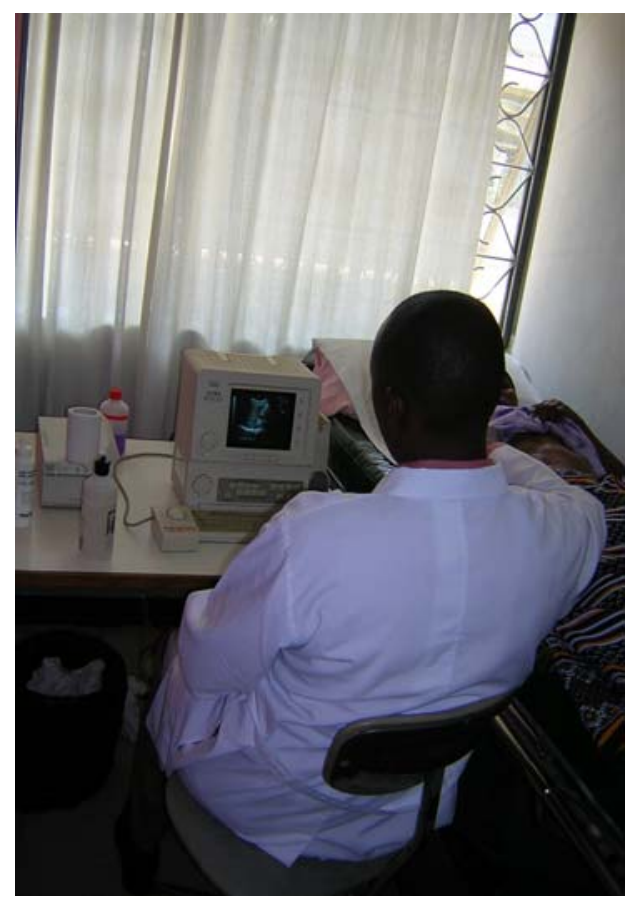

Figure 4.6: Ultrasound examination at Bugando Teaching Hospital performed by one of the radiographer-ultrasonographers. The ultrasound machine presented is the portable Aloka machine that is also referred to in the text. Notice the mobile chair on wheels (photo taken by author with permission of the photographed)

Preparing a pregnancy for ultrasound in the ultrasound room, in sum, consists of interlinking the main actors in making diagnostic images: the operator, the machine, the patient and the stretcher. The rigidity or flexibility of these emerging socio-technical configurations thereby were as much geared to an efficient use of time as they were necessary for generating accurate time of pregnancy, as the following sub-section will show.

\section{Scanning}

The second practice in making diagnostic images is scanning. Scanning comprises observing and measuring bodily insides. Observation begins with the touch down of the transducer onto the skin and its vertical and horizontal movements across the belly. Emitting and receiving ultrasound waves reflected by body tissue and organs, a transducer generates a 
continuous flow of images that are displayed in real time on screen. According to different density of body tissues that influences the speed of deflection and reception of echoes by the transducer, bodily insides are depicted in different scales of gray. Similarly to x-ray, ultrasound thereby has no respect for surfaces but works to "reconstruct a two-dimensional map of all the tissues that have been in the beams" (Palmer, 1995, p.3). In consequence, liquids such as amniotic fluid or urine that do not deflect ultrasound waves appear black. Due to their 'softness', organs appear gray. Bones, like the fetal skull, ribs, legs and arms that reflect the high frequency waves of ultrasound completely are displayed in white. Tabitha Juma's "bellyache" (Gh 12) by scan thus turned into a "a white dot in a black hole", a sign of early pregnancy, as Dr. Gray at Nalerigu Baptist Mission told her in English (Gh 10).

Whereas observation practices serve to display qualitative aspects of certain body parts, measurement adds quantitative aspects. As a function of the software program of ultrasound, in principle any part of the body is measurable. Particular measurements, however, yield results that go beyond the quantification of the length or width of body parts in centimeters. Measuring the biparietal diameter*, femur* length and abdominal circumference of the fetus, for example, yields pregnancy time. This capacity is a standard software function built into contemporary ultrasound machines. It works with fetal growth charts that are based on European and North American fetal measurements of these three body-parameters. Each measurement is assigned a corresponding gestation age in weeks and days. Measuring a new biparietal diameter sets into motion a computerized calculation by which the present head is compared to the heads stored in the software chart, put into sequential order and assigned a corresponding intrauterine lifetime.

Depending on the degree of technical sophistication, ultrasound calculates more than present gestation age. In contrast to SD 100, installed at District Hospitals in Tanzania, the Philips machine that traveled to Ghana and to Regional Hospitals in Tanzania, for example, could also calculate backwards and forwards from the present age, and estimate the last menstrual period and the expected date of delivery. Not all hospitals used all three parameters to generate the time of pregnancy. At Korle Bu Hospital, the two gynecologists swore by triangulation and always measured all three fetal parts, taking their average as the final, 'true' gestation age. At Bugando Hospital, the radiographer-ultrasonographers also measured all three body parts. Yet instead of relying on software calculation, they turned to printed fetal growth charts, one of which combined BPD and AC (the so-called Hadlock 
chart), the other FL and AC (the so-called Shepard chart) and thus reported two emerging times and fetal weights linked to these measurements. ${ }^{84}$ Halifa Salama, one of the ultrasonographers explained her turn to written charts with the breakdown of the calendar function of her favorite ultrasound machine, a portable Aloka. Due to the millennium passage, this calendar had been disrupted, which disabled calculation. While she found manually looking up corresponding gestation age a bit tedious, she said, she actually did not mind having lost the Expected Date of Delivery and Last Menstrual Period function due to this lack of calibration:

What is the point? Most children are not born at the calculated EDD anyway. And why restore a last menstrual period that maybe never has taken place at all? ( $\mathrm{Tz}$ 8a)

At Sengerema District and at Sekotoure Regional Hospital in Tanzania, in contrast, the ultrasonographers only measured the biparietal diameter routinely. All of them explained that with the two weeks of training they had received from Philips, they felt safest with head measurements as the fetal head was more readily recognizable than the abdomen and less mobile than the leg.

The limitation of measurements to particular body parts was not only an effect of the ultrasound software that made some measurements more valuable than others, but also a necessity given the number of ultrasound patients and the schedule of operators and ultrasound. This time pressure was most apparent in Korle Bu. As the original teaching device had taken over the role of a routine diagnostic tool for any pregnant woman booking with the facility and in addition served the high risk emergency cases of whole Accra, time for each patient was scarce. Referring to the origin of the ultrasound machine, Dr. Tennison, one of the gynecologist-ultrasonographers, once exclaimed that in Ghana they had only six minutes in total for a pregnant woman from her entering to her leaving the room. In the Netherlands, in contrast, time to play with ultrasound was abundant, he said:

In the Netherlands, you see, they use 45 minutes for each woman. 45 minutes! They can look at everything. They can play around, use different functions, follow up research questions. But they have only ten women, and we have plenty. You have a request - that is what you are looking for. (Gh 7)

\footnotetext{
${ }^{84}$ Both charts rest on birth-weight of premature babies and miscarriages, not on actual fetal parameters.
} 
Given this time pressure, it required special occasions to justify taking more time for each patient than those six minutes. One of these occasions had been the arrival of the new Philips machine as a teaching device for fellow doctors in the countryside and for the hospital's own medical students. Entrusted with the responsibility of teaching quality, Dr. Battir and Dr. Tennison carefully checked whether the new machine matched the standards of the old but more sophisticated Siemens device. In order to study the quality of the Philips ultrasound, the two gynecologists conducted a study of one of the serious obstetric risk factors, placenta previa. For the time of this study, every woman referred to Korle Bu got a scan. Close to delivery, the women who had been diagnosed with either a low lying placenta or a placenta previa were c-sectioned in order to "check whether the ultrasound had spoken the truth, whether it [the placenta, BMR] was really low lying or whether it covered the os*, or only parts of it" (Gh 6b). Checking eyesight against the previous 'ultra-sight', both doctors wanted to find out whether the ultrasound specifications in defining a placenta as low lying or as really blocking the delivery passage could be relied upon for the decision to follow up with a c-section or to proceed with a vaginal delivery. The results of this study were never published: by the time the two operators had reached the conclusion that the Philips machine was working as well as its 'German counterpart', there were so many women with regular requests to attend to, that they did not find the time to summarize the data, Dr. Battir explained. However, this study gave him and Dr. Tennison the certainty to diagnose a woman such as Mercy Prempeh with 'placenta previa partialis'. Moreover, by introducing a scan to all women attending the clinic during this research, the study served to prove the operators' capacity to perform booking scans for their fellow clinical colleagues.

Observation, the first scanning practice, includes a systematic search in order to get all inside structures 'in the picture'. Obtaining this overall picture is achieved by imagining the belly to be dissected into four quadrants. Measurement, in contrast, requires operators to be fast. The prerequisite for entering the measuring mode is to freeze that picture on screen that appears to be a "good shot", as William Chanji (Tz 9) at Bugando remarked, or a "nice picture" as Stella Ndogo (Tz 21c) at Sengerema Hospital put it: a picture that promises to provide the most accurate measurements. In contrast to abdominal or pelvic ultrasound, obstetric ultrasound thereby faces the difficulty that the main objects of interest, the fetus, constantly moves, bends its head, turns around, flexes its legs and even vanishes from sight every so often. In order to freeze the best picture, the particular configuration of pregnant 
woman, professionals and the material entities that I described above all play a crucial role. The rigidity of the whole socio-technical arrangement at Korle Bu enabled the operator to extend his right hand with the transducer to the belly while simultaneously having his left hand rest on the keyboard. At Sengerema District Hospital, in turn, the mobility of the ultrasound machine and operator echoed the flexible positioning of the woman on the stretcher and vice versa. While the ultrasound machines stood next to the head of the woman during observation, the ultrasonographer Stella Ndogo who remained standing next to the belly had to pull the device downwards when starting measurement procedures because the SD 100 had the freezing key inbuilt into the monitor. Due to the particular socio-technical configuration, observation and measurement at Sekotoure Regional Hospital and the District Hospitals in Ghana and Tanzania were organized in successive phases. In Teaching Hospitals, instead, they were alternating practices of observing, freezing, defreezing, observing and freezing again. At Sekotoure Hospital I witnessed a rather peculiar solution to the problem of having to move slowly in order to be able to catch a good picture and having to fast-freeze it at the moment it came into sight. Observation and measurement had been distributed to two different ultrasound machines. These machines stood perpendicular to each other, enclosing the operator's chair (Figure 4.7).

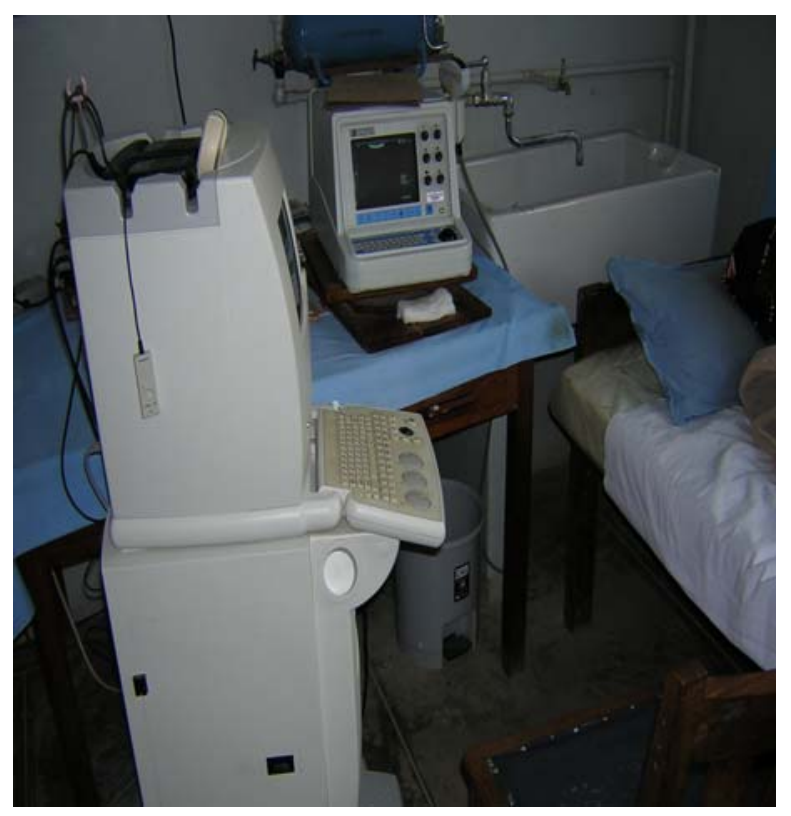

Figure 4.7: A photo of the socio-technical configuration at Sekotoure Regional Hospital. To the left is the Philips machine SD 240, in front of the operator the old American donated ultrasound machine (photo taken by the author) 
With the Philips machine standing to the left of the chair only observation was done.

Providing pictures of greater clarity, the Philips machine allowed him to see "things as they were", as the radiographer explained ( $\mathrm{Tz}$ 13). Subsequently he would then turn to the American donated machine fixed right in front of him, look for the head again, whose contours were indeed considerable less well distinguishable from its surroundings than they were at the Philips' machine - freeze it and measure it. In reply to my question as to why the hospital did not just rely on the new machine, he explained that the American device gave better measurements with regard to patients' anatomy. Pressed on how he knew this, he said the maternity ward had confirmed better alignment to actual delivery dates when women were measured with the American device.

Scanning, hence, is inextricably linked with and dependent on preparation. Making diagnostic images, that is 'good pictures' from which diagnoses can be derived, is based on the connection of local conditions (room size, equipment, assistants) with the particular outfit of an ultrasound device. In this context, ultrasonographers stressed the importance of scanning within the technology's 'window of accuracy', a time between the $18^{\text {th }}$ and $22^{\text {nd }}$ week of gestation during which the fetus could be displayed as a whole. The process of scanning, however, actually intertwines two different kinds of objects: while observation identifies African anatomy, measurement frames this anatomy according to North American and European standards. The 'good picture', hence, is quite a hybrid entity.

\section{Contrasting}

The third practice in making diagnostic images consists of contrasting the real-time images with other pictures. ${ }^{85}$ Other than the acts of preparing and scanning, which take place successively, contrasting happens simultaneously to scanning. Ultrasonographers mentioned four kinds of pictures that served them for orientating them to where they were and for determining what they saw.

All ultrasonographers used easily recognizable anatomical features on the outside of a woman to gain a grip on the anatomy underneath. With the start of the scanning procedure, the transducer was put on the belly button of a woman, and then moved downwards in the direction of the pubic bone. This move already provided vital information that guided an ultrasonographer's further action. An early pregnancy thereby showed as 'a white spot in

\footnotetext{
85 In her analysis of early x-ray, sociologist Bernike Pasveer describes a similar series of procedures (Pasveer, 1992).
} 
black hole', as for example in the case of Tabitha Juma (see previous section). In case of a suspected pregnancy but an empty uterus, the following moves went to the right and left to scan the tubes and the abdomen for a possible extra-uterine pregnancy. At a later stage in pregnancy, this first move downwards, in turn, displayed the fetal heart, and thus established fetal viability. If this move failed to display the characteristic 'pumping' action by which viability was asserted, scanning stopped here as measurements were considered a waste of time. In some cases, other structures had to be taken into account in order to verify fetal death. In the case of Janice Mtutu at Sengerema Hospital, for example, the first ultrasound had confirmed the suspicion of fetal death. As Janice Mtutu claimed to still feel movement of a child, the ultrasonographer Stella Ndogo started the second scan at a different place. Instead of moving from the belly button downwards, she placed the transducer immediately above the pubic bone where she had seen the fetal head during the first ultrasound examination. This placement displayed the characteristic staircase-pattern of a collapsing fetal skull once maceration had set in and thus reconfirmed the previous diagnosis.

Moving the transducer from the belly button downwards, the wrist of the ultrasonographer's hand holding the transducer meets with the pubic bone. Touching the pubic bone means that the structure simultaneously displayed at the screen is the urinary bladder. When filled, the urinary bladder can easily be distinguished from its surrounding organs because it appears as a black hole. Unfilled and thereby dissolving into its equally grayish surroundings, corresponding outside-inside anatomy then becomes the only way to 'see' the bladder. Moving the transducer upwards in the direction of the belly button again, the virtual 'cutting' through skin and flesh thereby displays organs in the anatomical sequence of the atlas similar to a dissection: the vagina, the cervix, and the uterus (see Hirschauer, 1991). Building the body bottom-up is crucial. Deviating from this route may result in mis-takes of what is and where it is. Both ultrasonographers and (angry) clinicians repeatedly told stories of pregnancies shown to be intrauterine by ultrasound that turned out to be extra-uterine upon operation. The ultrasonographer Halifa Salama at Bugando Hospital, for example, explained:

If you don't go by the bladder, cervix, uterus but you just start somewhere down, you may see a child and of course you think it is in the uterus. But if it is an abdominal pregnancy, sometimes it pushes the uterus away, that is, out of sight unless you really follow a woman's physiology. (Tz 8c) 
The sequence of movements establishes both physiological and pathological pregnant anatomy: both the intrauterine order of head-abdomen-leg-placenta, or of buttocks-abdomen-head-placenta is physiological but the latter is imbued with a higher risk at delivery; the visual sequence of no immediate fetal part-fetal abdomen-no fetal part displays a transverse lie, and constitutes a high risk for pregnancy and delivery; or ultrasound displays placenta-head-abdomen-leg as in the case of Mercy Prempeh at Korle Bu and Celina Kondo at Bugando Hospital - a topology that because of blockage of the birth canal implies a caesarean rather than a vaginal delivery.

Contrasting is difficult as fetuses constantly change in location and size. Instead of one fixed image, obstetric scanning requires operators to have a sequence of pictures in mind with which to assess pregnancy and fetal development. Equipped with this basic obstetric knowledge, nurse-midwives and doctors merely have to transform their anatomical into a 'sonographic' gaze. Used to the visual language of x-ray, radiographers, in contrast, often lack specific obstetric knowledge and have to acquire it. In some cases this lack led to rather surprising statements such as the comment of Mr. Olole at Sekotoure Regional Hospitals who was trained within the Philips Project. Asked why he did not measure the head of both children in a twin pregnancy -given the possibility (and risk) of different growth - he simple replied: "Twins, you know, twins are alike. That is what is meant by twins - they are the same" (Tz 13). Taking fetal development into account, Halifa Salama and William Chanji, two of the ultrasonographers at Bugando Teaching Hospital, sometimes rejected ultrasound requests on account of 'insufficient history'. This insufficiency pertained not only to the lack of sufficient information about the patient. The case of Elimika Pande rather illustrated that 'insufficient history' pertained quite literally to the lack of time in between two successive ultrasound examinations. Because every scan had a margin of correctness, a series of scans only showed significant differences when spread over a sufficient period of time. While the intern doctor had requested another scan three days after the previous one, in the eyes of Halifa Salama this request was non-science:

Of course you have a margin of measurement. That is you aim at making the best picture possible, a really nice picture, and then you set the cubicle cross and measure, the BPD, for example, from the inner outside of one parietal bone to the outer outside of the other; Or fetal length, from one end of the bone to the other. But you may just set the cross again a little too far and have thus produced another week [gestation age, BMR]. So if you send the woman to 
ultrasound within two days you don't know whether a gain is a gain or whether it is nothing but mis-measurement, within the normal range, I mean. (Tz 8c)

In addition to comparing outside-inside structures, ultrasonographers contrasted the pictures on screen with ultrasound pictures in textbooks. When I first met Stella Ndogo at Sengerema in August 2003, she had started doing ultrasound examinations three months earlier after the Dutch teaching course. At that time, she often turned to the manual given to her in the course and compared the images frozen on screen with the printed images in the book. When I came back in 2004 she did not need the manual anymore, she told me, as she had now memorized the manual's pictures.

A third way of identifying a seen structure was by using ponies. Certain bodystructures thereby were compared by appearance, shape or texture to common entities from daily life. "In the UK, they taught us that the abdomen looked like a teddy bear", Dr. Battir (Gh 8b) at Korle Bu remembered, laughed and added that he had to translate this particular pony into one more apt for his Ghanaian medical students. Placentas, he explained, looked like "cotton-wool", the fetal abdomen could be recognized by the two "bean-like" structures that represented the kidneys, and "a good picture of the fetal skull" showed the head divided by a whitish line that looked "like an arrow" (ibid.). These ponies helped in the recognition of structures that were vital in identifying fetal body-parts and measuring them correctly. Seeing 'the arrow' inside the fetal skull, for example, meant that the fetal head was now in the right plane to take the biparietal diameter as a perpendicular measurement through that arrow. Not seeing the arrow meant that the measurement taken was likely to be another than the biparietal diameter. Designating it to be the BPD hence meant the derivation of an incorrect gestation age.

In the beginning of their careers, ultrasonographers told me, they relied on the pictures in their textbooks and lay images of anatomical structures. Over time each of them, however, had developed her or his own 'archive' of images stored in their memory. It was this 'brain-map' against which they held present pictures during scanning. As this archive was rooted in the scanning experience of an individual ultrasonographer, this fourth way of contrasting was therefore unique. What they stored, ultrasonographers said, however were not only pictures as such but also knowledge of the way they had been made: the tacit knowledge of a slight tilt of the transducer that had generated a particular insight. Drawing on this self-made archive of past examinations, ultrasonographers might repeat this tilt in 
order to get a 'good image' or to find out about a particular problem. The majority of the ultrasonographers 'fine-tuned' their archive by following the history of certain patients, cases that they had found interesting, for example, or where they had not been entirely sure, or where a particular tilting had provided them with their diagnosis.

With years of experience, ultrasonographers thus had more images in mind with which they could contrast the pictures of a new patient. New ultrasonographers instead had to rely on already existing pictures made by others. Independent from the stage in their career, however, all ultrasonographers relied on the universal anatomical correspondence of outside and inside body structures as a contrast for orientation.

\section{Editing}

The fourth practice performed in the ultrasound room is editing. Editing entangles operators, machines, pictures and patients and simultaneously disentangles their tight arrangement in order for patients and pictures to become mobile again. It is a practice that may happen throughout scanning but is most prominent at preparation and after scanning. Editing is a writing practice. At the Teaching Hospitals, it started at preparation with writing a woman's name and age, and at Korle Bu also the operator's name on the screen. Only at Bugando, did editing take place during scanning. The ultrasonographer William Chanji, in particular, frequently used the ultrasound keyboard to designate anatomic identity to certain structures on the screen: 'Placenta' or 'head', for example, were the labels written next to their corresponding structures in order to present Celina Kondo as a case of placenta previa despite the misleading clinical symptoms of mere spotted bleeding. Labels for frozen pictures on screen, these designations, when printed out later, served as a proof for the findings reported. In contrast, Dr. Battir and Dr. Tennison at Korle Bu Hospital in Ghana labeled the print-outs with handwriting. Using the keyboard function took "too much time", Dr. Battir explained (Gh 6a). In his explanation as to why this rather crude designation of apparent heads and legs was necessary at all, he referred to the (perceived) knowledge-gap concerning ultrasound between him and Dr. Tennison and their fellow gynecology colleagues at the clinic:

See, they don't know about ultrasound yet. And if you write cephalic, they want to have a proof. But if you give them a print with a circle, they may say: 'what is that?' So you just write down 'head' to show them. (Gh 6a) 
Editing, thus, on the one hand served to match and store certain pictures with particular women and to restore the credibility of these images. On the other hand, it pertained to the writing of reports. In reporting their findings, ultrasonographers 'taught Dutch' referred to the methodical approach. The request for "dates?" in the case of Happiness Malolo at Makongoro Antenatal Clinic, for example, thereby turned into a standard sequence that reported fetal position, viability, lie, placenta location and pregnancy time. In her case this methodical report, for example, read "intrauterine pregnancy, alive, breech, placenta anterior, not previa, GA 32/40, LMP 14.03.03, EDD 21.06.04.” Ultrasonographers trained elsewhere, such as William Chanji at Bugando Hospital or Samuel Mfundi at Sengerema District Hospital, sometimes would merely answer the request: "fetal viability?", for example, would be answered with "viability positive". At Korle Bu, print-outs were routinely attached to these reports. At Sekotoure Regional Hospital print-outs were routine when I started my fieldwork. Due to budget constraints this routine practice abruptly stopped in the middle of my stay in Tanzania when the hospital board voted against stocking ultrasound paper in favor of x-ray films. At Bugando, only William Chanji routinely attached print-outs to obstetric scans. Halifa Salama, in contrast, made print-outs for obstetric cases only when something extraordinary had to be shown. She had gotten used to rationing expensive printing paper, she told me, when in the 1990s Bugando had suffered from massive shortages of supplies. Furthermore, for most obstetric cases, print-outs could not adequately mirror ultrasonographers' insights anyway:

$[\mathrm{R}]$ eal time cannot be pictured anyway. And so a head is but a head, whether you write it down or have a picture. And where you need to see movement, that is, to be certain of fetal viability, a still picture does provide a clue. (Tz 8c)

Dr. Gray at Nalerigu, in turn, had stopped making print-outs when realizing that his colleagues were not able to interpret them and only read his reports. And in contrast to all other devices, the ultrasound machine at Sengerema Mission Hospital did not have a printer attached. In cases where she wanted to make something that she had seen very clear, the ultrasonographer Stella Ndogo turned to drawing a picture of the pregnancy topography herself. Diagnosed by ultrasound with twins, for example, Evelyn Kijije's particular insides could not be displayed properly with words alone, Stella Ndogo explained: while presently both had their heads downward, the lie of the second twin was almost transverse (see Figure 
4.7). If she wrote 'cephalic' only, her colleagues might not be alerted to the possibility that the second child might turn and lie differently upon the onset of labor:

You see, by ultrasound they are cephalic, this is what they have asked for: fetal lie? But, this second one up there, maybe it will turn around still. The way it is curled now, it is likely it will turn into a breech position. But if I write just cephalic, and she comes in labor and the child has turned, nobody will be prepared. [...] So I draw this first one straight, and the second one curled up there [and] they will get the right idea. (Tz 21a).

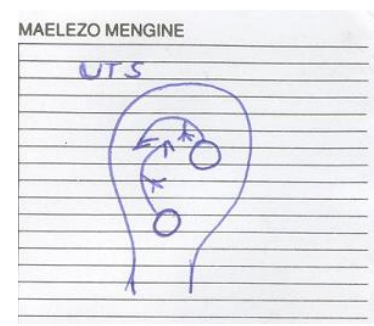

Figure 4.7: Drawing intrauterine topology of a twin pregnancy at the antenatal card. Maelezo mengine is Kiswahili for 'other examination'. The first twin lies cephalic, the second lies cephalic as well but shows tendencies to turn into either a transverse of a breech position (author: Stella Ndogo)

All ultrasonographers stressed that their task was to report what they had seen. In contrast, drawing conclusions about what an observation meant in contrast was the task of the clinical staff. Yet, where a follow-up examination was likely to yield a better picture, it was again the operator's responsibility to recommend another scan at a later point in time. This subtle but decisive difference between sonographic diagnoses in the sense of findings and clinical diagnoses in the sense of conclusions can be illustrated with the case of Paulina Mkumbi. Upon scanning, her uterus showed as empty on the ultrasound monitor whereas her one remaining tube displayed a grayish mass. Consequently, Halifa Salama said, she would and could not report a pregnancy as ultrasound did not show distinguishable fetal parts. Instead she reported her findings with: "Uterus empty, TOM*, maybe hydrosalpinx*" (Tz $8 \mathrm{~b})$. The decision as what this tubal ovarian mass might be was to be taken by the requesting doctor, she added.

The transformation of professionals into ultrasonographers providing a particular kind of service became most apparent in the process of editing. Rather than as doctors or nurse-midwives, ultrasonographers said they regarded themselves as 'technicians'. Dr. Battir, 
for example, referred to this transformation when explaining why he and his colleague never explained anything to ultrasound patients:

You see, we are just technicians. We don't know the woman, we don't know the history: does she want this child, does she not want it. So, of course we have to make sure that the woman getting an ultrasound is the same to the one on the card, but if we explained anything to her, we would be not doing our job. In fact we would be trespassing professional ethics [...] because telling the diagnosis is the doctor's job. (Gh $6 \mathrm{~b}$ )

This new position went along with a particular 'etiquette' of touch. For many ultrasonographers this etiquette included refraining from touching or talking to patients considered to be classical clinical tasks. The two gynecologist-ultrasonographers at Korle Bu, for example, never palpated a woman who was lying on the stretcher but simply performed the scan. In contrast, at Sengerema Hospital, Stella Ndogo continued to palpate a woman and often detected a cephalic lie or twins before scanning. When I asked her why she was still performing a scan although she was certain about the diagnosis, she stressed her position as somebody who was expected to answer her colleagues' request by using ultrasound alone. Mirroring Dr. Battir's explanation, she added that she did not know the whole story behind this request after all. Radiographers, in turn, told me that according to international ethical guidelines they were forbidden to tell a diagnosis to patients, since they were only paramedical staff. By all, this limitation was seen as a regulation for the protection of patients. This transformation into 'mere technicians' required the ultrasonographers at Bugando Teaching Hospital to have a nurse present at the examinations. Similar to Stella Ndogo, they said that their position as contributors to clinical diagnosis prohibited them from questioning clinical requests. The cases where Bugando ultrasonographers did send a request back on account of 'insufficient history' were those where they saw the quality and validity of the images as being hampered by clinical decisions, for example when the time span between two examinations was too short. To me, however, gynecologist- or nursemidwife operators frequently complained about the nonsense of such requests although I never saw them sending somebody back to the requesting agent.

Editing, hence, established the links necessary to make images represent bodies and to turn bodies into referents for these representations. It thereby aimed at generating the credibility of both ultrasound practices and of those in charge of them. Transferring real- 
time ages to the clinic is a process of writing things down. The transfer of information to women, however, is silenced on account of valuing patient-friendliness.

\section{Sound representations}

Sound representations of what lies beneath the skin are the effect of "intra-action" of a disciplined observational apparatus that makes the objects generated in this process inseparable from the agencies of observation (Barad, 1998, p.94). This apparatus consists of transducers, screens, operators, request forms, hands, minds, fixed or flexible chair, textbooks, ponies, aesthetic and scientific conventions and disciplinary ethics. What was considered to be scientifically sound differed between types of hospitals: while District Hospitals relied on one measurement only, basing gestation age on the result of the actually measured parameter, sound representations for Teaching Hospitals were based on the measurements of three parameters establishing pregnancy time as an average. For all hospitals, however, sound representations are the effect of a particular sequence of scanning practices. Observation following the so-called 'image tradition' establishes soundness as a matter or years of professional experience to think with eyes and hands; measurement, following the 'logic tradition' establishes soundness based on a list of fetal statistics. ${ }^{86}$ Ultrasound in Ghana and Tanzania thereby comes to share one transformation of the female body with 'the North' - the transformation of quality (morphology) into quantity (numbers). The other transformation is particular to Africa, however: while observed morphology is black, the numbers are 'white'. How do these transformations feed into care trajectories?

\section{Composing care trajectories}

After the images, women and reports travel back to the 'clinic', to antenatal departments or to maternity wards. Sometimes they travel together, when women themselves carry their representations, reports and print-outs back to those who requested the examination, for example at Korle Bu Teaching Hospital or at the District Hospitals in Ghana and Tanzania. At Bugando Teaching Hospital, only outpatients were allowed to carry their reports themselves, yet these were enclosed in a sealed envelope; reports of inpatients in contrast were delivered to the wards by nurse-aides. Back at the clinic, reports and pictures meet with

\footnotetext{
86 This distinction between the two representational traditions, the image and the logic tradition, stems from the sociologist Peter Galison. According to him, the image tradition relies on the preservation of form, while the logic tradition abstracts from the present form to rely on statistical arguments (Galison, 1997).
} 
clinical findings, with lab results, palpation outcomes, and obstetric histories that have to be drawn together in order to compose a suitable care trajectory. Based on my observations, three modes of composition can be distinguished: acceleration, dys-rhythmia, and sequence.

\section{Acceleration}

The ultrasound confirmation of an overdue pregnancy in the case of Venicia Machame at Bugando Teaching Hospital led to her admission, immediate referral to the labor ward, induction of labor and her delivery on the very same day. Ultrasound intervened in pregnancy time - it accelerated the termination of a pregnancy that was overdue instead of continuing to wait for nature to take its course. According to the nature of Makongoro Antenatal Clinic in providing outpatient services only, ultrasound did not directly intervene in pregnancy-time there in the sense of bringing about a faster delivery. Ultrasound's intervention rather resulted in anticipating the delivery in the sense of enabling timely preparation of the things needed for a hospital delivery. With the ultrasound provided knowledge of the Expected Date of Delivery, nurse-midwives advised women to get prepared two months prior to that date, that is, to have soap, children's clothes, women's pads and money ready for upcoming fees at the hospital and to inform their husbands, inlaws, and in Tanzania also the balozi of this date in order for them to arrange means of transportation ahead of the onset of labor. In case women lived further away, such as Happiness Malolo who lived across the lake, nurse-midwives advised women to move to town early enough in order to be independent from ferry schedules. Ultrasound here intervened in distance - it accelerated pregnancy cognitively with regard to its inevitable end and physically by decreasing spatial distances between homes and hospitals. In their pursuit of proper preparation of women for delivery, nurse-midwives at Makongoro Antenatal Clinic thereby stressed the particular risks, a 'big baby' or 'twins', brought forward in the ultrasound examination. This diagnosis was used to mediate between the legal regulations issued by a 'modern' nation state and the perceived backward traditions of many of its people:

We always tell them to give birth at the hospital because that is the new regulation: women should give birth at the hospital. But a lot of our women don't want to go there; they prefer giving birth at home. So we tell those with risk, like twins, they really have to go to the hospital because twins can cause you many problems at delivery. [...] We tell the same if woman turn out to just have a big 
baby, but we don't emphasize. If it is not the first, a singleton can

be born at home nicely. [...] If we stress the two [in the same way], then women won't believe that we understand their life. So we stress twins and stress less 'big babies to go to the hospital'. (Tz 15)

Ultrasound also intervenes in care trajectories by passing women on to places that are characterized by faster rhythms of surveillance and care. At Sengerema District Hospital, for example, ultrasound often resulted in the referral of women to the Waiting Home, called Mama Ngojea. This Kiswahili term encloses the particularities of the place and the women inhabiting it: all women are expecting and expectant - waiting to give birth. The Waiting Home is an institution in-between homes and the hospital. Women admitted to the Waiting Home continue with their household tasks (washing, cooking, cleaning) - yet with more 'free time' as women laughingly admitted - whereas these chores are taken over by relatives in the case of hospital admission. Similarly to a hospital, the Waiting Home at Sengerema provided 24-hour presence of a skilled health care professional. The retired nurse-midwife running the Waiting Home could be awakened at night to provide a first diagnosis of the condition at stake, and if necessary to accompany women to the hospital across the street. She also offered antenatal services twice a week and health care education every other day. For women such as Evelyn Kijije, diagnosed by ultrasound as carrying twins, the Waiting Home served acceleration in the two ways described above: it significantly shortened the journey she otherwise would have had to travel at the onset of labor, about three and a half hour by dalladalla* once arriving at the road, and about an hour walking or 30 minutes riding by bike in order to get to the road in the first place; and it subjected her as a 'risk pregnancy' to more frequent assessment patterns allowing a faster intervention in case of emerging complications.

Acceleration was most evident when women were admitted to the hospital in the case of emergencies, such as Mercy Prempeh at Korle Bu or Celina Kondo at Bugando Teaching Hospital on account of 'placenta previa'. Instead of attending antenatal care services once per calendar month or according to the FANC scheme at fixed gestation times, admission to the hospital subjected them to palpation twice a day, to laboratory tests once a week, to checking of their pads for blood loss every night, and to discussion every morning on the ward round of the interns and registrar and, once a week, to observation and assessment by the specialist during 'the big ward round'. 
This acceleration in institutional surveillance patterns led to what health care professionals referred to as 'buying time'. This time was not empty but was filled with activities geared to extend the duration of pregnancy as long as possible in order not to have to deal with a premature child, and keep it short enough to not endanger a mother's life at the same time. Among these activities, for example, were the application of surfactant*, a drug to mature fetal lungs in order to improve chances of survival in case a premature delivery was necessary nevertheless; or to get relatives to donate blood and have that blood tested for HIV before handing it over to the stock of blood at the hospitals' Blood Bank.

Of course, Dr Pumusi at Bugando Teaching Hospital explained, they had also dealt with cases of placenta previa without ultrasound before. In case of suspicion they had sent women for x-ray. Yet as x-ray only showed bones but no soft tissue, the presence of a placenta blocking the delivery passage remained a matter of probability deduced from the height of the fetal skull in relation to the mother's pelvic bones. ${ }^{87}$ When labor and dilatation would start, those women would be brought to the theatre, anesthetized and examined by speculum. If eyesight falsified the initial diagnosis, a woman would be woken up to deliver vaginally. If a speculum examination verified a placenta previa in situ, a c-section would be done. Since the manipulation of a placenta previa by the insertion of a speculum often led to severe bleeding, the c-section performed in such cases had to be done in haste. In contrast, ultrasound diagnosis of the condition prior to the onset of labor now enabled them to schedule a delivery date around the $36^{\text {th }}$ week, at which a child was old enough to survive outside the womb and labor would be unlikely to have started already, at daytime when sufficient theatre staff would be present. Scheduling this c-section on the operation plan in advance also allowed anesthesia to clear potential risk factors by a physical assessment the night before, as the chief anesthetist explained when I followed him for his assessment of Celina Kondo:

Of course, if a woman bleeds heavily and you don't know what it is, you just anesthetize her quickly, and open her up.[...] But if you don't know anything about the mother, her weight, allergies, maybe obstructions of neck or airways, you just do guess-work. You always have anesthetic risk, but pregnant women, for example, never have an empty stomach which increases the risk. Actually not only the bleeding will endanger the woman, but you do as well and ${ }^{87}$ A placenta previa that blocks the cervical canal often leads to the fetal head staying high in the pelvis instead of
descending down into the pelvis which would be the normal case towards the end of pregnancy. 
you may cause a mother to die while your task is to save her life.

$[\ldots]$ But with ultrasound you can put things nicely: instead of taking the child out quick and dirty, you can prepare, you can assess the mother and you can do a spinal instead of general anesthesia. This is how you ensure child health and increase safety. That is what ultrasound does - performing a more beautiful operation for all, $[\ldots]$ when everybody can perform at his best. (Tz 5)

While at the other hospitals acceleration pertained to the current pregnancy, at Sengerema Hospital this was not the only case for a successful ultrasound intervention. According to the ultrasonographer and matron of the labor ward, Stella Ndogo, it was rather the routine after-birth scan that had led to a significant decline of maternal mortality and morbidity due to the diagnosis of retained placenta products prior to discharge. Since the introduction of the Philips machine at the labor ward, she said, the hospital had hardly seen any women returning with uterine infections, or worse, puerperal sepsis due to left-over tissue. With regard to this achievement, Stella Ndogo repeatedly expressed her surprise that the Dutch teacher at the Philips course had never mentioned this capacity of ultrasound but told her to focus on getting a "clear head" (Tz 21c), when she mentioned the issue at the course.

One possible intervention of ultrasound into care trajectories, hence, is acceleration. This acceleration may be brought about by shortening the distance of travel to health care facilities as well as by passing pregnant women on to places where rhythms of surveillance are faster. As accelerating technology, ultrasound buys time that is filled with activities intended to prolong the life expectancy of mothers and children. At Bugando Teaching Hospital Celina Kondo is but one exemplary case for the success of such acceleration that I witnessed in Ghana and Tanzania. From a high risk case, ultrasound's clear-cut diagnosis of 'placenta previa' turned her pregnancy into an ordered, manageable sequence of affairs that, by keeping her close, by bed rest and surveying the emergence of potentially life threatening bleeding episodes, resulted in the delivery of a healthy boy close to term.

\section{Divertimento}

In music, divertimentos are compositions that consist of several sequential pieces, their main characteristic being the interplay of seemingly different parts that together form a whole, e.g. a dance interval in operas. I use this term here for a second interventionist mode of ultrasound into hospital worlds. Whereas ultrasound in the first mode that I described above 
seems to smoothly feed into clinical rhythms, in this second mode its appearance seems rather odd at first sight.

The case of Elimika Pande at Bugando Teaching Hospital in Tanzania may serve as illustration of ultrasound as divertimento. Her case was repeatedly discussed at the morning ward rounds following her admission on account of pregnancy induced high blood pressure and suspected intrauterine fetal growth retardation. The first ultrasound made at admission and a second ultrasound a couple of weeks later, after treatment with bed rest and antihypertensive drugs, had both confirmed that suspicion. The third ultrasound for fetal weight, performed two days after the second, reported this weight as $1500 \mathrm{~g}$, according to the Hadlock chart, and as $1800 \mathrm{~g}$, according to the fetal growth chart by Shepard. This weight equaled a gestation age of 30 weeks while according to the last menstrual period the child was already 36 weeks old. The dilemma for the doctors consisted of the following questions: should the pregnancy be continued, risking the life of both mother and child? Or should the pregnancy be terminated, saving the mother's but risking the child's life due to underweight and the facility's infrastructure that could not guarantee a high chance of survival of a child below two kilograms. While the interns tended to continue the pregnancy, the registrar Dr. Ratibia expressed his disbelief at the weight provided by ultrasound. Bending over Elimika Pande, he palpated her again, and then summoned the matron of the labor ward to do the same. "It is two kilos", she said upon which he agreed: "Two kilos, put her on the operation schedule for tomorrow" ( $\mathrm{Tz}$ 3). Explaining his decision to me later on, Dr. Ratibia pointed to the fact that a gestation age of 36 weeks meant that the fetal lungs were sufficiently mature for extra-uterine survival despite a low birth-weight. He also pointed to the value of this baby to the woman, stressing her age and particular obstetric history: "See this woman, she is thirty years old, all children are dead. If this baby is alive, we will have made her a woman!" (ibid.) Furthermore, he pointed to the value of ultrasound. While ultrasound measurements were good to monitor growth progress, its measurements could not be taken at absolute face value, he said since ultrasound only measured body parts. Palpating, in contrast, meant one really had "the whole baby in one's hands" (Tz 3).

Similar to Dr. Ratibia's reasoning to c-section Elimika Pande despite the visible counterargument of ultrasound at Bugando Teaching Hospital, the gynecologist Dr. Lema at Korle $\mathrm{Bu}$ Hospital also used ultrasound measurements in sequence with clinical conditions. While his colleague Dr. Battir, one of the ultrasound operators, stressed that tampering with 
ultrasound findings would be to fall-back into "rock science" (Gh 6b), Dr. Lema always added three weeks to any of the gestational ages he received from the ultrasound room. He told me he needed ultrasound to measure gestation age in case the woman could not provide her last menstrual period. These measurements, however, were to be seen in relation to the African context where Ghanaian fetal legs were not equal to the European legs the machine had been designed for. As the Ghanaian leg seemed to be 'misbehaving' with regard to submitting itself to the inbuilt standards, he therefore had to add "the Ghanaian factor" (Gh 3b), as he put it.

In ultrasound's intervention in the form of acceleration the clinical and the ultrasound- body collapse into one single body that is then passed along a linear care trajectory. In the form of a divertimento these bodies do not coincide, yet, other than a first glimpse might suggest, they still hang together. Ultrasound provides a necessary albeit not sufficient component in the legitimate composition of a particular care trajectory. The self evidence, that ultrasound exerts in the first mode, vanishes here. Instead, taken up into the composition are pieces that originate from a world beyond the hospital and biomedical standards, and that pertain to socio-cultural or socio-economic realities. This sequential treatment of ultrasound depends on certain experience, for example in palpation, or on convictions that are not necessarily shared by everybody. Ultrasound hence may pass patients on to different care trajectories: the pregnancy that for one professional reaches the operation theatre 'in time', for another would be a pregnancy that reaches the theatre 'too late'.

\section{Dys-rbythmia}

It is also possible that the clinical and the ultrasound body remain fragmented in the sense that the ultrasound body does not meet with the temporal orders of the clinic. There are different sorts of temporal disorders underlying this non-meeting, and often several orders clash with each other.

Bodily conditions have their own temporal order, for example. Placentas that block the delivery passage may come to rest and stop bleeding when women are ordered to bed rest, as in the case of Celina Kondo described above. Yet this kind of placenta can also return to severe bleeding at any minute and any time of the day, in particular at the onset of labor. In the case of Mercy Prempeh at Korle Bu Teaching Hospital in Ghana who was - 
unlike Celina Kondo at Bugando Teaching Hospital in Tanzania- diagnosed with a placenta that only partially covered the cervical canal, a decision had been taken to attempt vaginal delivery. Especially in the context of Africa where women often had many pregnancies, any surgical intervention had to be carefully balanced against the higher risk it posed for morbidity and mortality in a subsequent pregnancy, as the clinicians told me ${ }^{88}$ In case she started bleeding severely during labor again, a c-section was to be the second choice for delivery. Mercy Prempeh's labor started on a Saturday night. Due to the weekend, the second team of the ward was on duty rather than the team who had previously admitted her. ${ }^{89}$ While she was slowly dilating, her bleeding started to increase as well. At a certain point the intern on duty therefore informed his superior who ordered a blood transfusion to be given prior to the operation. The receptionist of the blood bank, however, refused to hand over the blood. At night, he claimed, he was only entitled to give blood to the team that had admitted the woman as an emergency. As the second team did not dare to do a csection without transfusion, Mercy Prempeh's bleeding continued throughout the night. When her own team took over on Sunday morning, a c-section was finally performed. By that time both mother and child suffered from severe anemia.

The unpredictability of bodily conditions, as the case of Mercy Prempeh demonstrates, clashes with a variety of temporal orders that organize hospital life, for example with clock-time, particular shifts and duty hours. I heard about Mercy Prempeh's case only retrospectively on the Monday after the c-section was performed. In the case of Laurentsia Shitindi at Sengerema District Hospital, in contrast, I was actively involved. Laurentsia had been sent to ultrasound for the diagnosis of 'fetal lie' on a Friday afternoon. As the Philips' ultrasound machine was primarily to be used for cases in the maternity and labor ward, the antenatal ward had referred her to be scanned in the theatre. The theatre ultrasound, however, had lost its measurement function. Since there was no guaranteed repair, other than for the Philips ultrasound, the hospital had not been able to fix it for a couple of weeks. In the case of Laurentsia this loss did not matter, the operator said, since the request only asked for fetal lie. This request had resulted from the inability to establish a

\footnotetext{
88 The scarring of the uterus due to c-section is clinically associated with a reduction of possible implantation, the possibility of uterine tearing in pregnancy and during delivery, a condition that leads to intrauterine fetal death and endangers the life of the mother as well.

89 The maternity block of Korle Bu encompasses five wards. Each ward is covered by two teams consisting of specialists, resident doctors and interns. Due to the rotating shifts of teams at the Outpatient Department, each team (and ward) generates its own patient collective for which it remains responsible throughout their stay.
} 
fundal height due to her touch-sensitive belly at the antenatal ward (see above). When scanning, the baby did look rather small, the operator said, and pointed to the remaining dark shadows surrounding the child: "You see this is just water. It is water only. She is not at term" (Tz 26). While his remarks suggested the condition of a polyhydramnion*, his report only answered the request stating the child's position with "cephalic". Returning from the scan, the antenatal care unit had already closed down. As services would not resume until Monday, I took Laurentsia to the labor ward, concerned about the condition that the ultrasound had diagnosed. Arriving at the labor ward, the nurse on night shift, however, interpreted Laurentsia's pain by basing her diagnosis on the baby's physiological position as reported and on her apparent closeness to being term. Instead of getting a bed at the maternity ward, Laurentsia was to eat something, wait or lie down on the corridor along with the other women waiting in front of the labor ward for their turn. A couple of hours later, and to the surprise of the midwifery student Samuel Giria who attended her, she delivered a premature baby that died soon afterwards. Recalling the incident, he told me later, he had believed her to be 'on term' and had not found any indication on her antenatal record that the situation was otherwise.

The case of Laurentsia Shitindi again shows a clash between the working hours of the antenatal care ward that are based on the clock and those of the theatre that are based on performing (and finishing) certain tasks. While operations were scheduled, the actual time needed was not entirely predictable. Thus when operations took longer, ultrasound examinations were simply postponed. Her case also points to the hierarchical relationship between clinics and diagnostics: while a clinically approved emergency case gets a fast-track ultrasound, an emergency case diagnosed by ultrasound may miss a fast-track connection. This became apparent in another case as well. Supposed to have an 'urgent scan' in the morning after her admission at night, Paulina Mkumbi at Bugando Hospital got an ultrasound at $2.30 \mathrm{pm}$ when she finally reported a full bladder. By the time Paulina's ultrasound report came back to the ward, the intern requesting the ultrasound had already gone, but had left instructions to call him in case the ultrasound showed an ectopic pregnancy. Yet, as the report stated only 'TOM' (tubal ovarian mass), the nurse on duty did not make a call. When at 4pm Paulina Mkumbi showed signs of shock, the registrar was called. After looking at the ultrasound, he immediately ordered an emergency laparatomy* on account of extra-uterine pregnancy. Upon opening the abdomen her one remaining tube 
had already ruptured. Among the interns, this case provoked a fierce discussion about the quality of the diagnoses provided by the radiographers. Listening to their discussion revealed that for the interns the sequence 'positive urinary pregnancy test' and 'empty uterus' automatically turned a pregnancy into an ectopic. Instead of writing 'TOM' and attaching the picture of a "somehow whitish tube", they said that the ultrasonographer should have attached the picture of an empty uterus first and then a picture of the other tube to allow comparison and confirmation of the extra-uterine location. The case of Paulina Mkumbi shows a difference in diagnostic sequence: while the ultrasonographers claimed to provide findings and leave the diagnosis to the clinicians, interns and nurses frequently regarded ultrasound findings already as diagnosis. In the case of Paulina Mkumbi this inability of ultrasound to coincide with the duty times of the doctor resulted in her inability to ever bear children again.

And so ultrasound intervention can also bring about dys-rhythmia, a clash of different rhythms that run (in) a hospital, for example of operative attendance with the duty time of nurse-midwives running antenatal outpatient services, of technically with clinically generated emergencies that do not always coincide, and of clock time with 'time in bodies'. Modern technologies thereby tend to dismiss old-fashioned practices such as biopsies by syringe while they cannot cope with African nights. Ultrasound, hence, may also bring about delays, and these delays can be deadly.

\section{Sound interventions}

Ultrasound intervenes into clinical practice. It helps health care professionals to make decisions about when and where to refer a patient to a facility of higher level or whether to deal with her on the spot, whether and when to refer a pregnant woman to the theatre for a c-section or to the labor room, whether to admit her to the hospital or send her home, whether to conserve a pregnancy or terminate it, and whether to evacuate a woman after birth or to regard the remnants of delivery as 'normal', and assume they will clear up by themselves. In short, ultrasound helps to run a hospital, that is, to pass patients through clinical space. What is a sound intervention thereby differs between professional groups with regard to different temporal frameworks: a sound intervention can be linked to bedeconomy and the turn-over of patients, to present and future careers, or to time in bodies. While patients are being passed on, no matter by whom they are handled, they may also fall 
in-between times, as ultrasound may fail to link with clinical times or may generate facts that require a faster pace than that envisioned earlier by the clinic. Rather than being inherent to the technology and thus evolving automatically with the installation of the artifact, speed is an achievement. A smooth trajectory involving ultrasound thus is the effect of aligning diverse temporalities.

\section{Time matters}

Following ultrasound to various health care facilities in Ghana and Tanzania in pursuit of the hospital apparatus, I have illustrated how time matters in and for technography. Ultrasound shapes time very obviously: unlike other diagnostic technologies that primarily provide information about sounds, samples, or structures of the body, ultrasound makes pregnancytime by generating present gestation age, past menstrual periods and future dates of delivery. Yet, as shown, ultrasound is also shaped by pregnancy time: the later a pregnancy meets with ultrasound, the less accurate the measurements become. Among the temporal orders shaped and shaping ultrasound, however, pregnancy-time is only one among many: there are also duty hours, schedules, day-and night-shifts, professional careers (a sequence of steps), generational time, certain time preferences, task-time, clock-time, history (in form of 'stone age' and modern obstetrics), and to some extent also seasonal time ${ }^{90}$ and with reference to previous chapters we could add warranty time, maintenance schedules, and technological life-time to this list of temporal orders affecting and affected by technology.

Two further examples will illustrate the interweaving of these temporal orders. At Korle Bu Teaching Hospital in Ghana, for example, the Dutch device shaped the temporal order of professional hierarchy. This hierarchy is composed of a rigid sequence of career steps that range from being a medical student via being an intern and registrar to becoming a specialist, each of these steps requiring a certain amount of time to pass through. Calling back Dr. Battir from retirement and allowing him and his expertise to re-enter the professional faculty, disorderd generation-time. Seen from the point of a teaching device, his return enabled a fast up-take of services as well as of teaching courses for rural operators and in-house medical students likewise. At the same time, his return disturbed the 'natural order'

\footnotetext{
${ }^{90}$ For a dependency of technology on seasons see, for example, Akrich's description of a gazogene in Costa Rica that could only work with dry wood (Akrich, 1993). While seasons in the case of ultrasound technology seem to play a lesser role than they might for agricultural technology, nurse-midwives at Sengerema told me that ultrasound had a higher workload during harvesting when women had a high workload, resulting in more births before arrival or retained placentas due to unskilled management of the placenta period at homebirths.
} 
of career sequence in the hospital, even more so given the fact that his age - biologically and socially - made him superior to the practicing specialists at present. In order to repair this temporal disturbance, ultrasound services by Dr. Battir and Dr. Tennison, the regularly practicing specialists, was divided evenly: each doctor got two days of ultrasound services. As Dr. Tennison, loaded with his regular practice as gynecologist from $8 \mathrm{am}$ to $2 \mathrm{pm}$, only had time in the afternoons, Dr. Battir was also to practice in this period of time. Given the load of the waiting patients every day (in these four working days for ultrasound and operators), each patient was left with six minutes of scan-time. This time, however, contradicted the ten minutes regarded as being the minimum time span to "see each and everything" by international standards as promoted by the Dutch teachers. At Makongoro Antenatal Clinic in Tanzania, ultrasound facilitates task-time: it enables nurse-midwives to send women in time' to the appropriate places for delivery and thereby to keep up their reputation as a reliable referral institution. The practice of sending women late for ultrasound, beyond the machine's 'window for accuracy', serves to extend pregnancy: as heads get smaller in advanced pregnancy due to their descent into the pelvis, expected dates of delivery get postponed (the smaller head suggesting a lesser gestation age). While this postponement works towards the referral of women as 'in time', with the onset of labor, it renders impossible a risk assessment of pregnancies that actually go over-due. While the premature birth of children has since long been a concern for health care professionals, the tendency of pregnancies to last 'too long' is a recent problem that nurse-midwives face - whereby 'too long' for the nurse-midwives at Makongoro Clinic included any pregnancy beyond 36 weeks. $^{91}$

Both examples show that reducing risk in one timeframe may increase risk in another. They stress the importance of actively building passages that interlink different temporal frames: introducing ultrasound into medical practice hence has to include the temporal-spatial practices that precede ultrasound. Building passages, as the sociologist Peter Peters (2006) argues, implies creating heterogeneous orders of elements that link time and space. In order to provide patient coverage for 24 hours at 365 days a year, hospitals, for example, organize time so that shifts of different groups of health care professionals partly overlap, that duty hours of experienced staff run partly parallel with those of inexperienced

\footnotetext{
${ }^{91}$ A Kenyan 'flying doctor', whom I met at Sengerema District Hospital, told me that this prolongation of pregnancy is due to better malaria treatment that prevents premature contractions caused by fever attacks.
} 
staff, so-called morning meetings link night-and day-shifts, and ward rounds link health care professionals at different career steps and of different professions with each other (see Zerubavel, 1979). The introduction of a new technology, however, may make or expose these devices as insufficient. Or, to be precise, a new technology may complicate the complexity of these temporal orderings, and things may get lost. Reports may not be read in time' as ultrasound-time differs from clinical time, 'naked' eye-sight may prevail over ultrasonographers' (and researchers') insights, clinical, or likewise ultrasound, reasoning is discarded as non-science by the respective other professional group, and ward rounds may be used to distribute guilt rather than to understand the problem of temporal alignment as something that has to be solved systemically.

The dimension of time first of all contributes to an understanding why Sokoine Regional Hospital suffers from a lack of ultrasound patients: pregnancy management there is still a matter for the clinic, and ultrasound if known at all, operates as a delaying factor in decision making. ${ }^{92}$ We can assume that similar absences of patients may be the reason for the requests of professionals to be reposted that Philips Medical Systems had to deal with in Ghana and Tanzania (see chapter 2). The dimension of time also points to a problem of resource management that the loss of a systematic encounter between pregnancy and ultrasound brings with it. If ultrasound patients have to be made, the time bought by state agencies for teaching operators (see chapter 3 ) is lost if those that work before ultrasound are not taught, and when operators and clinicians likewise believe that ultrasound equals or merely refines rather than transforms clinical time. Complementing the dimensions of space and resource with that of time furthermore serves to highlight the essential difference that being in another space with other resources has for pregnancy management: in countries where particular diseases are endemic, transport costs high and where national regulations allow free pregnancy care but charge mothers who return to the hospital after having been discharged, ultrasound's value may shift in terms of time: working to make the postpartum period safer may become more important and easier than dealing with the unpredictability of pregnancy.

\footnotetext{
92 In 2005, the hospital was to get a Dutch gynecologist. According to rumors I heard at my re-visit of Tanzania in December 2005, her arrival had reformed the ultrasound unit, now increasingly also including her pregnant patients. Whether this beginning of the institutionalization of ultrasound in the hospital's obstetric practices also included the nearby antenatal clinic is beyond my knowledge.
} 
What this chapter leaves us with regard to technography are the following questions: What are existing time frames to deal with a particular issue, here the management of pregnancy, delivery and the postpartum period? What are the temporal orders brought and required by the new technology? How can temporal orders be linked and whom do they include or exclude? It is the presence of unknown time-ordering actors such as Elias Kudzi, whose ideas of diagnostic 'freshness' undermine ultrasound's 'window of accuracy' bound to a time span between 18 and 22 weeks of gestation, that make these questions into a vital and empirical matter. It is Dr. Lema's mentioning of another Ghanaian anatomy, the experience of Mama Iringa's different time preference who, other than biomedicine, did not think that a past had to be kept stable in order to predict risks ${ }^{93}$, and the silencing of the 'after-birth scan' proposed by Stella Ndogo at Sengerema, that make me turn to the dimension of knowledge in the following chapter, in which I follow ultrasound into the lives of women

\footnotetext{
${ }^{93}$ The preference for present time that Mama Iringa expressed in our little conversation, and the variability of the past that her actions evoke and take into account, have by some authors been described as a salient feature of African thought (see, for example Mbiti, [1969] 1971). Writing on cultural time concepts and health-related time preferences in Burkina Faso, anthropologist Evelyn Wladarsch criticizes this assumption of an everlasting African presence. Scrutinizing the multiple time orders of Burkinabe, she argues for the acknowledgement of the different futures, pasts and presents that are expressed in practices of everyday-life and that feed into concepts of 'risk', 'health', and 'disease' but that may be not fit with international prevention and treatment schemes (Wladarsch, 2005).
} 


\title{
5. 'Doing Video' and 'Having a Kioo' - the women's apparatus
}

\author{
Tanzania: Muhimbili Teaching Hospital, 10.02.2004. Rehema Ntwale \\ returns to the antenatal ward after having had an ultrasound examination \\ two weeks ago in a private facility in Dar es Salaam. She is deeply \\ concerned. "Look here", she says in Kiswahili and points to the various \\ print-outs attached to her file. "The doctor explained to me: 'This is the \\ head, this is the leg, this is the belly." She turns to the female gynecologist \\ attending her: "Doctor, now that the machine has cut my baby into \\ pieces, how will it come out as a whole?" In English the doctor seeks my \\ sympathy: "You see now what we struggle with, they just don't \\ understand."
}

\begin{abstract}
Tanzania: Sengerema District Hospital, 17.06.2004. Sabina Mbeja's premature baby died in the early morning, a couple of hours after birth. According to ultrasound it was 26 weeks old. When I visit Sabina at midday, she emphasizes positive feelings rather than loss, referring to our first interview after the examination: "We saw it in the mirror, it was playing. It was born, there at the labor ward, they all saw it was moving, it cried and cried. You asked me how I will explain this examination to others who have not done it? The mirror was speaking [the] truth, this is what I will tell people. They all saw I carried a child, it was playing. My husband, my in-laws, me, we are all happy now." The present pregnancy is her $8^{\text {th }}$; according to her antenatal record, all previous pregnancies ended in 'miscarriages'.
\end{abstract}

In this last empirical chapter I will focus on those that are moved, in the sense of being 'affected' (Callon \& Rabeharisoa, 2004, p.17; Latour, 2004, p.205) by ultrasound - I will turn to women in Ghana and Tanzania. The common assumption, held by much of the current literature on women and ultrasound in 'the North' and by the actors that the previous 
chapters have focused on, is that ultrasound provides women with knowledge. ${ }^{94}$ This knowledge primarily focuses on the viability, the formation or malformation, the number, the sex and the intrauterine position of fetuses, and on the organs that sustain and surround them. Listening to women such as Rehema Ntwale and Sabina Mbeja in the two vignettes above, however, disrupts the ease with which this knowledge is assumed to be universal. This chapter, hence, begins with the supposition that as ultrasound travels it might meet with people who do not invest in epistemology in the way that Euro-American science does.

Focusing on the dimension of knowledge in pursuit of the question of how women appropriate ultrasound, I will argue that at the level of women, ultrasound becomes a 'kioo' in Northwest Tanzania and a 'video' in Ghana. Rather than being a mere translations of an examination done by ultrasound, 'doing video' or 'having a kioo' is fed by and feeds into 'local biologies' (M. Lock, 1993). Underlying them is a pregnant body that is constantly informed by a range of invisible and visible agents with the power to make or unmake children. In this context of contingency, ultrasound, as I will show, turns into a device to support women's ability to carry children. Supporting women's carry-ability, the Ghanaian 'video' and the Tanzanian kioo, however, do not necessarily serve to reduce maternal mortality statistics.

The pursuit of 'local biologies' requires me to concentrate on common bodies of knowledge, and thus to divert from talking about women in Ghana and Tanzania in general. Instead, the first section will present the particular practices of one ethnic group only: it will show how Wasukuma women get to know and manage pregnancy and pregnancy 'at risk'. My decision to focus on this ethnic group is based on the amount and depth of data I have been able to collect about Wasukuma practices in comparison to other ethnic groups. The point that the following section underlines, hence, is that it requires considerable knowledge about local knowledge in order to understand the particularities of ultrasound's embedments into women's pregnancy practices. While, as I will show, the practices of Wasukuma women in many ways resemble those used by women in 'the North', they enact a very different pregnant body whose chances to meet with ultrasound hinges on its ability to acquire

\footnotetext{
${ }^{94}$ The literature on women's experiences of ultrasound is vast. In particular, several chapters in the edited volume Bodies of Technology (Mitchell \& Georges, 2000; Morgan, 2000; Saetnan, 2000) exemplify how ultrasound operates as a culturally specific knowledge generating device. In 'the North', ultrasound knowledge is so wide spread that pictures of fetuses may meanwhile serve as advertisements for car safety, for example, without leaving the spectator puzzled about the shades of gray (Taylor, 1992).
} 
hospital qualities in the first place. In the second section I broaden the description of women's ultrasound experiences to include Ghanaian and non-Sukuma women in Tanzania again, thereby pointing to instances where local bodies of knowledge feed into the process of making sense of the new technology. The third section deals with the question of how the knowledge that women acquire by 'doing video' or by 'having a 'kioo' interacts with the ultrasound diagnoses women are provided with by health care professionals. I will demonstrate how women actively use the new technology to design the reproductive trajectories that seem to be the most appropriate in their pursuit of sustaining carry-ability, and how they make deliberate choices about health care. Following ultrasound to the level of women, this chapter thus at the same time provides an insight into the intricacies of medical pluralism. The fourth section will draw on the empirical material to argue that, and how, knowledge matters for technology assessment.

\section{Trialing a hospital pregnancy}

For the Wasukuma ${ }^{95}$, a child is only one among many other entities a woman can be pregnant with. Being pregnant-with-child, however, is the primary condition for which a pregnancy is taken to a biomedical facility to possibly meet with ultrasound. Getting to know whether a pregnancy is 'with child', requires women to engage in successive trials that substantiate pregnancy against a range of potential afflicting agents. As in other parts of SubSaharan Africa, in Northwest Tanzania these agents and their effects are referred to as 'maladies of God', 'maladies of spirits', and 'maladies of person'. ${ }^{96}$ These idioms give meaning to collectively understood experiences and guide actions in pursuit of turning undesirable into desirable states. A pregnancy considered to be hospital-able is the outcome of negotiations that establish a particular configuration of certain knowledge and uncertainty with regard to the actions of these afflicting agents.

\footnotetext{
${ }^{95}$ Usukuma is the area in which Wasukuma (pl.) or a Msukuma (sg.) live. Kisukuma is the language spoken by this ethnic group.

${ }^{96}$ This triad of afflicting agents, 'God', 'spirits', 'persons', seems to be widespread in SubSaharan Africa (see Steven Feierman, 2000; Janzen, 1982; Stacey Langwick, forthcoming; Susan Reynolds Whyte, 1997). Using the term 'malady' instead of the original 'illness' by Janzen, I take up the suggestion of anthropologist Stacey Langwick. Etymologically composed of the Latin 'habitus' and 'male', malady describes undesirable states as resulting from badly executed relationships with others. 'Malady', she argues, thus bypasses the disease/illness dichotomy and its associated nature/culture dyad (forthcoming, p.313f).
} 


\section{Bleeding patterns}

At the Waiting Home at Sengerema District Hospital my simple question 'How does a woman know that she is pregnant?' resulted in an engaged discussion in Kisukuma, Kiswahili and body language among the group of waiting women who were present: fingers were stretched out, and bent repeatedly, hands grabbed my arm and skirt to direct my eyes to a particular woman's belly, and some women pointed to the calendar at the wall while others pointed to the sunny sky. One of the older women finally summarized their consensus in Kiswahili with the words "It is counting!" [Kiswahili: Ni hesabu!)]. Counting was a practice that first of all required hands and heads to be certain of a definite cessation of menstrual bleeding:

You don't enter bleeding once, it can be anything, maybe sickness. You don't enter bleeding two times, you are certain you have gotten pregnancy. ${ }^{97}$ I will give you the example of this one [she points to her own belly]. I entered bleeding in March, I did not enter in May, I did not enter in June. I take this month, I know I have gotten pregnancy. You count nine months, you will deliver. ${ }^{98}$ (Tz 32)

Women added that while their grandmothers had bled when the moon was to the west, to the east, or directly above the house, they as "modern women" (ibid.) followed track of bleeding and cessation patterns by means of a calendar: days in paper form.

In order to know whether a woman was pregnant with child, however, it was not enough to observe the cessation of bleeding. Certainty about child-matter required the bleeding to have already been of a certain quality before the pregnancy: it had to be regular in terms of duration, flow, and quantity. Bleeding had to last not "more than three days" but also not less, and was not to "stop and come again" or "run heavily" (Tz 32). As a child was formed by the clotting of blood, irregularities of these patterns risked the ability to carry a child in the first place or to carry a child to term, as a child was then perceived to be lacking blood (see Allen, 2002, p.152f.). Formation of a child, however, was not seen as proceeding

\footnotetext{
97 In Kiswahili two common terms used refer to 'being pregnant': kupata mimba = getting/catching pregnancy and kupata uzito $=$ getting $/$ catching weight. The second term resembles very much the common expression with which women in Ghana referred to pregnancy "I have gotten [a] stomach". These expressions capture the uncertainty and contingency attached to this condition and the knowledge thereof that I describe in the remaining of this chapter. Translating these notions into English and referring to 'pregnancy', hence actually is precisely one of the misunderstandings that Latour (1988, p.65) refers to as the core feature of translation, and that I briefly pointed to in Chapter 1.

98 The Kiswahili term for 'to delivery' is kujifungua = to open oneself. As much as I - as a midwife - like the activity that this term suggests, for the purpose of easier reading I will stick to the term 'deliver' throughout the book.
} 
linearly. Instead a child was constantly in formation, attaining various shapes and stages of solidity throughout the duration of the pregnancy:

One, two, three months, it is clotted blood only. [In] the fourth month it becomes something like frog or lizard. Five, six, seven months it is a child again. [In the] eight month, it is not a child anymore, it loses its shape. [In the] ninth month, it becomes a child again. Then you deliver. ${ }^{99}$ (Tz 17)

This understanding of an ongoing transformative corporeality of child matter in the womb was used to explain the problems that babies had when they were born prematurely.

According to the stages of formation, children born at seven months would thereby survive more easily than children born at eight months. At the same time, this notion of being constanlyt in formation excluded the concept of a lasting malformation. Instead, women told me that even if a child missed certain body parts at one stage, these could grow at a later stage - any malformation hence was considered to be potentially remediable. If a child was born with visible malformation, this simply meant that 'God' had not wanted it to be otherwise. $^{100}$

A factor adversely affecting bleeding patterns and quality of blood was 'the syringe' [Kiswahili: sindano]. With this term women referred to the three months-injection contraceptive Depo Provera that was widely promoted during the health care education lectures accompanying the children's clinic. Many women in the focus group welcomed 'the syringe' as a means to space children in order to prevent a new pregnancy that might endanger the life of a still breastfed child (see also Varkevisser, 1973a, p.101). ${ }^{101}$ In the following explanation given by one of the women in the focus group, 'the syringe' interweaves 'traditional' pollution beliefs with 'modern' biomedical advice and population policy:

\footnotetext{
${ }^{99}$ According to anthropologist Marja-Liisa Swantz, Nyamwezi women living in the Southern Sukuma area believe that pregnancies for girls last seven months, while they last eight months for boys (1969, p.230). All my interviews, however, considered nine months to be the normal gestation period. It is possible that the increasing influence of biomedical health care education and antenatal care services have brought changes in perceptions about pregnancy duration.

${ }^{100}$ In Ghana, several women, including two nurse-midwives, said that women would never undergo abortion when diagnosed with spina bifida, an open back, or other malformations expecting that this hole would be closed or the body part in question would still form.

101 Anthropologist Corlien Varkevisser (1973b), one of the first anthropologists working with the Wasukuma, refers to the state of moral impurity evoked by feeding two children at the same time by the term 'lyusi' caused by the mixing of blood of the two children. While I did not hear this term used at all, I have to admit that breastfeeding or pollution beliefs were not at the centre of my research and thus may have slipped my attention. According to the anthropologist Wolf Bleek, women in the Kwahu in Southwest Ghana, are ridiculed as being "primitive" when having a very quick succession of births. Similarly to ideas held in Northwest Tanzania, in this region also breast-milk in pregnancy is regarded as poisonous (Bleek, 1976, p.149ff.).
} 
You get one [child]. You get another one following fast. The one which follows, this creature, it will make your milk get dirty. It does not feed nicely. The first, it will sit on your belly still. It does not want to move for another. You cannot feed both at the same time. So they [the nurse-midwives] tell us what? They tell us to take the syringe as we are modern women now, we know what to do. (Tz 33)

However, women also attributed particular problems to 'the syringe'. Some women complained that its power to "keep children apart" (Tz 33) could not always be trusted, a fact that some of them laughingly pointed at while touching their pregnant bellies. Asked how they thought they had become pregnant despite 'the syringe', they said that they believed that the injection used at Sengerema Hospital was manufactured "in India" (Tz 33). Had it been manufactured in Europe, they added, it would have worked - a conviction they underlined with their experience that all Europeans visiting Sengerema Hospital had a small number of children only. Most of the women furthermore agreed that 'the syringe' was "eating up" (Tz 33) their blood. The continuing absence of blood and bleeding provoked by 'the syringe', even after women had stopped the contraceptive, often resulted in their uncertainty about whether they were carrying a child. Eliana Ndenta at Makongoro Antenatal Clinic expressed this uncertainty after the ultrasound examination. In her opinion she had been sent to 'have the kioo' because even the nurses had not been sure whether there was a child inside her:

I took the syringe, then I stopped. I wanted to become pregnant again but the bleeding did not come back. I waited, waited. I realized I was having stomach but still I had not entered bleeding again. My mother in law sent me there to the dispensary for checking what is it. They referred me here to the hospital. The nurses sent me to have the mirror. It was pregnancy. [...] They said it is pregnancy now but I could not see a child. It was all black. [...] I ask you now: Is this the child? Is this the blood? ( $\mathrm{Tz} 18$ )

Causing a lack of blood, 'the syringe' was also seen to weaken the "pocket", as women called the carrying organ of a child [Kiswahili: mfuko]. Symptoms indicating this weakness were dizziness and a general lack of strength. In consequence, women regarded 'the syringe' as responsible for some of the problems for which they had been sent to have a 'kioo', had been admitted to the hospital or to the Waiting Home or had been "replenish[ed]" with blood when diagnosed with a "a lot of blood missing" (Tz 32). At Sengerema Hospital, for example, Ester Matatu attributed the transverse position of her 
child palpated by the nurse-midwife to the blood transfusion that she had had as a result of having taken 'the syringe' prior to the present pregnancy:

I took the syringe. I became pregnant again. Then I was lacking [blood] again. You feel tired, mama. You truly lack strength. The syringe takes your blood away. They gave me two [two units of] blood. One I got from my brother, the other one we bought from a stranger. I felt the stranger's blood, it was cold in my arm, my body went cold. Now, they tell me that my child has twisted, it is sleeping badly in the stomach. [...] It is caused by what? It is caused by the blood fighting with each other. (Tz 27)

The first practice, by which Sukuma women were trying to find out whether they were pregnant with a child, required carefully observing bleeding patterns. The pursuit of building a 'modern family', however, placed women in a dilemma: the irregularities in bleeding, a consequence of the hormonal intervention, increased women's uncertainty about whether they would become pregnant again or whether what they carried was a child at all. Aiming to "strengthen the blood" (Tz 33), many women, including nurse-midwives to whom I spoke, had taken traditional medicine immediately after stopping the contraceptive. Yet, for many women the pregnancies following the intake of this "white" medicine, remained potentially prone to 'stomach problems' that in turn could only be remedied by another "white", that is hospital, medicine.

\section{Mobilizing child}

Experiencing movements are a second source of knowledge that a woman is carrying "a true child" (Tz 33 [Kiswahili: ni mtoto kweli!]). Child movements, however, had to be distinguished from "women's things" (ibid.) that could also be growing inside and causing a belly to grow as if a woman was with child. Several of the women therefore emphasized that they had actively forced 'child' to reveal itself using their own body as the means against which to contour the existence and viability of another 'flesh':

You want to know is it child $[\mathrm{or}]$ is it woman? You try. [...] You turn to the right, it turns to the left. You turn to the left, you don't feel it turn right, it is not a child, it might just be woman's parts. Or it might be a child that died. You feel in the beginning it turns against you, then it turns with you the other day. You know it is dead. (ibid.)

Among the Wasukuma, it is moreover less women's experience of child movements than the public announcement that a child is moving [Kiswahili: mtoto anacheza] by 
someone else, mostly an elder woman in the family, that ensures the truth of a child pregnancy. This public announcement calls into being a child as a legitimate family member: it grants the unborn a social place. At the same time, it also fixes a child's place in the belly. Similarly to other SubSaharan African countries, a pregnancy in Northwest Tanzania can be turned to the back [Kiswahili: mimba kurudi mgongoni; Kisukuma: bugota kupindya kunganga]. ${ }^{102}$ Turning a pregnancy to the back could be the act of a woman herself, my interviewees said, for example when her husband was away for a long time and the woman did not want the baby to be born in his absence. ${ }^{103}$ Upon the return of her husband, she could turn the pregnancy back to the front with help of traditional medicine and/or with the help of a traditional healer. The child that had stopped growing in the meantime would then grow again until delivery. All the women I spoke to, however, agreed that turning a pregnancy to the back was something that could only be done in the first couple of months without harm.

Child movements, however, can be fake, caused by sorcery, that is, the ill-wishes and evil-doings of other people. ${ }^{104}$ Sorcerers were known to mimic pregnancy-with-child, while a woman was pregnant with stones, ashes or smoke, revealing this other pregnancy only by the fact that no delivery ever took place or that no child was born upon delivery. Furthermore, sorcerers were known to also turn pregnancies to the back, my interviewees said, yet unlike women themselves, sorcerers would turn pregnancies to the back in later stages, causing children to be born disfigured, with "twisted legs", "big heads"105 or "black with lots of body hair".

\footnotetext{
102 Kilbride \& Kilbride (1990, p.110) cite Kisseka (1973) who talks about a similar concept in Uganda, whereby women "tie up" unwanted pregnancies to make them disappear to the back. The notion of pregnancies to the back, however, seems to be even more widespread in SubSaharan Africa. Medical anthropologist Maud Radstake collected data about the same phenomenon in Ghana (personal communication, 07.10.2005).

103 According to the anthropologist Per Brandstroem, Wasukuma believe human beings to have a two-sided nature: they are brought into being by the conjunction of the left, the father's, and the right, the mother's side. What makes someone a social being, however, is the disjunction of the male and female principles into father's side (buta) and mother's side (migongo). A child without a socially recognized father is considered a child of the right (Brandstroem, 1991, p.22). The expression 'to turn a pregnancy to the back' whereby a child is removed from the womb thus mirrors the social displacement of a child conceived in an adulterous relationship.

104 Anthropologist Evans-Pritchard (Evans-Pritchard, 1977 [1937]) differentiates between witchcraft and sorcery. While the latter is consciously exerted, the former is not. Moreover, he claims witches to be born as such and containing 'witch-ness' in their bodies, albeit sometimes unknowingly. My English speaking interviewees commonly used the term 'witchcraft', their explanations of evil-doing, however, classified as sorcery according to the above definition. This blurring of boundaries between sorcery and witchcraft in my opinion stems from the fact that the Kiswahili term uchawi encompasses both intentional and unintentional evil acts (Arens, 1987). Following Evans-Pritchard, I use the term 'sorcery' throughout this book. This said, however, it is important to note that 'my' sorcerers thereby acquire a quality that the Tanzanian anthropologist Simon Mesaki (1993) attributes to witches: the ability to travel and act at night (see below)

${ }^{105}$ Due to endemic meningitis, hydrocephalus (water head) is a rather frequent condition among children in the region. Although Bugando Teaching Hospital performs shunt operations to drain the water, some children never get to the hospital
} 
Therefore, even if women felt or enforced movements, certain conditions such as an overlarge belly led to uncertainty as to whether a growing belly was the sign of a pregnancy with true or a pregnancy with a fake child. It was the difficulty in deciding between these two kinds of pregnancy that kept Mariamu Mpishi from seeking antenatal care at Makongoro Antenatal Clinic. Sent to ultrasound on account of 'unsure dates', Mariamu had been scolded by the nurse-midwife for "coming too late" (Tz 19). Only by ultrasound could it now be determined whether she was 30 weeks pregnant, as calculated by the last menstrual period, or 36 weeks pregnant as palpation suggested. In our interview Mariamu Mpishi explained her delay, saying that she had suspected sorcery had made her stomach "too big" for the number of months she had not witnessed any bleeding.

Immediately my mind went quite far, then I thought: 'Mmh, what problem do I have?' Maybe because [where] we live, there are different kinds of people. [...] What made me think so was our prevailing living condition - because there [may be] one who wants you to catch something. Now sometimes you find that during our time when we were growing up, our grandmother used to tell us that people in the past were being bewitched by being given medicine through uchawi*. You would see someone with a big stomach but nothing would be born. Now I started thinking about my stomach which had become big: 'If it is not water, then what is it?' [...] Others say that there are people who give birth to smoke, others are bewitched with traditional medicine even now, in fact my mind went very far. I told a colleague who questioned me: "Do you believe in evil or do you believe in God?" I told her that I leave everything to God. [She told me]: "You shall find some money so that you can go to the hospital to look for a [antenatal, BMR] card to start getting services." She gave me that money for the card. I arrived here. [...] Even the nurses are not sure now, they ask me: "Are you cheating us, mama, this is nine months by measuring [but] you tell us it is only seven?" What is it now? Maybe it is witchcraft, maybe just natural? (Tz 19)

Mariamu Mpishi's story points to the characteristic of these 'maladies of person'. They result from a horizontal disorder: from the unequal attainment of wealth or prosperity in the form of women, off-spring, land, or recently of money between people who share a certain place (geographically and in the social hierarchy). A plentiful harvest, a prosperous business or the visible swelling of a woman's body might attract the jealousy of others who

for such an operation or, when shunts clot, develop a hydrocephalus again. Kichwa kubwa, a 'big head', here may simply refer to simply a bigger head than normal, but also to this pathological condition. In combination with the other two symptoms it certainly denotes a visible malformation children may suffer from when 'turned to the back'. 
wish to consume these effects of (re)productive success. ${ }^{106}$ According to the social scientists Frank Wijsen and Ralph Tanner, 'maladies of person' mirror changes in practices of reciprocity (Wijsen \& Tanner, 2002, p.52, 100). This also accounts for the increasing rate of sorcery-related afflictions in urban areas. While Wasukuma traditionally lived among kin, yet in dispersed homesteads, in towns people share a limited space with strangers - with “different kinds of people", as Mariamu Mpishi put it in her account (Comaroff \& Comaroff, 1993; Geschiere, 1997). As an effect of medicines used in acts of sorcery, harvests might fall short, women may not be able to conceive any more and babies may die in the womb in consequence. Celina Kondo, for example, attributed the long years of unsuccessfully trying to become pregnant by her second husband to the ill-wishes of the father of her first-born twins whom she had refused to marry when finding out that he already had another wife.

Similarly to Mariamu Mpishi in Mwanza town, Laurentsia Shitinda who lived in one of the rural villages in Mwanza region explained the oversized swelling of her belly as the effect of uchawi [Kiswahili: sorcery/witchcraft, see footnote 104]. As this swelling had made it impossible to palpate her, she had been sent to Sengerema hospital where the nurse referred her further to 'have a kioo' where the operator diagnosed a polyhydramnion*. Told by the ultrasonographer that she suffered from 'too much water' (see chapter 4), Laurentsia Shitindi's explanation again made reference to the close relationship between the reproductive capacity of land and that of the female body. In her village, she explained, water was scarce. Women therefore had to get up before sunrise to walk to the waterholes in the dark to fetch water before the sun had dried them out. Walking at night-time, the time when only witches would usually travel, made women vulnerable to stepping on 'medicine' that these agents had put on the road. Several other women in Laurentsia's village had therefore suffered a "water problem" (Tz 28) during their pregnancies too:

[The nurses] now tell me, it is a problem of water. [...] My sister in law had another problem, swelling of the body, it was full of water. Other women in the village had the same. We have to get up in the dark to fetch water. It is then [that] you meet with witches. They

\footnotetext{
${ }^{106}$ For a detailed description of the relationship between production and consumption see the study of Barbara Schmoll on witchcraft amongst the Hausa in Niger (Schmoll, 1993).
} 
have thrown medicine to the ground. You step on it, you get a water problem. (Tz 28) ${ }^{107}$

In order to protect themselves from witchcraft and sorcery, people in the area do not normally travel at night by feet or bike - a fact that feeds into arrival times at hospitals in case of severe bleeding after birth, for example. In order not to attract the evil wishes of others, pregnant women often do not talk directly about pregnancy but circumscribe their condition with 'having gotten stomach'. Preventive practices also included constraining access to vulnerable body parts and body openings. Clothes used to cover the "private parts", including menstrual cloths, were not dried outside the house in public view of others who could come, fetch and use them for sorcery. Furthermore, many women I spoke to used protective medicine in form of necklaces. In Kiswahili this protective medicine is referred to as dawa za kukinga, literally meaning medicine to intercept or obstruct. These protective medicines work by positioning themselves between the afflicting agent and the person to be afflicted, thereby giving substance to both. Janice Mtutu, for example, wore such a necklace out of fear that the family and wife of her lover might use sorcery against her. According to her they had done so previously when killing four children resulting from this adulterous relationship:

Four children live with me still, those four from my husband. After he died, I had another man. I got pregnant, another four children, they all got lost in the stomach. [...] I went to the diviner [mfumu, $\mathrm{BMR}]$, he gave me this medicine. He said, if I wear this medicine, the harm will stay away, it will scare it. The medicine will make it fear. (Tz 29)

The abundant protective practices and devices that women employ to ensure their ability to carry children, expose jealousy in Northwest Tanzania to be very different from jealousy in 'the North': while in the latter it is an emotion, in Tanzania it is a circulating entity with the power to kill or mimic 'child'. ${ }^{108}$ Sorcery related afflictions are taken to the diviner

\footnotetext{
107 According to Varkevisser (1973a, p.50) there are four ways by which uchawi can be exerted: 1 . by putting a mixture of herbs and drinks in food or drinks (kulisha), 2. by placing medicine on a spot where a victim will step on it as in the case described (kupandya), 3. nhananhama makes sorcerers invisible so that they can blow medicine in the face of victims; 4. kunsonela makes a sorcerer angry so that s/he gets killed or kills himself (see also Reid, 1982).

108 Accusations of witchcraft/sorcery are taken extremely serious. During my fieldwork, for example, the District Medical Officer (DMO) of Sengerema was called to solve an accusation of witchcraft/sorcery brought forward against the nurse of one of the dispensaries in the district. While accusations of uchawi may include relatives, they are most often directed at strangers. Included amongst these 'strangers' can be biomedical personnel that by national regulations - to prevent corruption - are deliberately chosen to be from a different region than the patients they care for. The major concern for the DMO was to get there before people, as he said, "would take matters in their own hands" (Tz 38) and would kill the nurse. For the 1990s, Simon Mesaki, professor at Dar es Salaam University, has documented witch killings as a prominent and continuing phenomenon among the Wasukuma (Mesaki, 1993).
} 
rather than to biomedical facilities. In order to take a suspicious condition to the hospital, a pregnant woman hence has to undergo serious questioning of whether she is, for example, a believer in God or in evil as in the case of Happiness Malolo. Yet it can also be her trust in the working of protective medicines that makes a woman seek biomedical care: given the power of these protective medicines Janice Mtutu's experience of a child that 'plays badly', for example, then articulates not a sorcery afflicted condition but opens up the possibility for the condition to be caused by other agents.

\section{Consuming relations}

A third way by which a woman would acquire knowledge about carrying a child was to experience dizziness, lack of strength, tiredness or nausea. For a Sukuma woman, my interviewees told me, it was most important to "swallow" ( $\mathrm{Tz} 32$ ) these feelings, as complaining or being overheard vomiting, for example, would expose a woman as someone lacking the strength to carry and care for a child through pregnancy, delivery and thereafter (see also Varkevisser, 1973b).

In order to handle nausea and to build up their strength, all of the Sukuma women I spoke to had eaten earth. ${ }^{109}$ In different forms and quantity earth could be bought as red or gray clay at the markets in Sengerema and Mwanza. Asked why they practiced earth-eating, women responded that their grandmothers had done so as well, that it was simply something that "the Wasukuma did", that it "refilled the blood", and that the "child needed it" (ibid.).

Their answers display at once the crucial importance that earth has in agricultural societies and the close relationship between land and the reproductive power of the people that live from and on it. Earth - soil - is not only the basis for daily physical survival in the form of agricultural goods produced. It is also the place which is shared with kinfolk and the wider social community, and the ground where the ancestors are buried. In short, earth is "the origin and place of belonging of a person, geographically and genealogically" (P. W. Geissler, 2000, p.670). This close relationship between earth, land, reproduction and health echoes in the common formula 'uli mhola?' [Kisukuma: do you have mhola?], with which Wasukuma daily greet each other. Mhola thereby inquires about

\footnotetext{
109 Among my interviewees were also Wazinza, Wahaya, and Wanyamwezi, the three other ethnic groups inhabiting Northwest Tanzania. While women of these ethnic groups knew of the practice of earth-eating, only a few had practiced geophagy themselves. Several of them denoted this practice as 'primitive' and only something that Wasukuma would do.
} 
... the 'cool' state, the state of peace and good relations between the living and between the living and the dead where the women conceive, the herds and flock multiply and the land yields fruit. Mhola carries a notion of wholeness and completeness and refers to the desirable state of life. (Brandstroem, 1990, p.168)

While providing strength and re-filling blood, earth-eating was also seen to provoke nzoka. In Usukuma, nzoka is a key agent of affliction: it can startle a person to the extent that she or he fits; it may provoke swelling of different body parts; it may cause "stabbing" or "fierce" pain in the abdominal and genital region; it may cover women's eggs with pus so that a woman cannot conceive anymore; it makes babies "climb up" [Kiswahili: kupanda juu] the womb during delivery and thus may thus exhaust a woman to death; it may cause excessive bleeding during or after pregnancy, it may provoke the birth of babies considered to be abnormal such as twins, premature babies, or babies born in breech position; and it is known to "drink the blood" of mothers and children making the former feel tired and dizzy, and killing the latter because of "lack of blood" (Tz 33; [Kiswahili: upungufu wa damu]). In sum, nqoka acts as an unseen abortionist that may remove babies from the womb (Allen, 2002; Reid, 1982; Varkevisser, 1973a). ${ }^{110}$

The etiology of nzoka at first seems contradictory. While some people said nzoka was inherent to 'being Msukuma', thus something to be born with, others explained n₹oka as being something acquired in childhood by the practice of geophagy - earth eating. In particular older people I questioned told me that afflictions by nzoka had become more frequent in recent years since the big trees in the region had been cut down. These trees, whose bark had been used for preparing traditional medicine, had been the seat of spirits. When the trees had been cut down in pursuit of firewood, these spirits had come to embody people, in particular their heads and bellies. In reply to my inquiries, many people translated the Kisukuma term nroka into the Kiswahili term nyoka, which in English translates into 'snake' or 'worm' (see also Reid, 1982). ${ }^{111}$

\footnotetext{
110 Varkevisser (Varkevisser, 1973a, p.55) gives an overview of the different existing kinds of nzoka existing in Sukumaland: nzoka ya lubasu (in the ribs), nzoka ya mshikuba (in the chest), nqoka ya bashashi (in the backbone), nzoka ya bagosha (in the scrotum), nzoka ya bubale (in the vagina), nzoka ya ba ntwe or nzoka yipungu are the terms for a nzoka in the head. Nzoka in the head is considered to cause degedege. According to the medical anthropologist Stacey Langwick health care staff often translates degedege as cerebral malaria (Stacey Langwick, forthcoming).

111 In many African countries, worms are considered as belonging to human life (see for example Yoder, 1991). Perceived to be residing in the stomach, worms react to food-intake. Worms have to be appeased by good food or else react adversely to contaminated food. There is a striking similarity between terms. The Kiswahili term nyoka, for example, is also used among the Manica in Mozambique, and the Shona and Tsonga in South Africa and Swaziland (Green, 1997). The Luo, in turn, use the term 'njokla' (W. Geissler, 1998). As Geissler argues, the concept of worms stresses the idea of the dormancy of disease, and thus contains ideas about bodily boundaries and the difficulties of maintaining them (ibid.).
} 
The multiple qualities, forms and etiology of nqoka, albeit all rooted in the practice of earth eating, mirror the social (and ecological) transformation the area has undergone: a diminishing of traditional rules of conduct and authority, and the emergence of a new authority and key player in health care, that is, biomedicine. Thus, the role of earth and the explanation given by older Wasukuma provide a first hint of how to understand the ontological nature of n₹oka and of 'maladies of spirits'. Nooka strikes when elders, be these living or ancestral kin, are not being paid enough respect. A pregnant woman, who travels to her family against the wishes of her parents-in-law, for example, may provoke affliction by nzoka. Nzoka, women told me, can also cause mchango, the result of a husband "eating at other places" (Tz 32). ${ }^{112}$ The blood of husband and wife thereby become different. When mixed again this difference causes the blood 'to fight', thus hampering proper clotting and child formation. Mchango may also cover a woman's egg with pus, thus causing her to "stay far away" from having a child (see also Allen, 2002, p.133ff.). Biomedical discourse, in turn, condemns the practice of geophagy as unhygienic and causative of the many worm infections children and women in the Lake region suffer from (P. W. Geissler et al., 1998). ${ }^{113}$ This discourse brings women as bearers of tradition into conflict with biomedicine, but also into conflict with their fathers or husbands who are considered to be more open to the modern world, as medical anthropologist Wenzel Geissler argues in his analysis of geophagy and conceptions of 'worms' at the Luo, an ethnic group bordering Lake Victoria in Kenya (P. W. Geissler, 2000; W. Geissler, 1998; W. Geissler et al., 1999).

Salima Kuku's story bears witness to these multiple relationships, in which women's pregnant bodies are engaged. I met Salima Kuku in the ultrasound room at Sengerema Hospital with her $12^{\text {th }}$ pregnancy. All previous pregnancies had ended as miscarriages or stillbirths* that her family-in-law attributed to the working of n₹oka. During the current pregnancy it was her husband who finally urged her to attend the antenatal clinic in a nearby dispensary, which referred her to the hospital on account of 'bad obstetric history':

\footnotetext{
112 As the anthropologist Angelika Wolf has shown in her research on HIV/AIDS in Malawi, 'eating' is often used as a metaphor to refer to sexual intercourse. Since my interviewees here linked 'eating elsewhere' with conditions that health care professionals identified as syphilis, I take their usage of 'eating' as to be meant also figuratively to denote adulterous sexual relationships (Wolf, 1996, 2003).

113 Geissler and colleagues argue that geophagy may be a self-regulatory nutritional response to compensate for the irondeficiency many women in SubSaharan Africa suffer from due to malaria. The particular vulnerability of women and children to malaria, they argue, explains why especially women and among the Luo also schoolchildren eat earth. As women are frequently also anemic due to successive deliveries, the iron-rich earth that is eaten serves to build up iron, an important element to increase hemoglobin. The problem associated with geophagy is that it indeed contributes to infectious diseases, in particular with geohelminth or hookworm (P. W. Geissler, Mwaniki, Thiong'o, \& Frijs, 1998; P. W. Geissler et al., 1998).
} 
I told them [the nurses, BMR] before. When I was young I used to eat earth. Maybe that is what is causing it. [...] My father said, it will give you worms but I was still young living with my stepmother. I was eating earth then. [...] She did not tell me not to eat it, she was not my mother. She did not give me any medicine for diarrhea, for cleaning the stomach. This is how the nzoka came to sit in my stomach. Maybe it is worms, maybe it is nzoka. My first [and] my second child, it has drank their blood, the children got lost in the stomach. My in-laws brought me to the mganga*, he gave me medicine for nzoka to please it. He washed my stomach with that medicine, I heard it then. I heard its voice 'rrrrrrsh'. It came back in the next pregnancy. Then it moved here to the right, I heard it walking 'rrrrrrsh'. Now it hardens the stomach, so when the child grows and grows, it reaches the nzoka, it is bitten. The child dies. ( $\mathrm{Tz}$ 30)

Her story tells of the difficulty of diagnosing nzoka: it remains silent unless it is forced to reveal its existence by means of washing the belly with traditional medicine - a practice used to give 'more body' to the relatively undefined entity 'woman with child'. Erecting a border between woman and nzoka, traditional medicine thereby defines both the one who is to be afflicted and the afflicting agent. Nroka becomes an entity that has to be pleased, can be scared away, can be made to reveal itself by sound, and that can return and bite a child when displeased. Pointing to earth eating and a particular constellation that caused nqoka to strike - her disobedience towards her father and the presence of a stepmother uncommitted to the children of her predecessor - her story also revealed uncertainty as to whether what she was suffering from was nzoka or worms.

Taking the equivalence of nzoka and 'worms' at face value, however, in my opinion dismisses too easily the range of afflicting agents that condense in the Kisukuma term, and that turn 'maladies of spirits' into the effect of a "run-in with [...] non-human agents" as anthropologist Stacey Langwick has called it (Stacey Langwick, forthcoming, p.324). ${ }^{114}$ These agents have one thing in common: they mirror a vertical disorder, and hence exert their power vertically, affecting offspring rather than parents. Although in principle anybody, or to be more accurately any Msukuma, is likely to suffer from these kinds of afflictions, nzoka is strongly gendered: it is the child's unfinished state of being that makes a womanwith-child most vulnerable to these kinds of afflictions, and it is women who practice geophagy in pursuit of reproducing the lineage.

\footnotetext{
114 Having conducted fieldwork in Southwest Tanzania,, Langwick describes 'maladies of mashetani'. In some ways, for example in their capacity to provoke degedege (see previous footnote), the working of mashetani in Southwest Tanzania resembles that of 'nzoka' in Tanzania's Northwest.
} 
The relations that enable a woman to carry a child, in sum, are consuming. They require consuming - swallowing - anything that exposes a pregnancy to the outside word before a child is granted a legitimate position in a family by public announcement. At the same time, they require the consumption of earth - a literal incorporation of the lineage - in order to secure continuity over time. According to health care professionals, mchango is syphilis, and $n$ roka afflictions cover a whole range of diseases biomedically known as sexually transmitted diseases (STDs) resulting in infertility or intrauterine fetal death, hemorrhage, eclampsia, or cerebral malaria. Nzoka, however, designates these afflictions as being related to dis-eases within the social fabric of a family. ${ }^{115}$ Women, I talked to, thus stressed that there was 'mchango for the hospital' and 'mchango for the healer', the first one to be treated by 'white', the latter by traditional medicine, or in case of doubt, treated by both institutions successively.

\section{Testing wombs}

Younger, higher educated women, I spoke to in Mwanza town, often got to know about pregnancy by means of simple pregnancy tests available in the pharmacies downtown. One of them was Eunice Hokoro, a student of accountancy at the local university. "Testing her womb", as she put it ( $\mathrm{Tz} 10)$, provided her with knowledge of whether she had gotten pregnant and also established her as a modern woman. She circumscribed this acquired modernity with the expression of 'having open eyes' allowing an insight into all kind of things:

We have open eyes now. We study. We live in town. We are modern women here. You want to know [whether] you carry a child or not? Or are you just feeling different? Maybe your boyfriend wants to know. He wants to know, is this a woman to be married. Can she carry my child? [...] He wants to know is she carrying my child? (ibid.)

When I met Eunice Hokoro in front of the ultrasound room at Bugando Teaching Hospital, she had attended the general outpatient department asking for an ultrasound because she felt that she was pregnant while the test had been negative (see chapter 4). Another reason to pursue further testing was her boyfriend Edgar Nabusanke who had

\footnotetext{
115 It is likely that entities similar to nzoka inhabit other areas. Langwick's mashetani in Southern Tanzania seem to cause afflictions that resemble those of nzoka. For Northern Ghana, health scientists Pascale Allotey and Daniel Reidpath mention so called "spirit children" that seem to have similar effects (Allotey \& Reidpath, 2001).
} 
wanted proof that she was indeed pregnant before proposing to marry her. When I spoke to him independently, he stressed the importance of ultrasound, in particular for 'modern relationships':

A woman might tell you anything. She tells you: 'I am pregnant'.

You marry her. You pay the money. It turns out, she is not pregnant. She has cheated you. [...] So, what did you pay for? [...] I want a modern woman, a wife with some education. So you pay her family for that education too. But she has studied for a long time, she is not a girl, maybe she has already gone out with other men. So she may cheat on you telling you that. If you have a test, you know she is truly pregnant. If you have ultrasound you know it is a child, it is yours [...]. This is what we do nowadays. (Tz 11)

The statement of Edgar Nabusanke points to social changes that relationships in this region have undergone: an erosion of the traditional payment of bride-wealth in cows and a shift to money, the tendency of families to ask for reimbursement of the investments they have put in a girl, the older marriage age of women due to higher education, and the perception of a promiscuous life that this turn to the modern may also entail for women. 'Testing a womb' feeds into producing the 'modern world', which young couples in town feel they belong and want to belong to.

Women I met in the rural area around Sengerema, however, also tested their wombs: they counted the 'muscles' spent on each previous pregnancy and used the calculated loss as a decisive factor in considering where to give birth in order to ensure a safe delivery. ${ }^{116}$ Janice Mtutu, whom the ultrasound in her $9^{\text {th }}$ pregnancy diagnosed with intrauterine fetal death (see chapter 4), referred to a 'tired womb' by using the image of a bicycle tire getting more and more patchy due to frequent use.

You go to hospital with what? The parts are soft and loose and the stomach is tired. You have finished your energy, you have spent muscles because there are three, four babies. [...] So it comes to get tired because all the time it gets patches, it gets holes - like a bicycle, a tire, it gets punctured if you use it often. You will depart with some problems. You go someplace here [Sengerema District Hospital, BMR], you have been sent, seriously you go and they tell you: "Go to Mama Ngojea and continue [to stay] there because your stomach is loose!" [...] You get problems maybe, even labor

\footnotetext{
116 Anthropologist Caroline Bledsoe has written a beautiful book on fertility in the Gambia in which she describes a similar concept of muscles and strength that are endowed to a woman's family. She argues that this concept of 'reproductive endowment' helps to understand why women in Gambia made very different decisions about when and whether to take contraceptives than international experts had assumed (Bledsoe, 2002).
} 
cannot cool the baby. You will get problems because the parts are soft [and] too old. (Tz 29)

Less than the absolute number of pregnancies, as Janice Mtutu's account suggests at first sight, the kind of pregnancies or deliveries a woman had been subjected to in the past were indicators for a pregnancy 'at risk' for which to seek hospital rather than healers' or home care. Nyamwaga Lugari, pregnant with her $13^{\text {th }}$ child when I met her in the labor ward of Sengerema Hospital, was one of the women through which this difference between the biomedical definition of multiparity as a risk factor and women's definition of muscles spent as risk factor became clear to me. After having complained of 'leakage', Nyamwaga Lugari had been admitted to the labor ward to await the onset of labor. She had given birth to 11 children at home, she told me, and not attended a biomedical facility at all. Yet, when the last four children had died, she had gone to antenatal care with her $12^{\text {th }}$ pregnancy close to delivery and had ended having a c-section. Having spent "many muscles" (Tz 31a) on the four miscarriages and having been cut for the previous child, she had come to the hospital with this pregnancy as well, knowing that her womb now was 'tired'.

The loss of strength and tiredness of muscles was a common feature in the stories women told me. 'Muscles', their accounts suggested, were and had to be spent in endowment to bear children for the family. 'Tired' wombs, hence, and possible resulting disorders were conditions that "just happened" or were considered 'maladies of God'. My probing into the desired number of children at the focus group discussions at the Waiting Home in Sengerema was always answered by "six children" and an "equal numbers of boys and girls". Explaining their wish for sex parity, women referred to the fact that to marry off sons required the cows and money that daughters' marriage would bring. ${ }^{117}$ Upon my question as to why many of them had more than this desired number of children they told me that if they stopped bearing children, their husbands would go out, would "eat elsewhere" (ibid.), so that in the end they might have to take care of other women's children. Instead, they added, they preferred to take care of their own children only. ${ }^{118}$

Not all pregnancies thereby had the same effect on this loss of muscles: difficult births as well as miscarriages, for example, resulted in a higher toll on muscles than easier deliveries and living children; similarly, the repetitive birth of dead children both tested the

\footnotetext{
117 Among the Wasukuma, bride-wealth is paid from the family of the husband to the family of the bride.

118 According to Tanzanian law, a biological father can claim his children from their $5^{\text {th }}$ birthday onwards. His wife may then have to raise these children from an extramarital relationship together with the ones resulting from her own marriage.
} 
capacity of a woman's womb and demonstrated its tiredness. Giving birth to a live child in between stillborn children or miscarriages, thus could convince a woman that her womb was not yet tired and still capable of carrying children as was the case with Sabina Mbeja, whom I cited at the beginning of this chapter.

Be they the young women in town that had used a pregnancy test or the 'older' women in the rural areas that had counted a certain loss of 'muscles' and strength, all women who tested their wombs took their pregnancy to the hospital. The former seemed to regard this continuity of 'white medicine' as a proof of their modernity. The reasoning of the latter has less to do with attributing 'natural causes' to these maladies. Rather, 'maladies of God' are seen as conditions for which there is no protection. That these kinds of maladies are taken to the hospital suggests that what may blend into them is the history that biomedicine shares with mission hospitals that I mentioned in chapter 3.

\section{Hospital-ability}

In Northwest Tanzania, not all pregnancies meet with biomedical health care services.

Rather, hospital-ability is a characteristic that a pregnancy acquires (or does not acquire) by means of successive trials, that is, in confrontation with the particular features of the networks a pregnant woman is part of. The pregnancy that comes to be taken to the hospital is one of which women (and her relatives too) are certain to 'be with child' - speaking in biomedical terms this means that a pregnant woman reaches the clinic beyond the 16 weeks of gestation age promoted for the first antenatal care visit. ${ }^{119}$ It is also a pregnancy of which women are certain that their 'stomach problem' is not sorcery related, but it remains one of which women are uncertain about whether their 'stomach problem' is a 'malady of God', something that just happens, or a 'malady of spirits'. ${ }^{120}$ While these trials may substantiate child matter, they do not make fetuses in the sense of a bodily defined entity that shows

\footnotetext{
119 Women pregnant for the first time most often feel child movements around the $20^{\text {th }}$ week of gestation, women with multiple pregnancies experience child movements a bit earlier, around the $18^{\text {th }}$ week (Geist, Harder, KriegerowskiSchroeteler, \& Stiefel, 1995, p.86).

120 The 'stomach problems' Tanzanian women take to the hospital may thereby coincide with biomedical risk categories, or they may not or may only partially overlap with the latter. The 'tired uterus', for example, encompasses the biomedical riskcategory of habitual miscarriages, and may meet with the biomedical risk category of multiparity (above 5 children) but does not do so in every case, as shown above. According to a public health study in Southern Tanzania, full alignment between women's and biomedical risk categories concern the status after caesarean section, vaginal bleeding in the present pregnancy, breech position, fever, and severe anemia. Partial alignment was found for slight anemia, vaginal bleeding in the previous pregnancy, status after stillbirth or after miscarriage, multiparity, and first pregnancy. The conditions where risk assessment between biomedicine's body of knowledge and that of women differed the most, consisted of pelvic disproportion and limping (not seen as a risk by women) as well as pain and exhaustion (not seen as a risk by biomedical professionals) (Jahn, Kowalewski, \& Kimatta, 2000).
} 
particular features at particular points of time during pregnancy and then changes only in size. However, what happens to this child-matter when being scanned by a technology known to make fetuses? And how does ultrasound affect these certainties and uncertainties?

\section{Making sense of a new technology}

Referred to 'do video' or to 'have a kioo', many women in Tanzania and Ghana met with a technology they had often never seen nor heard about before. Left to see for themselves without much prior or real-time explanation, women nevertheless made sense of the new technology. The Ghanaian 'video' and the Tanzanian 'kioo' thereby turn into a different thing than what the observation of an ultrasound examination at first sight suggests. Working as a 'looking glass', a 'mender', and some kind of 'time-machine', the African versions do both more and less than the Dutch ultrasound. The ability to present bodily insides thereby literally remains a real-time effect.

\section{A looking glass}

All the women I interviewed in Tanzania and Ghana unanimously agreed that the 'kioo', respectively the 'video', could "see each and everything!" In answer to my question how she would know, Laurentsia Shitindi, who had had her scan at the theatre at Sengerema Hospital, for example, explained:

How can you be fooled? The doctor ${ }^{121}$ looked at the glass. This one [she points at me], the mzungu*, looked at the glass. [...] I looked at the glass. I saw the water, much water. All around the baby, I saw it swimming there. How can I know [that] it is water? He showed me, it was like waves, moving. It came to the shore, he told me: "This is the child there; this is the body of the child." You could see it, the child was lying there to the left, and the rest was water only. (Tz 28)

Laurentsia Shitindi's explanation illustrates that what women see depends on what is shown to them by the operators. In 'the North', the showing of a 'waving' or 'yawning baby' (Mitchell, 2001) is such a common practice that Laurentsia Shitindi’s remark at first sight seems to underline a universal know-how in performing ultrasound. ${ }^{122}$ In Tanzania and Ghana, however, showing a child on screen was not routinely done but rather part of a

\footnotetext{
121 At Sengerema Hospital in the theatre ultrasound is operated by anesthetic nurses. As these don't wear the usual nursing uniforms, they are often perceived as doctors by patients.

122 See the PhD thesis of medical anthropologist Maud Radstake for an outline of the real-time imaging capacity of ultrasound and other medical imaging technology (Radstake, forthcoming).
} 
teaching moment for staff members or for a researcher. The 'common practice' also barely mentions that 'seeing' rests on a common language, that is, the ability to translate medical into lay terms, or as was the case here, the ability (or willingness) to translate English into Kiswahili, or into Kisukuma. In urban Mwanza characterized by an abundant fluency of Kiswahili, all women at Sekotoure Regional Hospital 'saw' the head, the tummy and the leg, thereby repeating the exact order of things that the radiographers had outlined during the examination. Happiness Malolo, for instance, said:

I saw the child; he explained to me: "You go look for yourself, mama. This is the head, the leg, the tummy. The baby is playing, you feel it. You see it here moving. This baby is playing. ( $T z$ 20)

Husbands, sisters or mothers, who sometimes accompanied a woman to the examination at Sekotoure Hospital, however, frequently saw more or other things. Standing like me behind the chair of the operator, they saw the numbers and figures emerging on the screen of the American machine with which doctors did their measurements, whereas the women themselves could only see the screen of the Philips machine used for observation (see chapter 4). One husband explained:

First, he shows us these things: the head, the legs, the tummy. He uses the other instrument ${ }^{123}$, then you will see one thing, the round thing. You look sharp and you see numbers appearing there at the machine. It is measuring the child. Then the nurse can tell you there at the clinic, this child is some months old, [and] the woman returns at the date she [the nurse, BMR] tells her. (Tz 33)

Yet, even if not shown, women may see things: 'each and everything', for example, also entailed seeing moving pictures in black, white and gray, either when a woman was scanned herself, for example at Sengerema District Hospital, or when the following ultrasound patient was scanned, as was the case at Korle Bu Teaching Hospital. ${ }^{124}$ Many women took these moving pictures on the screen to be the moving child whereby the transducer was seen as a kind of 'eye' or a 'torch' by which the operator followed the child in its movement. Anastasia Kinondoni, who I met in Dar es Salaam before starting my fieldwork, for example said:

123 The second ultrasound machine, see chapter 4.

124 Observing the following scan had to do with the fact that once each woman had dressed again after her own examination in the front part, she had to enter the back part of the room in order to pay, thereby passing the ultrasound monitor. 
They take that instrument, they go and catch the child. The child moves and the torch goes after him and looks into what? Everywhere in the pocket [mfuko], it goes after the child. If the child is fast, it moves fast. Maybe the child is sleeping, this is why it also moves slowly, slowly. (Tz 36)

Women who had heard about ultrasound before, moreover frequently 'saw' all the things they had heard could be seen during such an examination. Delilah Sumve, for example, pointed to one of the shapes on her ultrasound print-outs from Sekotoure Regional Hospital, claiming that she thought that this was "the kidney" (Tz 16). Asked how she had come to know, she explained that her mother had had such an examination and had later been told that there was something wrong with her kidney. Her explanation points to another aspect of seeing 'each and everything': for all women, every thing consisted of the missing things that nurses or doctors had not been able to see before, such as the existence of a playing child, a heart beat, a position, twins or a single child. For Celina Kondo, for example, 'each and everything' thus consisted of a 'low-lying placenta'.

Trying to make sense of what had been on the pictures or was on the print-outs, some of the women asked me or my field assistant after the examination. Celina Kondo whom I accompanied back to the labor ward asked me outright what the 'round thing' on the print-out was that I was carrying on top of her file, stressing that I as a researcher on "these things" (Tz 12a) should know. Overhearing the nurse-midwife, to whom she returned the ultrasound report, saying "ah, the problem is placenta previa", Mercy Prempeh at Korle Bu Teaching Hospital in Ghana employed yet another means: she consulted the glossary of her pregnancy guide. When I asked her later on what the ultrasound had shown she presented the newly gained insights into pregnant topography with the following pictures (Figure 5.1, 5.2). 


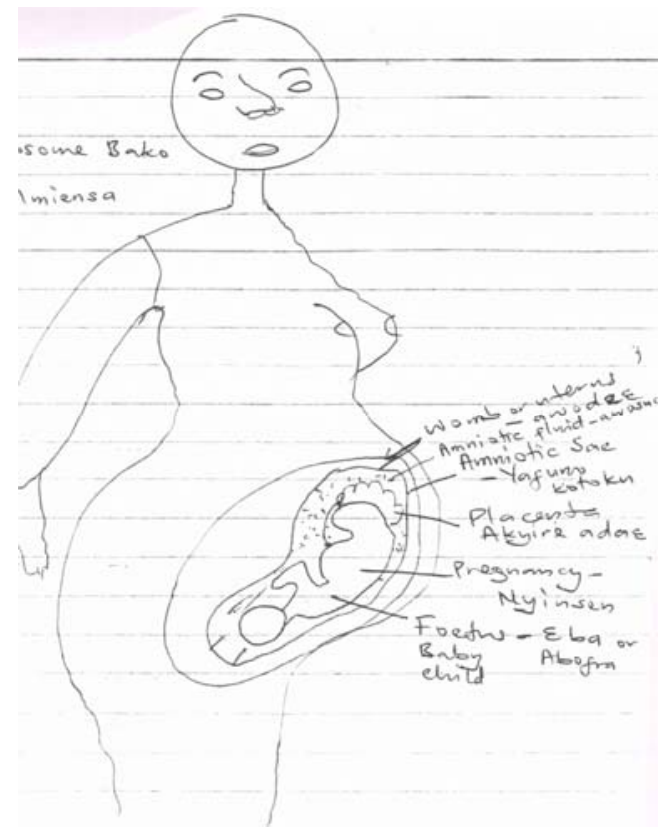

Figure 5.1 The illustration of a normal pregnancy in the pregnancy guide used by Mercy Prempeh which she copied into my fieldnotes. She designated the different body parts in English and Twi. (drawn while still pregnant, November 2002)

Figure 5.2 Her sketch of the disorder of the relation placenta to child of which she was diagnosed by ultrasound, a placenta lying before the child (drawn after the birth of her child, January 2003

The possibility of seeing what was inside a woman's body was attributed to the "medicine" used at the examination: ultrasound gel. This medicine, women said, made the skin smooth so that the transducer could bring the dark insides into light. The local application of the gel thereby shaped 'each and everything' too. The child's insides, for example, could not be seen, women said, adding that seeing inside the child would require 'the medicine' to be applied to the skin of the child's body. When asked, women, following the same logic, also explained that operators could only see whether a child was a girl or boy when a child was presenting its forefront to the machine's eye. The fact that they had not been told the sex was not regarded as a failure of the machine to be able to see each and everything but to the failure of the child to properly present itself. 
As gel was only put on the belly and the transducer only scanned a woman's forefront, a pregnancy that had turned to the back, women said as they laughed in response to my apparently absurd question, remained invisible. When I inquired whether they thought that the 'kioo' could see a pregnancy turned to the back when used on the back, most of the women firmly stated that this was a machine to see "stomach problems" only. Doubts, however, remained whether the 'kioo' could see 'maladies of spirits'. Mama Ceri, one of the traditional healers I talked to about the new technology, expressed her firm belief that the machine was only able to see 'white' and not Msukuma diseases:

You ask me whether this mirror can see the nzoka? It cannot. The nzoka is for the healer to see, it is a Msukuma disease. You need expertise to see it, to know 'this is nzoka!' [...] I know the hospital, it cannot see what? Nzoka. People tell me: 'You go to the hospital with nzoka, they tell you, it is worms.' This is what they see. Even with the mirror, they see worms only. [...] People get treated for worms. The condition is not [getting] better, they come to see me to be treated for nzoka. (Tz 34)

In contrast to Mama Ceri's claim of distinct realms of professional influence into invisible matters, many women were sure that the machine could have seen the nzoka if only the operator had looked at the right place. Salima Kuku, for example, showed me that the machine had been moved only on her lower abdomen while according to her the nzoka that had bitten her other children sat in the upper right part of her abdomen. The conviction that the new technology was also able to see afflictions evoked by nzoka that many women in Sengerema hold may have been triggered by the way some of the staff explained the visual capacity of the new technology to women who had been sent for ultrasound on account of intrauterine fetal growth retardation or death due to syphilis. The 'kioo', they said, had shown white spots that the woman had certainly been able to see herself, and it was these wadudu that were responsible for the death or malformation of the child. In Kiswahili, the term wadudu refers to 'small animals' - a way with which health care professionals attempt to describe bacteria or parasites. Yet it may also refer to 'spirits'. The translation of biomedical concepts into local language, thus, may have worked to uphold local concepts of affliction.

'Kioo' in Tanzania or 'video' in Ghana, hence, is a diagnostic imaging machine: it is capable of visualizing bodily insides and things that biomedical professionals were not able to see beforehand. Like a 'video', the machine thereby reels moving pictures in series. Dependent on 'medicine to see', however, the machine can only partially render the body 
transparent - 'kioo' works as a mirror that reflects the surface only, and so the inside of children's bodies remain opaque.

\section{A mender}

As well as diagnosing, many women were convinced that the new technology also treated certain conditions. Ester Matatu at Sengerema District Hospital, for example, told me that before the examination, her pregnancy had been 'hot' [Kiswahili: kali], a term which women frequently used to describe conditions that threatened the continuation of pregnancy: due to having taken 'the syringe' before this pregnancy and having received a blood transfusion on account of "lacking blood", her child had come to "lie badly" [Kiswahili: amelala vibaya]. Told after the examination that her child was now "lying nicely" (Tz, 27 [Kiswahili: analala vizuri]), she attributed this repositioning to the particular working of the 'kioo' that 'cooled' this condition: ${ }^{125}$

I just slept. They put the medicine from the bottle; it was water-like medicine. They washed the stomach. [...] They washed the stomach all over. Then they use this instrument. They go round, round and round. It cools you, it cools you, truly, mama. [...] It pushed the child into sitting nicely. "Your child is sitting nicely", the nurse at the mirror told me. (Tz 27)

Experiencing the new technology as a way to mend a perceived disorder, the practices of 'washing the stomach' resonates with traditional healer's practices to wash women's bellies with medicine when pregnancies are considered to be 'at risk'. It was in fact especially with regard to 'bleeding problems' that women's stories in both Ghana and Tanzania enacted the new device as a mender. In all these stories ultrasound gel, 'medicine' and the particular way of application feature as the key factors that provide the device with healing powers. Distributing 'the medicine' in circular movements, bodies were seen to become "closed" again. Proclaim Winston at Korle Bu Teaching Hospital in Ghana referred to 'the video' as being the agent that had stopped her bleeding and brought her children to life again. Emphasizing the continuous circular movement of the transducer on the outside of her belly her story seemed to suggest the existence of a blood cycle that had been interrupted, causing blood to flow out, which was restored to order by the technology.

\footnotetext{
125 In the ultrasound room, the nurse-midwife-ultrasonographer Stella Ndogo had palpated the child's return to a physiological long-lie already prior to scanning. Only after the examination, however, she told Ester Matatu that her child was "now" lying nicely.
} 
They go round and round. The blood that has been coming out, it does not come out anymore; it finds its way back to the body. It does make the child alive again; you feel it playing fiercely after the video. [...] They gave me a pen and a paper to write the movements for one hour. ${ }^{126}$ In one hour I had written down many of them. You see they, these two [by ultrasound she was diagnosed with twins, BMR] were alive again. (Gh 8)

Her story suggests an underlying body concept that builds on the idea of a blood flow that is interrupted when women bleed vaginally. This notion may be particular to the Fante, an ethnic group inhabiting the Southwest of Ghana, to whom she belonged, and it may be that the introduction of ultrasound had made new body images emerge. Her explanation, however, demonstrates how local bodies of knowledge may feed into making sense of new technologies.

In Mwanza town in Tanzania, Celina Kondo was one of the women who expressed the conviction that her child had been 'reanimated' by the 'kioo':
I had to go to Sekotoure Hospital since whenever I urinated blood began to flow heavily again. I was then referred here [Bugando Hospital, BMR]. I was thinking maybe my child is dead in the womb. How can it be alive with all that blood gone? He [the admitting doctor, BMR] asked me: "Do you feel the baby playing?" I told him I don't. Until he started to measure with the kioo, I then felt it moving again a little. [...] After staying there for three days I did not feel it playing and blood came again. When they were measuring, they failed to see it. [...] Then they measured me with kioo again. The answer was the same: the after-birth is below. [...] The doctor encouraged me and said: "But now we see it moving." Truly, I felt it again. [...] Now I just believed, I knew it was a reliable instrument. (Tz 12a)

The two stories of Proclaim Winston in Ghana and Celina Kondo in Tanzania show a different temporal order than commonly held by biomedicine. The latter keeps diagnosis and treatment apart: diagnosing a placenta previa results in standard biomedical practice to order women to lie down in order to alleviate the gravitational forces of the fetal head on the placenta. In most cases bed-rest leads to the cessation of bleeding. In Celina Kondo's and Proclaim Winston's accounts, in contrast, diagnosis and treatment coincide in the moment of examination. In this double and simultaneous function 'kioo' and 'video' align with traditional healing practices that intermingle the diagnostic process of inquiry into relationships and encounters with subsequent treatment (see Horton, 1967).

\footnotetext{
126 Proclaim Winston here refers to the so called 'kicking test' whereby a woman notes down the fetal movements she feels within one hour as an indicator for fetal well-being.
} 


\section{A time machine}

In pursuit of probing into women's experiences with a new technology, my field assistant at Sengerema District Hospital used the word 'to startle' [Kiswahili 'ku-shtuka']: "Were you startled that this machine could see your unborn child?" For women familiar only with Kisukuma, she translated the not-yet-there-ness of the entity we were talking about with the term kiumbe, creature. In Kiswahili she used the word kitoto thereby transferring the common term for child mtoto out of the class of living beings into the class of things. ${ }^{127}$ All my transcripts display a pause at this point, a hesitation and then women's question in return: What does she [I, BMR!] mean? [Kiswahili: anasema nini?] This forced me to explain myself: "Weren't you startled to see something that is not yet there?" Their answer in all cases was negative: neither the matter itself - seeing something invisible to the eye - nor the capability of the machine to visualize unseen matter startled them.

Probing further into the apparent normalcy of seeing things which are not there yet but are to come, women made references to their experiences with other technology that, as they said, brought 'news'. Mercy Prempeh at Korle Bu Teaching Hospital in Ghana, for example, referred to her experiences with operating a computer. Similar to a computer, 'the video' enabled one to see things ahead in time. Filling in present calculations, the video/computer calculated the rest when pressing the proper key:

It works like a computer. You know, I did computer work myself: you fill in some data of today, maybe numbers, or calculations with the keyboard. You push a key [and] what comes back to you is the numbers of tomorrow or next year. (Gh 9)

In rural Tanzania, Ester Matatu compared the working of ultrasound with that of television that she had seen in one of the bars at Sengerema Village when selling fruit and rice in the market. The ability of the ultrasound to tell 'news' for her had to do with the machine's connection to the electric power system:

It is like TV, mama. You get the news, all news. Things happen, they are there somewhere, you hear them, and you see them [although] you are here. You ask me how it will do so? I saw it; it is connected there to the wall to the power. So it will get the power from there. Like TV it tells you all things. (Tz 27)

\footnotetext{
${ }^{127}$ Kiswahili is a language that operates with classes. Each noun belongs to one of the ten classes which in turn determine the prefix of the noun and dependent grammatical structures like adjectives or verbs. Living beings in general belong to the $\mathrm{m} /$ wa class (see also Msukuma/Wasukuma for one Sukuma person or several) whereas many objects belong to the ki/vi class (e.g kitu=thing, vitu = things but also Kisukuma or Kiswahili for the language spoken by Sukuma or Swahili people.
} 
Statements like the above show that women made sense of the new technology in relation to other technology that resembled the new one in certain features: in its ability to calculate, for example, or in its hardware such as the existence of keyboard, or a monitor. Showing things that were invisible to the eyes, in consequence, were explained with the perceived working of these reference devices.

With regard to my question as to why they were not startled, some women, however, also told stories in which the working of ultrasound was linked with traditional practices of making invisible entities seen. At Makongoro Antenatal Clinic, Miriam Kihundo told a story of this second kind:

My father was called one day by my grandmother. She told him: "Go to that house and serve the people there!" My father replied that the house was empty and that there was nobody to be served. "You go there and serve them! Have you forgotten how to serve your fathers and mothers?" My father told her that the house was empty, [and] that he could not see anybody. My grandmother was a healer. She gave him medicine to put on his eyes. She told him again: "Go there and serve your fathers and mothers!" He went inside. He could seem them now. The house was full with those before him who were dead already. He served them food [and] drinks. When the night came, she took away the medicine from his eyes, he could not see them anymore. The family turned well. (Tz 17)

Her story resists the same easy reading of those narratives that link one modern technology with another. Taking her narrative as another serious answer to my question, however, her story reveals the necessary requirements to making unseen entities visible by common knowledge in Northwest Tanzania. Seeing, or rather making them seen is a purposeful action: it is not to be done easily. Visualizing the invisible moreover requires an expert, figuratively a person of age, either by biology (a grandmother) or by social position (biomedical staff, see chapter 3). It also requires 'medicine' that can be put on 'eyes' enabling somebody to see through or behind the apparently visible. Her story integrates the workings of kioo into local understanding of maladies as effects of badly held relationships with one's elders that have to be mended by paying respect. My careful objection that in her story by means of medicine her father was able to see 'the dead', that is, past beings, while 'the kioo' 
was showing the 'yet unborn' was dismissed by her remark that "grands and children are the same" (Tz 17). ${ }^{128}$

While Mercy Prempeh's comparison of ultrasound with a computer suggests the notion of a predictive value of 'video' parameters, women's stories in rural Northwest Tanzania rather stressed a past working on the present. The prognostic power of the device, in contrast, seemed rather limited. These limitations became particularly apparent to me in a discussion I had with Nyamwaga Lugari at Sengerema Hospital after she had been csectioned of a baby daughter. Bending over both her baby girl and a photograph of the ultrasound picture I had taken and that she had asked me to bring with me, our conversation proceeded as follows:

NL: I am happy now. You see, it is a child.

BMR: It was not a child before?

NL: It was, it was... maybe, you cannot be sure.

BMR: You told me that with the kioo, you were sure it was a child.

NL: The kioo showed it was playing, yes, it was a child.

BMR: So after the kioo you knew you were carrying a child?

NL: It is a child now.

BMR: So between the kioo and now, was it not a child again?

NL: A child is a child. You see it here. You remember the picture there, the white round with the dark in the white. You look [at] my baby now. She is white, you see the white with dark hair. ${ }^{129}$ You see now the ultrasound was speaking the truth. (Tz 31a)

In Nyamwaga Lugari's story the present head of her child mirrors the head that she saw on the ultrasound screen: yet it does so only retrospectively only. It is with a child in her hands that my questions seem indeed absurd - of course, a child is a child. Again, the past her coincides with the present, the predictive capacity of ultrasound to hold child matter stable between examination and delivery, however, remains an issue of uncertainty. What then are 'videos' and 'kioos' able to present?

\footnotetext{
128 The conceptualization that grandparents and grandchildren are the same is a common notion in SubSaharan Africa (see, for example, Susan R. Whyte \& Whyte, 2004).

${ }^{129}$ Nyamwaga Lugari here refers to the light skin with which many African babies are born. That her daughter had my skin color rather than hers, became a repeated joke between us.
} 


\section{Present-ability}

Asking women about their experiences with the new technology reveals that its ability to present any thing hinges upon the socio-technical configurations of the ultrasound room, the ability to see or to be made seeing, to share a language or find translators, be they operators, pregnancy guides or researchers, or to encounter particular silences. It also hinges upon local concepts of 'medicine' that allow visibility of bodily insides and of healing power to which biomedical tools may be subsumed, pregnancy guide books, and knowledge of other information technology. 'Kioo' and 'video' then present placentas, children, water, and child movements but their present-ability does not reach inside children. And while the local application of ultrasound's medicine continues to exclude sorcery inflicted conditions from entering the hospital, (un)certainty remains whether 'kioo' can present n₹oka. ${ }^{130}$ The temporary application of medicine makes the examination literally what it is - a real-time event whose prognostic capacity seems to be bound within hospital walls.

\section{Subjecting (to) ultrasound}

After having 'done video' or having had 'a kioo', women return to the health care professionals that referred them to the ultrasound room. Back at the clinic, women are confronted with what the ultrasound has shown according to the professionals, and what these experts consider the appropriate steps to follow from this diagnosis. Women were not passive recipients to these proposals, however. Rather, they used the diagnoses they were presented with to enact new subject positions that ranged from being passionate patients to being highly observant clients to being deliberate consumers of different health care trajectories. Each of these subjectivities aimed at sustaining women's ability to carry children albeit they did not necessarily align with the reduction of maternal and perinatal mortality statistics.

\footnotetext{
${ }^{130}$ While x-ray in Northern Ghana, as I heard, was known to be able to see witches, the few women I spoke to there did not indicate a similar capacity for 'video'. This may have to do with the brevity of my fieldwork in Northern Ghana due to the restrictions I explained in chapter 1, but it could also be the result of the technology's novelty, or my unfamiliarity with both the local language and acquaintance with people who would trust me enough to reveal these traditional entities to someone coming from afar.
} 


\section{Passionate patients}

When talking to women before and after ultrasound examinations I was often surprised by the co-existence of very precise knowledge of how to deal with pregnancies and pregnancies 'at risk' and the frequent declaration of un-knowledge when I asked them why they were attending the clinic, or what had brought them to ultrasound: 'I don't know. The nurses, they themselves, they know!' Women who had given birth several times would insist on me teaching them about pregnancy even when I pointed out that I was childless, and would ask me for explanations while they would not ask nurse-midwives or doctors. I was surprised by their positive evaluations of ultrasound and their stereotypical answers to my question of whether they would want to have such an examination in the next pregnancy: 'If the nurse sends me.' I had trouble bringing together the clear decisions to deliver at home with women's patience at sitting for hours on benches waiting to be weighed and palpated. Clearly, women would know themselves whether a pregnancy was developing well. And I often marveled at what biomedicine usually refers to as 'compliance': women attentively listening to the same health education classes over and over again while at the same time they told me that they never bothered to read or look at the many posters the antenatal care clinics were decorated with. It was at one of the focus groups at Sengerema District Hospital where my probing into their evaluation of their own knowledge versus that of health care professionals was poignantly answered by one of the elder women whose comment was seconded by vigorous consent by the other focus group participants:

You go to kliniki for what? You go there for measuring. Without the measuring, who will tell you about problems of the stomach? (Tz 33)

This answer that attributes knowledge about 'stomach problems' to the clinic, mirrors a pragmatic approach: 'problems are for knowing' (Dewey, 1984). The passion with which the clinic here is defended as the stronghold of knowledge, despite the high frequency of pregnancies in the area that are instead taken to a healer or stay at home, fades out the world before the hospital that is characterized by uncertainty about what to do. The pregnant women that I met in the hospital already carried a hospital-able pregnancy, that is, a pregnancy for which biomedical knowledge was considered the appropriate source of care. Knowing about not knowing, not caring or not daring to know, in my opinion suggests at once the acknowledgement of a defined other kind of expertise that can be sought out for 
information as well as demonstrating an implicit knowledge of how to behave in biomedical facilities. Young women who attended antenatal clinic for the first time and who spoke with a low voice or did not give answers, for example, were frequently told by older, more experienced women to 'speak up' and 'tell the nurse' in order to for the nurses to know about their 'stomach problems'.

Women's practices of waiting, listening, 'shutting up', smiling when scolded, not wanting to "disturb the doctor with questions" (Gh 8), and obediently following orders to lie down, undress, hurry up, and to be sent away for the following examinations hence are activities to step into the passive patient behavior required to enable them to become known to biomedical staff and to become able to be moved and move around. This ability to become recognizable as patients, however, required each woman to obtain an antenatal record card. Without such a card, women in Mwanza and Sengerema repeatedly told me, they would be turned away in case of emergency. I was never able to verify this statement, and all the biomedical health care professionals that I spoke to, denied its truth. The way that women were made to attend the health care education classes preceding the antenatal care service at Sengerema District Hospital, however, gave a glimpse into the kind of institutional constraints to which women were subject(ed). Well known among the nurse-midwives was women's eagerness to have a blood test. In fact, when I asked women to rate antenatal examinations according to their importance, all of them mentioned 'taking blood' first, explaining that by examining the blood "all the problems in the body" could be determined, for example, "if the stomach is troubling you, malaria, the waist, $[\ldots]$ typhoid, $[\ldots]$, why this person remains $\operatorname{slim}^{131}$, this other needs blood, or that this one has an unfaithful husband" (Tz 33). Taking advantage of this eagerness for blood tests, nurse-midwives coupled attendance at health care education classes and correct answers to their questions with a blood examination for syphilis.

Enacting "active passion" (Gomart \& Hennion, 1999), that is, giving in to the hospital apparatuses and becoming (a) patient, enables women to get what they want and have come for: it produces formerly unknown and vital information about what is at stake and what they and biomedical practitioners have failed to get known. ${ }^{132}$ At Bugando

\footnotetext{
${ }^{131} \mathrm{HIV} /$ AIDS is often spoken about in secretive ways. In my opinion this reference to 'slim', in particular in relation to the context of blood in which it appeared, points at the disease rather than to weight as such.

132 Similar to Emilie Gomart and Antoine Hennion, anthropologist Charis Cussins describes women's self-objectification at an infertility clinic as acts of subjectification, and of gaining agency (Cussins, 1996).
} 
Teaching Hospital Celina Kondo described her movement through (and by) clinical space with the following words:

Now here at the hospital, God is the one who guided the doctor, that is why special equipment has been placed.[...] I just believe because it is the equipment, which is brought for that activity - that the problem with its complications, it will be seen through ultrasound very clearly. Only if [...] powers of darkness [are] used [and] a person is being bewitched [while] you have the possibility of measuring, you fail to see anything. Myself, I just believed that if there is anything open, it will be seen and that's why it was like that. $[\ldots](\operatorname{Tz} 12)$

Letting go, actively and expertly in her case paid off. Deciding her bleeding episode to being a 'malady of God', her son's name mirrors the effect of her 'active passion': his name is Ebenezer - God's stone. ${ }^{133}$

\section{Observant clients}

In her study of women's perceptions of ultrasound in a District Hospital in Botswana, health scientist Sigrid Tautz describes women's fear of "the dark room" and of being "electrocuted" (Tautz, 1995, p.54-56). In contrast, all the women I spoke to told me that they had felt "fine". One explanation for this difference in experience may be the degree of sophistication of ultrasound machines. In contrast to the ultrasound technology of the past, even basic contemporary machines do no longer need a dark room to be able to generate correct pictures. ${ }^{134}$ Another explanation, at least in Northwest Tanzania, may be that familiar elements of traditional healing practices resemble (or are seen to resemble) those employed by biomedical practitioners when performing ultrasound, for example the 'washing of the body with medicine'. This does not mean that the new technology is uncontested. Janice Mtutu's denial to have labor induced on account of intrauterine fetal death - a child that had left the stomach, as the nurse-midwives put it - also speaks of mistrust of hospital medicine and its representatives. It was the alignment of the still picture made at the second ultrasound examination (scanning not for the heart but for a collapsing fetal skull, see chapter 4) with the statement that the 'child had left the stomach' that convinced Janice Mtutu that her child had indeed gone - subjecting the operator to ultrasound findings:

\footnotetext{
133 In the Bible Ebenezer means 'God's stone' (Book of Samuel, Chapter 7, Verse 12).

134 The main technological development enabling a departure from the 'dark room' has been a change in pixel quantity and contrast.
} 
At the first mirror, I saw it moving. She [the nurse-midwife, BMR] told me that the child has left the stomach [but] I saw it moving there at the glass. I felt it moving then. They want me to do what? Take the pipe ${ }^{135}$ to remove the dirt. [...] They brought me to have the mirror again. This time I did not see it moving. I saw dirt only, ashes. The child had truly left the stomach. (Tz 29b) ${ }^{136}$

Subjecting ultrasound to tests for safety became an issue at one of the focus group discussions at the Waiting Home in Sengerema. In several interviews before the ultrasound examination, women had asked me whether this kioo - ultrasound - was as dangerous as the other kioo, x-ray. The latter was known, they said, to "take years of life away from you" (Tz 32), and thus should not be done during pregnancy. When this issue of safety came up at one of the focus groups, some of the women, who had previously had an ultrasound, explained how they had become sure that the new kind of 'kioo' was rather harmless. In their explanations the body of the nurse, or more accurately the particular coordinates of this nurse-body in relation to the technology, became an indicator for safety that allowed women to hand themselves over:

With the other instrument, the mirror for legs, they [the staff, $\mathrm{BMR}]$ just leave you standing there. He will just go out, or stand behind a glass. [...] With this new instrument, the mirror, they just stay there, next to it. You ask me now 'would s/he want to hurt herself? ( $\mathrm{Tz}$ 32)

With regard to safety another prominent issue in the discussions concerned the medicinal power of the ultrasound gel. Above I have pointed out the purposeful application of medicine in order to make unseen things visible and repair existing disorders. This power is not to be misused, and is confined to the act of diagnosis/treatment. All women whom I had observed having a 'kioo’ at Sengerema District Hospital were eager to carefully remove any trace of the gel after the examination was done. The contamination of clothes with the gel thereby seemed to play a lesser role than the peculiar state and place of the child that the

\footnotetext{
135 Janice Mtutu hereby refers to the catheter with which labor is induced in cases of intrauterine fetal death. Hereby a urinary catheter is inserted into the cervix, blocked with $50 \mathrm{ml}$ of water at the other end and fixed to the inner upper leg of the woman in a way that the catheter pulls down. The mechanical forces thereby generated result in contractions and subsequent cervical dilatation without requiring the application of drugs or drips to induce labor.

136 This notion of a non-existent child is understandable with regard to a failure to 'see' a child on the screen when not shown. It seems paradoxical as even an induced abortion delivers a 'child'. What has to be kept in mind, however, is that women who don't give birth to a living child, are not shown these children. Rather these deliveries are immediately wrapped into khangas* and put away until the relatives of a woman upon her discharge or earlier take this bundle with them. Whether women at home opened this bundle again, I don't know. According to Sukuma tradition, stillbirths are not buried in the same way and in the same places as children who have lived and have died later. While the latter are buried by men in the fields, a stillborn child is buried at the outer edge of the house by women or their female kin.
} 
gel/machine connection had brought about. Most explicitly Nyamwaga Lugari pointed to the potential transformation and displacement of child matter during the examination:

Maybe the child is there in the machine, maybe here [points to her belly, BMR]. You feel it playing, they see it playing there. They finish seeing, you feel it here again. The mirror does not show it again. I could not see it there. I would not want my child to stay there. (Tz 31a)

It was the gel's transformative power that hindered the absolute settlement of the safety issue. Some women at the focus group in Sengerema expressed their certainty that the machine was safe - an opinion that women I talked to in Mwanza town or in Accra never questioned. Others, however, said that they thought their children were safe because the 'medicine' was not put directly on them, yet they remained uncertain about whether the device might diminish their life-time. The care with which women ensured the safe return of their child to its proper place in the belly was echoed by the importance that women attributed to keeping the examination to themselves, telling nobody than perhaps their husband about it.

Women, then, do not take the introduction of a new technology into maternal health care lightly. Rather, they observe very carefully how a device is handled, and use familiar elements and the movement of other actors in health care to evaluate the safety of a new practice. Professional bodies thereby become conditions for attaching to biomedical trajectories, and get - unknowingly - disciplined in the same process that disciplines patients. As much as women are subject to ultrasound, they also subject ultrasound to particular parameters aiming to establish the safest ground possible. What happens, though, when this careful evaluation results in the observation of safety gaps?

\section{Deliberate consumers}

Most of the women, I talked to, followed the care trajectories designed by biomedical health care professionals: they let themselves be admitted into the maternity or labor ward, they went home and returned at the date indicated on their antenatal record card for the following visit, they took great effort to get the money together for extra examinations, and they moved over to the Waiting Home at Sengerema Hospital to patiently await the day of delivery. Studying sophisticated health care technology such as ultrasound carries the problem of not being able to meet with those that do not come or do not return to 
biomedical facilities. Multi-sited ethnography at different health care facilities moreover makes it difficult to follow returning women from one health care visit to another, particularly as appointments of antenatal care visits are not fixed, and may be spontaneously shifted by women due to other obligations, lack of transport or money. Nevertheless I met with women who used ultrasound to design and to follow another trajectory than that proposed by biomedical professionals. To my surprise, all of these women were pregnant with twins. What was the particularity of twins that led to an untwining of women's attachment to hospital care?

At Korle Bu Teaching Hospital in Accra, it was Grace Kintampo whom I first saw making a deliberate decision to leave the hospital - secretly - after ultrasound had diagnosed a twin pregnancy and a placenta previa, making her a high-risk case in the eyes of the hospital staff. A couple of days before she left, Grace Kintampo had pulled me aside before the big ward round, requesting me to convince the doctors to let her go home: knowing that she carried twins, she said, she needed to go home in order to gain enough money to pay for the delivery and clothing of two. The fact that 'the video' had stopped her bleeding and the lively kicking she had monitored herself (see above) had convinced her that both children would be born alive. Her concern revealed a practical dilemma: uninsured, the birth of any new child always threatens to be a financial burden, yet twins - a biomedical risk factor cost a lot even before they are born. While mothers are exempted from fees theoretically, tertiary care such as the antenatal service at Korle Bu cost: a card 12.000 Cedi, a vaginal delivery 10.000 Cedi, a c-section 40.000 Cedi. In order to make women pay these fees, health care professionals kept babies when discharging women. These women then remained camped nearby the hospital until they had earned enough money to 'free' their children. Grace Kintampo's decision to leave the hospital against the advice of the doctors implied the impossibility of returning for delivery unless perhaps as a case of emergency.

At Nalerigu Baptist Medical Center in North Ghana I did not actually met with a woman deciding on an alternative trajectory due to ultrasound. However, one of the Traditional Birth Attendants I talked to, Ama Kwaku, recalled a story, explaining that this was how she had learned about the new technology in the hospital. Living across the street from the facility, women who came from the very interior often gave birth at her place, using this proximity to have the child vaccinated after birth before going home again. As she did not do antenatal care nor knew how to palpate, she was caught unaware by the birth of a 
second child born lifeless after the first child had been delivered without any problems. Immediately taking the second child to the hospital for possible reanimation, she then learned - when handing over the antenatal record card of that particular woman - that it was actually already known that this woman had carried twins due to an ultrasound examination a couple of weeks ago, that the woman was informed that she had to give birth at the hospital in order to ensure the survival of the children, and that this advice was also written on the card. Ama Kwaku's observation that the woman did not seem to be particularly sad about the eventual death of the second baby made her conclude that the woman had deliberately decided to attend her rather than hospital care to prevent the survival of both babies but insure the survival of herself with one child. In her explanation she referred to the danger that the birth of twins would pose to the entire community, and provided me with an understanding as to why many of the women begging in the streets of Accra were mothers of twins:

Where she comes from, there further down the bush, women who have twins are just chased away. [...] In the past, they killed the twins to make place for the following children and [for] the community to stay healthy. In these days, they [women who give birth to twins, BMR] are sent away for one year. One year she has to spend somewhere. Maybe then she can come back. (Gh 13)

Her story points again to the malleability of children and to the threat that the undefined state of children as persons pose for the family and wider community. In Ghana, it is after one year that children are giving a definite name, thereby transforming them from an inbetween state between the ancestral world and human beings into somebody belonging to the world of the latter. Twins, premature babies or children born in breech position are considered to be out of the ordinary. They are often given special names to carry and to be referred to throughout their lives to stress their extraordinary position, their naming being part of the social handling of their potential threat for everybody. ${ }^{137}$ Twins, albeit not a rarity in Usukuma (as among many other ethnic groups in SubSaharan Africa), are considered to be 'infectious'. A woman who is suspected of carrying twins, for example, is not allowed to clean the village well, which would dry up should she do so, people said.

\footnotetext{
${ }^{137}$ In Usukuma, people who have been born prematurely may thus be referred to as ndebile, the term used to designate a premature child, while children born in breech position are called taabu $=$ problem [Kiswahili]. The potential polluting power allocated to twins, referred to as kulwa and dhoto [Kiswahili: first, second], however, also pertains to subsequent children. Thus up to the $6^{\text {th }}$ child after the birth of twins, children are given special names (see Varkevisser, 1973a for a complete list of these names).
} 
At the focus group discussions at Sengerema Hospital, women who had been diagnosed with twins by the 'kioo' stressed the value of knowing beforehand. While non Msukuma said that they preferred delivering twins in the hospital in order to have their relatives at home prepare for the "big trouble" (Tz 33 [Kiswahili: mapacha ni taabu sana]), in particular younger Sukuma women diagnosed with a singleton 'big baby' instead of the suspected twins by ultrasound claimed that with twins they would have delivered at home, as two small babies would give less trouble than one big child. I met three women at the children's clinic, who had done so, two of them with twin babies, one of them with only one baby as the other had died. Women diagnosed with twins, hence, may leave the hospital again, considering a twin delivery to be less risky than that of a big child that "tears a lot of muscles", as Nyamwaga Lugari explained who had also given birth to twins at home ( $\mathrm{Tz}$ $31 \mathrm{a})$.

Next to practical problems of feeding and clothing twins, the problem of twins concerns the potential polluting effects that their delivery has for succeeding children of a family, and the entire community. Preventing this pollution requires the performance of 'traditional' healing practices or of 'healing practices' provided by biomedical facilities, albeit not by just any facility. Several of the Sukuma women who delivered twins at Sengerema Hospital, for example, emphasized the role of the church on the hospital ground. Twins, they said, would have to be "cleaned" with medicine before being presented to the community (see also Varkevisser, 1973b). This could be done by a ngoma ceremony, or by baptizing - 'washing' - the child before going home.

The issue of 'twins' hence evokes a different framework than that held by biomedicine. While international obstetrics hold twins to be a risk condition for both pregnancy and delivery, women in Ghana and Tanzania stressed the risk that twins posed for the time after birth. Twins spread risk horizontally and vertically, affecting future children and present communities. Knowing about twins is not a matter of ultrasound, 'video' or 'kioo' only - women or their communities may be suspicious of twin pregnancies, and twins may be palpated by health care professionals. Formerly, palpation in case of doubt, however, resulted in the warning of 'a big baby' whereas nowadays, ultrasound differentiates twins (more often). Meant to keep women at biomedical facilities to ensure a safe delivery, ultrasound allows women to choose the most appropriate care trajectory in order to sustain the well-being of themselves and those to whom they are related. 
Women's deliberate choices to go home, display the hospital as just one out of several trajectories to ensure safe motherhood. Going home or going to a healer is not done without deliberation, however: it requires trustfully handing oneself over to nurses and doctors beforehand and knowing what 'the hospital' is good for. Attaching is the precondition for detachment. This role of the hospital as a stepping stone became nowhere as apparent to me as in the piles of antenatal record cards that women left behind at the maternity ward at Sengerema Hospital after being discharged. Leftovers from the present pregnancy, they indicated that hospital business was done.

\section{$\underline{\text { Carry-ability }}$}

'Getting a stomach' in both Ghana and Tanzania raises questions: what is the matter, and what is to be done? Trials are set up that force actors to design new arrangements. Each arrangement calls for certain concessions: antenatal record cards may have to be obtained and paid for as much as ngoma rituals require financial or material investment, and certain entities may have to remain silent or be silenced. In the attempt to find the appropriate care (giver) for a pregnancy, be it at home or at the hospital, ultrasound turns into an agent for women to use as they negotiate the hospital arena as one possible trajectory for securing carry-ability. Opening up several trajectories, ultrasound knowledge thereby serves to increase women's survivability in a community where the ability to carry children is crucial. Going home may pollute statistics when it works against the survival of a present child - yet it will keep up child potential.

\section{Knowledge matters}

Exploring the women's apparatus, this chapter has shown how knowledge matters in and for technography. Knowledge that shapes and is shaped by ultrasound thereby comes in multiple forms: as book information (in pregnancy guides), as empirics (counting and observing bleeding patterns, for example), as experiment (enforcing child movements), as obsolete or modern knowledge, as silent or bidden knowledge, as tested and contested knowledge, as tacit knowledge, as knowledge about not knowing, as nurse- or 'white' knowledge and as body knowledge. The foremost characteristic of all knowledge, however, is that it is local, even if some of the knowledge aims for universality. This bounded-ness of knowledge becomes especially apparent in the 
place-bound entities that come to afflict pregnant bodies, in local spirits and contraceptive practices. This local knowledge, however, is by no means static. Rather, as I have shown, it integrates social and environmental transformations that places and people have undergone, for example, the labor migration of men, increasing urbanization, erosion of traditional values, the establishment of new authorities, and the introduction of 'modern' health care technologies. Knowledge, hence, is situated: it is adapted and adapting to particular places in particular historical moments, and to new situations that emerge in space and time (see Haraway, 1991).

The practices by which women in Northwest Tanzania come to know about pregnancy reveals that this pregnancy knowledge does not rest on a rigid, extracorporeal body of knowledge but on a process whose center is the body and that I would call "knowing in action"(VanderWolk, 1998). Thus, while the practices with which Sukuma women come to know about pregnancy resemble those used by women in the Netherlands, Germany or the United States (doing pregnancy tests, paying attention to menstrual calendars, etc.), the emerging object/subject of these practices differs from that in 'the North'. In 'the North' being pregnant, by definition, means 'being with child'; in Northwest Tanzania, in contrast, 'child' is contingent, subject to underlying constant formation, deformation and reformation throughout pregnancy. This contingency of bodily matters is rooted in the investment of a woman into the social relationships with kin, neighbors, husbands, and in-laws that have impact on her reproductive career. Having a body and being somebody, in short, rests on negotiations with one's surroundings, that is, on the making and breaking of social relationships. These social ties underlie all aspects of life, including physical growth, development and the decline of the body. Rather than being bound by skin, every body literally leads a relative existence while bodily trajectories are intrinsically contingent on each other. ${ }^{138}$ Women's particular vulnerability in this context rests on the indistinctiveness of the body of the unborn. Pregnant bodies, hence, are literally in-dividuable in the sense that they cannot be separated from the relationships that sustain and substantiate them. At the center of the trials that make and sustain pregnancy, hence, is not the individual pregnant woman but a hybrid collective, which consists of bodies, invisible

\footnotetext{
138 As historian of science Mieneke te Hennepe argues, the conceptualization of the body as being bound by skin, hence that of individuals as bodies separate from their surroundings, is the effect of visual technologies such as microscopy and photography in the $19^{\text {th }}$ century (Te Hennepe, forthcoming).
} 
agents, protective devices, negotiations, and, in short a 'collective patient', or 'patient collective' (Callon \& Rabeharisoa, 1998).

The effect of 'knowing in action' is that knowledge remains partial, unfinished and only temporarily acquires stability. Both the body of knowledge and the body physical remain in flux, (con)tested, and contingent. Instead of diminishing, 'knowing in action' in principle maintains uncertainty. It thereby also allows women to keep up hope, for example, with regard to the potential mending of intrauterine malformations. 'Knowing in action', hence, keeps open different trajectories. It is important to note that the logic underlying Tanzanian women's management of uncertainty is not to 'wait and see' - what is at stake is too important to simply let go. Rather, women in Northwest Tanzania actively engage in uncertainty practices that include solidifying certain insights (child movement), acknowledging uncertainty (allowing for multiple etiologies of bleeding), falling back on experience and agreeing to certain procedures, for example the requirement of having an antenatal card in order to be treated at any time (see Van Asselt , 2005). ${ }^{139}$ As epistemic entities - be they scientific or non-scientific - become articulated through activities that resist their efforts, women transform a vague mass of threats in the world into manageable trajectories and establish certain 'stomach problems' as objects of particular therapeutic practice. If, as Latour (2004, p.206) has argued, "[t]he body is the dynamic trajectory by which we learn to register and become sensitive to what the world is made of", 'having a kioo' or 'doing video' allows more articulations to be realized and thereby increases carryability and the ability to go home and survive.

It is interesting to note that women in Ghana and Tanzania do not seem to perceive there to be a separate realm of epistemology. Words, thoughts and intentions are actions in the world that can have significant effects on people's physical states no matter whether they are acted out in the hospital or at home. This rather tangible knowledge orders ontology in a way that fits to the contingent lives that many women in Tanzania and Ghana find themselves in and set out to manage with regard to their and their children's health. To this tangible knowledge belongs the secrecy of knowing things. Thus, women do not only keep their pregnancies secret until they are firmly placed in societal contexta, but remain secretive

\footnotetext{
139 In an innovative article on uncertainty management, however in a different research context than mine, social scientist Marjolein van Asselt (2005) disentangles the different manners and logics of uncertainty practices, upon which I fall back here.
} 
with regards to acknowledging the presence of pregnancy in public, at least as far as local terms are concerned. In Northwest Tanzania ultrasound also falls into that silence: husbands, or other people, may be told about the new examination if they ask questions. This silence demonstrates the power of words to heal and to evoke evil; they also point to the particular precarious situation of pregnant women as attendees of biomedical facilities. While hospitals are considered as "no-go areas" (Last, 1992, p.398) for spirits and witches, pregnant women as classic outpatients are subjected to afflictions the minute they leave the hospital gate. Living in contingent worlds, I suggest, thus also alters what knowledge is for: rather than for certainty - as science has it - knowledge here is acquired for security.

The dimension of knowledge helps to understand Sabina Mbeja's happiness although her child died: born moving and crying in front of witnesses in the corridor of the labor ward (retrospectively confirming child matter by ultrasound), this public child re-established her carry-ability which had been undermined by her habitual miscarriages. Adding the dimension of knowledge to those of space, time, and resources also serves to solve some of the puzzles of previous chapters. Rather than women's un-knowledge, or "ignorance" that health care professionals claim to be the reason for women coming "too late" to the clinic, it is women's explicit knowledge of different kinds of pregnancies that makes them come only after 'child' is established (see chapter 4). Likewise, it is women's pursuit of security that makes them attend antenatal care at least once in order to get an antenatal record card, thereby preventing the closing off of a hospital care trajectory in case it is needed in the future (see chapter 3). Exploring the dimension of knowledge shows that "Western science is not the lingua franca of knowledge systems" (Gorenstein, 1998, p.5). The acknowledgement that knowledge and expertise are elsewhere too, thereby broadens current debates on the factors that disable women from attending biomedical services. So far, these debates focus mainly on lack: of money, transport, proper gender relations, and of quality of health care services, for example in terms of staff friendliness or drug availability (Anderson, 2004; Gil-Gonzalez, Carrasco-Portino, \& Ruiz, 2006; Jahn, 1998, 2000; Kowalewski, Jahn, \& Kimatta, 2000; Mebrahtu, 2000; Thaddeus \& Maine, 1994; see, for example, E. Urassa, Massawe, Lindmark, \& Nystroem, 1997; WHO, 1986a). These are certainly important aspects when thinking about quality improvement of biomedical health care services. It is either not or too little acknowledged, however, that hospital-ability is also rooted in specific 'local biologies', and situated ways of managing pregnancy and pregnancies 'at risk'. While 
women's knowledge may sometimes be unruly, it is liable to get lost when it stops being unruly and disturbing the hospital body. It is, however, knowledge that may be valuable for survival in local contexts and thus should inform international and national experts in order that they may be better prepared to work with it.

What the dimension of knowledge leaves us with, are questions that at once pertain to existing knowledge about the matter at stake (here pregnancy management) and to the meeting of different kinds of knowledge. With regard to the latter I suggest that the question of which knowledge then to privilege should not and does not need to be answered in absolute terms but should rather be answered in relative terms. The more important questions thus would be: How much of the biomedical body does ultrasound need? And how much local knowledge can it bear? The two introductory vignettes to this chapter documenting how my interviewees and I were disconcerted by our encounters with the respective other body of knowledge (the encounter of the biomedical with the contingent body), demonstrate the importance of these questions. It is the notion of 'the informed patient' held by a consumer-friendly ultrasonographer that cuts Rehema Ntwale's baby into bits and pieces The dimension of knowledge stresses once more the importance of knowing about places: it is places where politics matter. Returning from 'the field' to the table of a social scientist, it is the politics of ultrasound in Ghana and Tanzania that I will turn to in the final chapter of this book. 


\section{Doing technography - an assessment apparatus}

Pinned to the door of Makongoro Antenatal Clinic is a list with the sexual and reproductive rights as promoted in the International Declaration of Human Rights translated into Kiswahili. Haki ya kufaidikia na maendeleo ya kisayansi na teknolojia - the right to benefit from progress in science and technology is number ten on the list, the one article that, as the nurse-midwives pointed out, referred to my study on ultrasound in Tanzania. ${ }^{140}$ Indeed, ultrasound increasingly travels precisely with this promise of extending human rights. In documenting these ultrasound travels by following ultrasound machines to Tanzania and Ghana, however, the previous chapters have shown that claiming human rights for one group may exclude another group of people, that the question of what that 'benefit' is, may remain ambigious and be a different thing at different places altogether, and that all kinds of things may go awry along the way. I have been able to show this by moving ultrasound from its common worksite in medical practice to an academic fieldsite: to the table of a social scientist. Imbuing ultrasound with STS concepts and Medical Anthropology's insights, I have claimed ultrasound to be both a changeable object and an object for change - and thus to be world making. In order to study this world-making capacity, I have proposed to do technography, that is, to follow and to meticulously document what a technology does in different contexts, and to capture technology in use. The central concern of this book has therefore been travel - not in the conceptualization of transfer as being technically smooth or more difficult, but as a political maneuver. The question of 'what happens if a technology travels to contexts that differ in many ways from those in and for which it was originally designed?' that has driven this book, hence, asks to consider ontological and epistemological questions.

Back at the table of a social scientist, this final chapter will concentrate on what doing technography has yielded. In a way, this chapter is therefore once more a travelogue. In three sections I will travel backward to highlight certain aspects of what has been said previously, and it will travel forward to point to what this means for a context-sensitive study of technology transfer. The first section will present two kinds of politics of ultrasound in

\footnotetext{
140 The original wording of Article 27 in the Universal Declaration of Human Rights of 1948 reads: "Everyone has the right to freely participate in the cultural life of the community, to enjoy the arts and to share in scientific advancements and its benefits." The emphasis on science and technology in this context is mirrored in the transfer of these elements into Article 15 of the International Convention in Economic, Social and Cultural Rights of 1966, the binding version of the Declaration of Rights (http://www.ohcr.org).
} 
Ghana and Tanzania, the politics of governance and the politics of distribution. Both presuppose the travel of machines and of researchers likewise, however to a different extent. Delineating the travel I envisage from the travel done by those usually involved in technology assessment, the second section will focus on the contribution of technography as a heuristic device for assessing technology 'in the making'. In order to do so I will use common health care technology and the STS answer to it, the so-called constructive technology assessment approach, as stepping stones to point to the particularities of technography. I will argue that technography should be considered as a process of experimental learning. Rather than planning a route ahead of travel, that is, before setting technology into motion, as common technology assessment does, patching a route while traveling may be more successful in terms of enabling a sustainable and accountable togetherness of society and technology. Considering what this learning process entails with regard to the composition of the necessary trial communities, I will use the final section for recommending new research practices and politics. The argument that transfer should be reconsidered as travel requires all disciplines concerned with technology transfer (STS, Medical Anthropology, Public Health and Feminist Studies) to move, be moved and get affected. Staying 'clean' while setting out to research the untidy practices of the encounters between society and technology, hence, is not sustainable, nor desirable.

\section{Reviewing: the politics of ultrasound in Ghana and Tanzania}

One of the influential insights and driving forces of STS has been that artifacts have politics. ${ }^{141}$ In reviewing ultrasound travels with regard to the politics of a medical technology traveling to new contexts, I understand ultrasound in Ghana and Tanzania to have politics in two respects. The first kind of politics refers to big Politics, that is, to matters in which governments are involved, and in which technology transfer becomes a policy issue, and part of the public domain. The second kind consists of the 'small' politics. Politics here, as I have illustrated above, entail the creation and distribution of space, time, resource, and knowledge. These are hidden in the sense of not being the matter of official records but emerging in the process of travel, thus learning about these politics requires a particular traveling attitude.

${ }^{141}$ The provocative question 'do artifacts have politics?' was first posed by Langdon Winner (1999). 


\section{Ultrasound travels as a politics of governance}

Ultrasound travels are worked out on international, national and regional levels of policy making. The politics for ultrasound in Ghana and Tanzania, hence, begins in meetings at WHO, in the air-conditioned offices of the World Bank, in professional bodies such as the WFUMB, in discussions of the European Parliament about technological standards, in councils, in reports and research papers, and in Dutch, Ghanaian and Tanzanian state agencies, where these travels become part of development and health care policy, and where parliaments negotiate about budgeting, profiling and prioritizing project plans. These places thereby do not act (only) as singular entities. Rather, they are linked together by participating in Health Care International. Health Care International, as has been shown in chapter 2, thereby functions as a "vortex" (Fairhead \& Leach, 2003, p.26), attracting and attaching more and more actors while describing and prescribing the world's health problems and solutions. Disease classification, documentation, and diagnostic practices in this process get standardized - yet this does not mean that practice is necessarily the same everywhere. World health standards developed at the World Health Organization, the World Bank, or elsewhere, as has been demonstrated in Ghana and Tanzania, still need to have the political support of national governments and professional approval on regional and local levels. ${ }^{142}$

Being linked together in and as a form of global governance, however, does not mean that the interests of these levels cannot be opposed to each other, or that strategies are always coordinated. Programs may clash. An example of one such clash is the case of the prescribed Economic Recovery Program in Tanzania guided by the International Monetary Fund which froze all loans and thus directly clashed with the Dutch ORET system that called for reimbursement of loans up front before any ultrasound machines could be shipped (see chapter 2). A further example of the non-alignment of policy levels is the misfit between antenatal record cards and ultrasound. While ultrasound as a routine examination in most countries of 'the North' forms part of the antenatal record card, the new FANC record did not only not include ultrasound but also did not leave space to record any other than the examinations listed. At the district government level at Mwanza, this exclusion led to the practice of charging women for ultrasound at the Regional Hospital - against the Tanzanian

142 An example to illustrate this problem is the recently developed new Child Growth Standard (Onis, Garza, Onyango, \& Martorell, 2006). While developed and promoted as an international standard with worldwide applicability, in particular 'developed countries' have been slow in its uptake, and continue to rely instead on nationally developed standards (Mercedes de Onis, WHO, 13.12.2006, personal communication). 
national exemption policy for pregnant women and paupers - with the argument that anything not listed did not belong to the national pregnancy policy.

The salient feature of this macro-politics is that it takes place in the public domain: in parliamentary discussions, in papers that have to be accounted for, in hearings, and in audits, etc. The most striking characteristic of Health Care International in which these levels intersect thereby is the unwavering hope that is put forward by this transnational apparatus. This enacted politic of expectation, however, is at the same time paired with a particular kind of amnesia. Thus, that 'Health for All by the year 2000' was not reached in 2000 , that some diseases have turned to the worse rather than to the better, and that maternal mortality numbers are stagnant, are not perceived to be indicators that approaches taken might have to be reconsidered but that the extent of efforts, the money spent, or the technology chosen are still insufficient (or inefficient). ${ }^{143}$

As illustrated in chapter 2, Health Care International can be described as a space that is sustained by a particular kind of knowledge, that 'feeds' from the era of globalization, and that allocates resources in a way that reproduces its own existence like a perpetuum mobile. In some ways 'Health Care International' can thus be seen as akin to Michael Hardt's and Antonio Negri's notion of 'Empire' (2000). Yet medical practices, as this book has shown, are connected to forms of governance through networks that define and get defined by the circulation of objects. In contrast to Hardt and Negri I thus suggest the empire of 'Health Care International' does not rule by political institutions only, but also by such mundane artifacts as ultrasound machines. Hence, as much as 'Health Care International' constitutes a space wherein ultrasound legitimately becomes a device to reduce maternal mortality statistics in Africa, ultrasound, embodying new systems for classifying, standardizing and ordering people and knowledge, (re)produces certain relationships, identities and bodies

\footnotetext{
143 An interesting excrescence of this politics of expectation/amnesia, for example, is that the Dutch government (nota bene the Ministry of Foreign and Economic Affairs) allows a medical technology exported for the reduction of maternal mortality statistics while 'at home', in the Netherlands, the Dutch government (here the Ministry of Health) supports the minimization of technocracy in obstetrics and homebirth as a guarantee for safe motherhood. Backed by international health numbers and predefined relations, ultrasound export to African countries here provides a further clash of politics between foreign and internal health politics. For a good comparison of the 'natural' Dutch with the 'technocratic' French politics of giving birth, see the study of Madeleine Akrich and Bernike Pasveer (Akrich \& Pasveer, 1996).
} 
along the dimensions of time, space, knowledge, and resource (see also Star \& Bowker, 1999, p. 13-16). ${ }^{144}$ It is to this second kind of politics that I turn to in the following section.

\section{Ultrasound travels as a politics of distribution}

Ultrasound travels work out to generate distributions of space, time, resources, and knowledge. The politics of ultrasound in Ghana and Tanzania, hence, also start at Sengerema Hospital where Sabina Mbeja delivered her child in public on the corridor of the labor ward and became convinced that ultrasound is speaking the truth, in the house of Paulina Mkumbi in Mwanza where the hope of having a second child had to be buried with the loss of the second tube despite an ultrasound examination that indicated that something was blocking the tube, or at the school of Tabitha Juma in Northern Ghana that expels pregnant school girls, and where a mission ultrasound may thus lead to unsafe abortion rather than - as intended - to maternal safety. Thus, ultrasound carries new knowledge, new agency, new modes of prevention, but also new constraints: pregnancy's capacity to be a resource may be furthered by ultrasound as much as its status as a restriction on women's life worlds.

These distributions take place at every level of societal organization. Thus, what happens at the level of individual women has a history, albeit not a linear and simple one. Rather, the women's apparatus hangs together with other apparatuses in a complex network. It can thus not be reduced to a linear sequence of activities with clear-cut interdependencies. In the previous chapters I have traced the multiple genealogies that are embodied in a particular ultrasound at a particular place, and that turn any ultrasound device into an apparatus, that is, into a set of context-specific multi-layered practices that are the result of previous intersections between 'natural' and 'social' elements. Each apparatus hence may be viewed as an ultrasound placement into different contexts of practices where ultrasound is implicated differently: it is simplified in the particular context and made to entail specific attributes, and only in doing so, does it become relevant in that particular setting. Looking at technology transfer as a politics of distribution, however, also requires considering amongst whom space, time, resource and knowledge are being distributed. For international agencies, multinational manufacturers, national state agencies, and health care professionals 'women',

\footnotetext{
144 I hereby pick up on the argument made by Clark Miller in his analysis of the International Research Institute for Climate Prediction that politics are not only found in and written by obviously political institutions but also in the manifold production sites of science and technology (Miller, 2004).
} 
'fetuses', 'pregnancy', or 'professionals' are univocal terms. As I have shown, however, by traveling from the international level to the level of individual women not only ultrasound but everything changes. As 'women', 'the unborn', 'health care professionals' and other actors are implicated, that is enrolled, to explicate a certain ultrasound, for example 'the state apparatus', they are simultaneously being transformed. Thus, 'African woman' and 'pregnancy' are different things at different levels and for different groups. This means that questions (see chapter 1) such as why women want ultrasound, what objects ultrasound depicts, or how ultrasound changes existing health care arrangements have to be asked in each context again, instead of allocating the first question to guide a 'woman's chapter', and the issue of health care arrangements as part of 'the state's chapter' only. The relationships and movements between different levels of societal organization can in sum be displayed as in figure 6.1. Instead of a top-down relationship between the international and the local level, there are movements back and forth and there is agency, innovation, and transformation all over the place:

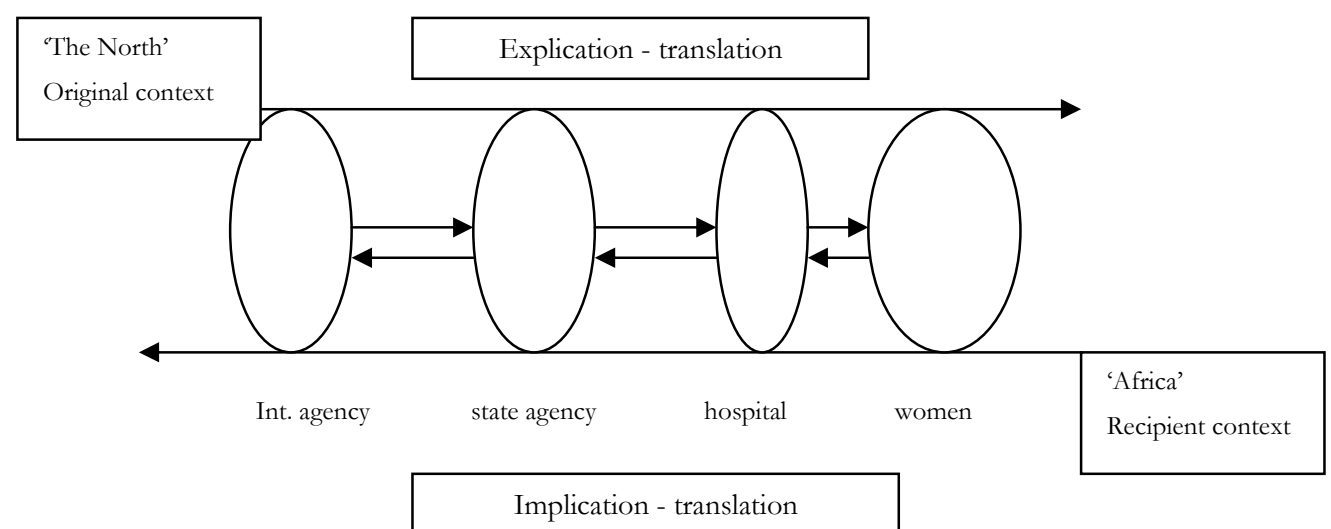

Figure 6.1: Illustration of transfer as a two way process, the four circles showing the instances at which this book documents particular encounters. Women, hospitals, the state (and donors) are implicated by each of these social groups to explicate the particular ultrasound apparatus taking on form in these contexts. 'Africa', hence, sits in the international apparatus as much as the international apparatus sits - albeit transformed - in women. Both implication and explication enact translations and thereby things may get lost.

Whereas the politics for ultrasound, that I have pointed in the previous subsection, make ultrasound transfer appear controllable, looking at the politics of distribution exposes the unpredictability of technology's work in other cultural contexts: when traveling, ultrasound has intended and unintended consequences. I have shown that in extending the 
network of ultrasound, although everything appear translatable, this is not the case. New worlds are however not made from scratch. Rather, ultrasound can only go where there are already some 'rails' - for example biomedical health care professionals, antenatal care services, plugs, or pregnancy practices (see, for example, chapter 4). In order to spread, ultrasound requires the structures it attempts to change at the same time. Hence, as everything works on something that is already in place, there are limits to socio-technological translatability.

There are two interesting observations to be made here. The first is that this book shows that ultrasound translations have in fact worked quite well. Rather than ending up as a 'white elephant', ultrasound makes it into the clinical practice of Ghanaian and Tanzanian health care professionals and the homes and bodies of Ghanaian and Tanzanian women, yet it may work differently than intended. Notwithstanding the transformation that ultrasound undergoes while traveling, it thus does not lose its form entirely; it does not stop being a device for medical practice, even though 'being a medical device' may include a machine that works primarily to get a doctor for the clinic again (see chapters $2 \& 3$ ). Ultrasound can thus be seen as a boundary object: as an object that is flexible enough to adapt to multiple worlds while keeping its core identity (Star \& Griesemer, 1989). The translations that ultrasound undergoes, however, are lost to Philips. Thus, rather despite than due to Philips Medical Systems, ultrasound is enabled to work in Ghana and Tanzania.

The second observation is that the different apparatuses both enable and constrain each other. As I have shown in the previous chapter, ultrasound networks (of machines, people, institutions, power, etc.) overlap but do not necessarily connect: different entities thus co-exist without recognizing each other. It is thus the particular silences of the hospital apparatus, for example, that enable the survival of the women's apparatus, for instance of the 'kioo' as incapable of diagnosing pregnancies 'turned to the back' and thus keeping up safe motherhood. Stopping or refusing to being translated, or being left out of the translation does not necessarily mean being left aside, rather it identifies where certain networks connect and where they do not or cannot.

Translations hence may be productive in the sense of extending the reach of biomedicine (ultrasound being 'kioo'). However, as I have indicated above, something is always lost in translation, or as Latour has argued translation is "by definition always a misunderstanding" (Latour, 1988, p.65). Health care professionals are still lost despite 
ultrasound's transformation into a 'whiteman's thing', women are lost to ultrasound diagnoses at night or in-between departments, unborns, albeit in different form, get lost at every level, and the device to reduce maternal mortality statistics is lost to the women's level and apparatus, as much as the potential of kioo is lost to the international apparatus. If there was more, or perhaps other, knowledge, technology transfer could be more successful with regard to achieving public health that more people could live (with). As this book is currently the last transformation of ultrasound in the described chain of reference (Latour, 1999), its task is to transfer the things that allow one to know, and to show (or ask) how translatability can be steered in a more productive way.

\section{Travel and transfer epistemology}

How does one know about the politics of a medical technology in Ghana and Tanzania? Accessing the realm of macro-politics is comparably easy, since one of the main features of the bureaucratic 'paperasserie' of international and national politics is that many things travel easily in the form of reports that are principally open to everybody. Getting to know about the 'small politics', in contrast, requires the researcher (or rather, those who do the assessment) to travel: not only because things do not work as written down in these papers, but also because new functioning follows from new relationships that emerge along the travel path. Getting to know potentially different ontologies of technology and society likewise, hence, requires a travel epistemology. Having claimed that, however, there is an immediate problem. As I have shown, Philips Medical Systems travels to the field as well and yet did not see what I argue has to be seen, and what I have documented above. The quick answer to the question, of how to account for this difference, is that one cannot see any difference where the world is already made the same. A longer answer has to go into more detail about different approaches to health care technology assessment and must attend to the question of how technological development can be affected so that more justly ordered worlds can be brought into being.

\section{Prospecting: technology in context}

By doing technography I attempted to develop a heuristic apparatus for assessing technology not as 'ready-made' but as 'in the making'. Taking into account the co-constitution of technology and contexts, technography shares roots with 'Constructive Technology 
Assessment' (CTA), the STS answer to common (medical) technology assessment, yet it complements and refines the latter's approach. In the following section I will thus delineate technography both from common health care technology assessment and from CTA, using the latter's critique of the former as my point of departure as I outline the edges and peculiarities of technography. ${ }^{145}$

\section{What and How}

Common medical technology assessment (MTA) ${ }^{146}$, as the example of Philips Medical Systems has also shown, focuses on economic aspects (cost-benefit-analyses, feasibility studies), on safety and technological efficacy and efficiency, and on the so-called 'social impacts' of technology, for example, on job satisfaction, patient compliance and satisfaction, coping mechanisms, etc. (see, for example, Tan-Torres, 1995). ${ }^{147}$ The focus on these exogenous factors by which technology is reduced to "blackbox variables" (Soete, 1995, p.37) is set by the official definition of the US based Office of Technology Assessment. Here medical technology assessment is described as "in the narrow sense, the evaluation or testing of a medical technology for safety and efficacy. In a broader sense, it is a process of policy research that examines the short- and long-term consequences of individual medical technologies" (OTA, 1982, p.3). The gold standard within medical technology assessment is the randomized clinical trial. One of its methodological principles is to measure the correlation between an intervention and results, thereby excluding noise variables. These circumscribed sets of elements and possible sub-elements are obtained by means of predesigned checklists, and mainly provide quantitative data (Remmen, 1995). Conceptualizing technology as 'ready made', the aim of technology assessment is to prevent negative effects

\footnotetext{
145 With regard to sketching out the ideas and premises of 'Constructive Technology Assessment' I rely primarily on the edited volume by the Rip et al. (1995), the first and only systematic compilation of STS articles concerned particularly with technology assessment.

146 'The alternative term 'health care technology assessment' rather than medical technology assessment is also coming into use. While the former encompasses a broader spectrum of assessment objects, the latter is still more commonly used (Mayall, 1993).

147 These assessment parameters have been introduced at different times: while the 1970s have focused on efficacy and safety issues, the 1980s emphasized economic aspects; social aspects became crucial indicators to focus on in the $1990 \mathrm{~s}$. The parameter currently in the focus of much work in health care technology assessment is the so-called DALY (Disability Adjusted Life Year), a summary measure for the illness state of populations (the so termed Burden of Disease). The DALY is a methodological framework for the measurement of health outcomes that integrates information about morbidity and mortality and expresses this in a single-based number. The lifetime that is lost to disease and due to premature death is presented as 'Years of Life Lost'. In terms of DALY, the effectiveness of a medical technology is thereby conceptualized with regard to the duration and quality of life that patients achieved (for a critical review, see Arensen \& Nord, 1999).
} 
or to alleviate the most detrimental, and to promote the positive effects of technology (Smits \& Leyten, 1991).

The focus of Constructive Technology Assessment is not primarily on the social impacts of technology but rather on the changeable nature of technology itself. Hence, society is not only what is impacted on by technology, but also what impacts on technology. Concerned with transformative processes, CTA explores the networks of emerging and changing relationships between human and technical entities (Callon, 1995, 309-312). Rather than showing that medical practices or skills change and become more or less scientific, for example, CTA studies show that what 'skillful' or 'scientific' means get transformed.

Likewise, it is not the quality of life that interests constructive technology assessment but the sort of life that is built into technology (Willems, 1995). Not whether technology is effective but which effects a technology has, and not whether it has side effects but which different advantages and disadvantages do technologies carry with them, become the central questions. Central to these analyses thus are issues of interests, political struggles, and values of and between different participants of the networks (Remmen, 1995; Weijers, 1995; Wynne, 1995). In short, 'noise' is the focus of attention.

Conceptualizing technology as 'in the making', the aim of Constructive Technology Assessment is to make user representations explicit (Akrich, 1995), to broaden design and implementation of technological systems and stimulate social behavior (Callon, 1995, p.9) or, as Remmen puts it, to "influence a transformation that occurs anyway" (1995, p.202). Rather than working with checklists, assessment is regarded by its proponents to be based on an interactive process. This becomes apparent in the various terms used to designate this other kind of assessment, among them "participatory assessment" (Hennen, 1999), "constructive realization" (Arie Rip, Thomas J. Misa, \& Johan Schot, 1995), "social experimentation" (Herbold, 1995; Remmen, 1995), "cooperative games" (Jelsma, 1995), "social learning" (Callon, 1995), or “responsive evaluation” (Horstman \& Houtepen, 2005). While dialogue for all these authors seems to be the means to another end - that is, to assess technological culture rather than technology and society as distinct realms - it is striking to notice how vague many of them are with regard to how exactly go about and what to focus on. It seems as if working with the conceptual kit of STS frees CTA from being specific about the questions to be asked or the indicators to be looked for and at. An exception remedying that gap is the toolbox for Research and Technology for Development developed by technosociologist 
Wiebe Bijker (2001). His toolbox of questions aims at assessing research and technology in such a way that politics can be formulated to make science and technology contribute to development in a more targeted way.

Similarly to CTA, technography analyses technological culture. Like CTA it thereby starts from the conceptualization of technology as being 'in the making', and draws on four concepts that have been developed within STS - script, appropriation, translation, and modes of ordering. These concepts, as demonstrated in the previous chapters, provide an analytical view as to the multiplicity of active efforts involved in rendering a technology accessible to use and users, allow for the empirical treatment of different users and their interrelations. In short, they capture the notion of ultrasound in Ghana and Tanzania as process. Taking seriously anthropologist Arturo Escobar's claim that "culture sits in places" (2001), technography in addition consists of a dimensional component. The questions that have been developed in the context of each of the four dimensions - space, time, resource, and knowledge - address a variety of cultural, that is, both factual and normative issues (table 6.1.):

\begin{tabular}{|l|l|}
\hline Dimensions & Associated questions \\
\hline space & $\begin{array}{l}\text { Which relationships (of technology and society) are fore grounded, and which are bracketed? } \\
\text { What kind of space do these relationships embody and exert? } \\
\text { Who is setting the terms? } \\
\text { Whose play areas are privileged, that is who moves, who is to move, and who or what controls the } \\
\text { movements? } \\
\text { What is in place in the places to which a new technology travels? }\end{array}$ \\
\hline time & $\begin{array}{l}\text { What are the existing time frames that deal with the issue at stake? } \\
\text { What are the temporal orders brought and required by the new technology? }\end{array}$ \\
\hline resource & $\begin{array}{l}\text { What are the resources at hand at a particular place? } \\
\text { What are the resources required for a new technology? } \\
\text { How does the exchange transform places, and whom or what does a move include or exclude? }\end{array}$ \\
\hline knowledge & $\begin{array}{l}\text { What is the local knowledge about the matter at stake? Whom does it include or exclude? } \\
\text { How do people know? } \\
\text { How much of the standardized, global knowledge (here, the biomedical body) does a technology } \\
\text { need? And how much local knowledge can it bear? }\end{array}$ \\
\hline
\end{tabular}

Table 6.1: A compilation of the questions posed in the empirical chapters 2-5. Leaving aside the particular example of ultrasound technology, some of the questions have been reformulated in a more general way. 
The conceptual component that technography shares with CTA (here the concepts script, appropriation, translation, and modes of ordering) makes technography sensitive to the heterogeneous strategies employed in making particular user worlds as well ast it combine structural and actor-oriented aspects. ${ }^{148}$ The dimensional component that is particular to technography as heuristic device and assessment apparatus thereby not only specifies what aspects to focus on. The four dimensions space, time, resource, and knowledge also enable an ethnographer, or to be more precise a technographer, for entering and describing very different kind of situations, groups, relations and contexts, while maintaining a mind open to the unexpected. Furthermore, these dimensions allow looking at all contexts with the same lense, and thus acknowledging both 'science and an African logic'. ${ }^{149}$ Likewise they serve to explain the success and failure of an artifact symmetrically. Exploring technological culture along these dimensions, I claim, thus makes it possible to see a number of things that otherwise remain hidden but that are vital to know for a more successful technology transfer. What technography works with is the 'logic of association' (see Marcus above) - both as a precondition and a particular effect. Hence, what it requires is a mood and mode of questioning and imagining potential connections. When and where do these questions have to be posed?

\section{When and Where}

The definition of the OTA, that sets the standard for medical technology assessment, does not only state the core elements of technological evaluation; it also establishes a hierarchical relationship between them. It is only after safety and efficacy are assessed that a broader approach towards the social impacts is possible and considered necessary. Social impacts thereby turn into second-order effects (see Ten Have, 1994, 2004). Underlying this relationship is the conceptualization of the life-cycle of a technology (see also chapter 2). This life-cycle begins with the discovery of new knowledge, followed by its translation into technology, then the evaluation of that technology's safety and efficiency, and finally technology's diffusion. This sequence implies that technology assessment has to take place at the right moment. Common medical technology assessment thereby knows two right moments in time. The first is before the technology is introduced in clinical work practice;

\footnotetext{
148 The dimensions proposed in this book, I suggest, can thereby be seen as indicators that the political scientist Michiel Schwarz has been called for in his plea to assess technological culture rather than technology as such (Schwarz, 1993). ${ }^{149}$ This poignant expression is borrowed from the title of the book by STS scholar Helen Verran (2001).
} 
here randomized controlled trials are performed that set the objectives of treatment in a very early phase. The second is after a technology is already firmly entrenched in clinical practice, when it suddenly causes a problem. Accordingly, the locations where technology is being assessed are either labs or clinics What happens in between these two poles of technological working remains out of sight, as in-between actors are regarded as mere intermediaries (see, for instance, Koch, 1995).

Whereas common medical technology assessment is rather static, CTA is concerned with dynamic processes. Starting from the notion of the malleability and transformability of technology throughout its life-time, CTA claims that assessment is also an ongoing process. Assessment here commences at the beginning of technological development, including the phase where knowledge is made (rather than discovered), and encompasses the whole range of development phases (Jelsma, 1995; Verbeek, 2006; Walsh, 1995; Weijers, 1995). The focus of STS on technology 'in the making', as Akrich as argued, thereby not only requires constant movement back and forth between the projected and the real users (Akrich, 1992). Also, not only designers or end users, but various user groups thereby come into the focus of analysis. Consequently, the places of assessment vary: they may include labs, and clinics as well as parliaments, professional and national councils, state agency offices, professional associations, and peoples' homes.

Despite its claim to assess technology as a process touching and touched upon by designers and various user groups, the edited volume Managing Technology in Society: The approach of constructive technology assessment by Rip et al. (1995) still focuses mainly on designers and researchers. More recent work in STS (and Medical Anthropology likewise), however, has taken up and emphasized the role of the in-between agents as active mediators (Oudshoorn, 1997; Oudshoorn \& Pinch, 2003b; Susan Reynolds Whyte, van der Geest, \& Hardon, 2002). It is in this wake that technography operates. Thus, what the previous chapters have shown, is that technology transfer to contexts that differ from those the technology was originally designed in - here Ghana and Tanzania - initiates a new process of sociotechnical change that implicates designers and the new user contexts. The four main sites - manufacturers/suppliers, national state agencies, health care facilities, and women that I have described in this book, however, may differ from technology to technology and society to society. As each agent meeting with a technology in transit has the potential to divert intentional technological paths and creatively design new ones, technography stresses 
the importance of assessment as a multi-sited endeavor. The 'where' and the 'when' thereby intertwine. Thus, as assessment takes place alongside the travel of technology to various contexts, the localities of prospecting technology in contexts consist of the different fieldsites the technology comes to work at. Technography, hence, cannot only take place before the introduction of ultrasound into a particular hospital, for example. Rather, it has to be followed by an assessment of ultrasound in clinical practice (in reception areas, teaching situations, daily care services, etc.) after which observations are fed back to both clinical practitioners, national and international agencies, and patients, to be followed by another round of assessment if (and after) modifications have been made. In principle, assessment thus remains an unfinished business.

Following technology to various contexts of use, technography enables and requires a mobile positioning in terms of time and space. Likewise, it enables and requires the potential maintenance of a broad variability of actors and contexts to play a role and be affected in this endeavor. In short, technography works (and should work) against an apriori settlement of the question of who is an inappropriate(d) actor. Having said this, however, raises the question who is to do the assessment and for whom?

\section{Who and For Whom}

The assessors in common medical technology assessment are external experts, for example consultants who are flown in at the particular moment of assessment, and are preferably not linked to any of the parties involved in the introduction and usage of technology (see, for instance, chapter 2). Their data collection and reports are used for project planning and policy making. As defined by the OTA, assessment is a kind of policy research. Common (medical) technology assessment here works with a particular labor division by which experts do assessment about the public for policy, while assessment itself is considered to be bare of politics.

Starting from the idea of assessment as dialogue, not only designers and consultants are considered as experts by proponents of Constructive Technology Assessment, but users are too. Consequently, CTA argues that different groups should have an equal voice in design, diffusion, and evaluation processes. The notion of 'social learning' (see above) thereby describes a new kind of interaction in which 'learning' consists of providing all participants with the information they need, including critical information. Rather than as a 
one-way education, this learning process is conceived to take place as an open encounter between the classic 'experts' and 'the public' with the aim of modifying the effects of the technology that is to become embedded in society (Jelsma, 1995). Having multiple people participate in the process of technology design and diffusion - hearing all voices, so to speak - these proponents claim, leads to more democracy:

Modern society has bound its fate to technology. The key is to replace the combination of modernist support and even glorification of technology, and the social, often distant and thus "outsider's" criticism of technology, by socio-technical criticism. This is constructive, not in the sense that technology can now be implemented and diffused more easily, but that the technology which does survive the socio-technical criticism is a better technology in society. (Arie Rip, Thomas J. Misa, \& Johan Schot, 1995, p.10)

The main problem proponents of CTA see with regard to the openness of this envisioned dialogue is that learning might be constrained by uncertainty and by the strategic behavior of actors. According to them, this interaction therefore requires discipline and controlling organs. Consensus among the authors named above thereby is that governments are not the most suitable agents for this. Instead, Remmen proposes inter-organizational networks to function as regulatory regimes, which are kept together by everybody appreciating that something is at stake. In short, the departure from the considering technology assessment and politics as distinct realms that is crucial to social learning, results in a decentralization of control and responsibility.

However, while many CTA proponents put 'social learning' at center stage, the edited volume by Arie Rip, Thomas Misa and Johan Schott that compiles most of these works, still focuses primarily on designers. This suggests that CTA rather than leaving the outcome of the assessment open works as a lubricant for managers - as the title of the edited volume also indicates. Following ultrasound travels to Ghana and Tanzania I have shown that costs and benefits can be distributed very differently though. Thus, even when ultrasound reduces maternal mortality statistics, high prices paid elsewhere should be included in the analysis. If costs are 'too' high, this could lead to reconsidering the very introduction of the technology. Moreover, STS scholar Marc Berg warns us to fall to easily for the assumptions that giving voice to everybody automatically entails more democracy, or that there is a guarantee that any technology can be patched up by listening to divergent world views. CTA in this respect, he criticizes, is blind to its own politics (Berg, 1998). 
Indeed, as the present book has illustrated, including the voices and worlds of Wasukuma women does not necessarily result in a more democratic technology. While 'ultrasound in the North' includes the fetus as a patient to be cared for, thereby threatening to exclude women as agents with own rights, 'ultrasound in Northwest Tanzania' excludes fetuses and thus threatens to survival of unborns and mothers likewise. How then to keep one's politics, to build a working technology while acknowledging divergent worlds and world views without simply falling into an analytical mode that is more detailed and cover more levels, but still focuses mainly on impacts? ${ }^{150}$

Doing technography, rather than serving only a constructive technology assessment, I would like to suggest, is better to be understood and practiced as reflexive assessment of technological culture. The previous chapters thereby allow us to draw four conclusions from the empirics that illustrate what this reflexive mode may entail, and hence what technography consists of. The first conclusion is that one always speaks from somewhere (see chapter 2), the second is that virtually situations have to be created with what is at hand (see chapter 3), the third is that technology transfer requires work, in particular the building of passages that link existing with emerging practices (see chapter 4), and the fourth is that all knowledge is essentially situated (see chapter 5). It seems as if the last conclusion, in particular, leads us to the same gridlock that CTA faces. However, what happens, for example, if African doctors, albeit biomedical practitioners, are given the opportunity to speak of their own locally specific knowledge. In his article When Physicians Meet Steven Feierman beautifully describes the encounter of biomedical bodies, the observable similarities and differences between them with regard to problems faced in daily practice, in short the emerging multiplicity of biomedicine in Africa (Feierman, forthcoming). In addition to emphasizing the public good of local knowledge that speaks for situated reality, technography can also be used to emphasize thinking along more axes than only that of a biomedical practitioner, for example. As I have shown in the present book, nurse-midwives in Northwest Tanzania, for example, are powerful bearers and users of traditional knowledge too, thereby blurring the boundaries between speaking as a woman/potential mother and as a professional. Spokespersonship, if reflected, hence can lead to assembling a broad range of existing worlds (and their interconnections).

${ }^{150}$ For this critique of CTA's contemporary approach see also Brian Wynne (1995, p.32f). 
Drawing on and exploring the multiple and multi-layered relations between technology and society, the present technography has illustrated the situated character of ultrasound practice, rather than its universality. Doing technography, I suggest, thereby enables stressing the local universality of (any) standards (Timmermans \& Berg, 1997). Achieving maternal safety then is not only a distributed activity but also an objective that can (and has to be) reached by different means that acknowledge different kinds of safety. Perhaps rather than getting more and critical information, it is learning to appreciate a different kind of outcome that counts. In this context, technography alerts us to another character of surprises that are inevitably to be encountered when technology travels. Rather than regarding them as obstructive, they should be seen as innovative, that is, as proofs of the translatability of a technology.

Who is to do such a technography? Similarly to CTA, I would say all together - in principle. Yet in practice technography requires outsiders and insiders for the evaluation of technological culture, and it should be kept in mind that bringing together everybody to the same table is not only not feasible but also not possible as particular technologies emerge within particular contexts and thus have to be assessed in a piecemeal fashion. In order to work, technography requires an attitude such as the one described above. Constructive nudging (see Wynne, 1995, p.32), that is, being 'sand' to a machinery which so far tends to jump to seemingly smooth and fast solutions should be a matter of all, including the STS schooled researcher as an integral part of such an assessment endeavor. Technography, in consequence, evolves as a flexible flow-chart that is shaping and is being shaped by its participants and structures, and that allows to depict and explores technologies-in-contexts while paying attention to whom or what gets excluded and included within a particular apparatus. As this depiction allows comparing alternative network of things and humans, technography keeps open the variability of worlds enacted by introducing a new technology into existing practices. Technography thereby aims to make the politics explicit that lie in designing not only technologies but worlds. Hence, there is third kind of politics in ultrasound travels to Ghana and Tanzania, the politics of deliberation. 


\section{Technography as a politics of deliberation}

If ultrasound is always ultrasound in use, that is, if reality emerges in practice, it is complex, changing - and political (see Mol, 1999). What is good in one context is not necessarily good, or working in another. Technography hence involves deliberation, not between one ultrasound machine or another, but between apparatuses, that is, worlds. Perhaps then technography's main task is to interrupt the notion of technology's neutrality and to look for clashes, ordering processes, and combinations - in short, for how to shape translatability. This requires negotiations about the objectives to reach, and it requires the usage of the dimensions of space, time, knowledge and resources as currents to get there and as orientations with regard to the present worlds enacted (with regard to this objective). Regarding technography (and in its wake technology transfer) as a politics of deliberation emphasizes that there are never innocent but only argued choices. The intricacy of technology transfer, in sum, requires the displacement of an attitude - of listening, looking and searching, and of developing a sensibility for what is at stake at different places.

\section{Concluding: 'white machines' and 'black bodies', or what would be a sound science?}

This is a book about the politics of ultrasound in Ghana and Tanzania or, in more general terms, about the politics of technology transfer to contexts that differ in many respects from those the technology was designed for and in. It is also a book about reproductive and public health, about globalization, development cooperation, and about contemporary research politics. As such, my book started with the provocative question of a Public Health expert as to why I would want to study ultrasound in Africa. In answer to this question I claimed ultrasound to be a strategic site to show that ultrasound - and any other technology traveling to cultural contexts different from its original contexts - is not a ready-made technology but a technology 'in the making' shaped by and shaping society alongside its travel. Following ultrasound machines to different contexts, I have argued that ultrasound transfer to Ghana and Tanzania does not mean that 'white machines' come to work on 'black bodies'. Rather, as I have demonstrated, ultrasound technology and African bodies mutually shape each other from the very first moment, that is, from the phase of designing 'ultrasound for Africa' in a Dutch factory up into Ghanaian and Tanzanian women's homes (see also figure 6.1). Illustrating the intersections of ultrasound technology with its various 
contexts of use, I have thereby presented a colorful area that is characterized by negotiations, interest, struggles, standards, knowledge, uncertainty and situated practices. What do these insights yield for the four disciplines that I claimed to meet in their mutual concern about public health care problems in Africa?

It is no doubt important that technology works, that is, that it does not crash, that the information about and of a particular technology is sufficient and that it can be displayed adequately. Yet it is equally important to scrutinize how technology works out, that is, how it changes the whole network of things, people, identities, conventions, and practices that it becomes part of. Technology does more than the usual packaging suggests, and it does more than what it is intended to do. These effects have to be made explicit and evaluated too - so the claim and conclusion of the present book. An approach that continues to regard diseases and the human body as universally given, and technologies as working in the same way, and depicting the same objects no matter where it lands, as currently held by Public Health is incapable of meeting with the problems that Africa faces, also with regard to these global goods. Fetuses may thus cease to exist in contexts where having and being somebody is a contingent matter drawing on other than biomedical relations, and where medicines, worms, nzoka, earth, contraceptives, traditional healers and biomedical staff undo the stability of the body. Likewise, malaria does not exist outside the network of relationships that consist of parasitology, mosquitoes, laboratories, blood slides, bednets, and chloroquine (Langwick forthcoming). My answer to Dr. Arnold's allegiation hence is brief and simple: focusing on human-machine interactions is not bizarr but is all there is! At the same time, though, my answer is complex: as there is not just one 'better life' but several, there is also no simple and clear-cut answer to Dr. Dodoma's request in the way that he might have wished for.

There is also no doubt that it is important to explore how a diverse range of women exposed to reproductive technologies use and make sense of these interventions. As this has been the credo of feminist studies, we have the methodological commitment to study ultrasound (or other technology) empirically rather than to assume a particular working, impact, or form. Ultrasound in Ghana and Tanzania may not be as 'shocking' as ultrasound in India engaged into 'girling' fetuses or as 'sanitized' as ultrasound in North America or Europe engaged into sorting fetuses according to (dis)ability, yet, as I have shown, it is no less political with regard to questions of maternal safety and reproductive and public health. 
Substantiating my counterclaim against Dr. Arnold and Dr. Dodoma, I have drawn on Medical Anthropology and STS. Nevertheless, this book also holds insights for these two disciplines. For Medical Anthropology, the present research underpins the importance of extending the study of materia medica, in its literal material sense, from low key to the more and more sophisticated medical technologies that travel due to ongoing globalization (Geest van der \& Whyte, 1988; Susan Reynolds Whyte, van der Geest, \& Hardon, 2002). In this context it also stresses the importance to engage in multi-sited ethnography. It is anthropology's traditional focus on 'thick descriptions' and its grasp on describing the complexity of relations that make up a network that has impregnated STS to a large extent. It is the strength of STS to have transformed some of the insights of both disciplines into handy concepts. While these allow to explore and to keep the uniqueness of experience, they also allow ethnographic insights to travel and make its insights applicable beyond the boundaries of just one village, culture, and technology. Scholars increasingly use STS and ethnography to intervene in medical practice in form of an 'action-oriented STS' (see, for example Balka, 2005; Jensen, 2005; Mesman, 2005; Zuiderent, 2002). I see the present book in the wake of these studies, that is, as a device to enrich debates about and evaluations of the role of medical technology in public health practices.

Technography, as developed in this book however, does not need to be confined to the field of medicine, nor to Ghana and Tanzania. Rather, I argue, it is applicable to a variety of other cases and contexts (see figure 6.2):

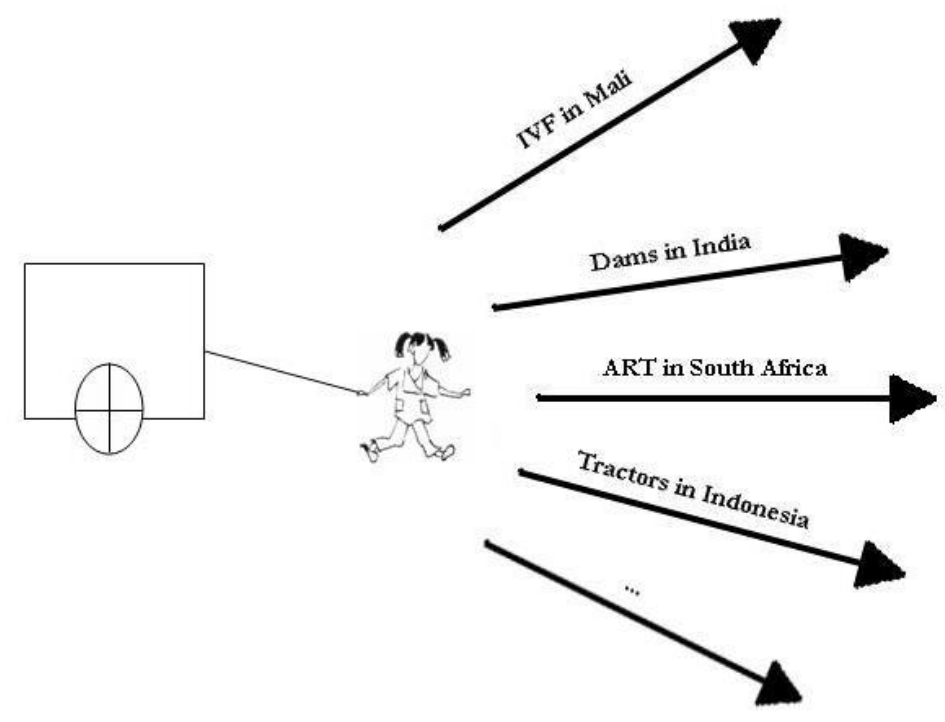

Figure 6.2: Technography 'wheeling' towards new cases and contexts 
In sum, what my book aims to promote is an alternative politics of research. Scientific research and researchers, as I have attempted to show, should neither act as a gray eminence operating behind the scenery equipped with the only true knowledge, nor should they act in twilight-, a gray zone that obscures their engagement. Instead, I propose a more 'colorful' and mobile encounter between disciplinary bodies and an engagement in showing not only that things could have been but that they can be otherwise. This requires research and researchers to be attentive to new things that travel, be these ultrasound or assessment devices. It is in this context that I hope my book will travel. 


\section{Bibliography}

\section{Archival sources}

Tanzanian National Archive (TNA), in Dar es Salaam, Tanzania

In this text I have drawn from British Provincial Records concerning Lindi, a region South Tanzania

\section{Philips Medical Systems - Files}

All correspondence, reports, drafts, and contracts filed are kept at the office of the Financial Manage at Philips Medical Systems in Eindhoven, The Netherlands. In Chapter 2, I refer to File PMS/ORET 399 "Contracts | and PMS/ORET Tanzania 883.

\section{All other sources}

AbouZahr, C., \& Royston, E. (1992). Excessive hazards of pregnancy and childbirth in the Third World. World Health Forum, 13(4), 343-345.

Adas, M. (1988). Machines as the measures of men. Ithaca: Cornell University Press.

Agyepong, I. (1995). Implementing PHC under severe economic constraints. In J. Chabat, J. Harnmeijer \& P. H. Streefland (Eds.), African Primary Health Care in times of economic turbulence. Amsterdam: Royal Tropical Institute.

Ahluwalia, P., \& Zegeye, A. (2001). Multiparty Democracy in Tanzania. Crises in the union. African Security Review from http://www.iss.co.za.html (retrieved 03.01.2000)

Akrich, M. (1992). The De-Scription of Technical Objects. In W. Bijker \& J. Law (Eds.), Shaping Technology/ Building Society. Studies in sociotechnical change (pp. 205-224). Cambridge, MA: MIT Press.

Akrich, M. (1993). Essays of Technosociology: A gazogene in Costa Rica. In P. Lemmonier (Ed.), Technological Choices. Transformations in material cultures since the Neolithic (pp. 289337). London: Routledge.

Akrich, M. (1995). User Representations: Practices, methods and sociology. In A. Rip, T. Misa \& J. Schot (Eds.), Managing Technology in Society. The approach of Constructive Technology Assessment (pp. 167-184). New York: Academic Press.

Akrich, M., \& Pasveer, B. (1996). Comment la naissance vient aux femmes. Les techniques de l'accouchement en France et aux Pays-Bas. Le Plessis-Robinson: Synthelabo.

Allen, D. R. (2002). Managing Motherhood, Managing Risk: Fertility and Danger in West Central Tanzania. Ann Arbor: The University of Michigan Press.

Allotey, P., \& Reidpath, D. (2001). Establishing the causes of childhood mortality in Ghana: The 'spirit child'. Social Science \& Medicine, 52, 1007-1012.

Amit, V. (2000). Introduction: Constructing the field. In V. Amit (Ed.), Constructing the Field. Ethnographic fieldwork in the contemporary world (pp. 1-18). London: Routledge. 
Anderson, H. M. (2004). "Villagers": Differential treatment in a Ghanaian hospital. Social Science \& Medicine, 59(10), 2003-2012.

Anonymous. (1996). Capacity for reproductive health research grows stronger in Africa. Progress in Human Reproduction Research, 34, no pages.

Anonymous. (1999). Sengerema Hospital 1959-1999. Bukoba: Rumuli Printing Press.

Appadurai, A. (1986a). Introduction: Commodities and the politics of value. In A. Appadurai (Ed.), The social life of things. Commodities in cultural perspective (pp. 3-63). Cambridge: Cambridge University Press.

Appadurai, A. (1986b). The social life of things. Commodities in cultural perspective. Cambridge: Cambridge University Press.

Arens, W. (1987). Taxonomy and dynamics revisited: The interpretation of misfortune in a polyethnic community. In I. Karp \& C. S. Bird (Eds.), Explorations in African Systems of Thought (pp. 165-180). Washington, DC: Smithsonian Institute.

Arensen, T., \& Nord, E. (1999). The value of DALY life: Problems with ethics and validity of disability adjusted life years. BMJ 319, 1423-1425.

Armah-Idan, G. (2002, October 19). Doctor-patient ratio inadequate. Daily Graphic, pp. 1,3.

Asiedu, W. A. (2002, November 23). Help! Police Hospital in 'coma'. The Mirror, pp. 1,3.

Aune, M. (1996). The Computer in Everyday Life. Patterns of domestication of a new technology. In M. Lie \& K. H. Sorensen (Eds.), Making Technology our Own? Domesticating Technology into Everyday Life. (pp. 91-120). Oslo: Scandinavian University Press.

Balka, E. (2005, April 25-26). Disparate Interests, Common Goals? Moving an action-oriented health technology assessment agenda forward in Canada. Paper presented at the Practices of Assessment and Intervention in Action-Oriented STS Amsterdam.

Barad, K. (1998). Getting Real: Technoscientific Practices and the Materialization of Reality. Differences: A Journal of Feminist Cultural Studies, 10(2), 87-128.

Barger-Lux, M. J., \& Heaney, R. P. (1986). For Better and Worse: The technological imperative in health care. Social Science \& Medicine, 22(12), 1313-1320.

Behar, R. (1995). Introduction: Out of exile. In R. Behar \& D. A. Gordon (Eds.), Women writing culture (pp. 1-29). Berkeley et al.: University of California Press.

Behar, R., \& Gordon, D. A. (Eds.). (1995). Women Writing Culture. Berkeley University of California Press.

Belghiti, A., De Brouwere, V., Kegels, G., \& Van Lerberghe, W. (1998). Monitoring unmet obstetric need at district level in Morocco. Tropical Medicine and International Health, 3 , 584-591.

Bennett, S., \& Ngalande-Banda, E. (1994). Public and private roles in health. A review and analysis of experience in Sub-Saharan Africa. Geneva: World Health Organization Division of Strengthening Health Services.

Benson, J. S. (2001). The impact of privatization on access in Tanzania. Social Science \& Medicine, 52, 1903-1915. 
Berg, M. (1996). Practices of Reading and Writing. The constitutive role of the patient record in medical work. Sociology of Health and Illness, 18, 499-524.

Berg, M. (1998). The politics of technology: On bringing social theory into technological design. Science, Technology and Human Values, 23(4), 456-490.

Berg, M., \& Bowker, G. (1997). The multiple bodies of the medical record: Toward a sociology of an artifact. The Sociological Quarterly, 38(3), 513-537.

Berg, M., \& Mol, A. (Eds.). (1998). Differences in medicine. Unravelling practices, techniques and bodies. Durham: Duke University Press.

Bijker, W. (1995a). Of Bicycles, Bakelites, and Bulbs. Toward a theory of sociotechnological change. Cambridge, MA: MIT Press.

Bijker, W. (1995b). Sociohistorical Technology Studies. In S. Jasanoff, G. Markle, J. Petersen \& T. Pinch (Eds.), Handbook of Science and Technology Studies (pp. 229-256). London: Sage Publications.

Bijker, W. (2001). Research and Technology for Development (RTD) through EU-ACP Policy Dialogue. Scientific Background, Methodology, and Toolbox. Unpublished Report. Maastricht.

Bledsoe, C. H. (2002). Contingent Lives. Fertility, time and aging in West Africa. Chicago: The University of Chicago Press.

Bleek, W. (1976). Sexual relationships and birthcontrol in Ghana. A case study of a rural town. Unpublished Dissertation, Universiteit van Amsterdam, Amsterdam.

Blume, S. S. (1992). Insight and Industry. On the dynamics of technological change in medicine. London: MIT Press.

Boerma, T. (1987). Research Note: The magnitude of the maternal mortality problem in Sub-Saharan Africa. Social Science \& Medicine, 24(6), 551-558.

Boserup, E. (1970). Women's role in economic development. New York: St. Martin's Press.

Bosse, G., Massawe, S. N., \& Jahn, A. (2002). The partograph in daily practice: it's quality that matters. International Journal of Gynecology and Obstetrics, 77, 243-244.

Brandstroem, P. (1990). Seeds and soil: the quest for life and the domestication of fertility in Sukuma-Nyamwezi thought and reality. In A. Jacobson-Widding \& W. Beek (Eds.), The creative communion: African folk models of fertility and the regeneration of Life (pp. 167186). Uppsala: Acta Universitatis Uppsaliensis.

Brandstroem, P. (1991). Left-hand father and right-hand mother: Unity and diversity in Sukuma-Nyamwezi thought. In A. Jacobson-Widding (Ed.), Body and space: symbolic models of unity and division in African cosmology and experience (pp. 119-141). Stockholm: Alqvist and Wiksell International.

Braun-Thürmann, H. (2002). Künstliche Interaktion: wie Technik zur Teilnehmerin sozialer Wirklichkeit wird. Wiesbaden: Westdeutscher Verlag.

Bruchhausen, W. (2003). <<Practicing hygiene and fighting the native's diseases $>>$. Public and child health in German East Africa and Tanganyika territory, 1900-1960. Dynamis. Acta Hisp. Med. Sci. Hist. Ilus., 23, 85-113. 
Callon, M. (1986). Some Elements of a Sociology of Translation: Domestication of the scallops and fishermen of the St. Brieuc Bay. In J. Law (Ed.), Power, Action, and Belief: A new sociology of knowledge (pp. 196-233). London: Routledge.

Callon, M. (1995). Technological Conception and Adoption Network: Lessons for the CTA Practitioner. In A. Rip, T. Misa \& J. Schot (Eds.), Managing Technology in Society: the approach of constructive technology assessment (pp. 307-330). London: Pinter.

Callon, M., \& Rabeharisoa, V. (1998). Articulating bodies: The case of muscular dystrophies: Centre for the Sociology of Innovation, Ecole des Mines de Paris. Unpublished paper.

Callon, M., \& Rabeharisoa, V. (2004). Gino's lesson on humanity: genetics, mutual entanglements and the sociologist's role. Economic and Society, 33(1), 1-27.

Cassels, A., \& Janovsky, K. (1991). A time of change: Health policy, planning and organization in Ghana. Geneva: World Health Organization, Division of Strengthening Health Services.

Comaroff, J., \& Comaroff, J. (Eds.). (1993). Modernity and its malcontents. Chicago: University of Chicago Press.

Corea, G. (1985). The mother machine: Reproductive technologies from artificial inseminations to artificial wombs. New York: Harper and Row.

Cromwell, E. (1996). Case Study for Tanzania. In D. Reed (Ed.), Structural Adjustment, the Environment, and Sustainable Development (pp. 107-127). London: Earthscan Publications.

Cussins, C. M. (1996). Ontological Choreography: Agency through objectification in infertility clinics. Social Studies of Science, 26, 575-610.

Daston, L. (2000). Biographies of Scientific Objects. Chicago: The University of Chicago Press.

Davis-Floyd, R. (1992). Birth as an American rite of passage: . Berkeley: University of California Press.

Davis-Floyd, R., \& Sargent, C. (1997). Childbirth and Authoritative Knowledge. Berkeley, CA: University of California Press.

Dewey, J. (1984). The quest for certainty. In J. A. Boydston (Ed.), Jobn Dewey: the later works, 1925-1953 (Vol. 4: 1929). Carbondale, Illinois: University of Southern Illinois Press.

DGIS, \& Ministry of Foreign Affairs. (2002). ORET/MILIEV Regulations 2002. The Hague: Government Press.

Dilger, H.-J. (2005). Leben mit Aids. Krankheit, Tod und soziale Beziebungen in Afrika. Frankfurt: Campus.

Duden, B. (1993). Disembodying women: Perspectives on pregnancy and the unborn. Cambridge: Harvard University Press.

Dumit, J. (2004). Picturing Personhood: Brainscans and biomedical identity. Princeton: Princeton University Press.

Ehrenreich, B., \& English, D. (1978). For Her Own Good: 150 years of expert's advice to women (Vol. Doubleday). Garden City, NY. 
Escobar, A. (1995). Encountering Development. The Making and Unmaking of the Third World. Princeton: Princeton University Press.

Escobar, A. (2001). Culture sits in places: reflections on globalism and subaltern strategies of localization. Political geography, 20, 139-174.

Evans-Pritchard, E. E. (1977 [1937]). Witchcraft, Oracles and Magic among the Azande. Oxford: The Clarendon Press.

Fabian, J. (1983). Time and the Other: How anthropology makes its object. New York: Colombia University Press.

Fairhead, J., \& Leach, M. (2003). Science, Society and Power. Environmental knowledge and policy in West Africa and the Caribbean. Cambridge: Cambridge University Press.

Feierman, S. (2000). Explanation and uncertainty in the medical world of the Ghaambo. Bulletin of the History of Medicine, 74(2), 317-344.

Feierman, S. (forthcoming). When Physicians Meet: Local medical knowledge and global public goods. In P. W. Geissler \& S. Molyneux (Eds.), An ethnography of medical research. London: Berghahn Publishers.

Ferguson, J. (1990). The anti-politics machine: Development, depoliticization, and bureaucratic power in Lesotho. Cambridge: Cambridge University Press.

Foucault, M., \& Rabinow, P. (Eds.). (1997). The essential works of Foucault, 1954-1984, Vol. 1. New York: The New Press.

Galison, P. (1997). Image \& Logic. A material culture of microphysics. Chicago, London: The University of Chicago Press.

Gardner, K., \& Lewis, D. (1996). Anthropology, development and the postmodern challenge. London: Pluto Press.

Geest van der, S., Speckmann, J. D., \& Streefland, P. H. (1990). Primary Health Care in a Multi-level Perspective: Towards a research agenda. Social Science \& Medicine, 30(9), 1025-1034.

Geest van der, S., \& Whyte, S. R. (Eds.). (1988). The Context of Medicines in Developing Countries. Studies in Pharmaceutical Anthropology. Amsterdam: Het Spinhuis.

Geissler, P. W. (2000). The significance of earth-eating: social and cultural aspects of the geophagy among Luo children. Africa, 70(4), 653-682.

Geissler, P. W., Mwaniki, D., Thiong'o, F., \& Frijs, H. (1998). Geophagy, iron status and anaemia among pregnant women on the coast of Kenya. Transactions of the Royal Society of Tropical Medicine and Hygiene, 92, 549-553.

Geissler, P. W., Shulman, C., Prince, R., Mutemi, W., Mnazi, C., Frijs, H., et al. (1998). Geophagy as risk factor for geohelminth infections: a longitudinal study of Kenyan primary schoolchildren. Transactions of the Royal Society of Tropical Medicine and Hygiene, 92, 7-11.

Geissler, W. (1998). 'Worms are our life', part 1: understanding of worms and the body among the Luo of western Kenya. Anthropology \& Medicine, 5(1), 63-79. 
Geissler, W., Prince, R. J., Levene, M., Poda, C., Beckerleg, S. E., Mutemi, W., et al. (1999). Perceptions of soil-eating and anaemia among pregnant women on the Kenyan coast. Social Science \& Medicine, 48, 1069-1079.

Geist, C., Harder, U., Kriegerowski-Schroeteler, G., \& Stiefel, A. (Eds.). (1995). Hebammenkunde. Lebrbuch für Schwangerschaft, Geburt, Wochenbett und Beruf. Berlin: de Gruyter.

Geschiere, P. (1997). The modernity of witchcraft: Politics and the occult in Postcolonial Africa. Charlottesville: The University of Virginia Press.

Gharbi, H. A., \& Wachira, M. W. (1994). Ultrasound imaging in developing countries. World Health Forum, 47(6), 16-17.

GHS. (2002). The Ghana Health Service Council. Accra: Government Press.

Gil-Gonzalez, D., Carrasco-Portino, M., \& Ruiz, M. T. (2006). Knowledge gaps in scientific literature on maternal mortality: a systematic review. Bulletin of the World Health Organization, 84, 903-909.

Ginsburg, F. D., \& Rapp, R. (Eds.). (1995). Conceiving the New World Order. The global politics of reproduction. Berkeley: University of California Press.

GoG. (1999). Medium Health Strategy Towards Vision 2020. Accra: Ministry of Health, Government Press.

GoG, \& MoH. (2000). Consolidating the Gains: Managing the Challenge. 1999 Health Sector Review. Accra: Ministry of Health, Government Press.

GoG, \& MoH. (2001). The Health of the Nation. Reflections on the First Five Year Health Sector Programme of Work 1997 to 2001. Accra: Ministry of Health, Government Press.

Gomart, E., \& Hennion, A. (1999). A sociology of attachment: music amateurs, drug users. In J. Law \& J. Hassard (Eds.), Actorand After Network Theory (pp. 220-247). Oxford: Blackwell Publishers.

Good, B. J. (1994). Medicine, rationality and experience: an anthropological perspective. Cambridge: Cambridge University Press.

Goodman, N. (1978). Ways of World Making. Indianapolis: Hackett Publishing Company.

Gorenstein, S. (1998). Introduction: Knowledge Systems. Knowledge and Society, 11, 1-13.

Green, E. C. (1997). Purity, pollution and the invisible snake in southern Africa. Medical Anthropology 17, 83-100.

Guardian Reporter. (2003, Sept. 1). Era of donations is over - Mkapa. The Guardian, pp. 1,5.

Hacking, I. (1992). The self-vindication of the laboratory sciences. In A. Pickering (Ed.), Science as practice and culture. Chicago: University of Chicago Press.

Hammerslough, C. (1991). Demographic Approaches to Studying the Effects of Maternal Mortality on Children. In Defense for Children International (Ed.), The Effects of Maternal Mortality on Children in Africa. An Exploratory Report on Kenya, Namibia, Tanzania, Zambia and Zimbabwe (pp. 1-7). New York: Defense for Children International. 
Haraway, D. (1991). Situated Knowledge: The Science Question in Feminism and the Privilege of Partial Perspective. In D. Haraway (Ed.), Simians, Cyborgs, and Women: The Reinvention of Nature (pp. 183-202). New York: Routledge.

Harcourt, W. (2005). The Body Politic in Global Development Discourse: A women and the politics of place perspective. In W. Harcourt \& A. Escobar (Eds.), Women and the Politics of Place (pp. 32-47). Bloomfield: Kumarian Press.

Hardt, M., \& Negri, A. (2000). Empire. Cambridge, Mass.: Harvard University Press.

Harley, J. B. (2004). Deconstructing the map. In N. Thrift \& S. Whatware (Eds.), Cultural Geography. Critical Concepts in the Social Sciences (pp. 71-93). London: Routledge.

Hartouni, V. (1992). Fetal Exposures: Abortion politics and the optics of allusion. Camera Obscura, 29(Fall), 130-149.

Heesterbeek, S. (2000). Ultrasound and Bhroon Jaanch. Similar but different medical technologies in two cultures. Unpublished M.A., Maastricht University, Maastricht.

Hennen, L. (1999). Participatory technology assessment: a response to technical modernity. Science and Public Policy, 26(5), 303-312.

Hennepe te, M. (forthcoming). Depicting skin: Visual culture in 19th century medicine. Unpublished $\mathrm{PhD}$ thesis, Maastricht University, Faculty of Arts \& Social Sciences, Maastricht.

Herbold, R. (1995). Technologies as Social Experiments. The construction and implementation of a high-tech waste disposal site. In A. Rip, T. Misa \& J. Schot (Eds.), Managing Technology in Society. The approach of Constructive Technology Assessment (pp. 185-198). London: Pinter Publishers.

Hirschauer, S. (1991). The Manufacture of Bodies in Surgery. Social Studies of Science, 21, 279319.

Hiscock, J. (1995). Looking a gift horse in the mouth: the shifting power balance between the Ministry of Health and donors in Ghana. Health Policy and Planning, 10(Supplement), 28-39.

Horstman, K., \& Houtepen, R. (2005). Worstelen met Gezond Leven. Ethiek in de preventie van hart-en vaatziekten. Amsterdam: Het Spinhuis.

Horton, R. (1967). African Traditional Thought and Western Science. Africa, 37, 155-187.

Hunt, N. R. (1999). A Colonial Lexicon of Birth Ritual, Medicalization and Mobility in the Congo. Durham: Duke University Press.

Iliffe, J. (1998). East African doctors: a history of the modern profession. Cambridge: Cambridge University Press.

Illich, I. (1975). Medical Nemesis. The expropriation of health. London: Marion Boyars.

Imrie, M. (2003, February 10-16). Korle-Bu nurses use lantern... to deliver babies. Public Agenda, pp. 1, 5.

Jahn, A. (1998). Obstetric care in southern Tanzania: does it reach those in need. Tropical Medicine and International Health, 3(11), 926-932. 
Jahn, A. (2000). Gesundheitssysteme im internationalen Vergleich: Die Betreunng bei Schwangerschaft und Geburt unter besonderer Berücksichtigung des Risikokonzepts. Unpublished Habilitation, Karl-Ruprecht-Universität, Heidelberg.

Jahn, A., Kowalewski, M., \& Kimatta, S., S. (2000). Why do at-risk mothers fail to reach referral level? Barriers beyond distance and cost. In A. Jahn (Ed.), Gesundheitssysteme im internationalen Vergleich: Die Betreunng bei Schwangerschaft und Geburt unter besonderer Berücksicbtigung des Risikokonzepts. Heidelberg: Unpublished Habilitation. KarlRuprecht-Universität, Medizinische Fakultät: Öffentliches Gesundheitswesen.

Janzen, J. M. (1982). Lemba, 1650-1930: A drum of affliction in Africa and the New World. New York: Garland Press.

Jelsma, J. (1995). Learning about Learning in the Development of Biotechnology. In A. Rip, T. Misa \& J. Schot (Eds.), Managing Technology in Society. The approach of Constructive Technology Assessment (pp. 141-166). London: Pinter Publishers.

Jensen, C. B. (2005, April 25-26). Sorting Attachments: On intervention and usefulness in STS and Health Policy. Paper presented at the Practices of Assessment and Intervention in Action-Oriented STS research, Amsterdam.

Kaisi, M. (1988). The rest of the iceberg. Paper presented at the Tanzania Media Women's Association's Seminar on Maternal Mortality, Goethe Institute, Dar es Salaam, Tanzania.

Kapuscinski, R. (2001). The shadow of the sun. New York: Vintage Books.

Karnik, N. S. (2001). Locating HIV/AIDS and India: Cautionary notes on the globalization of categories. Science, Technology and Human V alues, 26(3), 322-348.

Kilbride, P. L., \& Killbride, J. C. (1990). Changing Family Life in East Africa. Women and children at risk. University Park: Penn State University Press.

Kiondo, A. S. (1994). The new politics of local development in Tanzania. In P. Gibbon (Ed.), The new local level politics in East Africa. Studies on Uganda, Tanzania and Kenya (pp. 50-88). Motala: Nordiska Afrikainstitutet.

Kisseka, M. (1973). Heterosexual Relations in Uganda. Unpublished PhD thesis, University of Missouri.

Kleinman, A. (1995). Writing at the Margin. Discourse between anthropology and medicine. Berkeley: University of California Press.

Koch, E. (1995). Why the Development Process Should be Part of Medical Technology Assessment: Examples from the development of medical ultrasound. In A. Rip, T. Misa \& J. Schot (Eds.), Managing Technology in Society. The approach of Constructive Technology Assessment (pp. 231-260). London: Pinter Publishers.

Kopytoff, I. (1986). The cultural biography of things: commoditization as process. In A. Appadurai (Ed.), The social life of things. Commodities in cultural perspective (pp. 64-91). Cambridge: Cambridge University Press.

Kowalewski, M., Jahn, A., \& Kimatta, S., S. (2000). Why do risk-mother fail to reach referral level? Barriers beyond distance and cost. In A. Jahn (Ed.), Gesundheitssysteme im internationalen Vergleich: Die Betreunng bei Schwangerschaft und Geburt unter besonderer 
Beruecksichtigung des Risikokonzepts. . Heidelberg: Medizinische Fakultaet der KarlRuprecht-Universitaet, Fach Oeffentliches Gesundheitswesen. Unpublished habilitation.

Kruk, G. (2000). Frauen in Ghana. Alltaegliche Handlungsraeume zwischen Modernisierung und Marginalisierung. Hamburg: LIT.

Kuhn, T. S. (1962). The role of scientific revolutions. Chicago: University of Chicago Press.

Kurjak, A., \& Kos, M. (1998). Ultrasound screening for fetal anomalies in developing countries: wish or reality. Annals of the New York. Academy of Sciences, 847, 233-237.

Laet de, M. (1998). Intricacies of Technology Transfer: Travel as mode and method. Knowledge and Society, 11, 213-233.

Laet de, M. (1999). Using patents: another intellectual property mode. Paper presented at the Workshop Science, Technology, and Law, Max Planck Institute Berlin, August 2327.

Laet de, M. (2000). Patents, travel, space: ethnographic encounters with objects in transit. Environment and Planning: Society and Space, 18, 149-168.

Laet de, M. (2002). Patents, Knowledge, and Technology Transfer: On the politics of positioning and place. Research in Science and Technology Studies, 13, 213-237.

Laet de, M., \& Mol, A. (2000). The Zimbabwe Bush Pump. Mechanics of a fluid technology. Social Studies of Science, 30(2), 225-263.

Langenscheidt, P., Wilbrand, T., \& Clarke, J. (1996). Zur Wertigkeit der Sonographie für Chirurgie in Entwicklungsländern. The value of ultrasound for surgeons in developing countries. Der Unfallchirurg, 252, 40-48.

Langwick, S. (forthcoming). Devils, Parasites and Fierce Needles: Healing and the politics of translation in Southern Tanzania. Medical Anthropology Quarterly.

Langwick, S. (forthcoming). The Matter of Maladies: Ontological politics in postcolonial healing in Tanzania.

Last, M. (1992). The Importance of Knowing about Not Knowing: Observations from Hausaland. In J. Janzen \& S. Feierman (Eds.), The Social Basis of Health and Healing in Africa (pp. 393-406). Berkeley: University of California Press.

Latouche, S. (1992). Standards of Living. In W. Sachs (Ed.), The Development Dictionary: A guide to knowledge as power (pp. 250-263). London: ZED Books.

Latour, B. (1987). Science in Action. Cambridge, MA: Harvard University Press.

Latour, B. (1988). Drawing things together. In M. Lynch \& S. Woolgar (Eds.), Representation in Scientific Practice (pp. 19-68). Cambridge et al.: MIT Press.

Latour, B. (1996). Aramis or the love of technology. Cambridge, MA: Harvard University Press.

Latour, B. (1999). Pandora's Hope. Essays on the Reality of Science Studies. Cambridge, MA: Harvard University Press.

Latour, B. (2004). How to talk about the body? The normative dimension of science studies. Body \& Society, 10(2-3), 205-229. 
Law, J. (1994). Organizing modernity. Oxford: Blackwell Publishers.

Leeuw de, P. (2005, December 15). Rehabilitation of Diagnostic Services/ Tanzania. Paper presented at the Conference "Lessons learnt from Tanzania" Eindhoven.

Lie, M., \& Sorensen, K. H. (1996). Making Technology our own? Domesticating Technology into Everyday Life. In M. Lie \& K. H. Sorensen (Eds.), Making Technology our own? Domesticating Technology into Everyday Life (pp. 1-30). Oslo: Scandinavian University Press.

Lock, M. (1993). Encounters with aging: Mythologies of menopause in Japan and North America. Berkeley: University of California Press.

Lock, M., \& Gordon, D. A. (1988). Biomedicine Examined. Dordrecht: Kluwer Academic Publishers.

Long, N., \& Long, A. (1992). Battlefields of knowledge: The interlocking of theory and practice in social research and development. London: Routledge.

Marcus, G. E. (1998). Ethnography in/of the World System: The emergence of multi-sited ethnography (1995). In ibid. (Ed.), Ethnography through thick and thin (pp. 79-104). Princeton: Princeton University Press.

Martin, E. (1994). Flexible bodies: Tracking immunity in American culture from the days of polio to the age of AIDS. Boston: Beacon Press.

Massey, D. (2005). For space. London: Sage Publications.

Mayall, J. M. (1993). Technology assessment: A feminist perspective Philadelphia Temple University Press.

Mbaruku, G. (2004, 29.-31.03.2004). Provision of comprehensive reproductive health care services to poor rural women in Tanzania: a millennium challenge. Paper presented at the International Conference 'Improving Maternity Care: Concepts, evidence and local adaptation', Dar es Salaam.

Mbaruku, G., \& Bergstroem, S. (1995). Reducing maternal mortality in Kigoma, Tanzania. Health Policy and Planning, 10(1), 71-78.

Mbiti, J. S. ([1969] 1971). African Religions and Pbilosophy. London: Heinemann.

Mebrahtu, S. (2000). What we need is timely assistance: Heavy workloads and Safe Motherhood in Eritrea. In M. Turshen (Ed.), African Women's Health (pp. 27-48). Trenton: Africa World Press.

Mesaki, S. (1993). Witchcraft and Witch-killings in Tanzania: Paradox and Dilemma. Unpublished $\mathrm{PhD}$, University of Minnesota.

Mesman, J. (2002). Ervaren pioneers: Omgaan met twijfel in de intensive care voor pasgeborenen. Amsterdam: Aksant.

Mesman, J. (2005, April 25-26). Action-Oriented Research: Processes of Fine-tuning and Alignment. Paper presented at the Assessment and Intervention in Action-Oriented STS, Amsterdam 
Miller, C. A. (2004). Resisting Empire: Globalism, relocalization, and the politics of knowledge. In S. Jasanoff (Ed.), Earthly Politics: local and global environmental governance. Cambridge, MA: MIT Press.

Mindel, S. (1997). Role of imager in the developing world. Lancet, 349, 426-429.

Mitchell, L. M. (2001). Baby's first picture. Ultrasound and the politics of fetal subjects. Toronto: University of Toronto Press.

Mitchell, L. M., \& Georges, E. (2000). Cross-Cultural Cyborgs: Greek and Canadian women's discourses on fetal ultrasound. In A. R. Saetnan, N. Oudshoorn \& M. Kirejczyk (Eds.), Bodies of Technology. Women's involvement with reproductive medicine (pp. 384-409). Columbus, Ohio: Ohio State University Press.

MOH. (1977). Health Planning Data Book for Ghana. Accra: National Health Planning Unit, Ministry of Health, Ghana.

MoH. (1992). Safe Motherhood Strategy for Tanzania. Dar es Salaam: Ministry of Health; Government Press.

MoH. (2002). National Health Policy. Dar es Salaam: Ministry of Health, United Republic of Tanzania.

MoH, \& GoG. (2000). Consolidating the Gains: Managing the Challenges. 1999 Health Sector Review. Final Draft. Accra: Ministry of Health \& Health Partners, Republic of Ghana.

MoH Tanzania. (2002). Manual for quantification of national requirements of equipment and supplies for laboratories, radiology, dental and health care technical services in Tanzania. Dar es Salaam: Department of Hospital Services; Government Press.

MoH Tanzania. (2004). National Health Care Technology Policy Guidelines. Dar es Salaam: Department of Curative Health Services, United Republic of Tanzania.

Mol, A. (1999). Ontological politics. A word and some questions. In J. Law \& J. Hassard (Eds.), Actor Network Theory and After (pp. 74-89). Oxford: Blackwell Publishing.

Mol, A. (2002). The body multiple.Ontology in medical practice. Durham: Duke University Press.

Mol, A., \& Berg, M. (1994). Principles and practice of medicine. Culture, Medicine and Psychiatry, 18(2), 247-265.

Moore, S. F. (2001). The international production of authoritative knowledge. The case of drought-stricken West Africa. Ethnography, 2(2), 161-189.

Morgan, L. M. (2000). Magic and a Little Bit of Science: Technoscience, Ethnoscience, and the Social Construction of the Fetus. In A. R. Saetnan, N. Oudshoorn \& M.

Kirejczyk (Eds.), Bodies of Technology. Women's involvement with reprocductive medicine (pp. 355-367). Columbus, Ohio: Ohio State University Press.

Morgan, L. M., \& Michaels, M. (Eds.). (1999). Fetal Subjects, Feminist Positions. Philadelphia: University of Pennsylvania Press.

MUCHS. (2002). Curriculum for the diploma in diagnostic radiography. Dar es Salaam: Muhimbili University College of Health Sciences.

Mueller, A. (1987). Peasants and Professionals: The social organization of women in development knowledge. Unpublished PhD Thesis, Ontario Institute for Studies in Education. 
NEI. (1997). Rehabilitation of Diagnostic Services, Tanzania. ORET 97/10. Draft Report. Rotterdam: Netherlands Economic Institute.

Nguvu, P. (2004, April 30). Dar hospitals grapple with congestion. The Guardian.

Nyamtema, A. S. (2004). Obstetric care. Factors affecting provision of care and pregnancy outcome in Dar es Salaam District Hospitals - 2002., Dar es Salaam.

Office of Technology Assessment. (1982). Strategies of medical technology assessment. Washington, D.C.: Government Printing Office.

Onis, M. d., Garza, C., Onyango, A., \& Martorell, R. (2006). WHO Child Growth Standards. ACTA PAEDIATRICA. International Journal of Paediatrics, 95(Supplement 450).

Opare, M., \& Mill, J. E. (2000). The evolution of nursing education in a postindependence context - Ghana from 1957 to 1970. Western Journal of Nursing Research, 22(8), 936-944.

Oudshoorn, N. (1997). From Population Control Politics to Chemicals: The WHO as an intermediary organization in contraceptive development. Social Studies of Science, 27, $41-72$.

Oudshoorn, N., \& Pinch, T. (2003a). Introduction: How users and non-users matter. In N. Oudshoorn \& T. Pinch (Eds.), How users matter. The co-construction of users and technology (pp. 1-25). Cambridge, MA: MIT Press.

Oudshoorn, N., \& Pinch, T. (Eds.). (2003b). How users matter: The co-construction of users and technology. Cambridge, MA: MIT Press.

Palmer, P. E. S. (1995). Manual of diagnostic ultrasound. Geneva: World Health Organization; World Federation for Ultrasound in Medicine and Biology.

Pasveer, B. (1992). Shadows of Knowledge. Making a representing practice in medicine: x-ray pictures and pulmonary tuberculosis, 1895-1930. Unpublished PhD, University of Amsterdam, Amsterdam.

Pasveer, B. (1994). De coproduktie van afbeelding en ziekte: Roentgenfoto's en longtuberculose aan het begin van de twintigste eeuw. In S. van der Geest, P. ten Have, G. Nijhof \& P. Verbeek-Heida (Eds.), De Macht der Dingen (pp. 20-43). Amsterdam: Het Spinhuis.

Patterson, K. D. (1981). Health in Colonial Ghana: Disease, Medicine, and Socio-Economic Change. Waltham, Mass.: Crossroads Press.

Perrin, K. M., Matthews, T., Carter, R., \& Perry-Casler, S. (2001). International aspects of prenatal care: a review The International Electronic Journal of Health Education 4, from (http://wwwiejhe.org)

Perry, S., \& Marx, E. S. (1992). What technologies for health care in developing countries? World Health Forum, 13(4), 356-362.

Petchesky, R. P. (1987). Foetal Images: the Power of Visual Culture in the Politics of Reproduction. In M. Stanworth (Ed.), Reproductice Technologies: Gender, Motherhood and Medicine (pp. 57-80). Cambridge: Policy Press.

Petchesky, R. P. (2003). Global Prescriptions: Gendering health and buman rights. London: ZED Books. 
Peters, P. F. (2006). Time, Innovation and Mobilities. Travel in technological cultures. London: Routledge.

Pickstone, J. (2000). Production, Community and Consumption: The Political Economy of Twentieth-Century Medicine. In R. Cooter \& J. Pickstone (Eds.), Medicine in the Twentieth Century (pp. 1-20). Amsterdam: Harwood Academic Publishers.

Pigg, S. L. (1995). Acronyms and Effacement: Traditional Medical Practitioners (TMP) in International Health Development. Social Science \& Medicine, 41(1), 47-68.

Pinch, T., \& Bijker, W. (1987). The Social Construction of Facts and Artifacts: Or How the Sociology of Science and the Sociology of Technology Might Benefit Each Other. In W. Bijker, T. Hughes \& T. Pinch (Eds.), The Social Construction of Technological Systems. Cambridge, MA: MIT Press.

Piraino, M. (1991). Pathways of Child Survivors of Maternal Mortality in Africa. In D. f. C. International (Ed.), The Effects of Maternal Mortality on Children in Africa. An Exploratory Report on Kenya, Namibia, Tanzania, Zambia and Zimbabwe (pp. 9-72). New York: Defense for Children International.

Prooijen van, W. (2005, December 15). Tanzania-lessons learned. Paper presented at the International Workshop Philips Medical Systems, Eindhoven.

Quaye, R. (1996). Underdevelopment and Health Care in Africa. The Ghanaian Experience. Lewiston, NY: Mellen University Press.

Radstake, M. (forthcoming). Visions of Illness. An endography of real-time medical imaging. Unpublished $\mathrm{PhD}$, Maastricht University, Faculty of Arts and Social Sciences, Maastricht.

Raikes, A. (1989). Women's Health in East Africa. Social Science \& Medicine, 28, 447-459.

Ranger, T. (1992). Godly Medicine: The Ambiguities of Medical Mission in Southeastern Tanzania, 1990-1945. In S. Feierman \& J. Janzen (Eds.), The Social Basis of Health and Healing in Africa (pp. 256-282). Berkeley: University of California Press.

Rapp, R. (1997). Real-time Fetus: The role of the sonogram in the age of monitored reproduction. In G. L. Downey \& J. Dumit (Eds.), Cyborgs \& Citadels: Anthropological inventions in emerging science and technologies (pp. 31-48). Santa Fe: School of American Research Press.

Rapp, R. (1999). Testing Women, Testing the Fetus. New York: Routledge.

Rapp, R. (2000). Testing Women, Testing the Fetus. The social impact of amniocentesis in America. New York: Routledge.

RCHS. (2000). National Package of Essential Reproductive and Child Health Interventions in Tanzania. Dar es Salaam: United Republic of Tanzania, Ministry of Health, Reproductive and Child Health Section.

Reid, M. (1982). Patient/Healer Interactions in Sukuma Medicine. In S. Yoder (Ed.), African Health and Healing Systems (pp. 121-158). Los Angeles: Crosswood Press.

Remmen, A. (1995). Pollution Prevention, Cleaner Technologies and Industry. In A. Rip, T. J. Misa \& J. Schot (Eds.), Managing Technology in Society: The approach of constructive technology assessment (pp. 199-222). London: Pinter. 
Rip, A., Misa, T. J., \& Schot, J. (1995). Constructive Technology Assessment: A new paradigm for managing technology in society. In A. Rip, T. J. Misa \& J. R. Schott (Eds.), Managing Technology in Society: The approach of constructive technology assessment (pp. 1-12). London: Pinter.

Rip, A., Misa, T. J., \& Schot, J. (Eds.). (1995). Managing Technology in Society: The approach of constructive technology assessment. London: Pinter.

Rist, G. (1997). The History of Development: From Western origins to global faith. New York: ZED Books.

Rothman, B. K. (1986). The tentative pregnancy: Prenatal diagnosis and the future of motherhood. New York: W.W. Norton.

Rothman, B. K. (1989). Recreating motherhood: Ideology and technology in a patriarchal society. New York: W.W. Norton.

Rubayiza, F. (2001). Daily ultrasound in General Medicine, Gynaecology, Obstetrics. Accra.

Sadik, N. (1990). Investing in Women. New York: United Nations Population Fund (UNFPA).

Saetnan, A. R. (2000). Thirteen Women's Narratives of Pregnancy, Ultrasound, and Self. In A. R. Saetnan, N. Oudshoorn \& M. Kirejczyk (Eds.), Bodies of Technology. Women's involvement with reproductive medicine (pp. 331-354). Columbus, Ohio: Ohio State University Press.

Schmoll, P. G. (1993). Black Stomachs, Beautiful Stones: Soul-eating among the Hausa in Niger. In J. Comaroff \& J. Comaroff (Eds.), Modernity and its malcontents (pp. 193-220). Chicago: University of Chicago Press.

Schwarz, M. (1993). The Technological Culture: Challenges for technology assessment and policy. Science and Public Policy, 20(6), 381-388.

Scott, J. (1998). Seeing like a state. How certain schemes to improve the human condition have failed. Yale: Yale University Press.

Shrum, W., \& Shenav, Y. (1995). Science and Technology in Less Developed Countries. In S. Jasanoff, G. E. Markle, J. Petersen \& T. Pinch (Eds.), Handbook of Science and Technology Studies (pp. 627-651). Thousand Oaks: Sage Publications.

Smith, D. (1974). The social construction of documentary reality. Sociological Inquiry, 44(4), 275-268.

Smith, D. (1984). Textually mediated social organization. International Social Science Journal, 36(1), 59-75.

Smith, D. J. (2003). Patronage, Per Diems and the "Workshop Mentality": The practice of family planning programs in Southeastern Nigeria

World Development, 31(4), 703-715.

Smits, R., \& Leyten, J. (1991). Technology assessment: waakhond of speurneus? Naar een integraal technologiebeleid. Zeist: Kerckebosch.

Soete, L. (1995). (Constructive) Technology Assessment: An economic perspective. In A. Rip, T. J. Misa \& J. R. Schott (Eds.), Managing Technology in Society: The approach of constructive technology assessment (pp. 37-49). London: Pinter. 
Stabile, C. (1992). Shooting the mother: fetal photography and the politics of disappearance. Camera Obscura, 28, 180-205.

Star, S. L., \& Bowker, G. (1999). Sorting Things Out. Classifications and its consequences. Cambridge, MA: MIT Press.

Star, S. L., \& Griesemer, J. R. (1989). Institutional ecology, "translations", and boundary objects: Amateurs and professionals in Berkeley's Museum of Vertebrae Zoology, 1907-1939. Social Studies of Science, 19, 387-420.

Stinnesberg, T. (n.d. [1960?]). 33 Jahre Missionsaerztliche Taetigkeit im Ndandagebiet in Tanganyika: Unpublished report.

Swantz, M.-L. (1969). The religious and magical rites connected with the life cycle of the woman in some Bantu ethnic groups in Tanzania. Unpublished PhD thesis, University of Dar es Salam, Dar es Salaam.

Swantz, M.-L. (1996). Sharing in Community-Based Social Services in Rural Tanzania: A Case Study of Mtwara and Lindi Regions: The United Nations University; World Institute for Development Economic Research.

Tan-Torres, T. (1995). Technology assessment in developing countries. World Health Forum, 16, 74-76.

Tautz, S. (1995). Ultrasound at a Botswana District Hospital. Perceptions of pregnant women and health professionals. Unpublished M.A. thesis, University of Heidelberg: Institute of Tropical Medicine and Public Health, Heidelberg.

Taylor, J. (1992). The public fetus and the family car: From abortion politics to a Volvo advertisement. Public Culture, 4(2), 67-80.

Ten Have, H. (1994). Evaluatie van medische technologie. Een filosofische (na)beschouwing. In S. van der Geest, P. ten Have, G. Nijhof \& P. Verbeek-Heida (Eds.), De Macht der Dingen. Medische technologie in cultureel perspectief (pp. 224-243). Amsterdam: Het Spinhuis.

Ten Have, H. (2004). Ethical perspectives on health technology assessment. Int. Journal of Technology Assessment in Health Care, 20(1), 71-76.

Thaddeus, S., \& Maine, D. (1994). Too far to walk: maternal mortality in context. Social Science \& Medicine, 38(8), 1091-1110.

Thompson, W., Gustafson, K., Diefenthal, H., \& Knoedler, J. (1993). Radiology in East Africa. AJR, 158, 1167.

Timmermans, S., \& Berg, M. (1997). Standardization in Action: Achieving local universality through medical protocols. Social Studies of Science, 27(2), 273-305.

Timmermans, S., \& Berg, M. (2003). The practice of medical technology. Sociology of Health and Illness, 25, 97-114.

Truman, H. ([1949]1964). Public Papers of the President of the United States: Harry S. Truman.Unpublished manuscript, Washington, D.C. : US Government Printing Office. 
Turshen, M. (1984). The political ecology of disease in Tanzania. New Brunswick: Rutgers University Press.

Turshen, M. (1999). Privatizing Health Services in Africa. New Brunswick: Rutgers University Press.

Twumasi, P. A. (1981). Colonialism and International Health: A study in social change in Ghana. Social Science \& Medicine, 153, 147-151.

Twumasi, P. A. (1982). Improvement of Health Care in Ghana: Present perspectives. In S. Yoder (Ed.), African Health and Healing Systems (pp. 199-215). Los Angeles: Crosswood Press.

Twumasi, P. A. (1992). Colonial Rule, International Agency, and Health: The experience of Ghana. In T. Falola \& D. Itayavyar (Eds.), The Political Economy of Health in Africa (pp. 107-120). Athens, Ohio: Ohio University Center for International Studies.

UNDP. (1997). Human Development Report 1997 [Electronic Version] from http://hdv.undporg/reports/global/2001/enl/.

UNDP. (2001). Human Development Report 2001. Retrieved 05.07.2005, from http://hdv.undporg/reports/global/2001/enl/

UNICEF. (1990). Women and Children in Tanzania. A situation analysis. Dar es Salaam: United Nations Children's Fund; The Government of the United Republic of Tanzania.

UNICEF. (1999). The progress of nations. Retrieved 0.3.01.2006, from http://www.unicef/org/pon99/

United Republic of Tanzania. (1990). National Health Policy. Dar es Salaam: Ministry of Health; Government Press.

United Republic of Tanzania, \& MoH. (2002). National Health Policy. Dar es Salaam: Ministry of Health.

Urassa, D. P., Carlstedt, A., Nystroem, L., Massawe, S. N., \& Lindmark, G. (2002). Quality assessment of the antenatal programme for anaemia in rural Tanzania. Journal for Quality in Health Care, 14(6), 441-448.

Urassa, E., Massawe, S. N., Lindmark, G., \& Nystroem, L. (1997). Operational factors affecting maternal mortality in Tanzania. Health Policy and Planning, 12(1), 50-57.

van Asselt, M. (2005). The complex significance of uncertainty in a risk area: logics, manners and strategies in use. Int. J. Risk. Assessment and Management, 5(2/3/4), 125-158.

VanderWolk, M. L. (1998). Knowing in Action: Men's Work in the Northern Forest. Knowledge and Society, 11, 63-85.

Vangeenderhuysen, C., Abdellahi, M. B., \& Isselman, S. (2002). La formation des sagesfemmes en echographie obstetricale dans les payes en developpement: pourquoi et comment? J Gynecol Obstet Biol Reprod, 31, 100-106.

Varkevisser, C. (1973a). Socialization in a Changing Society: Sukuma childhood in rural and urban Mwanza, Tanzania. The Hague: Centre for the Study of Education in Changing Societies. 
Varkevisser, C. (1973b). The Sukuma of Northern Tanzania. In Institute of African Studies (Ed.), Cultural source materials for population planning in East Africa (Vol. III, pp. 234248). Nairobi: East African Publishing House.

Vaughan, M. (1991). Curing their Ills. Colonial Power and African Illness. Cambridge: Polity Press.

Ventevogel, P. (1996). Whiteman's things: training and detraining healers in Ghana. Amsterdam: Het Spinhuis.

Verbeek, P.-P. (2006). Materializing Morality. Design ethics and technological mediation. Science, Technology \& Human Values, 31(3), 361-380.

Verran, H. (2001). Science and an African logic. Chicago: University of Chicago Press.

Villar, J., \& Bergsjo, P. (1996). New WHO antenatal care model. Geneva: World Health Organization.

Volodin, V., \& Hanson, G. (1996). Use of ultrasound in the WHO programme for diagnostic imaging in developing countries. Der Unfallchirurg, 252, 23-27.

Walsh, V. (1995). Social Criteria in the Commercialisation of Human Reproductive Rights. In A. Rip, T. Misa \& J. Schot (Eds.), Managing Technology in Society. The approach of Constructive Technology Assessment (pp. 261-284). London: Pinter Publishers.

Watney, S. (1990). Missionary Positions: AIDS, "Africa", and Race. In R. Ferguson, M. Gever \& T. Minh-ha (Eds.), Out There: Marginalization and contemporary cultures (pp. 89103). Cambridge, MA: MIT Press.

Weijers, T. (1995). Decision Structures and Technology Diffusion: Technical and therapeutic trajectories for diabetes care. In A. Rip, T. Misa \& J. Schot (Eds.), Managing Technology in Society. The approach of Constructive Technology Assessment (pp. 285-303). London: Pinter Publishers.

Weissköppel, C. (2004). A Sudanese Snack Bar in Berlin: Vitalization and presence in the diaspora. In P. Probst \& G. Spittler (Eds.), Between Resistance and Expansion. Explorations of local vitality in Africa (pp. 91-114). Münster: LIT.

Wertz, D., \& Wertz, R. (1977). Lying in: A bistory of childbirth in America. New York: Free Press.

WHO. (1985a). Future use of new imaging technologies in developing countries. Report of a WHO Scientific Group. Geneva: World Health Organization.

WHO. (1985b). Preventing Maternal Mortality. Report of a WHO International Meeting. Geneva: World Health Organization.

WHO. (1986a). Maternal mortality: helping women off the road to death. WHO Chronicle, 40(5), 175-183.

WHO. (1986b). Prevention of Maternal Mortality. Geneva: World Health Organization.

WHO. (1989). Measuring Reproductive Morbidity. Report of a Technical Working Group. Geneva: World Health Organization.

WHO. (1995a). Appropriate technologies can help make motherhood safer. Safe Motherhood, 2(18), 4-8. 
WHO. (1995b). World Health Report 1995. Geneva: World Health Organization.

WHO. (1996). Revised 1990 Estimates of Maternal Mortality. A New Approach by WHO and UNICEF. Geneva: World Health Organization.

Whyte, S. R. (1997). Questioning misfortune. The pragmatics of uncertainty in Eastern Uganda. Cambridge: Cambridge University Press.

Whyte, S. R., van der Geest, S., \& Hardon, A. (2002). Social Lives of Medicine. Cambridge: Cambridge University Press.

Whyte, S. R., \& Whyte, M. A. (2004). Children's Children: Time and Relatedness in Eastern Uganda. Africa, 74(1), 76-94.

Wijsen, F., \& Tanner, R. (2002). 'I am just a Sukuma'. Globalization and identity construction in Northwest Tanzania. Amsterdam: Rodopi.

Willems, D. (1995). Tools of Care. Explorations into the semiotics of medical technology. Unpublished $\mathrm{PhD}$ thesis, Maastricht University, Maastricht, The Netherlands.

Winner, L. (1999). Do artifacts have politics? In D. MacKenzie \& J. Wajcman (Eds.), The social shaping of technology (pp. 28-40). Buckingham: Open University Press.

Wladarsch, E. (2005). Time-Health-Culture: Cultural time concepts and health-related time preferences in Burkina Faso. Berlin: Reimer

Wolf, A. (1996). Essensmetaphern im Kontext von Aids und Hexerei in Malawi. In A. Wolf \& M. Stürzer (Eds.), Die gesellschaftliche Konstruktion von Befindlichkeit. Ein Sammelband zur Medizinethnologie (pp. 205-221). Berlin: VWB.

Wolf, A. (2003). AIDS und Kanyera in Malawi: Lokale Rezeption eines globalen Phänomens. In A. Wolf \& V. Hörbst (Eds.), Medirin und Globalisierung: Universelle Ansprüche - lokale Antworten (pp. 203-229). Münster: LIT.

World Bank. (1979). Recognizing the "Invisible Woman in Development": The World Bank Experience. Washington, D.C.: World Bank.

World Bank. (1982). World Bank Report 1982. New York: Oxford University Press for the World Bank.

World Bank. (1993). World Development Report: Investing in Health. Washington, D.C.: World Bank.

World Bank. (1994). Better health in Africa: Experiences and lessons learned. Washington, D.C.: World Bank.

World Bank. (1997). The State in a Changing World. Washington, D.C.: World Bank.

World Bank. (2000). Can Africa claim the 21st Century? Washington, DC: The International Bank for Reconstruction and Development; The World Bank.

Wynne, B. (1995). Technology Assessment and Reflexive Social Learning: Observations from the risk field. In A. Rip, T. Misa \& J. Schot (Eds.), Managing Technology in Society. The approach of Constructive Technology Assessment (pp. 19-36). London: Pinter Publishers 
Yoder, P. S. (1991). Cultural conceptions of illness in the measurement of changes in morbidity. In J. Cleland \& A. Hill (Eds.), Health Transition: Methods and Measures (pp. 43-60). Canberra: Australian National University.

Young, A. (1995). The harmony of illusions: inventing post-traumatic stress disorder. Princeton: Princeton University Press.

Yoxen, E. (1987). Seeing with sound: a study of the development of medical images. In W. E. Bijker, T. Hughes \& T. Pinch (Eds.), The Social Construction of Technological Systems (pp. 93-95). Cambridge, MA: MIT Press.

Zerubavel, E. (1979). Patterns of time in hospital life. Chicago: University of Chicago Press.

Zuiderent, T. (2002). Blurring the Center: On the politics of ethnography. Scandinavian Journal of Information Systems, 14(2), 59-78. 


\section{Appendix}

This appendix consists of a list of interviewees (Appendix A); a graphic overview of the relationship between hospitals and persons within these facilities that complements the map in the introduction (Appendix B); a list of explanatory terms and abbreviations used in the text (Appendix C); and a note on prices of diverse items during the time of the study in order to show the lifetime costs of my interviewees (Appendix D). 


\section{Appendix A}

\section{List of Interviewees}

All interviews (formal and informal) of the following list were conducted by the author. Interviews in Dutch (Nl) and English (E) were conducted by the author alone; interviews in Kiswahili or Kisukuma were conducted by the author with the help of field assistants and later translated verbatim by Tanzanian translators experienced in anthropological health research, Mr. Shitindi, Mr. Gogomoka and Mr. Kitigwa. All interviews held in either Kiswahili (Sw) or Kisukuma (Sk) were tape-recorded and transcribed. Interviews in English are for some part telephone interviews and are either based on tape-records of written notes during the talk complemented by a memory protocol.

The list of interviews is split in three parts in order to allow for easy reference to the text. 'General interviews', in the text abbreviated Ai, comprise of communication with people who cannot be allocated clearly to either one of the two country fieldsites. Interviews in Ghana, abbreviated Gh, include interviews held with people in Ghana, likewise does the category 'interviews in Tanzania' refer to interviewees in Tanzania. All names used in the list below are pseudonyms. The date indicates the day at which the communication that I refer to in the text took place. It does not necessarily mean that I spoke to that particular person only once.

\section{General interviews (Ai)}

\begin{tabular}{|l|l|l|l|}
\hline $1 \mathrm{a}, \mathrm{b}$ & Peter Bruggen & Philips Medical Systems & $(29.08 .02 ; 14.10 .02$ by phone, E) \\
\hline 2 & Ger Steen & Philips Medical Systems & $(02.02 .05, \mathrm{Nl})$ \\
\hline 3 & Jan Vermeulen & Philips Medical Systems & $(31.10 .05, \mathrm{Nl})$ \\
\hline 4 a, b & $\begin{array}{l}\text { Mats } \\
\text { Timmerman }\end{array}$ & Philips Medical Systems & $(18.10 .02, \mathrm{E} ; 02.02 .06, \mathrm{Nl})$ \\
\hline 5 & Ram Patel & Philips Medical Systems & $(25.02 .04, \mathrm{E})$ \\
\hline 6 & Jeroen Smits & $\begin{array}{l}\text { Royal Dutch Embassy, } \\
\text { Accra, Ghana }\end{array}$ & $(30.04 .04$, by email, E) \\
\hline 7 & Mieke Moerman & $\begin{array}{l}\text { Royal Dutch Embassy, } \\
\text { Dar es Salaam, Tanzania }\end{array}$ & $(20.02 .04, \mathrm{E})$ \\
\hline 8 a, b & Noortje Gerrits & Fontys University & $(25.06 .03 ; 02.07 .03$ by email, E) \\
\hline 9 & Stefan ten Horst & Fontys University & $(18.09 .02, \mathrm{E}, \mathrm{Nl})$ \\
\hline
\end{tabular}


Interviews in Ghana (Gh)

\begin{tabular}{|c|c|c|c|}
\hline 1 & Dr. Aryeetey & Ministry of Health, Accra & $(15.02 .03, \mathrm{E})$ \\
\hline 2 & Dr. Bonsa & $\begin{array}{l}\text { Radiologist, } \\
\text { Korle Bu Teaching Hospital }\end{array}$ & $(18.10 .02, \mathrm{E})$ \\
\hline $3 a, b$ & Dr. Lema & $\begin{array}{l}\text { Gynecologist, } \\
\text { Korle Bu Teaching Hospital }\end{array}$ & $(02.11 .02 ; 5.11 .02, \mathrm{E})$ \\
\hline 4 & Lucia Owusu, & $\begin{array}{l}\text { Nurse-midwife, ultrasound } \\
\text { assistant, Korle Bu Teaching } \\
\text { Hospital }\end{array}$ & $(03.11 .02, \mathrm{E})$ \\
\hline 5 & Elias Kudzi & $\begin{array}{l}\text { Receptionist, Korle Bu } \\
\text { Teaching Hospital }\end{array}$ & $(04.11 .02, \mathrm{E})$ \\
\hline $6 \mathrm{a}, \mathrm{b}$ & Dr. Battir & $\begin{array}{l}\text { Gynecologist, ultrasound } \\
\text { operator, Korle Bu } \\
\text { Teaching Hospital }\end{array}$ & $(07.11 .02,11.11 .02, \mathrm{E})$ \\
\hline 7 & Dr. Tennison & $\begin{array}{l}\text { gynecologist, ultrasound } \\
\text { operator, Korle Bu } \\
\text { Teaching Hospital }\end{array}$ & $(11.11 .02, \mathrm{E})$ \\
\hline 8 & $\begin{array}{l}\text { Proclaim } \\
\text { Winston }\end{array}$ & Korle Bu Teaching Hospital & $(17.11 .02, \mathrm{E})$ \\
\hline 9 & Mercy Prempeh & Korle Bu Teaching Hospital & $(25.11 .02, \mathrm{E})$ \\
\hline 10 & Dr. Gray & $\begin{array}{l}\text { Family health doctor, } \\
\text { ultrasound operator, Baptist } \\
\text { Medical Center }\end{array}$ & $(17.02 .03, \mathrm{E})$ \\
\hline 11 & Gloria Akampo & $\begin{array}{l}\text { Nurse-midwife, Nalerigu } \\
\text { Baptist Mission Center }\end{array}$ & $(17.01 .03, \mathrm{E})$ \\
\hline 12 & Tabitha Juma & Baptist Mission Center & $(02.02 .03, \mathrm{E})$ \\
\hline 13 & Ama Kwaku & $\begin{array}{l}\text { Traditional Birth Attendant, } \\
\text { Nalerigu village }\end{array}$ & (18.02.03, E, Mampruli) \\
\hline 14 & Dr. Kwame & ENT specialist, Accra & $(22.12 .04, \mathrm{E})$ \\
\hline
\end{tabular}

Interviews in Tanzania (Tz)

\begin{tabular}{|c|c|c|c|}
\hline $1 \mathrm{a}, \mathrm{b}$ & Mr. Chanika & $\begin{array}{l}\text { Ministry of Health, } \\
\text { Dar es Salaam }\end{array}$ & $\begin{array}{l}(15.03 .04, \mathrm{E} ; 11.01 .05 \text { by phone, } \\
\text { E) }\end{array}$ \\
\hline 2 & Dr. Pumusi & $\begin{array}{l}\text { Gynecologist, } \\
\text { Bugando Teaching Hospital }\end{array}$ & $(05.03 .04, \mathrm{E})$ \\
\hline 3 & Dr Ratibia & $\begin{array}{l}\text { Registrar, Bugando } \\
\text { Teaching Hospital }\end{array}$ & $(20.05 .04, \mathrm{E})$ \\
\hline 4 & Justin Itete & $\begin{array}{l}\text { Intern, Bugando Teaching } \\
\text { Hospital }\end{array}$ & $(22.04 .04, \mathrm{E})$ \\
\hline 5 & Dr. Micha & $\begin{array}{l}\text { Anesthetist, } \\
\text { Bugando Teaching Hospital }\end{array}$ & $(21.04 .04, \mathrm{E})$ \\
\hline 6 & Dr. Kilima & $\begin{array}{l}\text { Gynecologist, } \\
\text { Bugando Teaching Hospital }\end{array}$ & $(13.07 .04, \mathrm{E})$ \\
\hline 7 & Dr. Kamenga & $\begin{array}{l}\text { Gynecologist, Bugando } \\
\text { Teaching Hospital }\end{array}$ & $(12.05 .04, \mathrm{E})$ \\
\hline
\end{tabular}




\begin{tabular}{|c|c|c|c|}
\hline $\begin{array}{l}8 \\
\mathrm{a}, \mathrm{b}, \mathrm{c}, \mathrm{d}\end{array}$ & Halifa Salama & $\begin{array}{l}\text { Ultrasonographer, } \\
\text { Bugando Teaching Hospital }\end{array}$ & $\begin{array}{l}(02.04 .04 ; 21.04 .04 ; 11.06 .04 ; \\
23.7 .04, \mathrm{E})\end{array}$ \\
\hline 9 & William Chanji & $\begin{array}{l}\text { Ultrasonographer, Bugando } \\
\text { Hospital }\end{array}$ & $(23.04 .04, \mathrm{E})$ \\
\hline 10 & Eunice Hokoro, & Bugando Teaching Hospital & $(14.04 .04, \mathrm{E})$ \\
\hline 11 & $\begin{array}{l}\text { Edgar } \\
\text { Nabusanke, }\end{array}$ & $\begin{array}{l}\text { Boyfriend of Eunice } \\
\text { Hokoro }\end{array}$ & $(14.04 .04, \mathrm{E})$ \\
\hline 12 & Celina Kondo & Bugando Teaching Hospital & $(15.04 .04 ; 03.05 .04 ; 01.07 .04, \mathrm{Sw})$ \\
\hline 13 & Mr. Olole, & $\begin{array}{l}\text { Radiographer, Sekoutoure } \\
\text { Regional Hospital }\end{array}$ & $(20.05 .04, \mathrm{E})$ \\
\hline 14 & Evelyn Turukwe & $\begin{array}{l}\text { Nurse-midwife, Makongoro } \\
\text { Antenatal Clinic }\end{array}$ & $(21.04 .04, \mathrm{E})$ \\
\hline 15 & Mama Ndovu & $\begin{array}{l}\text { Nurse-midwife, Makongoro } \\
\text { Antenatal Clinic }\end{array}$ & $(13.04 .04, \mathrm{E})$ \\
\hline 16 & Delilah Sumve & Makongoro Clinic & $(27.06 .04, \mathrm{E})$ \\
\hline 17 & Miriam Kihundo & Makongoro Antenatal Clinic & $(22.04 .04, \mathrm{Sw})$ \\
\hline 18 & Eliana Ndenta & Makongoro Antenatal Clinic & $(20.05 .04, \mathrm{Sw})$ \\
\hline 19 & Mariamu Mpishi & Makongoro Antenatal Clinic & $(22.04 .04, \mathrm{Sw})$ \\
\hline 20 & $\begin{array}{l}\text { Happiness } \\
\text { Malolo }\end{array}$ & Makongoro Antenatal Clinic & $(17.04 .04, \mathrm{Sw})$ \\
\hline $\begin{array}{l}21 \\
a, b, c\end{array}$ & Stella Ndogo & $\begin{array}{l}\text { Nurse-midwife, } \\
\text { ultrasonographer, } \\
\text { Sengerema District Hospital }\end{array}$ & $(16.07 .04 ; 01.08 .04,13.06 .04, \mathrm{E})$ \\
\hline 22 & Alena Vipimo & $\begin{array}{l}\text { Nurse-midwife, } \\
\text { Sengerema District Hospital }\end{array}$ & $(18.07 .04, \mathrm{E})$ \\
\hline 23 & Mama Iringa & $\begin{array}{l}\text { Nurse-midwife, Sengerema } \\
\text { District Hospital }\end{array}$ & $(18.08 .04, \mathrm{E})$ \\
\hline 24 & Dr. Mbeki & $\begin{array}{l}\text { Assistant Medical Officer, } \\
\text { Sengerema District Hospital }\end{array}$ & $(07.06 .04, \mathrm{E})$ \\
\hline 25 & Mama Bukumbi & $\begin{array}{l}\text { MCH Aide, Sengerema } \\
\text { District Hospital }\end{array}$ & $(25.06 .04, \mathrm{Sw}, \mathrm{E})$ \\
\hline 26 & Samuel Mfundi, & $\begin{array}{l}\text { Anesthetic nurse, uts- } \\
\text { operator (theatre), } \\
\text { Sengerema District Hospital }\end{array}$ & $(25.06 .04, \mathrm{E})$ \\
\hline 27 & Ester Matatu & Sengerema District Hospital & $(18.06 .04, \mathrm{Sw})$ \\
\hline $\begin{array}{l}28 \\
\mathrm{a}, \mathrm{b}, \mathrm{c}\end{array}$ & $\begin{array}{l}\text { Laurentsia } \\
\text { Shitindi }\end{array}$ & Sengerema District Hospital & $(25.06 .04,27.06 .04, \mathrm{Sk}, \mathrm{Sw})$ \\
\hline 29 & Janice Mtutu & Sengerema District Hospital & $(11.06 .04, \mathrm{Sk})$ \\
\hline 30 & Salima Kuku, & Sengerema District Hospital & $(15.06 .04, \mathrm{Sw})$ \\
\hline $31 \mathrm{a}, \mathrm{b}$ & $\begin{array}{l}\text { Nyamwaga } \\
\text { Lugari }\end{array}$ & Sengerema District Hospital & $(29.06 .04,05.07 .04, \mathrm{Sk})$ \\
\hline 32 & Focus Group 1 & $\begin{array}{l}\text { Waiting Home, } \\
\text { Sengerema District Hospital }\end{array}$ & (16.05.04, Sw, Sk) \\
\hline 33 & Focus Group 2 & $\begin{array}{l}\text { Waiting Home, } \\
\text { Sengerema District Hospital }\end{array}$ & $(25.06 .04, \mathrm{Sw}, \mathrm{Sk})$ \\
\hline
\end{tabular}




\begin{tabular}{|l|l|l|l|}
\hline 34 & Mama Ceri & $\begin{array}{l}\text { Traditional Healer, } \\
\text { Sengerema Village }\end{array}$ & $(23.06 .04, \mathrm{Sw})$ \\
\hline 35 & Mama Nusu & $\begin{array}{l}\text { Nurse-Midwife, District } \\
\text { Medical Office, Sengerema }\end{array}$ & $(27.07 .04, \mathrm{E})$ \\
\hline 36 & $\begin{array}{l}\text { Anastasia } \\
\text { Kinondoni }\end{array}$ & GTZ, Dar es Salaam & $(17.02 .04, \mathrm{E}, \mathrm{Sw})$ \\
\hline
\end{tabular}


Appendix B
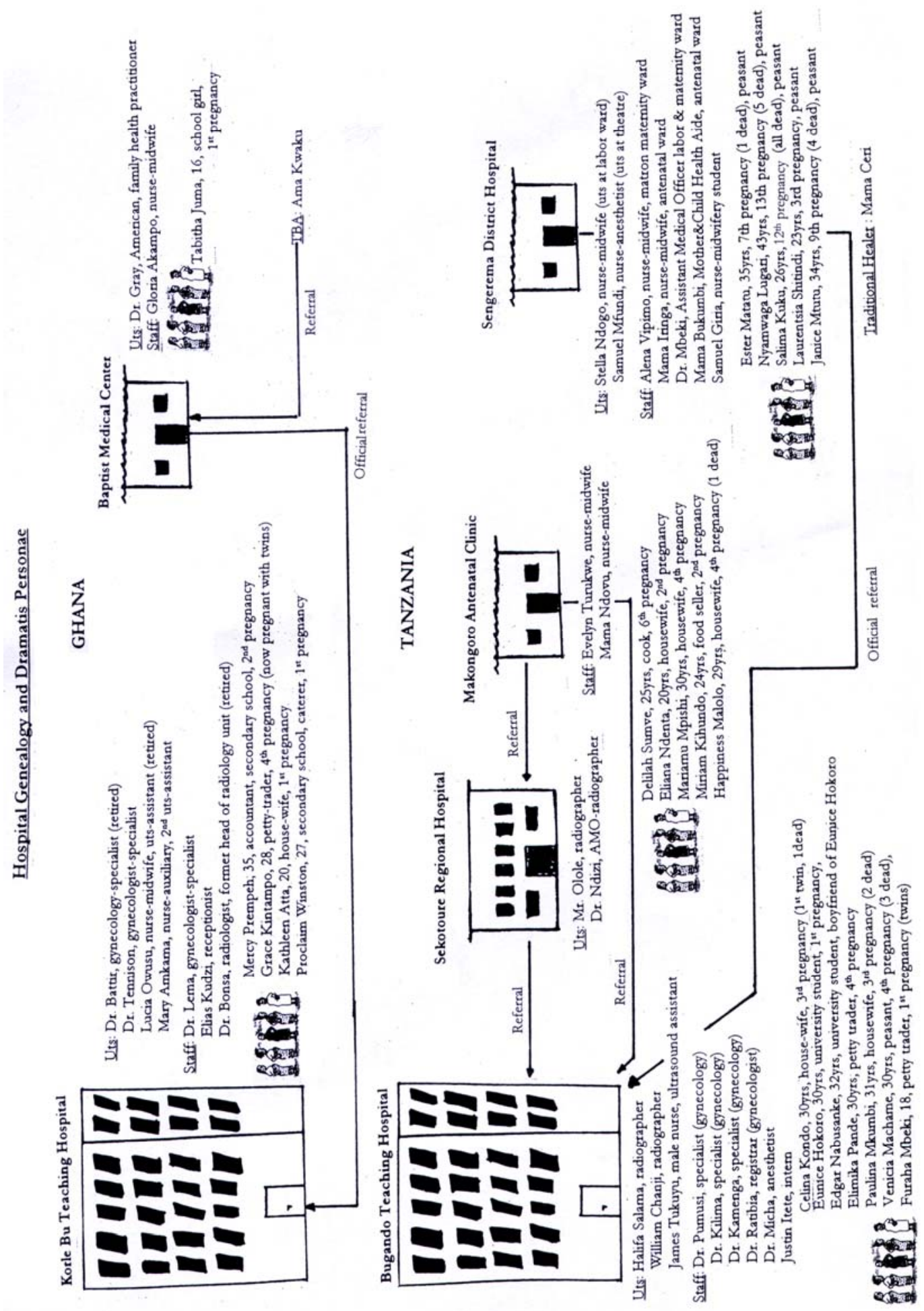


\section{Appendix C}

Explanatory List of Terms \& Abbreviations

Abruptio placenta

$\mathrm{AMO}$

balozi

BBA

BEU

Biparietal diameter (BPD)

Cephalic

Dalladalla

Eclampsia

Ectopic

EFM

Femur
The undue tearing off of the placenta from the uterine wall during pregnancy leading to intrauterine fetal death

Assistant Medical Officer. Due to the shortage of Medical Doctors Tanzania invented another category of doctors, AMOs whose training was much shorter. While working rather as assistants and paramedics in Regional Hospitals, in District Hospitals AMOs function as full blown medical doctors

Kiswahili for the so called ten cell leader, an administrative unit whose existence dates back to Ujamaa politics whereby 10 households formed one cell (see chapter 3). Knowing someone's balozi is often the only means to find a particular house in rural areas.

Birth before arrival (in the hospital)

Biomedical Engineering Unit, the Ghanaian state department responsible for biomedical technology

The diameter between the two lateral bones of the head (os parietalis)

Head... a cephalic lie means the child lies with its head downwards (opposite to breech position)

Term used in Tanzania to designate collective taxis

See PIH

An extra-uterine pregnancy that implanted in the tubes or the abdomen

Electronic Fetal Monitoring: device to register intrauterine fetal heart beat. Interchangeably also CTG = cardio-tokograph is used in obstetrics, however, my interviewees referred to EFM only. EFM includes forms of intermittent electronic fetal monitoring without print-outs such as Doppler or sonicaid)

The upper leg bone 
$\mathrm{FN}$

fundi

Fundus

Hemorrhage

hydrosalpinx

IAEA

ITN

KCMC

LAP

laparatomy

LMP

MCH Aide

mganga

$\mathrm{MoH}, \mathrm{MoF}$

Multipara

Mwalimu mkubwa

Mzee
I use this abbreviation here to refer to my fieldnotes.

Kiswahili for technician, mechanic, plumber

The upper part of the uterus. Palpating the fundus during pregnancy is used to determine the fundal height which allows to assess pregnancy time in terms of fetal growth (fundal height-time as I call it in chapter 4)

(severe) bleeding

A condition by which the tube that is blocked with retained water after an infection of the tube system, for example, due to sexually transmitted diseases.

International Atomic Energy Association

Insecticide Treated Nets (for malaria prevention)

Kilimanjaro Christian Medical Centre situated in Moshi. One of the four Teaching Hospitals in Tanzania, originally Lutheran, as opposed to the governmental Teaching Hospital Muhimbili in Dar es Salaam and the originally Catholic Bugando Teaching Hospital (one of the fieldsites).

Lower Abdominal Pain

Abdominal section

\section{Last Menstrual Period}

Mother and Child Health Aide. Similar to AMOs, MCH Aides form a professional group established to compensate for the lack of nurse-midwives. Most $\mathrm{MCH}$ Aides work at dispensaries where they provide antenatal and child care services.

Kiswahili for traditional healer

Ministry of Health, Ministry of Finance

According to international obstetric standards, a multipara is a woman with more than five pregnancies. Multiparity is one recognized risk factors asked for on antenatal records

Kiswahili for 'big teacher'. Name of honor for Julius Nyerere who was a teacher before leading Tanzania to independence

Kiswahili for 'old man', used to refer to biological age but also to express respect in the sense of social age 
mzungu

Obstetric ultrasound

Oligohydramnion

Os

Perinatal mortality

PIH

Placenta previa

PMS

Polyhydramnion

PPH (post partum hemorrhage)

pret-echo

Puerperal

Pv bleeding

RNE
Term used to denote white people, people who are strangers, come from far, those who do not belong to the place of the speaker

Ultrasound is commonly divided into abdominal, pelvic and obstetric examinations. Obstetric ultrasound covers examinations of pregnancies beyond 12 weeks of gestation.

Too little amniotic fluid. This condition may point to renal or urinary pathology of the fetus (see in contrast polyhydramnion)

Latin for mouth, refers here to the opening of the cervix

Perinatal mortality encompasses neonatal mortality (death within the $1^{\text {st }}$ week after delivery) up to child death within the first month after delivery

Pregnancy Induced Hypertension. The severest complication from PIH is eclampsia, a toxemic condition associated with metabolic shock, which leads to convulsions. In $15-25 \%$ of all cases, eclampsia results in maternal death with a high incidence of intrauterine fetal or neonatal death

A placenta that covers the cervical opening partially or totally. While with a partial placenta previa a vaginal delivery can be attempted, a total covering requires a c-section. Placenta previa is not only a risk factor for delivery but also for pregnancy as it frequently leads to bleeding episodes.

Philips Medical Systems (abbreviation used by the company itself)

Too much (poly) amniotic fluid can be a sign of fetal malformation, e.g. of spina bifida (open back) or hydrocephalus (water head). The increased amount of amniotic fluid can lead to premature labor, distortions of labor and of placenta tearing after child birth as well as to severe bleeding post partum.

Severe bleeding post partum

Dutch: An ultrasound for fun [=pret]

Latin: puerperium is the time after childbirth until the complete involution of the delivery organs and the cessation of postnatal bleeding (lochia)

Bleeding per vagina

Royal Netherlands Embassy (also Royal Dutch Embassy) 
Sepsis

STD

Stillbirth

Surfactant

TOM

trotro

UPT

Uts

WFUMB

WHO
Blood poisoning. A puerperal sepsis is an infection causally linked to delivery or postnatal period.

Sexually Transmitted Diseases

A child that is born dead after the legally prescribed age at which the delivery counts as childbirth and not as abortion. In many countries this age border lies by 28 weeks of gestation.

A drug used to intrauterine mature the lungs of a fetus in order to improve survival chances in case of premature delivery

Tubal Ovarian Mass

Minibus - the Ghanaian equivalent of the Tanzanian dalladalla

Urine Pregnancy Test

Ultrasound

World Federation of Ultrasound in Medicine and Biology

World Health Organization 


\section{Appendix D}

\section{A note on the buying power of the Ghanaian Cedi and Tanzanian Shilling}

In order to give a sense of how some of the health-care costs that are listed throughout this book translate into local economic terms, I provide a list of the approximate costs of some basic food and non-food items. When I began my fieldwork in Ghana in October 2002, one Euro was equivalent to 7900 Cedi. At the end of my stay in March 2003, one Euro bought 8800 Cedi. The salary of a nurse-midwife ranges from 1,5 -3 million (starter-experienced) Cedi. A specialist earns about 3-5 million Cedi. To both salaries allowances are to be added.

\begin{tabular}{|l|c|l|}
\hline One finger plantain & 2.000 & (Accra) \\
\hline One chicken & 12.000 & \\
\hline Five tomatoes & 2.000 & (Accra) \\
\hline One egg & $500-1.000$ & (seasonal) \\
\hline One bread (tea bread) & 2.000 & \\
\hline Sugar ( 150g) & 500 & \\
\hline One liter of kerosene & 5.500 & \\
\hline Trotro (collective minibus) & 1.500 & (Accra town) \\
\hline Ultrasound at Korle Bu & 30.000 & \\
\hline
\end{tabular}

When I began my fieldwork in Tanzania in February 2004, one Euro was equivalent to 1350 Tanzanian Shillings. By the end of my stay in September 2004, one Euro bought 1280 Tanzanian Shillings. The salary of a fully-qualified nurse-midwife is about 60.000 TSh per month. Resident doctors earn about 250-300, specialist up to 600 Euros per month. The average salary of my interviewees' husbands, most of them fishermen amounted to 40.000 TSh.

\begin{tabular}{|l|c|l|}
\hline One kilo of rice & 550 & \\
\hline One kilo of ugali flour & 350 & \\
\hline One chicken & $2.500-4.000$ & $\begin{array}{l}\text { (according to } \\
\text { size) }\end{array}$ \\
\hline One kilo of beans & 450 & \\
\hline One egg & 150 & \\
\hline One bread (white loaf) & 350 & \\
\hline One kilo of sugar & 800 & \\
\hline Charcoal per tin & 300 & \\
\hline One liter of kerosene & 900 & \\
\hline Dalladalla & 300 & (in town) \\
\hline Ultrasound at Bugando & $3.000 / 5.000$ & Referred/ private \\
\hline Ultrasound at Sekotoure & 1.500 & \\
\hline
\end{tabular}




\section{Curriculum Vitae}

Babette Mueller-Rockstroh (Berlin, 1969) trained as a midwife and subsequently studied Cultural Anthropology at the Georg-August-University in Goettingen where she graduated with distinction in 2000. After graduation she followed a postgraduate course at the International Women's University, Project Area 'Body'. Thereafter, she worked as junior researcher in an interdisciplinary project geared to develop process-oriented assessment parameters for midwife-led home delivery at the University of Applied Sciences in Osnabrueck, Germany. From October 2001 until February 2006, she held a PhD position in the Department of Science, Society and Technology Studies at the Faculty of Arts \& Social Sciences at Maastricht University. She currently is a research fellow in the interdisciplinary research project 'Biomedicine in Africa - Anthropology of Law, Organization, Science and Technology' at the Max-Planck-Institute for Social Anthropology at Halle (Saale) in Germany. 
Since the mid 1980's, international agencies increasingly promote ultrasound as 'appropriate technology' for Africa. Small, comparatively cheap, portable and modest in its infrastructural requirements, ultrasound promises to solve many of the burning problems of public health in 'developing countries', among others high maternal mortality rates. Following ultrasound to contexts that differ in many ways from those the technology was originally designed for and in, however, shows that ultrasound upon leaving the manufacturing hall and traveling the world - here to Ghana and Tanzania - may do different things than intended as the technology interacts with practices already in place. The dynamic of technology as being simultaneously a changing object and an object of change - and thus being world-making and political - is the central focus of this book: What are the obstetric facts depicted by ultrasound and what normative value do these facts carry? Why do women 'want' ultrasound, and how does ultrasound change their pregnancy experiences? How does ultrasound affect existing health care arrangements and, in turn, how is it affected by them? To what extent are changes both on the level of images and the institutional level deliberately intended or accidentally developed? By developing technography as a heuristic device to assess technology 'in the making', this book is of interest to both academic scholars and practitioners concerned with technology transfer, public health care and development.

Babette Müller-Rockstroh is a midwife and anthropologist of medical science and technology. Her current work as a research fellow in the interdisciplinary project 'Biomedicine in Africa - Anthropology of Law, Organization, Science and Technology' at the Max-Planck-Institute in Halle combines her expertise in reproductive health, Medical Anthropology and Science \& Technology Studies. 